11343 


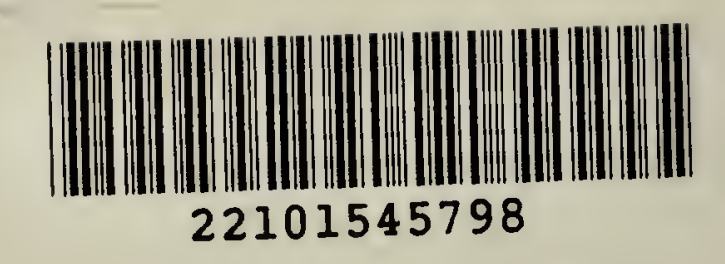







Digitized by the Internet Archive in 2017 with funding from Wellcome Library 


\title{
CARL VON LINNÉ
}

ALS

\section{ARZT UND MEDIZINISCHER SCHRIFTSTELLER}

\author{
VON \\ OTTO E. A. HJELT \\ PROFESSOR EMERITUS AN DER UNIVERSITÄT ZU HELSINGFORS
}

ÜBERSETZUNG AUS DEM SCHWEDISCHEN

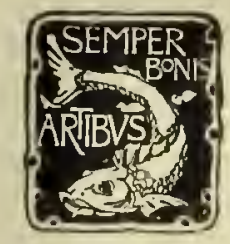

JENA

VERLAG VON GUSTAV FISCHER 1909 
306143

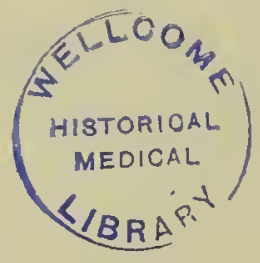


In der Geschichte der medizinischen Wissenschaft hat bisher Carl von Linné einen verhältnismäßig anspruchslosen Platz zugewiesen erhalten. Seine Forschung und schriftstellerische Tätigkeit auf dem Gebiete der Medizin hat nur wenig Beachtung gefunden. Der Glanz seines Namens als des vielseitigen Reformators der Naturwissenschaft hat so die Blicke der Forscher geblendet, dafo sie ganz übersehen haben, was er für die damalige Schwesterwissenschaft der Botanik, die Medizin, geistreich gedacht und kraftvoll ausgeführt hat.

Zu dem Jubelfest der Universität Upsala im Jahre 1877 gab Verf. eine Schrift über Linné als Arzt und seine Bedeutung für die medizinische Wissenschaft in Schweden heraus. Anläßlich der Gedächtnisfeier, die bei der 200 -jährigen Wiederkehr seines Geburtstages stattfinden sollte, richtete das Linné-Komitee der Schwedischen Akademie der Wissenschaften eine Aufforderung an den Verf., auf Kosten der Akademie eine neue Auflage seiner Schrift herauszugeben. Die Aufforderung wurde mit Dankbarkeit angenommen, und Verf. versprach, die Schrift auf Grund neuer, nunmehr zugänglicher Quellen umzuarbeiten. Diese Bearbeitung wird nun in dem vorliegenden Werkchen geboten, dessen Vollendung seinem Verfasser Freude in dem Spätherbst seines Lebens bereitet hat.

Einen sehr wichtigen Beitrag zur Kenntnis der medizinischen Anschauung Lin nés findet man in seiner "Clavis medicinae". Durch die gütige Vermittlung der Schwedischen Akademie der Wissenschaften hat der Verfasser das Glück gehabt, ein Exemplar dieser in Linnean Society (London) aufbewahrten Schrift mit eigenhändigen, 
bisher ganz unbekannten Bemerkungen Lin nés benutzen zu können und hat eine Abschrift davon in dem schwedischen Originale dieser Abhandlung als Beilage mitgeteilt. Diese vom Verf. nun systematisch geordneten Aeußerungen Linnés werfen ein unerwartetes Licht auf das reiche Wissen auf dem Gebiete der Physiologie und der praktischen Medizin, das er in seinem medizinischen Unterricht verwendete.

Ohne Uebertreibung dürfte man sagen können, daß Lin né auch auf dem Gebiete der Medizin in vielen Hinsichten seiner Zeit vorauseilte, besonders darin, daß er in seinen oft geistvollen Hypothesen vorausschauend Forschunğsaufgaben für die spätere Zeit andeutete und die Notwendigkeit betonte, in der medizinischen Forschung die Methode der Naturwissenschaft zu befolgen.

Den I8. April 1907. 
Als der Lektor an dem Gymnasium zu Wexiö, Johan Roth man, es auf sich nahm, Carl Linnaeus in der Physiologie, wie man zu jener Zeit die allgemeinen Grundlagen der Naturwissenschaften benannte, zu unterrichten, knüpfte er seinen Namen unvergänglich an eines der schönsten Blätter der schwedischen Literaturgeschichte. Sein Wissen und seine warme Liebe bereitete den wißbegierigen, begabten Jüngling $z u$ der hohen Aufgabe vor, zu der er im Reiche der Wissenschaften ausersehen war, indem er ihm Mut und Hoffnung eingab, auf dem Wege weiterzugehen, wo große Zukunftsträume seinem jugendlichen Gemüt vorschivebten. Als der Professor, spätere Archiater Kilian Stobaeus in Lund sich wohlwollend des jungen akademischen Mitbürgers annahm, und seine ersten unsicheren Schritte auf dem Felde der Naturwissenschaften leitete, konnte er nicht voraussehen, daß dieser Jüngling beim Schein der Lampe in der engen Bodenkammer, wo er unerlaubterweise nächtens S to ba eu s' Bücher durchstöberte, den Grund zu seinem künftigen Weltruhm legte, und als der ehrwürdige Olof Celsius im botanischen Garten zu Upsala den schüchternen wißbegierigen Studenten kennen lernte, ahnte er wohl wenig, daß dessen Name auf Jahrhunderte hinaus seinen Glanz über die älteste Hochschule Schwedens verbreiten sollte.

Obwohl Linnés Name, seine Arbeit und sein Ruhm an die Hochschule in Upsala geknüpft sind, darf man gleichwohl bei der Beurteilung seiner wissenschaftlichen Entwicklung nicht vergessen, daß auch die Universität zu Lund ihn zu seinen Jüngern gezählt hat. Als Linné im Alter von 20 Jahren als Student an der Akademie zu Lund im Jahre 1727 eingeschrieben wurde, hatte er das Glück, in Stobaeus nicht nur einen wohlwollenden Lehrer, sondern auch einen warmen Gönner und Freund $z u$ finden. Durch den persönlichen Umgang mit Stobaeus und die Benutzung seiner reichen 
Bibliothek hatte Linné freilich Gelegenheit, nach mannigfachen Richtungen hin auf verschiedenen Gebieten der Naturwissenschaft seine IKenntnisse $\mathrm{zu}$ erweitern, er genol aber den unschätzbaren Vorteil, von ihm die erste Anleitung in der Ausübung der ärztlichen Kunst zu erhalten. Dieser angesehene und hochgefeierte Arzt wandte Linné als Gehilfen in seiner ausgedehnten privaten Krankenpraxis an, und auf diese Weise wurde er frühzeitig in den medizinischen Beruf eingeführt. Dieser Vorteil war um so größer, als zu jener Zeit in Schweden noch keine klinische Unterrichtsanstalt für die Ausbildung der jungen Aerzte bestand. Es war damals Brauch, daß die jungen Leute, die sich dem Studium der Medizin widmeten, bei älteren Aierzten in den Dienst traten, die sie dann bei ihren privaten Krankenbesuchen mitnahmen und auf diese Weise allmählich in ihren Beruf einführten. Es ist Stobaeus' Verdienst, Linné in die Ausübung der medizinischen Kunst eingeweiht und eine sichere Grundlage für seine Studien und Forschungen auf dem Gebiete dieser Wissenschaft geschaffen zu haben. Als Linné Lund verlassen und sich nach Upsala begeben hatte, erinnerte er sich mit Dankbarkeit dieses Wohlwollens seitens Stobaeus', und er schreibt darüber mit Bedauern :

„Nachdem ich nun eine Zeitlang gemäß der wohlwollenden Ermahnung des hochgeehrten Herrn Professors in der Therapie mich umgesehen habe, ist sie mir nicht weniger anziehend erschienen als historia naturali selbst, sonderlich da ich einigermaßen Anleitung von Herrn Dr. Rosén erhalten habe, habe jedoch nicht Gelegenheit, das Krankenhaus zu frequentieren und aus dem eigenen Munde des Leidenden zu lernen, wie vordem. $\mathrm{O}$ mi praeteritos jupiter si referat annos, aber Kindheit und Weisheit gehen nicht zusammen, hinc illae lacrimae" 1 ).

Es war die Hoffnung, bessere Gelegenheit zu einer wissenschaftlichen Ausbildung zu erhalten, die Lin né nach Upsala hinzog. Gemäß den akademischen Konstitutionen vom Jahre 1655 bestand die dortige medizinische Fakultät aus zwei Professoren und einem Adjunkten, zwischen denen die Lehrfächer in der Weise verteilt waren, daß der erste Professor über Therapie, Diätetik, Chirurgie und Pharmazie, der zweite über Physik, Chemie, Anatomie, Pathologie (morbi et signa morborum) und Botanik vorlesen sollte, während der Adjunkt bei den Uebungen in den verschiedenen Wissenschaften $\mathrm{zu}$ assistieren hatte $\left.{ }^{2}\right)$. Ueber die medizinische Fakultät hatte der viel-

I) De la Gardiska Archivet, IX, Lund I837, S. 223.

2) Die Konstitutionen bestimmen: „Ex professoribus medicinae primus practicus erit, et ex institutionibus medicinae quotannis proponet quae sanitatem tam tuendam quam restituendam, medendique methodum et media diaetetica, chirurgica et pharmaceutica con- 
seitige, geistvolle $\mathrm{O}$ lof $\mathrm{Rudbeck}(1639-1702)$, der sich bereits während seiner Studienzeit mit Untersuchungen über die Lymphgefäße beschäftigte, deren Entdeckung ihm gelang, ein Ansehen und einen Glanz gebreitet, der mit seinem Tode nicht verblich. Der große anatomische Hörsaal, für 200 Zuhörer berechnet, wurde unter Rudbecks energischer und einsichtiger I.eitung erbaut und ein botanischer Garten, über dessen großartigen Umfang und Reichtum die Forschungen der jüngsten Zeit Licht gebreitet haben, war von ihm angelegt worden ${ }^{1}$ ). Ein zahlreicher Kreis von Schülern, unter welchen sich die Namen der hervorragendsten schwedischen Aerzte der folgenden Zeit befinden, ein $\mathrm{Urban} \mathrm{H}$ järne, O. Bromelius J. Rothman, E. Odelstjerna u. a., sammelten sich um diesen ausgezeichneten Mann, der in seinen Bemühungen um die Förderung der medizinischen Studien kräftig von dem fleißigen, kenntnisreichen Pehr Hoffvenius (1630-1682) unterstützt wurden. Während des späteren Teiles seines tatenreichen Lebens widmete sich jedoch Ol of Rudbeck, wie bekannt, fast ausschließlich antiquarischen Untersuchungen. Sein Sohn Olof Rudbeck der Jüngere (1660 bis 1740), der nach ihm den Lehrstuhl für Anatomie und Naturgeschichte erhielt, war in jüngeren Jahren ein angesehener Botaniker und ein fleißiger Mitarbeiter an der großen botanischen Arbeit Campi Elysei, er hatte aber die Liebe des Vaters zur Altertumsforschung geerbt und wurde sogar i 720 von dem Halten medizinischer Vorlesungen beurlaubt, um sich ungeteilt der vergleichenden Sprachforschung widmen zu können. Der originelle Lars Roberg (1664-I742), der den Lehrstuhl für praktische Medizin innehatte, bestrebte sich zwar anfangs, das Studium der Medizin zu fördern, und ihm gebührt auch das Verdienst, daß das seit lange in Aussicht genommene akademische Krankenhaus zustande kam, aber zur Zeit des Aufenthaltes Linnés in Upsala war seine Lehrtätigkeit äußerst erschlafft. Seine Vorlesungen waren sowohl der Form wie auch dem Inhalt nach sehr màngelhaft. Das Krankenhaus kämpfte mit den größten Schwierigkeiten und war in späterer Zeit teils unbervohnbar, teils aus Mangel an Mitteln gänzlich geschlossen.

cernunt. - Secundus quotannis tradet physicam, et ex institutionibus medicinae eam partem quae agit de corpore humano, morbis et signis morborum: atque ideo anatomicen, botanicen et chymicen, suo quamque modo et tempore, convenienter tractabit ct juventuti ob oculos ponet.":

I) Botaniska trädgården i Upsala 1655-1807 (Der botanische Garten in Upsala I655-I807), I. Von M. B. Swederus. Ups. I877. 
Gegen Ende der 17 2oer Jahre war bei dem vorgerückten Alter Rudbecks und Robergs das Studium der Medizin und der Botanik in Upsala mehr und mehr vernachlässigt worden und war schließlich nahe daran, gänzlich auszusterben. Mit Ausnahme der anatomischen Demonstrationen, welche einige von den Mitgliedern des Collegium medicum in Stockholm während des Winters I729 anstellten 1), und denen er nebst einer und der anderen Sektion in Upsala hat beiwohnen können, scheint Li n n é während seiner Studienzeit daselbst kaum irgendwelchen medizinischen Unterricht erhalten $\mathrm{zu}$ haben. Um so fleißiger benützte er die Universitätsbibliothek, um durch das Studium medizinischer Schriftsteller sich in der Wissenschaft zu vervollkommnen, der er sich widmen wollte. Treffend sagt Th. Fries, dalo Linné „fast ohne alle Anleitung - und zwar im Laufe weniger Jahre - sich zu einem Meister und einem Bahnbrecher nicht allein auf dem naturwissenschaftlichen, sondern auch auf dem rein medizinischen Gebiete entwickelte. Ohne Kenntnis der geringen Hilfe, die Li n n é während seiner Studienjahre von Lehrern erhielt, tritt seine ungewöhnliche Begabung und energische Arbeit nicht deutlich hervor. Erst gegen den dunkleren Hintergrund zeichnet sich Linnés Bild in seiner wirklichen Klarheit und Größe ab" ${ }^{2}$ ). „Niemand sah eine Anatomie, niemand Chemie, und Linnaeus hatte nie eine botanische Vorlesung weder publice noch privatim zu hören bekommen", äu(bert er später selbst $\left.{ }^{3}\right)$. L in n é fand seine liebsten Hoffnungen vollständig vereitelt, und gern wäre er zu seinem „holden“ Stobaeus zurückgekehrt, wenn er die Mittel dazu gehabt hätte. Aus ganzem Herzen gestand er seine Unbedachtsamkeit, nach Upsala überzusiedeln, ein und schreibt selbst an Stobaeus, daß er es aufs höchste bereute,

„insonderheit da an meinem Sinn stets die große Obligation nagt, in der ich dem Herrn Doctor gegenüber stehe, welche nächst meinen Eltern größer ist als gegen irgend jemand in der Welt, was ich vor jedermann zugestehen will und muß. Und wie ich Gutes mit Bösem vergolten, was teuflisch ist, dies bekenne, bereue und depreciere ich“"4).

I) S. des Verf.s Aufsatz: De medicinskt-vetenskapliga institutens uppkomst och förhållande till läkekonstens utvickling (Die Entstehung und das Verhältnis der medizinischwissenschaftlichen Institute zur Entwicklung der Heilkunde) in Patologisk-anatomiska instatutionens festskrift, Heisingfors, 1890.

2) Th. M. Fries, Linné, Stocliholm 1903, I, S. 44.

3) Egenhändiga Anteckningar af $\mathrm{Carl} \mathrm{L}$ innaeus om sig sjelf (Eigenhändige Aufzeichnungen von $\mathrm{C}$ arl $\mathrm{L}$ in $n$ a eus über sich selbst), Upsala 1823 , S. I5.

4) Brief vom 8. Nov. 1728, in De la Gardiska Archivet, IX, S. 2 I3. 
Als gleichzeitig Armut und der Mangel am Notwendigsten zum Leben mehr und mehr Linné zu drücken begann, war es der Domprobst Ol. Celsius, selbst ein ausgezeichneter Botaniker, der ihn aus seiner verzweifelten, hoffnungslosen Lage herausriß und O1. $\mathrm{Rudbecks}$ Aufmerksamkeit auf den fleißigen, kenntnisreichen Studenten lenkte. Von dieser Stunde an eröffnete sich durch Celsius' Vermittelung eine neue Bahn für den bisher unbekannten, zurückgesetzten Jüngling. Im Konsistorium erklärt $\mathrm{Rudbeck}$

„daß der Studiosus medicinae Carl Linnae us Smolandus einer unserer tüchtigsten Jünglinge ist, der mit der Zeit zu einem Docens in der Fakultät wohl brauchbar wäre, und wäre es deshalb gut, wenn er in Ansehung seiner Armut, dabei aber seinem fleißigen und regsamen Betragen, sonderlich im studio botanico, vorläufig mit duplici stipendio regio soulagiert werden könnte. Da ziemlich jedem der Herren Professoren das Geschick dieses stud. Linnaeus wohlbekannt war, genehmigte man, daß er bei Illustriss. Cancellarium demütigst zum Genuß des ebengenannten stipendii duplicis vorgeschlagen wurde" ${ }^{\text {1) }}$.

Dieser Vorschlag fand weitere Unterstützung seitens des Konsistoriums, wo der Rektor beklagte,

„daß das studium medicum hier an der Akademie nicht mit dem Nachdruck hantieret werde, wie es vordem gewöhnlich gewesen, weshalb man in Zukunft die schlimmen Folgen zu befürchten hätte, daß man aus Mangel an Nationalen genötigt sein werde, von auswärts Fremdlinge sowohl zur Bekleidung der Professuren im Reiche wie auch des Archiateramtes und anderer solcher vornehmen Aemter in diesem Studium zu berufen. Dem könnte jedoch beizeiten vorgebeugt und Abhilfe geschaffen werden, wenn nur regsamen und bescheidenen Jünglingen, die zuvor einen guten Grund in philosophischen Wissenschaften gelegt hätten, und nun daran dächten, fleißig in der Medizin fortzufahren, als Stipendiaten angenommen würden, und keine anderen, die pro forma sich dazu anmelden und dann gleich das Studium aufgeben; oder auch nur die, welche Chirurgie verstehen. Diese nützlichen und soliden subjecta müssen auf alle Weise unterstützt und in tunlichstem Maße ermuntert werden" 2).

Nachdem Linné bereits vorher an Studierende der Medizin Privatunterricht erteilt hatte, wurde die öfentliche Demonstration in der Botanik, welche Wissenschaft, wie erwähnt, zu jener Zeit und noch lange danach in Upsala dem Gebiet der medizinischen Fakultät angehörte, während der Beurlaubung Prof. O1. Rudbecks im Jahre 1730 Linné übertragen. · Durch die praktische Richtung, die er seinem Unterricht und den botanischen Exkursionen, die er anstellte, gab, erwarb sich Linné allgemeinen Beifall und zahlreiche

I) Protokoll des Consistorium Academicum vom 4. April 1730.

2) Protokoll des Consistorium Academicum vom 25. April I730. 
Zuhörer. Dieses vertrauensvolle und für jene Zeit ungewöhnliche Verfahren, daß einem jungen Studenten ein Teil der Obliegenheiten eines Fachprofessors übertragen wurde, sollte zu Linn és zukünftigem Beruf und seinem späteren Erfolg den Grund legen. Er erhielt nämlich nicht lange danach von dem Landeshauptmann in Dalarne, Nils Esbjörnson Reuterholm, den Auftrag, auf seine Kosten diese Landschaft zu bereisen und ihre Natur zu untersuchen. Dies wurde $z u$ einem Wendepunkt in seinem Leben. Unter anderen Freunden, die Linné sich in Falun erwarb, war auch Johan Browallius, derzeit Hauslehrer beim Landeshauptmann Reuterholm, später Professor und Bischof in Åbo. Zwischen ihm und Linné entwickelte sich eine innige Freundschaft. Es scheint, als wenn er es gewesen, der zuerst Linné auf den Gedanken brachte, nach der Sitte jener Zeit an einer ausländischen Universität sich den medizinischen Doktorgrad zu erwerben. Linné selbst schreibt darüber :

„Aber Browallius sah keinen Ausweg für ihn, auf einen grünen Zweig zu kommen, wenn er nicht ins Ausland reiste und Doctor würde, wo er dann heimgekehrt Freiheit hätte sich niederzulassen, wo es ihm behagte, und wo er dann unfehlbar sein Auskommen finden würde. Da aber Geld erforderlich war, so blieb nichts anderes übrig, als daß Linnaeus sich mit einem reichen Mädchen engagieren mußte, das zunächst ihn glücklich machen könnte und dann er sie. Dieser Satz gefiel Linnaeus theoretice, ungeachtet aller Vorschläge aber kam dabei nichts heraus" 1 ).

Während seines Aufenthaltes in Falun hatte sich Linné indessen großes Vertrauen als Arzt erworben und war außerdem dem Stadtphysikus Dr. Johan Moraeus in seiner Praxis behilflich gewesen. In Moraeus' Haus aufgenommen, verliebte er sich in dessen älteste Tochter Sara E1isabeth und gewann ihre Zuneigung und Liebe. Als Bedingung für sein Jawort verlangte jedoch der zukünftige Schwiegervater, daß Lin né den Doktorgrad an einer auslänđischen Universität erwerben sollte ${ }^{2}$ ). Es können hier die Worte Anwendung finden, die Linné viel später an einen seiner Schüler schrieb:

„Das Schicksal bietet uns selten unser Glück mehr als einmal. Wagen wir es dann anzunehmen, so sind wir glücklich oder unglücllich ein für

I) Egenhändiga Anteckningar, S. 22.

2) Zu jener Zeit wurde noch nicht der medizinische Doktorgrad an den schwedischen Universitäten erteilt, sondem es wurde für einen schwedischen Arzt als unumgänglich nötig erachtet, sich ihn im Auslande zu erwerben. Siehe Otto E. A. Hjelt, Svenska och Finska Medicinalverkets Historia 1663-1812 (Geschichte des schwedischen und finnländischen Medizinalwesens 1663-I812), Helsingfors 1891, I, S. 466-474. 
alle Mal. Da müssen wir zusehen, ob Gott uns dazu bestimmt hat, was aus der Neigung und Lust zu ersehen ist, die Gott der Herr zuvor in uns gepflanzt hat; da er es selbst getan hat, ist er imstande, alles zu einem guten Ende zu führen" 1 ).

Von allen Ländern stand damals Holland auf der Höhe seines Ansehens als die Heimat der medizinischen Wissenschaften. Vor allem lockte Boerhaaves weltberühmter Name Scharen von wißbegierigen Jünglingen aus allen Ländern Europas nach den Hörsälen Leidens. Das Studium der Anatomie und Botanik wurde mit Vorliebe betrieben, und auch die klinische Unterrichtsmethode war schon frühzeitig aus Italien nach Holland verpflanzt worden. Die reichen, blumenliebenden Holländer besaßen prachtvolle Gärten, wohin Pflanzen aus weitentlegenen Weltteilen übergeführt wurden, und welche eine seltene Gelegenheit zur Forschung in der Welt der Blumen boten. Hierher lenkte nun der junge schwedische Gelehrte, der bald ganz Europa mit seinem Ruhm erfüllen sollte, seine Schritte. Nachdem er den vorgeschriebenen Prüfungen sich unterzogen und eine Abhandlung "Dissertatio medica, in qua exhibetur Hypothesis Nova de Febrium Intermittentium causa", $24 \mathrm{~S}$. in $4^{0}$, herausgegeben hatte, erlangte Linné in Harderwyk am 24. Juni 1735 den medizinischen Doktorgrad. Das von seinem Promotor Johannes de Gorter ausgestellte Zeugnis enthält u. a.: „Um einem jeden kundzutun, daß ich bei Carl Linn a eus aus Schweden, nunmehr Medicinae Doctor, eine so hervorragende Erfahrung und Gelehrsamkeit nicht nur in allen Zweigen der Medizin, sondern auch in der Botanik gefunden habe, daß er als einer der ausgezeichnetsten Doktoren der Medizin angesehen werden muß, habe ich, indem ich ihm allen Erfolg in der Behandlung der Kranken wünsche, nicht gezögert, dies mit meinem Namen zu unterschreiben" ${ }^{2}$ ).

Die von Linné herausgegebene Abhandlung, eine neue Theorie über die Ursache der intermittenten Fieber enthaltend, ist seine erste medizinische Arbeit. Obwohl infolge der Macht der Umstände im fremden Lande veröffentlicht, berührt diese Abhandlung viele einheimische Verhältnisse und stützt sich auf in Schweden gemachte Beobachtungen. Ohne Zweifel ist sie auch zum größeren Teil schon ausgearbeitet worden, bevor Linné seine Reise antrat. Da diese

I) Brief an C. P. Thunberg vom 27. April I77I in Collectio cpistolarum, quam ad viros illustres et clarissimos scripsit C. à Linné. Edidit D. H. S toever, Hamburg 1792, S. 78 .

2) Nähere Einzelheiten über Linnès Promotion finden sich bei Th. M. Fries, Linne, I, S. 207-208. 
Abhandlung sehr selten und im allgemeinen wenig bekannt ist, dürfte es zur Beurteilung des wissenschaftlichen medizinischen Standpunktes nicht ohne Interesse sein, weiter unten, wenn wir uns mit seinen medizinischen Arbeiten beschäftigen werden, die wichtigsten Ansichten mitzuteilen, die in dieser Schrift ausgesprochen werden, obgleich schon hier im voraus erwähnt werden mag, daß Lin né selbst später gewisse darin ausgesprochene Sätze zurücknahm. Diese Arbeit wurde jedoch einige Jahre später ( $174 \mathrm{I}$ ), als es sich um die Anstellung Linnés an der Universität in Upsala handelte, plötzlich Gegenstand eines heftigen Angriffes seitens seines Mitbewerbers um die Professur der Medizin, des Adjunkten Johan Gottschalk Wallerius.

Es ist allgemein bekannt, daß das Studium der Botanik und die rastlose Vollendung der großartigen, schon in Schweden begonnenen naturwissenschaftlichen Arbeiten, die ihn rasch zu der ersten Autorität in dieser Wissenschaft machten, Linné drei Jahre lang in Holland festhielten ${ }^{1}$ ). Dagegen ist es weniger bekannt, daß Linné während einer Zeit, wo er mit der ganzen Lebhaftigkeit seiner Seele mit der Durchführung der umfassendsten Reformen in den verschiedenen Zweigen der Naturwissenschaft beschäftigt war, gleichwohl auch weiterhin sich dem Studium der Medizin widmete und mit Freuden jede Gelegenheit zur Ausbildung in dieser Wissenschaft benutzte. Er besuchte fleißig Boerhaaves öffentliche wie auch private Vorlesungen, nahm an den Visiten im Krankenhause teil und begleitete ihn auf seinen privaten Krankenbesuchen. Während Li n né bei Clifford in Hartecamp weilte, reiste er oft nach Leiden, um Boerhaave zu hören und aus seinen lehrreichen und sehr ausgedehnten Erfahrungen Nutzen zu ziehen. Boerh a a ve, dessen Freundschaft von vielen gesucht, von wenigen aber erlangt wurde, umschloß seinerseits Linné mit warmer Liebe und besonderem Vertrauen, ja zeichnete ihn vor allen anderen aus. In einem Briefe, den Linné mitnahm, als er den berühmten Sloane in London besuchte, schrieb Boerhave:

„Linnaeus, der Ihnen diesen Brief überreicht, ist allein würdig, Sie zu sehen, und allein wert, von Ihnen gesehen zu werden; wer Sie zusammen sieht, der sieht zwei Männer, derengleichen die Welt kaum besitzt."

1) „Ego infelix peregrinus omnia citissime corradere debeo, aliis curam preli committere, hinc ut fit, non mirum.“ „Mea omnia opuscula sunt parva et qualia exsulis vel peregrinatoris esse solent, qui omnia secum portare debet." Brief an A. v. Haller vom 8. Okt. I737. 
Es ist rührend zu lesen, was Linné selbst über den Abschied von dem sterbenden Boerhave berichtet, der seiner Krankheit und seiner Schmerzen wegen schon eine Zeitlang genötigt gewesen war, alle Besuche von Fremden abzuweisen.

"Linnaeus war auch der einzige, der hineinkommen durfte, um die Hand seines großen Informators mit einem traurigen Vale zu küssen, als der schwache Greis noch so viel Kraft in seiner Hand hatte, daß er Linn a e s' Hand an seinen Mund führte und sie wiederküßte, indem er sagte: Ich habe meine Zeit und meine Jahre gelebt und getan, was ich vermocht und gekonnt habe. Gott erhalte Dich, dem all dies noch bevorsteht. Was die Welt von mir verlangt hat, hat sie erhalten. Sie verlangt aber weit mehr noch von Dir. Leb wohl, mein lieber Linnaeus"1).

Der Einfluß, den Boerhaave auf Linnés medizinisch-wissenschaftliche Entwicklung ausübte, war und blieb von außerordentlicher Bedeutung. Alle seine Schriften zeigen mehr oder weniger Spuren davon. Der naturwissenschaftliche Charakter, den die ärztliche Bildung in Schweden während des I8. Jahrhunderts erhielt, wurzelt, wie wir weiter unten finden werden, zu nicht geringem Teil in den Lehren, die Linné in Boerha aves Schriften fand und später durch dessen eigenen Unterricht sich $\mathrm{zu}$ eigen machte.

Schon in seiner frühen Jugend hatte Linné mit Boerhaaves Arbeiten Bekanntschaft gemacht. Während er noch auf der Schulbank im Wexiöer Gymnasium saß, erteilte ihm der Lektor Dr. Joh an Rothman, der auf sein lebhaftes Interesse für die Naturwissenschaften aufmerksam geworden war, privaten Unterricht in den diesbezüglichen Fächern. $\mathrm{Zu}$ jener Zeit war die Botanik so eng mit der Medizin verknüpft, daß es undenkbar war, jemand könnte sich ohne gründliche Kenntnisse in der Botanik der Medizin widmen. Linné hatte Roth man seine Zukunftspläne, Arzt und Botaniker zu werden, mitgeteilt. Dieser, der seine ungewöhnlichen Anlagen für Naturforschung kennen gelernt hatte, begann ihn privat zu unterrichten, und zugrunde legte er hierbei u. a. Boerhaaves „Institutiones medicae", welche Arbeit auch eine Darstellung des allgemeinen physiologischen Wissens jener Zeit enthielt ${ }^{2}$ ). Diese vielbenutzte Schrift

I) Egenhändiga Anteckningar, S. 3I. Linné schreibt: „In B o erhaave habe ich den aufrichtigsten Freund, den treuesten Lehrer, den besten Beschützer verloren; ein glückliches Geschick hat mir aufs neue einen solchen in Ihnen gegeben (per te fata benignissima eundem mihi concesserunt)", in einem Brief vom 21. Jan. 1740 an Sauvages, abgedruckt in Lettres inédites de Linné à Boissier de la Croix de Sauvages, recueillies par M. le Baron D'Hombres-Firmas. Alais 1860.

2) Hermann Boerhaave, Institutiones medicae in usus annuae exercitationis domesticos, Lugd. Batav., 1707, $8^{\circ}$. Th. M. Fries teilt mit, daß in der Bibliothek der 
las R othman seinem Schüler vor und erklärte sie ihm „mit größter Gelehrsamkeit", und „wenn er nach gehaltenem Collegium den Burschen examinierte, fand er, daß er alles, was er dargelegt, bis auf das Tüpfelchen verstanden hatte" $\left.{ }^{1}\right)$. So wurde schon frühzeitig bei Linné Hingebung und Verehrung für Boerhaave, „communis Europae praeceptor", erweckt.

Als Linné dann später in ein enges Freundschafts- und Umgangsverhältnis zu Boerhaave trat, war es natürlich, daß ebenso dessen Krankheitstheorie wie dessen Heilmethode bei Linné Anklang finden multe. Seine umfassenden Kenntnisse der Natur und sein scharfes Auge für die Erscheinungen derselben ließen ihn klar erkennen, ein wie enges und innig verknüpfendes Band zwischen der wissenschaftlichen Medizin und der exakten Naturforschung bestand.

Es ist nicht Aufgabe dieser Schrift, Linnés Arbeit und Erfolge in Holland zu schildern. Es liegt außerhalb des Rahmens dieser Abhandlung, die Bedeutung zu untersuchen, die sein Aufenthalt in diesem Lande und die Bekanntschaft, die er dort, wie auch in England und Frankreich, mit Gelehrten, einem Gronow, Burman, van Royen, Dillenius, Ant. und Bernh. de Jussieu, Réa umur u. a. machte, auf seine zukünftige Tätigkeit als Naturforscher ausübte. Es muß dies dem überlassen bleiben, der künftig einmal Linnés bisher noch nicht in ihrem inneren Zusammenhang geschilderte Säkularbedeutung für die Naturwissenschaften darstellen will. Hier wollen wir nur versuchen, einige Beiträge zur Kenntnis der Verdienste Linnés um die ärztliche Wissenschaft in seinem Vaterlande zu sammeln.

Als Linné im Herbst 1738 nach Schweden zurückkehrte, war sein Name hoch geachtet von den Gelehrten des Auslandes. Das Ansehen, das der junge schwedische Naturforscher erlangt hatte und sein ganzes Leben hindurch behielt, stand in seiner vollen Blüte.

„Ihr Name“, schreibt S a uvages, „liegt ständig auf den Lippen unserer Gelehrten. Ueberall sind sie bestrebt, Ihre Schriften zu erhalten und zu zitieren. Wer sie besitzt, verbirgt sie und bewahrt sie sorgfältig auf. Ich kann aufrichtig sagen, daß Sie in der Naturwissenschaft sind, was Karl der $Z$ w ölfte in der Kriegskunst ist, nur mit dem Unterschied, daß die ganze botanische Welt Thnen für alle Zeiten untertan ist" "2).

Linnean Society ein eigenhändiges Manuskript von Linnés Hand aufbewahrt wird: "Experimenta nonnulla Medica praecipue physiologica", das wahrscheinlich aus Aufzeichnungen aus $\mathrm{R}$ othmans Lektionen besteht.

I) Egenhändiga Anteckningar, S. 8.

2) "Quod totum orbem botanicum tibi in aeternum subjicis". Brief an Linné vom 12. Aug. 1740 (abgedruckt in Orbis cruditi judicium de C. Lin na e i scriptis). 
In seinem Vaterlande unbekannt und unbeachtet, ließ sich Lin n é in Stockholm nieder, in der Absicht, sich der praktischen Ausübung der medizinischen Kunst zu widmen. Er schreibt darüber selbst: "Linnaeus gedachte hier als Doktor sich zu versorgen, da er aber allen unbekannt war, wagte es in diesem Jahre niemand, sein teures Leben den Hïnden eines unbekannten Doktors anzuvertrauen, ja, nicht einmal seinen Hund, so daß er oft an seinem Fortkommen im Reiche verzweifelte. Er, der überall im Auslande als ein princeps Botanicorum geehrt wurde, war zu Hause wie ein Klimius ${ }^{1}$, aus der unterirdischen Welt hervorgekommen, so daß $\mathrm{Linnaeus,} \mathrm{wenn} \mathrm{er}$ nicht verliebt gewesen, unfehlbar wieder weggereist wäre und Schweden verlassen hätte. Nachdem Lin na eus gesehen hatte, daß er auf keine Weise eine praxis medica bekommen konnte, begann er die gewöhnlichsten Speisequartiere zu frequentieren, woselbst er die jungen Cavaliere, die in castris Veneris blessiert worden waren, abstemios sitzen sah, wo er ihnen zusprach, sie sollten guten Mutes sein und ein Quartier Rheinwein trinken, mit der Versicherung, daß er sie innerhalb I 4 Tagen kurieren wolle, wo endlich zwei, die vergebens mediziniert hatten, ihr Leben seinen Händen anzuvertrauen wagten und er sie gleich kurierte, wonach er innerhalb eines Monats den größten Teil der Jugend in seine Kur bekam“ “2).

Diese Art von Praxis scheint zunächst hauptsächlich Linn é beschäftigt zu haben und zugleich sehr einträglich gewesen zu sein. Er erkundigt sich sogar nach der Erfahrung ausländischer Aerzte in der Behandlung von venerischen Krankheiten. Er schrieb später an seinen Freund Sauvages und bittet ihn um Auskünfte über seine Methode zur Behandlung der Gonorrhöe.

„Während der ganzen kurzen Zeit, die ich in Paris zubrachte, war ich von meiner leeren Börse abhängig (jussit vacua crumena). Arm bin ich geboren und arm bin ich stets gewesen. Ins Vaterland zurückgekehrt, ging der Stem des Glückes mir zu Anfang des vergangenen Jahres auf. Aus mir unbekanntem Anlasse strömten Kranke in großer Zahl zu mir. Ich erhielt hier in der Hauptstadt Stockholm, wo ich lebe, eine bedeutende ärztliche Praxis, vielleicht die größte unter den Aerzten des Landes.

Aber o weh (proh dolor), die schlimme Gonorrhöe hat infolge des Umganges mit leichtfertigen und schamlosen Weibern (prostatae pudicitiae puellis) fast alle Jünglinge in unserem Vaterlande angesteckt. In Holland habe ich Hunderte von Malen diese Krankheit bekämpft. Nun aber kann

I) Anspielung auf $\mathrm{H}$ olbergs bekanntes, zu jener Zeit vielgelesenes Buch "Nikolai Klimii iter subterraneum" (Niels Klims underjordiske Reise), ins Dänische 1742 , ins Schwedische 1746 übersetzt.

2) Egenhändiga Anteckningar, S. 36, 37 . 
ich es kaum mehr. Ich habe gehört, daß Sie in Montpellier sehr erfahren in der Behandlung dieses Leidens sind. Um der großen Freundschaft willen, die Sie zu mir hegen, bitte ich Sie, mich zu lehren, wie man sie heilt. Ich brauche keine allgemeine Theorie, sondern Rezepte und eine wirkliche Heilmethode. Tun Sie das, so schenken Sie mir tausend Dukaten (nummos aureos) das Jahr“ ${ }^{1}$ ).

Der Ruf, den Linn é so schnell in der Hauptstadt als praktischer Arzt gewann, beruhte jedoch nicht nur auf einer erfolgreichen Behandlung der oben angedeuteten speziellen Krankheit, sondern auch darauf, daß er von Patienten als ein besonders geschickter "Brustarzt" gepriesen wurde. „Hierdurch begann sein Kredit während der damals grassierenden Pocken und Wechselfieber zu steigen", so daß er schon gegen Ende des Jahres einem Freunde mitteilen konnte: „Ich bin unverschuldet in eine solche Praxis gekommen, daß ich von morgens 7 Uhr bis abends 8 Uhr kaum soviel Zeit übrig habe, daß ich eine kurze Mittagsmahlzeit einnehmen kann. Es schafft mir dies wohl Geld in den Beutel, nimmt aber mir so gänzlich meine Zeit weg, daß ich keine Stunde Ruhe finden kann, weder für mich, noch für meine treuesten Freunde." Nach einiger Zeit konnte er wieder mitteilen, daß er "allzuviel ein paar Monate hindurch zu tun gehabt hat, meistens jeden Tag 40 bis 60 Patienten “ ${ }^{2}$ ).

Es mag hier erwähnt werden, daß Linné bei seiner Rückkehr nach Stockholm es unterließ, sich im Collegium medicum zur Anstellung des Verhörs anzumelden, das den Vorschriften gemäß zur Erlangung der Approbation mit jedem im Auslande promovierten schwedischen Arzte angestellt werden sollte, und daß er demnach eigentlich unberechtigt war, medizinische Praxis auszuüben oder in den Staatsdienst zu treten. Das Kollegium scheint jedoch die Anstellung des Verhörs gar nicht verlangt zu haben.

Die Bekanntschaft mit dem damaligen Landesmarschall Carl Gustav Tessin, in dessen Haus Lin né wohnte und dessen Freundschaft und Vertrauen er gewonnen hatte, machte ihn „mit den Vornehmsten beim Reichstage" bekannt, und führte ihn als Arzt auch in die höheren Gesellschaftskreise ein, wodurch Linnaeus' Praxis unglaublich stieg, so daß er allein sie so groß hatte, „wie alle die anderen Medici zusammen“. Im selben Jahre 1739 wurde Linné durch Graf Car1 Gustav Tessins Vermittlung zum Admiralitätsarzt in Stockholm ernannt. Da das Marinekrankenhaus täglich 100

I) Brief an Sauvages vom 2I. Jan. 1740. In einem späteren Brief vom 30. Sept. desselben Jahres dankt Linné für die Antwort.

2) Brief an C. F. Mennander vom I. Dez. 1738 und vom 30. März 1739. 
bis 200 Kranke beherbergte, verschaffte dieses Amt Linné eine außerordentlich gute Gelegenheit, seine medizinische Erfahrung $z u$ erweitern, und besonders verwandte er, wie er selbst berichtet, viel Sorgfalt auf die Untersuchung der Wirkung der einfachen Heilmittel. Die Erfahrung, die Linné dabei erwarb, war ihm später, wie wir weiter unten sehen werden, von großem Nutzen bei der Ausarbeitung seines pharmakodynamischen Systems ${ }^{1}$ ). Auch die pathologische Anatomie war ein Gegenstand, dessen Wichtigkeit Linné bei der praktischen Ausübung der ärztlichen Kunst einzusehen begann, und dem er seine Aufmerksamkeit widmete. Er suchte und erhielt die Erlaubnis, im Krankenhaus Leichenöffnungen vorzunehmen, was bis dahin nur in außerordentlichen Fällen gestattet gewesen war. Auf Linnés Initiative wurde auf diese Weise eine wichtige Prinzipfrage gelöst.

„Endlich habe ich"“, schreibt er, „das Recht erhalten, die Leichen von denjenigen, die im Marinekrankenhaus gestorben sind, zu untersuchen, was ich bisher nicht gekonnt habe. Wenn ich noch ein Jahr lang lebe, will ich Antwort auf die Frage nach der nächsten Ursache der Fieber geben, aber nicht früher; ich werde keine Hypothesen aufstellen, sondern ewige Wahrheiten“ ${ }^{2}$ ).

$\mathrm{Zu}$ Linnés Verdiensten um die Entwicklung der Medizin in seinem Vaterlande sind daher diese Bemühungen, eine wissenschaftliche Untersuchung der krankhaften Veränderungen im menschlichen Körper nach dem Tode einzuführen, zu rechnen. Von dieser Zeit an findet man in den in Schweden herausgegebenen medizinischen Arbeiten einen größeren Reichtum an pathologisch-anatomischen Beobachtungen und eine klarere Einsicht in die Notwendigkeit, die Auffassung von den Krankheitserscheinungen auf die Kenntnis von pathologischen Störungen zu gründen, als in der dem Umfange nach reicheren Literatur vieler anderer Länder. Unter diesen Verhältnissen wuchs Linnés Ansehen als Arzt von Tag zu Tag. Seine Praxis nahm in demselben Umfange zu. Da er durch die Umstände vorzugsweise in die Kreise eingeführt war, die den Ansichten der sog. Hutpartei huldigten, wurde er im Scherz „Archiater (Leibarzt) der Hüte" genannt. Selbst erzählt er, daß das Vertrauen zu ihm zugenommen hatte und seine Einnahmen so gestiegen waren, daß er

I) "In specificis multum profeci per nosocomia." Brief an Sauvages vom 2I. Jan. 1740. Selbst bemerkte L inné hierzu: Ibi (in nosocomio) vere occasionem habui per 3 annos noscendi morbos et remedıa per observationes et experimenta, dein usu hæc fuere, quum Genera morborım ederem. D. H. Sto ever, Leben des Ritters Carl von L inné, II (1792), S. 299.

2) Brief an Sauvages vom 21. Jan. 1740. 
nun in Stockholm jährlich 9000 Taler Kupfermünze verdiente ${ }^{1}$ ). Daß Linné, so hoch er auch die medizinische Wissenschaft stellte, gleichwohl nicht von seiner Tätigkeit als praktischer Arzt befriedigt vvar und gern damit aufgehört hätte, geht aus vielen seiner Briefe hervor. Seine Neigung zog ihn unwiderstehlich zu der Liebe seiner Jugend, zur Wissenschaft der Blumen, die nun während seiner rastlosen Tätigkeit vor den verschiedenartigen Geschäften des praktischen Arztes hatte zurückweichen müssen. Er selbst äußerte einmal:

„Sollte ich einmal nach Upsala kommen, so wollte ich ganz und gar der medizinischen Praxis entsagen und mich nur mit Pflanzen beschäftigen" 2).

Ja, viele Jahre später schreibt Li n né:

„Die goldene Praxis hat ihre Anziehungskraft, wenn man aber zwei Freundinnen hat, schwächt die Liebe zu der einen den Wert der anderen" 3 ).

Tief und bitter fühlte er diese Zersplitterung seiner Kraft und seiner Neigung, wie ein lieblicher Traum lebte in ihm die Erinnerung an die glücklichen Tage, die er unter den duftenden Schätzen in C1 iffords Garten zugebracht hatte. Er begann sich nach seinen wissenschaftlichen Beschäftigungen zurückzusehnen, und die Möglichkeit, sich doch einen Platz in fremdem Lande suchen zu müssen, begann vor seiner Seele aufzutauchen.

Schon während seines Aufenthalts in Holland hatte Linné mehrere Anerbieten erhalten, dazubleiben, und seine Freunde benutzten jede Gelegenheit, um ihn zu überreden, sich dort niederzulassen. Hollands feuchtes Klima war jedoch nachteilig für seine Gesundheit und hatte ihn schon mehrmals auf das Krankenlager geworfen, vor allem aber trieb ihn die Liebe zu seiner Verlobten mit unwiderstehlicher Macht ins Vaterland zurück. Als die Aussichten auf eine Tätigkeit, die seiner Neigung entsprach, noch unsicher waren, als die Hoffnung, sich gänzlich wissenschaftlicher Forschung widmen zu können, sich mehr und mehr in der Ferne verlor, begann der Gedanke, einem Ruf ins Ausland zu folgen, in seinem Sinn Wurzel zu fassen. Linné schreibt darüber an A 1 brecht vor Haller:

„Wenn ich nicht die botanische Professur in Upsala erhalte, und Sie nach drei Monaten mich berufen wollen, werde ich kommen, wenn es mir erlaubt ist, meine kleine Frau mitzunehmen" ${ }^{4}$ ).

I) Egenhändiga Anteckningar, S. 39. 9000 Taler K. zu jener Zeit dürften ungefähr 1000 Kronen heutiger Geltung entsprochen haben.

2) Brief an A. von Haller vom 15. Sept. 1739.

3) „Aurea praxis medica multum valet, cumque duae habentur amicae, alterius vires subtrahit alter amor", Brief an P. D. Giseke vom 20. Dez. 1774 (bei Stoever, S. II2).

4) Brief an A. von Haller vom 12. Sept. 1739. 
Haller scheint nämlich $L$ in né seine Professur nebst der Oberaufsicht über den botanischen Garten in Göttingen angeboten zu haben, da er sich nach seincm Heimatland, der Schweiz, zurücksehnte.

„Ich bitte Sie, von dem Flora mehr als von irgend einem anderen Botaniker erwartet, ein glückliches Geschick zu benutzen und in ein milderes Klima zurückzukehren. Wenn das Vaterland mich einmal zurückruft, und ich hoffe, daß es geschehen wird, so habe ich, falls es Ihren Beifall gewinnt, Sie zum Erben des Gartens und meiner Stelle bestimmt. Zu diesem Zwecke habe ich mit denen gesprochen, in deren Händen alles liegt, denn einem Würdigeren kann ich sie nie übergeben“" ${ }^{1}$.

Glücklicherweise gingen diese Pläne nicht in Erfüllung, und einer der größten Namen der schwedischen Geschichte, Li n né, blieb dem Vaterlande erhalten.

Wenden wir uns nun nach Upsala zurück, um einen Blick auf den letzten Abschnitt der Periode zu werfen, die Linnés Auftreten als akademischer Lehrer voranging. Olof Rudbeck und Lars Roberg hatten immer noch ihre Aemter inne, während die Sorge um den medizinischen Unterricht allein auf den Schultern Nils Roséns ruhte, der jedoch als diensttuender Leibarzt oft genötigt war, von der Universität abwesend zu sein und seinen akademischen Dienst zu vernachlässigen. Er fand seine Stellung als stellvertretender Professor unbequem, und es ist nicht zu verwundern, daß Rosén sich danach sehnte, einen ordentlichen Lehrstuhl in der Fakultät zu bekleiden. Am 26. April 1738 reichte Rosén ein Gesuch ein, zum dritten Professor der Medizin ernannt zu werden. Die Sache wurde im Konsistorium am I4. Juni 1739 behandelt und gab zu weitläufigen Ueberlegungen Anlaß. Die beiden Professoren der Medizin Rud beck und Roberg widersetzten sich seinem Verlangen, „da aber die Pluralität der Mitglieder des Konsistoriums für das Gesuch des mehrerwähnten Königl. Leibarztes Hrn. Assessor Rosén war, so wurde resolviert, daß Illustrissimus Cancellarius diesbezügliche Mitteilungen erhalten sollte".

Dieser Vorschlag scheint jedoch zu keiner Maßnahme geführt zu haben, denn am 30. Juni i 739 wurde das Konsistorium durch eine Königl. Verfügung folgenden Inhalts überrascht:

I) Brief an Linné vom 24. Nov. $173^{8}$ und 12. Jan. 1739 (bei Stoever, S. 168). Siehe Th. M. Fries, Linné, I, S. 252. Ueber Linnés Stellung zu Haller vergl. man des Verf.s Aufsatz "Carl von Linné $i$ sitt förhållande till Albrecht von Haller" in Lännetär VI (1878), deutsch (,Carl von Linné in seinem Verhältnis zu Albrecht von Haller") in Arch. f. Gesch. d. Medicin, III (1880). 
„Daß alle hochbejahrten Professoren in der hiesigen Akademie, die ihre Aemter nicht zum vollkommenen Nutzen der Jugend zu versehen vermögen, den Abschied nehmen und sich mit ihrem Gehalt und ihrem Pfründengut begnügen sollen, damit dann zu den frei gewordenen Aemtern die geschicktesten Personen vorgeschlagen werden, die zur Verfügung stehen u. S. w."

Als diese 'Königl. Verfügung im Konsistorium am 22. Sept. wiederum verlesen wurde, meinte der Archiater Rudbeck

„nicht zu denen gerechnet werden zu können, die nicht ihre Aemter $z u$ versehen vermögen, zumal da er trotz seines Alters von 8o Jahren vollkommen rüstig sei und täglich an einem weitläufigen und langwierigen Werke „Thesaurus linguarum Asiae et Europae harmonicus" arbeite, und behielt er sich vor, seine Professur wieder aufzunehmen und darin zu dozieren, falls als Grund gegen ihn angeführt werden sollte, daß ihm durch Königl. Gnade ein Vicarius gestellt worden sei, um besser seine anderen mannigfaltigen Arbeiten ausführen zu können, von denen jährlich einige im Druck ausgehen, vermutlich zu Gottes Ehre und des Vaterlandes Ruhm, worüber die Nachwelt ihr Urteil fällen werde."

Als die Angelegenheit dann am 24. Sept. behandelt wurde, fragte Prof. Roberg:

„ob noch jemand anders außer ihm und Herrn Archiater Rudbeck da sei, den dieses angehen könnte, und ob nicht auch noch andere, zum Exempel der Herr Rektor (And. Grönwall) und Herr Dr. Celsius hochbejahrt seien", worauf der Rektor antwortete, "„daß sie freilich zu hohem Alter gekommen seien, gleichwohl aber vollkommen ihre Arbeiten versehen könnten“. Außerdem wollte Prof. Roberg, „bevor die Post abginge, morgen eine Liste darüber abgeben, was er in den letzten Semestern publice zum Nutzen der Jugend und in Verwaltung seines Amtes getan habe". Zwischen Rosén, der nun vor das Konsistorium geladen wurde, und Rudbeck kam es zu einem langen Streit über den botanischen Garten, seine Pflege und seinen Verfall. „Betreffs des Umstandes, daß Herr Prof. Roberg nicht völlig sein Amt versehen habe, iterierte Herr Assessor Rosén alles das, was er in seiner untertänigen Supplik an Sr. Maj. den König angeführt hatte und erklärte, es, wenn es nötig sei, durch Zeugniisse Alumnorum medicorum beweisen zu können“, und fügte der Herr Assessor Rosén hinzu, „daß der Herr Prof. Roberg seit I73 I selten publice, nie aber privatim vorgelesen habe, was bewiesen werden lönne“. Darauf wurde geantwortet, daß hier nicht mehr als I 2-I3 medizinische Studenten seien, die nicht mehr als Einen zu hören brauchten, der in der Physiologie vorlese. Der Beschluß des Konsistoriums ging dahin, daß, „obwohl Herr Archiater Rudbeck (der von I 72 I an stets seinen Vicarium gehabt und ihn noch hat) jetzt erklärt hat, $d a ß$ er sich so großer Rüstigkeit zu erfreuen habe, $d a B$ er noch bereit sei, sein Amt wieder aufzunelmen und seine anderen Arbeiten aufzugeben, das Consistorium auch nicht bestreiten könne, daß der Herr Archiater eine außerordentliche Gesundheit und Kräfte habe, es doch dem Consistorium ziemlich schwer falle, bestimmt sich darüber 
auszusprechen, ob und inwiefern der Herr Archiater, als bereits zu selır hohem Alter gelangt, imstande sein könne, fortan allen zur Professur gehörenden Obliegenheiten völlig nachzukommen". Auch mit Bezug auf Prof. Roberg heißt es in dem Beschluß des Konsistoriums, „muß gleichfalls das Consistorium anerkennen, da $\beta$ er ebenfalls in Anbetracht seines hohen Alters eine außerordentliche Gesundheit und Rüstigkeit besitze, gleichwohl aber könne es nicht zuverlässig sich darüber äußern, ob und inwiefern er hinfort seine Professur in allen ihren Teilen vollkommen wahrzunehmen vermöge".

Hier handelte es sich also um nichts Geringeres, als daß die beiden Professoren der Medizin von ihren Aemtern zurücktreten und neuen Kräften Platz machen sollten. Daß es Rosén war, der diese Maßregel ins Werk gesetzt hatte, dürfte aus einem Brief hervorgehen, den er am 28. Sept. 1739 an Linné schrieb, der damals in Stockholm weilte:

„Endlich ist es so weit gekommen, daß Herr Archiater Rudbeck und Professor Roberg von dem Konsistorium als unter die Verfügung betreffend der Pensionierung gehörend erachtet worden sind. Sie protestierten hiergegen hautenent, benahmen sich, besonders der erstere, im Consistorium so wild, daß ich nie desgleichen gesehen habe, denn ich wurde auch vorgeladen, weil Rudbeck immer wieder zu Protokoll gegeben hatte, daß ich an dem Ruin des botanischen Gartens schuld sei. - Rudbeck behauptet, daß er 1730 zu den besten horti botanici in Europa zählte und zwar dank den Bemühungen Martins'). Er sagte, Sie, Herr Doctor, können dies bezeugen. Ergo, sehen Sie sich vor, wenn er Ihnen schreibt. Denn es wird ihm wegen dieser Sache schauderhaft übelgehen, wie auch wegen der Aecker und anderen Eigentums der Academie. Ich fordere endlich Bezahlung von ihm für das Vicariat. Mit nächster Post soll der Brief an den Kanzler abgehen, da wäre es am besten, wenn Sie, Herr Doctor, ihm gute Prinzipien und eine richtige Vorstellung von der Sache beibrächten."

Der Tod machte indessen diesen Streitigkeiten ein Ende, als O1. Rudbeck am 23. März I740 aus dem Leben schied. Der botanische Lehrstuhl, wozu auch die Anatomie gehörte, war auf diese Weise erledigt. Außer Rosén und Gottschalk Wallerius meldete sich Linné als Bewerber um diese Stelle an. Bei der im Konsistorium am I6. Mai I740 vorgenommenen Abstimmung wurde Linné von den Professoren Andr. Celsius, Boberg und O1. Celsius an die erste Stelle, von den Professoren Ihre, Klingenstjerna, Grönwall, Beronius, Asp und Winbom an die zweite und von Roberg, Ekerman, Mathesius, Ullén, Frondin und Melander an die dritte Stelle gesetzt. Das Gutachten,

I) Adjunkt der Medizin Dr. Pehr Martin, Ol. Rudbecks Schwiegersohn, gest. 1727. Der Brief gütigst von Dr. Swederus mitgeteilt.

Hjelt, Carl von Linné. 
das Prof. Roberg auf Verlangen des Konsistoriums über die Bewerber abgab, sei, als besonders charakteristisch, hier wiedergegeben:

Ich danke Ew. Magnificenz für Communication der schriftlichen Gesuche der Herren, die sich zur professio medica botanica et anatomica angemeldet haben, und gebe ich nach Ordres diese meine unvorgreifliche Antwort und unterstelle sie ergebenst der Prüfung venerandi Consistorii. Ich danke Gott, daß das Publikum bei dieser Gelegenheit und dieses Mal unter so tüchtigen und meritierten Subjecta zu wählen hat, wie sie sich das Consistorium nur jemals hat wünschen können. Wahrhaftiglich, wäre hier nur an eine botanica professio zu denken, nicht ein kleiner, sumpfiger hortus Upsaliensis am Svartbäcken, sondern ein jardin royal in Paris mit einer in Europa pflanzennamenskundigen Autorität in aller Pflanzenkunde $\mathrm{zu}$ besetzen, der vor dem Königl. Hause und den Augen der Herrschaften seine demonstrationes curiosas et novas anstellen sollte, so würde ich Herrn Doctor Carl Linnaeus für würdig halten, auch von auswärts herberufen zu werden, wenn er nicht bereits hier bei uns im Lande wäre. Aber abgesehen davon, daß wir nicht mehr als Io bis I 2 Stück Medicinae studiosos stipendiarios besitzen oder zu allen Zeiten besessen haben. Auch deren curiosité schwerlich befriedigt sein wird. Außerdem brauchen dieselben auch eher eine notitiam singularium et usualium als eine künstliche ordinationem und classificationem universalium. Die Medici fragen auch mehr nach plantarum vires und anatomen Svecorum als nach conformationem externam partium petalorum et pistillorum. So mögen wir uns auch mit der Pflanzenrangordnung behelfen, die bisher im Gebrauch ist, bis die dictatores botanici untereinander accordieren, welches Einteilungssystem in der Welt der Pflanzen $\mathrm{zu}$ befolgen ist. Vornehmlich, da dieser Professur außerdem obliegen cadaverum dissectiones cruentae, institutionum taediosae continuataeqve praelectiones, collegia, disputatoria und andere scholastica officia. Außerdem sterile Practique an einem kleinen Ort, wie es nun Upsala ist." Nachdem er Dr. Rosén an erster und Dr. G. Wallerius an zweiter Stelle aufgeführt hat, fährt Roberg fort: „Doch wie ich zuerst gesagt, so schließe ich auch honoris causa mit Herrn Dr. Carl Linnaeus, um seiner Meriten in der Botanique vor allem anderen willen. Dem von fremden und im Auslande für dieses studii genus mehr Ehre und Höflichkeit widerfahren ist als zuvor irgend einem unserer peregrinierenden Schweden. Der auch allein jetzt unter uns der Aufgabe gewachsen und mit ihr betraut werden könnte, eine Historia naturalis Scandinaviae magna auszuarbeiten oder wenigstens eine Reparation des früheren botanischen Werkes der Rudbeckiorum, Campi Elysei, das der Academie mehr Stipendienmittel gekostet hat, als ich hier sagen mag. Auch wurden bei der großen Feuersbrunst in Upsala die Exemplaria mit den Formstöcken zusammen verzehrt und zerstört. Will jedoch mit diesem meinem Gutachten Niemandes Prätentionen hierbei auch nur in denkbar geringstem Maße zu nahe treten."

In Anbetracht seiner überwiegenden akademischen Meriten und seines Dienstalters erhielt Rosén den botanischen Lehrstuhl nach Rudbeck. Hierüber schreibt Lin né an seinen Freund $\mathrm{S}$ a u va ges in Montpellier: 
"Ich habe mich um den Lehrstuhl in der Botanik beworben, um auf die medizinische Praxis verzichten zu können und in den Staatsdienst zu treten, sowie ganz und gar mich der Naturwissenschaft hinzugeben. Der Prokanzler der Akademie hat mir jedoch entgegengearbeitet, und Dr. Nils Rosén, der nicht einmal die Nessel kennt, hat Rudbecks Stelle erhalten. So geht es bei uns $\left.z u^{\prime \prime} 1\right)$.

Roberg war unterdessen von seiner Professur der praktischen Medizin entbunden worden. Im Konsistorium wurde nämlich am 19. April I 740 eine Verfügung des Kanzlers vom 17. desselben Monats verlesen, in welchen das Konsistorium ersucht wird,

„dem Herm Prof. Roberg vorzustellen, wie wohl er gegen sich handele, wenn er, als nun zu so hohem Alter gekommen, sich an der Gnade Sr. Maj. des Königs genügen ließe und um Abschied unter Belassung seines Gehaltes bis zu seinem Tode einkäme, auf daß seine Hochgräfl. Excellenz sich nicht im Anschluß an das Schreiben des Consistorii Academici vom 2. Oktober I 739 veranlaßt sehen möge, die Sache Sr. Maj. dem König untertänigst vorzutragen und dabei für den Herrn Prof. unangenehme Gründe zu gebrauchen usw."

Roberg reichte demzufolge am 26. April eine längere Erklärung ein und erklärte sich bereit, den Abschied zu nehmen. Am 8. Mai wurde für ihn die Pensionierungsurkunde ausgefertigt, in welcher „ihm für seine vieljährigen und getreuen Dienste allergnädigst gestattet wird, auf Lebenszeit das gewöhnliche und für die Professur ausgesetzte Gehalt sowie das Pfründengut zu behalten“. Beim Verlesen dieser Verfügung im Konsistorium am 3. Juni „gratulierten Rector und Consistoriales Hrn. Prof. Roberg zu dieser für sein Alter erhaltenen Linderung und königl. Gnade; worauf er mit einer Danksagung erwiderte“.

Zu dem so erledigten Lehrstuhl der Medizin meldete sich nun Li n né als Bewerber an, nebst dem Adjunkten der Medizin Dr. Joh a n Gottschalk Wallerius und Dr. Abr. Bäck. Es scheint, als wenn der damalige Kanzler der Universität zu Upsala, Graf Ca r1 Gyllenborg, nicht nur Linné aufgefordert, sich um diese Stelle zu bewerben, sondern zugleich den Plan aufgestellt habe, daß, nachdem Linné zu Robergs Nachfolger ernannt sei, er und Rosén die Lehrfächer miteinander tauschen sollten. Dieser Plan stieß auf allerhand Schwierigkeiten, und ihm wurde im Stillen in Upsala entgegengearbeitet. Man sieht deutlich, daß es Lin né nicht an Gegnern innerhalb des akademischen Kreises fehlte, und daß es Personen gab, die gegen ihn intrigierten und $\mathrm{zu}$ verhindern suchten, daß er die fragliche Professur erhielt. Nicht genug damit, daß Linnés Gresuch

I) Brief an Sauvages vom 20. Sept. 1740. 
um Befreiung von der Ablegung der üblichen Disputationsprobe Anlaß zu weitläufigen Ueberlegungen im Konsistorium gab 1), man: versuchte sogar öffentlich sein wissenschaftliches Ansehen herabzusetzen. Linnés Mitbewerber, Dr. Wallerius, Roséns Schüler und Freund, gab nämlich eine Disputation „Decades binae Thesium medicarum" am 25. Febr. 174I heraus, in welcher er aufs heftigste eine Menge von Linné ausgesprochener medizinischer Ansichten angriff und überhaupt die Bedeutung seiner Schriften zu verringern suchte. Wer hierbei Wallerius unterstützte, und welche Hoffnungen man auf sein Auftreten setzte, ist nunmehr schwer zu sagen. Einige Aeußerungen in der von Wallerius herausgegebenen Abhandlung zeugen davon, daß er sich wenigstens mit Rosén beraten und von ihm Auskünfte bezüglich seines Themas erhalten hat.

$\mathrm{Da}$ Wallerius sich nicht gescheut hatte, einige Sätze teils aus ihrem Zusammenhange herauszureißen, teils ihnen eine mehr oder weniger falsche Bedeutung unterzulegen, so ging daraus wohl klar genug seine Absicht hervor, das wissenschaftliche Ansehen Linnés zu untergraben. Der bittere Ton, der die Abhandlung durchzog, war augenfällig. Die Ventilation der Walleriusschen Disputation war für jene Zeit recht stürmisch und gab zu lärmenden Auftritten unter der akademischen Jugend Anlalo ${ }^{2}$ ).

Selbst verteidigte sich Linné weder gegen diese noch andere Angriffe, da er es im allgemeinen vermied, sich in polemischen Schriftwechsel einzulassen. Nur auf indirekte Weise erwiderte Li n n é auf dieses Pamphlet, da es ihm Anlaß gab, „Orbis eruditi Judicium de Caroli Linnaei M. D. scriptis" (8 Bl., kl. $8^{0}$ ) herauszugeben ${ }^{3}$ ). In dieser äußerst seltenen und ohne Druckort und Jahr (I74I) erschienenen Broschüre finden sich Linnés Schriften aufgezählt und Urteile von mehreren der hervorragendsten Gelehrten jener Zeit (Boerhaave, Burman, Sloane, Dillenius, Sauvages, Haller u. a.) über Linnés Schriften angeführt, wie sie teils in Briefen an ihn selbst,

I) Protokoll des Consistorium Academicum vom 18. Aug. und 25. Aug., 4. Okt. und 6. Dez. 1740. Die Professoren Klingenstjerna und Ol of Celsius sahen sich genötigt, am 20. März I74I das Konsistorium daran zu erinnern, „daß, da von denen, die sich angemeldet und zu disputieren haben, keine Kandidaten für die medizinische Professur mit ihren Proben zurückstehen, wohl zur Abstimmung und zur Abgabe von Vorschlägen $z u$ schreiten wäre."

2) Die in der ersten (schwedischen) Ausgabe dieser Schrift gegebene Darstellung von dem fraglichen Disputationsalkt ist hier weggelassen worden, nachdem Th. M. Fries in seiner großen $\Lambda$ rbeit über L in nć (I, S. 288-304) eine ausführliche, auf alle zugänglichen Akten gestïtate Schilderung von demselben gegeben hat.

3) Diese Schrift ist als Faksimileausgabe aufs neue erschienen, Berlin 190 I, I6 S. in $8^{0}$. 
teils in gedruckten Arbeiten ausgesprochen worden sind. Diese Schrift, die dem großen Publikum nicht zugänglich gewesen zu sein scheint, wurde nur an Linnés Freunde und einige Mitglieder des Reichstages verteilt.

Linné wurde zum Professor der theoretischen und praktischen Medizin am 5. Mai 1741 ernannt. In der Freude darüber, das Ziel erreicht zu haben, das zu erreichen er so lange gewünscht und erhofft hatte, schrieb er gleich darauf an Sauvages:

„Durch Gottes Gnade bin ich nun von der elenden Praxisplackerei in Stockholm befreit; ich habe die Stelle erhalten, die ich mir so lange gewünscht; der König hat mich zum Professor der Medizin und Botanik an der Universität Upsala ernannt und mich dadurch der Botanik zurückgegeben, von der ich drei Jahre lang, die ich unter Kranken in Stockholm habe zubringen müssen, verbannt gewesen bin. Bleiben mir Leben und Gesundheit vergönnt, werden Sie, hoffe ich, mich nun etwas in der Botanik ausrichten sehen" ${ }^{1}$ ).

Nachdem Linné während des Sommers seine auf Ersuchen der Stände vorgenommene Öländische und Gotländische Reise ausgeführt hatte, begann er im Herbst 1741 seine Vorlesungen über das System der Krankheiten (historia morborum) oder, wie wir nun sagen, allgemeine und Ispezielle Pathologie, ein Gegenstand, den er später oft behandelte ${ }^{2}$. Z Zu Beginn des folgenden Jahres wurde der Austausch der ILehrfächer, von dem oben bereits die Rede gewesen, zwischen Rosén und Linné zur Ausführung gebracht. Das Protokoll des Konsistoriums vom 14. Nov. I741 teilt nämlich mit, daß der Kanzler in einer Verfügung vom I. desselben Monats ein Gutachten des Consistorium academicum über die Supplik eingefordert habe,

„,in welcher die Professoren der medizinischen Fakultät in dem Wunsche, mit vereinten Kräften das studium medicum hierselbst zu Ansehen zu bringen und sich dadurch einigermaßen des Wohlwollens Sr. Hochgräfl. Excellenz würdig zu machen, und in der Berücksichtigung dessen, was ein jeder von ihnen mit größtem Vergnügen treibt, und wozu er am meisten Anlage zu haben scheint, um die gnädige Erlaubnis Sr. Excellenz nachsuchen, zwischen sich die Vorlesungen in der Weise repartieren zu dürfen, daß der Königl. Leibmedicus Herr Prof. R osén praxin medicam, anatomiam, physiologiam, pathologiam und chymiam pharmaceuticam übernimmt, der Herr Prof. Doctor Linnaeus dagegen in der Botanik, chymia metallurgica, semejotica, diaetetica und materia medica unterrichtet, sowie die Intendenz über den botanischen Garten übernimmt, und da Herr Prof. Linnaeus solchermaßen mietsfrei im botanischen Hause wohnen werde,

I) Brief an Sauvages vom I4. Mai I741.

2) "Nunc totus sum in historia morborum, quam publice doceo". Brief an A. von Haller vom 10. April 1747. 
welche Vergünstigung sonst Herrn Prof. Rosén zukam, so bittet sich letzterer 'Herr Prof. dagegen aus, gleichfalls mietsfrei ebensoviel Zimmer im Nosocomium academicum bewohnen zu dürfen, woselbst er beabsichtigt, an gewissen Tagen der Woche in Gegenwart der Studierenden der Medizin kranke Leute zu examinieren, ihre Krankheit festzustellen und nach bestem Wissen ihnen dafür Rat zu erteilen."

Nachdem der Kanzler am 21. Jan. 1742 den Vorschlag genehmigt hatte, übernahm Rosén Anatomie, Physiologie, Aetiologie und die Lehre von der Zusammensetzung der Medikamente nebst der Oberaufsicht über das akademische Krankenhaus, während Linné über Botanik, Materia medica, Semiotik, Diätetik und Naturgeschichte vorlesen sowie die Pflege des botanischen Gartens übernehmen sollte.

Obwohl Linné von dieser Zeit an sein Interesse hauptsächlich der Naturwissenschaft widmete, war er gleichwohl ebensosehr infolge seiner früheren Tätigkeit und seiner Dienstobliegenheiten als der engen Verbindung, die damals zwischen Botanik und Heilwissenschaft herrschte, ständig mit der Erörterung und Bearbeitung medizinischer wissenschaftlicher Fragen beschäftigt. Nach der Sitte jener Zeit, in öffentlichen Disputationen die Resultate seiner Forschungen niederzulegen, gab Linné eine sehr große Zahl akademischer Abhandlungen heraus, und sie sind es hauptsächlich, aus denen wir Kenntnis seiner medizinischen Ansichten ,und Lehren gewinnen. Diese Abhandlungen kamen gewöhnlich in der Weise zustande, daß Linné, nachdem er in seinen Vorlesungen ein Thema behandelt hatte, einen seiner Schüler, der gerade eine Abhandlung zur Erlangung des Doktorgrades herauszugeben hatte, dasselbe näher ausarbeiten, die Literatur durchsehen und der Darstellung die gebührende Form geben ließ. Viele von diesen Abhandlungen tragen freilich den Namen des jungen Verfassers, obwohl sie zum größten Teil entweder direkt aus Linnés Feder hervorgegangen sind, oder der Hauptsache nach Aufzeichnungen bei seinen Vorlesungen darstellen ${ }^{1)}$. Sie bilden die

I) Hierüber teilt J. G. A crel in seiner bekannten "Tal om Läkarevetenskapens grundläggning och tillväxt vid rikets älsta lärosäte $i$ Upsala" (,,Rede über die Begründung und das Wachstum der ärztlichen Wissenschaft an der ältesten Hochschule des Reiches in Upsala“) (1796), S. 156 folgendes mit: „Selten waren seine Lektionen auf größeren Blättern als einem länglichen Papierstreifen geschricben, den er gefaltet $z$ wischen den Fingern hielt, und an dem er mit dem Daumen die Stelle, wo er schloß, markierte. Alle Disputationen schrieb er dictando, teils auf schwedisch, teils auf lateinisch, deren Ordnung und Feilung dann Sache der Respondenten war: und obwohl er sich selbst nicht um die Latinität in ihncn bekümmerte, gab cr doch seine Zufriedenheit zu erkennen, wenn sie gut gcschrieben waren, und umgekehrt. Eine Disputation zu schreiben, nahm daher kaum drei Stunden in Anspruch, denn an und für sich war sie nichts anderes als eine Lektion über den Gegenstand, die der Respondent aufzeichnete." 
wichtigsten Quellen für das Studium der medizinischen Schriftstellerei Linnés und gewähren uns die sicherste Vorstellung von seinem medizinischen Standpunkte.

Von den verschiedenen $Z$ weigen der medizinischen Wissenschaften waren es vor allem die systematische Krankheitslehre (Nosologie), die Pharmakodynamik und die Diätetik, die Linné interessierten und seine Tätigkeit als Lehrer und Schriftsteller in Anspruch nahmen. Einen ziemlich großen Teil des akademischen Arbeitsjahres widmete er dem Unterricht in den ihm obliegenden medizinischen Lehrgegenständen. Während Linné in den Frühlings- und Sommermonaten über Botanik vorlas und seine fröhlichen Exkursionen in die Umgebung von Upsala anstellte, las er gewöhnlich im Herbst und Winter über Diätetik, Nosologie oder Materia medica vor. Der Einfluß, den er als Lehrer auf die Entwicklung und Verbesserung der ärztlichen Bildung in Schweden ausübte, läßt sich kaum hoch genug einschätzen. Im folgenden werden wir die sprechendsten Beweise für Linnés in dieser Beziehung außerordentliche, oft übersehene Bedeutung für sein Land kennen lernen. Eben von diesem Gesichtspunkte muß Linné als Arzt beurteilt werden, um von uns seinem vollen Wert nach gewürdigt werden zu können. Bei der Beurteilung von Linnés Verdienst als medizinischer Schriftsteller haben die, welche sich mit der Geschichte der Medizin befaßt haben, weder ein Auge für diese Seite seiner Tätigkeit gehabt, noch scheinbar seinen Schriften ein tieferes Studium gewidmet ${ }^{1}$ ). Mehrere überraschende Zeugnisse finden sich jedoch dafür, daß seine pharmakologischen und pharmakodynamischen Arbeiten noch bestehende Verdienste, auch für die allgemeine medizinische Wissenschaft besitzen, obwohl seinem pathologischen System und seinen medizinischen Ansichten

I) Davon zeugen Kurt Sprengels, Heinr. Haesers u. a. Bemerkungen oder Stillschweigen. Vgl. hierüber weiter unten. In seiner Anzeige der Arbeit des Verf.s über "Linné als Arzt" (1877) bemerkt Th. Husemann in den Götting. gel. Anzeigen, Stück 4I (1878): „Ueber Linnés Verdienste als Naturforscher, die der nordischen Universität Glanz und Ehre verliehn, über seine Leistungen als Gesetzgeber in den drei Naturreichen ist in allen Sprachen der civilisierten Welt geschrieben worden, aber daß der große Botaniker noch Zeit, Genie und Liebe für die von ihm gelehrten medizinischen Disziplinen iibrig behielt und durch seine Leistungen in diesen ein wohlbegründetes Anrecht sich erworben hat, auch in der Geschichte der Medizin ein bleibendes Monument zu erhalten, wird von den wenigsten gewürdigt. Es ist deshalb wohl kaum zu begreifen, wie ein deutscher Medizinalhistoriker den Klassifikationsversuch von Sauvages als wichtig, dagegen den von Linné als einen der Natur der Saclie nach nicht gelingenden bezeichnen kann. Im übrigen liegt Linnés Verdienst um die Medizin keineswegs hauptsächlich in diesem System." 
gleich denen seiner Vorgänger, Zeitgenossen und vieler späterer Schriftsteller, nunmehr nur historische Bedeutung zukommt. Es verging noch eine lange Zeit, bevor man in der anatomisch-physiologischen Forschung eine zuverlässige feste Grundlage für die Entwicklung der praktischen Medizin fand. Daß Linnés Aeußerungen jedoch zu vielen in der neueren Pathologie anerkannten Wahrheiten Anregung gegeben und sie vorbereitet haben, dürfte die detaillierte Darstellung im folgenden erkennen lassen.

Nachdem Rosén und Linné den medizinischen Lehrștuhl in Upsala übernommen hatten, wuchs die Zahl der Studierenden der Medizin schnell an, das Interesse für das Studium wurde allgemeiner und die Forderungen, die man an eine gründliche und vielseitige ärztliche Bildung stellte, größer. Die von Linnés Hand geführten Protokolle der medizinischen Fakultät geben uns Aufschluß darüber, wie die medizinischen Examina an der Universität Upsala um die Mitte des i 8. Jahrhunderts beschaffen waren, und welche Forderungen in dieser Hinsicht an zukünftige Aerzte gestellt wurden. Man ersieht daraus, daß schon zu jener Zeit ziemlich umfassende Studien zur Erlangung des medizinischen Doktorgrades erforderlich waren $\left.{ }^{1}\right)$. Das Licentiatexamen wurde nicht selten im Krankenhaus in Gegenwart

I) Da Linné eigenhändig die Fragen bei den von ihm angestellten Prüfungen notiert hat, so läßt sich ein klarer Einblick in die damaligen Verhältnisse gewinnen. Bei dem theoretischen Examen, das am Io. März 1742 mit Johan Westman angestellt wurde, kamen u. a. folgende Fragen vor:

Prof. C. Linnaeus:

\section{In semioticis :}

Tritaeus quis morbus?

Hujus signa quae?

Pleuritis quid?

Causa proxima pleuritidis quae?

Sedes pleuritidis an in vasis bronchialibus?

Signa essentialia pleuritidis quae?

Signa salutaria et lethalia quae?

Nephritidis calculosae signa quae?

Signa essentialia quae?

Siphilitidis signa essentialia?

Symptomata quae?

Quando exacerbantur symptomata?

\section{In diaeteticis:}

Senium qua diaeta acceleretur?

Carnium esus an salubris?

Puntz Anglorum an noxius?

Quomodo paratur ab Indis Puntz? 
aller Studierenden der Medizin angestellt, worüber Linné sich folgendermaßen äußert: „Daß examina rigorosa publice geschehen, ist meines Erachtes recht nützlich, denn dadurch erkennen die studiosi medicinae die Länge, Weite und Tiefe der Wissenschaft und gewinnen einen rechten methodum studendi und sehen, was ihnen fehlt,

Prof. Rosén:

\section{In anatounicis :}

Quaenam membrana maximi universalis?

$\mathrm{Ab}$ inedia an fibrae consumantur?

Auris quomodo dividitur? Meatus auditorius unde?

Glandulae quotuplices dantur?

Hepar an glandula conglomerata?

\section{In physiologicis :}

Transpiratio insensibilis an detur?

a quo inventa et descripta?

retenta an morbus causet?

Sudor et transpiratio an idem?

\section{In pharmaceuticis:}

Syrupus violarum an per coctionem paratur?

Syr. tussilaginis, papaveris albi quo modo?

Paregoricis quibus habemus opus?

Bei dem darauf folgenden praktischen Examen am 30. April 1742 hatte der Kandidat folgende Fragen zu beantworten:

Prof. Linna eus:

Quae cura apoplectici recentis?

Quae cura et signa iliacae passionis?

Quamdiu durat?

Cholerae signa et cura?

Opiata an tuto hic adhibenda?

Diuretica vegetabilia quae?

Parejae bravae quae dosis?

Purgans quoddam minime debilitans?

Vomitoria quaenam primaria?

Asari rad. an grosse vel tenue pulverisandus?

Doses purgantium et vomitoriorum?

Prof. N. Rosén :

Malignitas in morbis quid?

Prostratio virium a sphacelo unde?

Viscera in malignis febribus an inflammata?

Exanthematum in petechiis color, quid indicat?

Subito retrocedentes cur periculosae?

Phrenitidis imminentes signa quae?

Quamdiu durat phrenitis?

Scirrhi hepatis quae signa? quae cura?

Schließlich wurde in Rezepten examiniert, worauf der Kandidat einige purgantia, laxantia, succos expressos et innumera alia interna medicamenta verschrieb. 
abgesehen davon, daß mancher Studiosus dadurch abgehalten wird, allzufrüh sich ins Examen zu begeben.“

Der medizinische Studienkursus in Upsala war gemäß dem Fakultätsprotokoll vom 20. Febr. I749 auf folgende Weise eingeteilt:

Questio, in wie langer Zeit ein cursus praelectionum publicarum in facultate medica absolviert werden soll, wurde folgendermaßen beantwortet:

$$
\text { Rosén. }
$$

r. Demonstrationes anatomicae jeden Winter.

2. Pharmaceutica I Jahr.

3. Physiologia I Jahr.

4. Pathologia $I \frac{1}{2}$ Jahre.

5. Praxis $\mathrm{I} 1 / 2$ Jahre.
Linnaeus.

I. Demonstrationes plantarum in horto jeden Sommer.

2. Materia medica I Jahr.

3. Semiotica I Jahr.

4. Diaeta $I \frac{1}{2}$ Jahre.

5. Historia naturalis $\mathrm{I} 1 / 2$ Jahre.

Wenn zu der eigentlichen medizinischen Unterrichtszeit die Zeit hinzugerechnet wird, die zur Erlangung des philosophischen Grades erforderlich war, so ist die damalige akademische Studienzeit der Aerzte mit 8- ro Jahren anzusetzen.

Linné verstand es, ein zahlreiches und angeregtes Auditorium um sich zu sammeln. Seine Vorlesungen zeichneten sich durch Klarheit und praktische Richtung aus. Gern und oft wandte er die Lehren der medizinischen Wissenschaft auf die Verhältnisse des täglichen Lebens an. Dadurch wurde auch bei anderen als eigentlichen Medizinern Neigung und Lust erweckt, seine Vorlesungen zu besuchen. Weder vor noch nach seiner Zeit dürfte jemals ein Professor der Medizin in Schweden sich eines so zahlreichen Zuhörerkreises zu erfreuen gehabt haben, wie Linné. Wenn die Vorlesungen Systema morborum (Pathologie) und andere rein medizinische Themata behandelten, konnte die Anzahl der Schüler sich auf 50-60 belaufen. Besonders wurden die Vorlesungen über die „Diät" oder, wie man es heutzutage nennen würde, die spezielle Gesundheitslehre, sehr besucht. So zeichneten sich während der Frühlingssemester 1748 und $175^{6}$ nicht weniger als $\mathrm{r} 44$ und ror Zuhörer ein, aber „doppelt so viel auditores habe ich publice gehabt, als die sich haben einzeichnen lassen", und das bei einer Studentenanzahl von fünf bis sechshundert. Als Linné im Jahre ${ }_{17} 60$ zum fünften Male über dieses Thema vorlas, hatte er nicht weniger als 239 Zuhörer, die sich eingezeichnet hatten. In die Matrikel der medizinischen Fakultät wurden während Linnés Zeit nur 344 Studierende eingeschrieben, da aber zu seinen Vorlesungen, besonders den botanischen und den so viel erwähnten "herbationes Upsalienses“, eine zahlreiche Menge von den anderen Fakultäten hinzuströmte, kann man sich denken, 
welch ausgedehnten Schülerkreis er während der langen Zeit um sich gesanmelt hat $\left.{ }^{1}\right)$.

Mit ungeteilter Neigung und inniger Hingabe widmete sich Li nné dem Lehrberuf. Es war seine Lust und Freude, lauschenden Zuhörern die Früchte seiner Forschungen und den Reichtum seines Wissens mitzuteilen. Der Unterricht war stets Linnés liebste Beschäftigung, die Erweckung von Neigung und Lust zum Studium hat er als eine der wichtigsten Obliegenheiten des Universitätslehrers betrachtet. In Anbetracht der ausgedehnten Praxis und Dienstleistung bei Hofe, die Rosén von Rosenstein oblag, und infolge deren er ziemlich oft von der Universität abwesend war, scheint die Fürsorge für den Unterricht und die Geschäfte der Fakultät hauptsächlich auf Linnés Schultern geruht zu haben, der auch darüber klagte, daß er nicht selten allein die Vorlesungen für die zukünftigen Aerzte halten müßte. Sehr oft mußte er sogar in Rosensteins Fächern examinieren und war, als der bei den Fakultätssitzungen einzig Anwesende, derjenige, der die von der Fakultät verlangten Gutachten beschloß und abfaßte. Ja, Linn é hat während einer langen Reihe von Jahren mit eigener Hand die Protokolle der Fakultät geführt. Er schreibt darüber:

„Archiater Rosén kam den einen Tag von Stockholm und den anderen Tag reiste er auf sein Gut, so daß die studiosi medicinae ihn nicht mehr als zweimal gehört haben. Es ängstigt mich recht, denn wenn ich auch noch so sehr in meinem Fach arbeite, wenn nicht der andere ebenso auf der anderen Seite arbeitet, so fällt das Ganze doch hin“ "2).

Nur Linnés beharrlicher Fleiß und die Leichtigkeit, womit er arbeitete, machten es ihm möglich, die Last so mannigfaltiger und verschiedenartiger Beschäftigungen zu ertragen. Doch klagte er darüber, wie angestrengt er war. Schon früh schrieb er an seinen Freund $\mathrm{Abraham} \mathrm{Bäck:}$

„Wundere Dich nicht, lieber Freund, daß Du keine Antwort auf den zweiten Brief bekommen hast. Ich habe mit allem Briefwechsel im Lande und fast auch nach dem Auslande aufgehört, da ich in zehnjähriger Experience gesehen habe, daß er mir Mühe und wenig Gewinn oder Ruhe, wohl aber viel Schmerz bereitet hat.

Ich will mich jedoch bemühen, Dir, lieber Freund, auf das meiste zu antworten. Ich habe zehn Jahre lang meinem Körper keine Ruhe weder Tag noch Nacht gegeben. Kein Postgaul ist so übel hantiert worden, als ich von mir. Ich habe diese Eitelkeit endlich eingesehen und gefunden, daB sie mir nicht das mindeste außer Aerger, Gram, Sorge, Scham, Unlust und $\mathrm{Ha} B$ ein-

I) Th. M. Fries, Linne, II, 4, 148.

2) Brief an Abrah. Bäck vom 23. Febr. I75I. 
gebracht hat. Ich sah, daß die anderen, die ihren Dienst taliter qualiter taten, et sinebant mundum vadere prout vadat, vere beati lebten, geliebt von allen, zufrieden mit sich selbst, ruhig an Seele und Leib. Da faßte ich den Entschluß, meinen Dienst zu tun, zu essen und zu schlafen und froh zu sein. Ich habe nun auch nach einem Monat Experience mich ganz wohl befunden und meine frühere Krankheit eingesehen. Obwohl es einem anfangs etwas sauer wird, seine Natur und Gewohnheit zu wechseln, so sehe ich doch schon die Möglichkeit und schmecke, wie süß es ist" ${ }^{1}$ ).

Später entwirft er in einem vertraulichen Briefe an einen Freund folgendes Bild von seinem täglichen Leben:

„Jeden Tag lese ich öffentlich eine Stunde vor und gehe danach mit einer Anzahl Zuhörer ein Privatlollegium durch. Dann habe ich weiter noch eine Stunde mit Dänen und zwei mit Russen. Nachdem ich so vor dem Mittagessen fünf Stunden gesprochen, lese ich am Nachmittag Korrelitur, schreibe Manuskripte für den Buchdrucker und Briefe an meine botanischen Freunde, besuche den Garten und beschäftige mich mit denen, die mich besuchen, sehe auch nach meinem Stückchen Land, so daß ich manchen Tag kaum Zeit habe zum Essen. Wenn Sie mich sehen würden, würden Sie mein Los bedauern, der ich, umgeben von einer zahlreichen Familie, dennoch Zeit haben muß zum Umgang sowohl mit Landsleuten als mit Ausländern, die hier ankommen. Während meine Amtskameraden täglich die Annehmlichkeiten dieses Lebens genießen dürfen, habe ich Tage und Nächte an der Erforschung einer Wissenschaft zugebracht, die nicht Tausend werden vollenden können, gar nicht $z u$ reden davon, daß ich täglich meine Zeit mit wissenschaftlichem Briefwechsel vertue und so mir ein vorzeitiges Alter zuziehe. Wenn der Höchste mir noch einige Jahre vergönnt, will ich das alternde Pferd vom Joche befreien, auf daß es sich nicht völlig auslaufe und schließlich lächerlich werde (solvam senescentem equum, ne currat ad extremum ridendus et ilia ducat). Wenn es mir dann gelingt, in meinem Garten ein paar seltene Pflanzen zu haben, so will ich mich ihrer freuen ${ }^{2}$ ).

Zahlreiche Zuhörer strömten zu Li n n és Hörsälen aus Schweden wie aus dem Auslande ${ }^{3}$ ). Verf. empfindet es als eine Pflicht der Dankbarkeit, hier daran zu erinnern, daß auch Finnland das Glück gehabt hat, eine Anzahl Männer zu besitzen, die in seiner Schule erzogen worden sind. Die Protokolle der medizinischen Fakultät in Upsala erwähnen unter denen, die sich Lin nés Unterricht zu Nutze gemacht haben, nicht weniger als I5 Finnländer und 3 aus dem Viborger Län. Sei es uns erlaubt, ihre Namen mit dem Tribut der

I) Brief vom 2. Jan. I75 I.

2) Briefe an N. J. Jacquin vom 20. März I 76 I und vom I. April I764, abgedruckt in Caroli Limnaei Epistolae ad Nic. Jacquin, ex autographis ed. C. N. à Schreibers, Vindobon, I $84 \mathrm{I}$.

3) Ueber Linnés Schüler, schwedische und ausländische, vergl. Beilage XIX in Th. M. Fries' Biographie. 
Verehrung und Liebe zu verflechten, der nun von dankbaren Herzen dem Andenken seiner unvergänglichen, weitumfassenden Tätigkeit dargebracht wird. Viele von den schönsten Blättern, welche Finnlands Literaturgeschichte aufzuweisen hat, knüpfen sich an diese denkwürdige Zeit in Schwedens neu erwachtem wissenschaftlichen Leben. Mit Freuden erinnern wir uns, dal manche kräftige Anregung für die Entwicklung der finnländischen Kultur letzthin ihre Wurzel in dem überwiegenden Einfluß hat, den Linné auf dem Gebiete der Naturwissenschaft ausübte. Verf. hat bereits in einer anderen Schrift Linnés Bedeutung in dieser Hinsicht dargestellt und braucht hier nicht bei dieser Seite seines Andenkens zu verweilen ${ }^{1}$.

\section{II.}

Von allen den vielen Aerzten und Naturforschern unter Linnés Zeitgenossen, mit denen er in wissenschaftlichem Briefwechsel stand, gibt es keinen, dem L in né größeres Vertrauen und innigere Freundschaft entgegenbrachte, als Boissier de la Croix de Sauvages, Professor an der medizinischen Schule zu Montpellier ${ }^{2}$ ). Dreißig Jahre ihres Lebens hindurch standen diese Männer, die einander nicht gesehen oder persönlich gekannt haben, in einem lebhaften und emsigen gegenseitigen Austausch ihrer Ideen und Erfahrungen. Für die Beurteilung von Linné als Arzt und medizinischem Schriftsteller gibt es keine reichere Quelle als dieser Briefwechsel mit Sauvages. Er gewährt uns einen tiefen Einblick sowohl in seine medizinisch-theoretische Anschauungsweise als in die mehr praktische Seite seiner Tätigkeit. Es hat daher ein großes Interesse, gelegentlich diese eigenen Aeußerungen Linnés an seinen Freund Sauvages mitzuteilen, wenn auch die Uebersetzung sicherlich sie zu einem Teil ihrer eigentümlichen saftigen Färbung beraubt.

Von der Stunde an, wo Linné zum ersten Male Sauvages' Arbeit über die Krankheitsklassen sah, wurde er von einer tiefen, innigen Freundschaft für den Mann erfaßt, bei welchem er dasselbe Bedürfnis zu systematisieren, denselben ordnenden Geist wie bei sich selbst wiederfand. Obwohl Linné eben zu jener Zeit rastlos und eifrig an der Herausgabe der botanischen Schriften arbeitete, die seinen Ruhm begründeten und plötzlich ihn auf den Platz erhoben,

I) Otto E. A. Hjelt, Naturalhistoriens studium vid Abo universitet (Das Studium der Naturwissenschaft an der Universität Ảbo), Helsingfors 1896.

2) Geb. am 12. Mai 1706, zuerst Botaniker, dann Professor der Medizin, gest. am 19. Februar 1767 . 
den er seitdem in der Geschichte der Wissenschaft eingenommen hat, sieht man gleichwohl, wie Linn e mit der ganzen Lebhaftigkeit seines Wesens und seiner Liebe sich auch zur Heilwissenschaft hingezogen fühlte. Diese Arbeit erweckte in dem Grade Linn és Aufmerksamkeit und Bewunderung, daß er sofort am 20. Februar 1737 an Sauvages schrieb und die Bekanntschaft mit ihm mit der Bitte um sein Buch einleitete ${ }^{1}$ ).

„Nach Ihrem Methodus morborum“ schreibt er, „habe ich vergebens in Schweden, Lappland, Norwegen, Dänemark, Deutschland, Holland und England gesucht, aber, nachdem ich bei einem Arzt in Leyden diese Arbeit zu sehen bekommen, habe ich Sie mit Erstaunen angeschaut und mein Innerstes von neuen Gedanken schwellen fühlen (praecordia intima sentii attonitus novis intumuisse curis). Ich habe gesehen, mit welch glücklichem Erfolg Sie eine schwere und verwickelte Wissenschaft in eine leichte verwandelt haben. Ich bedaure, daß die Anfänger (tyronum turba) nicht Kenntnis von Ihrer Arbeit besitzen, denn in ihr findet sich sowohl Methode als Kritik. Man hat bisher keine Methode in der Pathologie (historia morborum) gehabt; die ihre Regeln für Methode halten, sind urteilslos und gehen in die Irre (carent cerebro et excutiunt). Die Bestimmungen für die Krankheitsgattungen können nur den Krankheitszeichen entnommen werden (e signis exposcenda est omnis indicatio generica). Ich kann unmöglich Ihrer Schrift entraten, jeder Tag, an dem ich Ihr Buch entbehre, ist mir eine Pein" ").

Nachdem Linné Sauvages Arbeit erhalten und sich mit seiner Darstellung des Systems der Krankheiten näher bekannt gemacht hat, schreibt er bereits am 2. Nov. desselben Jahres an den Verfasser:

„Mit größter Dankbarkeit habe ich Ihr Geschenk empfangen, eine systematische Arbeit über die Krankheiten, die weder ich noch andere ohne großen Verlust entbehren können. Ich finde darin in der vollendetsten Weise das entwickelt, was ich vergebens in anderen Schriften gesucht habe. Mein stumpfes Denkvermögen kann nur das erfassen, was systematisch zu begreifen ist, ob andere es können, weiß ich nicht, bezweifle es aber. Wer Sinn für Methode hat, findet in Ihrer Arbeit Wahrheiten, die kein anderer in vielen Jahren hätte entschleiern können. Ihre generischen Charalitere sind so einfach, daß sie von einem Blinden erfaßt werden können! Wie

I) Nouvelles classes de Maladies, qui dans un ordre semblable à cehi des Botanistes, comprennent les genres et l'especes de toutes les maladies avec leurs signes et leurs indications. Avignon $1731,12^{\circ}$. In diesem Brief stellt sich Linné mit folgenden Worten vor: "Tuam, vir illustris, expecto gratiam peregrinus licet et ignotus; sum enim ex iis, qui in eodem quo tu triumphasti campo, flores lego." - Der Titel dieser Arbeit ist nach "British Museum Catalogue of Printed Books" angegeben worden. Bemerkenswert ist, daß der Titel etwas anders von Hoefer und Quérard mit Paris als Druckort angeführt wird, wàhrend das Buch überhaupt nicht von Brunet und anderen Bibliographen erwähnt wird.

2) Brief an Saugag vom 20. Jan. 1737 . 
genau, wie richtig haben Sie nicht die Krankheitsarten zusammengesucht und dargestellt; Sie allein"1).

Linné erlaubt sich sogar, Sauvages gute Ratschläge bezüglich seiner Schrift zu geben, und bittet ihn, er möchte Synonyme und Zitate aus anderen Verfassern hinzufügen, wie die Botaniker zu tun pflegen. Schließlich bedauert Linné, daß diese Arbeit nicht lateinisch herausgegeben sei, und fordert $\mathrm{S}$ a u va ges wiederholentlich auf, sie in die genannte Sprache zu übersetzen.

"Wenn meine Bitten etwas bei Ihnen bedeuten, bitte ich Sie inständig, Ihre Krankheitsklassen in römischem Gewande herauszugeben. Tun Sie dies, so werden nicht nur ich und unsere schwedischen Hochschulen, sondern die ganze Welt Ihnen verbunden und dankbar sein. Sie sind unter den Aerzten der einzige Systematiker. Sie allein haben das Eis gebrochen und den Weg gebahnt. Wenn Sie es nicht einst tun, was soll ich nur sagen! Sie dürfen es nicht übel nehmen, wenn ein anderer es übernimmt, und, sollte er es auch schlecht tun, so muß doch das Wohl des Allgemeinen den Vortritt haben, und Ihr Ruhm wird wider Ihren Willen sich ausbreiten" ${ }^{2}$ ). "Ich bitte Sie darum, Ihre ,Classes morborum" in lateinischer Sprache herauszugeben. Es ist meine Absicht, über Ihre Arbeit vorzulesen, sie sowohl Anfängern als Gelehrten zu empfehlen, ein anderes damit vergleichbares Buch kenne ich nicht. Sie haben es versprochen, ich bitte Sie, halten Sie Ihr Versprechen (promisisti, quaeso et promissis tene); ich beschwöre Sie darum (per sacra medicinae obsecro) “ ${ }^{3}$ ).

Linné gibt in seinen Briefen unaufhörlich der ungeteiltesten Bewunderung für Sauvages' Verdienste um die wissenschaftliche Medizin Ausdruck und schreibt:

„Falls es wahr ist, wie es stets der Fall sein wird, daß die Heilwissenschaft sich auf zwei Grundpfeiler, die Kenntnis der Krankheiten und der Arzneimittel stützt, falls es wahr ist, was der Neid selbst zugibt, daß Sie zuerst die Natur der Krankheiten entschleiert haben (solus cognitionem morborum primus denudasti), falls es wahr ist, daß die Kenntnis der Arzneimittel sich auf die Kenntnis der Pflanzen gründet, denen die vortrefflichsten Arzneimittel entnommen werden, wahrlich in all diesem müssen Sie als groß angesehen werden, der Prophet gilt aber nichts in seinem Vaterlande. Glückliche Landsleute, wenn sie ihren Reichtum wüßten (felices agricolae, bona si sua norint $)^{4}$ ). Ich bitte Sie, senden Sie mir Ihre Pathologie, Sie allein schätze ich als Verfasser (tu mihi unicus author); andere mögen sagen was sie wollen, die Unwissenden verstehen nicht, was Methode ist. Sie allein haben den Weg erschlossen, die blinden Maulwürfe weigern sich, ihn zu betreten" ${ }^{5}$ ).

I) Brief an Sauvages vom 2. Nov. 1737 .

2) Brief vom 21. Jan. 1740.

3) Brief vom 20. Sept. 1740.

4) Brief vom 14. Okt. 1755 .

5) Brief vom 30. Okt. 1758. 
Man dürfte nicht zu weit gehen, wenn man den Gedanken ausspricht, daß es nächst Boerhaave keinen gegeben, der größeren Einflulo auf Linnés Stellung zu der medizinischen Wissenschaft ausgeübt hat als Sauvages. Er war es, der andauernd Linnés Liebe und Interesse für die Medizin wachhielt. Es ist sogar wahrscheinlich, daß ohne die enge und innige Freundschaft, die diese Meister der Wissenschaft miteinander verband, L in né unter der wachsenden Last seiner naturwissenschaftlichen Arbeiten allmählich die Liebe seiner Jugend zur Medizin verloren hätte. Der Einfluß von Sau va ges' Schriften auf Lin nés medizinische Arbeiten ist unbestreitbar, und noch gröluer zeigt sich dieser Einfluß hinsichtlich seiner 'Tätigkeit als Lehrer in einigen der Zweige der medizinischen Wissenschaft.

Um zu verstehen, wie Sa uva ges' Schriften ein so warmes und lebhaftes Interesse bei Linné erweckten, müssen wir uns daran erinnern, dal die spezielle Pathologie bis dahin noch von niemand methodisch bearbeitet worden war. Linnés reich entwickelte Anlage zu einer systematischen Betrachtung der Natur zwang ihn, sie auch auf dem Gebiet der Medizin anzuwenden. Als nun Sa v va ges der selbst ein hervorragender Botaniker war, in seiner Arbeit über die Klassifikation der Krankheiten eine Methode eingeführt hatte, die in vielem an die Art und Weise der Botaniker, die Pflanzen zu ordnen und aufzustellen, erinnerte, war es klar, daß Linné mit Begeisterung ein solches System aufnehmen würde.

Zwar finden sich auch schon aus früherer Zeit Aeußerungen in dieser Richtung. Schon Sydenham forderte dazu auf, die Krankheiten nach dem Vorbilde der Botaniker $z u$ ordnen ${ }^{1}$, und auch Baglivi erachtete es für notwendig, daß ,alle Krankheiten, um leichter und sicherer voneinander unterschieden werden zu können, nach botanischer Methode in bestimmte Gattungen und Arten gebracht werden müßten“. Sa u va ge s gebührt jedoch das Verdienst, den Versuch gemacht zu haben, auf Grund gemeinsamer Symptome die Krankheiten in bestimmten Klassen, Ordnungen und Gattungen nach ihrer größeren; oder geringeren Uebereinstimmung miteinander z.u ordnen. So unsicher dieser Grund zufolge der mangelhaften Kenntnis jener Zeit voll der Natur der Krankheiten in Wirklichkeit auch war, und so sehr auch eine solche Einteilung teils verwandte Leiden voneinander trennte, teils wesentlich verschiedene vereinigte, so konnte doch dieses System Sauvages nicht umhin, Linnés

I) „Primo expedit, ut morbi omnes ad definitas ac certas species revocentur, eadeın prorsus diligentia ac $\alpha \dot{x} \varrho i \beta \varepsilon \iota \alpha$, qua id factum videmus a botanicis scriptonbus in suis phytologiis“, Opera Universa, Lugd. Bat. 1754, S. I3. 
Bedürfnis nach bestimmten leitenden Grundsätzen bei der Ordnung der Erscheinungen in der Welt der Krankheiten zu befriedigen.

Obwohl Sauvages demnach Linné die erste Anregung zur Bearbeitung der Systematik der Krankheiten gegeben und er in seinen Vorlesungen über Nosologie, wenigstens $\mathrm{zu}$ Beginn seiner Lehrtätigkeit, Sauvages' System und der von ihm aufgestellten Klassifikation der einzelnen Krankheiten folgte, führte doch Linné später, je mehr er sich seinem Gegenstand widmete und größere Erfahrung in der praktischen Medizin gewann, wesentliche Veränderungen darin ein. Wie wir weiter unten sehen werden, wurde Linnés Aufstellung der Krankheiten mit der Zeit immer selbständiger und führte ihn zur Aufstellung eines eigenen medizinischen Systems. Da diese Einteilungsversuche durchaus von der bis dahin gewöhnlichen Methode abwichen, erregten sie große Aufmerksamkeit, und Linné schreibt darüber:

„In meinen öffentlichen Vorlesungen bin ich bis zu den Paralysen gekommen. Die Anzahl der Zuhörer ist jeden Tag sehr groß. Ich verstehe nicht, wie Sie alle Schriftsteller in dieser Frage haben durchgehen können; die meisten habe ich von der Bibliothek erhalten, alle die Schriften aber, die Sie angeben, habe ich mir nicht verschaffen können. Wahrhaftig, welche Blindheit bei den Aerzten (summa amaurosis medicorum), die Ihr goldenes Buch entbehren können. Anfangs wurde ich von meinem Amtsbruder ausgelacht, als ich ihm sagte, ich beabsichtigte, die Krankheiten in Klassen, Gattungen, Arten, Synonymen usw. einzuteilen, und er meinte, ich könne die Krankheiten nicht anders auffassen als ein Botaniker die Pflanzen. Nun tut er es nicht mehr, da fast alle Studierenden der Medizin mich hören, ihn aber nur wenige. Er fragte, wer dieser Sauvages ist; anfangs billigte er nicht die Methode, weil er sagte, er kenne die Krankheiten nach ihren nächsten oder inneren Ursachen. Ich gestehe, daß ich ohne Ihre Arbeit nicht über Semiotik vorlesen könnte" "1).

Es ist leicht ersichtlich, daß es eben die Bekanntschaft mit Sa uvages war, die Linné dazu führte, schon zu Anfang seiner akademischen Lehrtätigkeit die Vorlesungen über allgemeine und spezielle Pathologie zu halten, an denen er später fortgesetzt Umänderungen vornahm ${ }^{2}$. Durch einen seiner Schüler, der in einer akademischen Abhandlung seine Aufzeichnungen aus diesen Vorlesungen mitgeteilt

I) Brief an Sauvages vom 2. Dez. I74I. Später hatte Linné die Genugtuung, daß Rosén von Rosenstein selbst über seine Genera morborum vorlas. Vgl. Stoever, a. a. O., II, 199.

2) „Während dieses Herbstes (174I) habe ich mit Ihrer Erlaubnis öffentlich über Thre Arbeit „Classes morborum" Vorlesungen gehalten. Wenn die Studenten es verlangen (exigant), will ich sie in Uebereinstimmung mit Thren Krankheitsbeschreibungen in der Pathologie besonders herausgeben." Brief an Sauvages vom 2. Dez. I74I.

Hjelt, Carl von Linné. 
hat, besitzen wir Kenntnis von ihrem hauptsächlichsten Inhalt $\mathbf{1}$. Linné war auch selbst darauf bedacht, zur Anleitung für seine $\mathrm{Zu-}$ hörer diese scine Vorlesungen über Nosologie herauszugeben. Auf Grund derselben erschien später seine Schrift über „Genera morborum", 1763 .

Lin né, den Sauvages' Ansichten und seine Darstellungsweise lebhaft anmuteten, verfolgte mit großer Aufmerksamkeit die wissenschaftliche Tätigkeit dieses Gelehrten und konnte nicht genügend starke Ausdrücke für seine Bewunderung finden. ,Entweder ist zwei mal zwei nicht vier, oder es ist Ihre Methode zur Klassifizierung der Krankheiten der einzige bisher entdeckte medizinische Weg. Wenn dem nicht so ist, verstehe ich nichts von systematischer Wissenschaft ${ }^{2}$. Täglich studiere ich Ihre Physiologie, aber da ich nicht genug in der Mathematik bewandert bin, entgeht mir vieles. Wo ich Sie verstehe, erkenne ich mit Verwunderung, wie Sie tiefer in die Wissenschaft haben eindringen können als irgend jemand vor ihnen" ${ }^{3}$ ).

Nachdem $\mathrm{S}$ a u va ges weiter sein medizinisches System entwickelt und die Ergebnisse seiner Forschungen und seiner Erfahrung in der großen Arbeit "Nosologia methodica sistens morborum classes juxta Sydenhami mentem et botanicorum ordinem", Amstelodami i763, $8^{0}, 5$ Bde., die viele Auflagen erlebte, zusammengefaßt hatte, schreibt Linné:

„Weder will ich Ihnen schmeicheln, noch erlaubt das meine aufrichtige Freundschaft, aber das ist vollkommen sicher, daß nun eine neue Epoche für die Medizin beginnt (novum adeatur medicinae exercitium), da Sie allen Aerzten die Augen geöffnet haben, daß sie den Weg sehen und ihn in hellem Licht soweit wandern können, wie es uns Menschen möglich ist. Alles, was ich jemals von anderen gelernt habe, finde ich bei Ihnen wieder, aber noch tausendmal mehr als mir oder einem anderen bekannt gewesen ist. Für mein Teil beginne ich von neuem zu studieren, und ein jeder, der es versteht, möge beginnen, wie gründliche Kenntnisse er auch zu besitzen vermeint." „Ich habe keinen Fehler in Ihrer Arbeit „Systema morborum" gefunden; ich habe sie wie ein Schüler (tyro) gelesen, nicht einmal Aristarchus würde Fehler finden, sondern sie mit Erstaunen lesen“4).

I) „Seit der Zeit, wo der Herr Präses sein akademisches Lelıramt angetreten, hat er seinen Schülern eine systematische Kenntnis von den Krankheiten beizubrıngen (inculcare) gesucht und unermüdlich es jedes dritte Jahr wiederholt." Joh. Schröder, Genera morborum, Diss. acad., Upsaliae 1759.

2) Brief an Sauvages vom 11. Nov. 1748.

3) Brief vom 14. Okt. 1755 an Sauvages, der kurz vorher seine „Elementa physiologine", Amstelodami 1755, herausgegeben latte.

4) Briefe vom 3. Aug. I764 und 3. Mai 1765. Die für die vorliegende Arbeit benutzte Auflage ist in Amsterdam 1768 gedruckt und enthält 1602 Seiten in $4^{\circ}$. 
Die große Bedeutung, die Linné den Arbeiten Sauvages' für das Studium der Medizin beimaß, zeigt sich deutlich darin, daß er sie den Studierenden der Medizin zum Lesen empfahl und Sa uvages aufforderte, eine größere Anzahl Exemplare seiner Pathologie zum Verkauf nach Schweden zu senden. Er sagt, er brauche bis zu einhundert Exemplaren, und verspricht, sie an einem einzigen Tage zu verkaufen ${ }^{1}$ ). Die Kenntnis von Sauvages' System verbreitete sich auf diese Weise allgemein unter Linnés Schülern. Der Einfluß, den Sauvages auf die ärztliche Bildung in Schweden ausgeübt hat, list sehr groß gewesen, und dieser französische Gelehrte dürfte in keinem Lande, sein Vaterland kaum ausgenommen, größeres Ansehen genossen haben als in Schweden.

Sauvages seinerseits fühlte sich in hohem Grade durch die Anerkennung geschmeichelt, die Linné ihm widerfahren ließ. Nicht nur in seinen Briefen drückt er seine Dankbarkeit für den Beifall aus, den Linné seinen Arbeiten und seinen Forschungen schenkte, er äußert auch gleichzeitig, daß dieses günstige Urteil um so höher zu schätzen sei, als es von einem Manne ausgesprochen wurde, der den Wert einer wissenschaftlichen Methode zu beurteilen vermöge ${ }^{2}$.

Durch Linnés Vermittlung wurde Sauvages' Name sogar der schwedischen Literatur einverleibt. Anläßlich einer in Schonen I745 ausgebrochenen epidemischen Viehseuche (dysenteria boum febrilis) teilte Sauvages auf Linnés Bitte seine Erfahrungen über die Natur lund Behandlung dieser Seuche mit, die auch in Südfrankreich 'geherrscht hatte. Diesen Brief Sauvages' übersetzte Linné und lief ihn in den Abhandlungen der Schwedischen Akademie der Wissenschaften I746 unter dem Titel: „Ueber die im Jahre I746 in Europa grassierende Viehseuche" schwedisch erscheinen; er schreibt darüber:

„Dieser Brief hat allen so sehr gefallen, daß man darüber neidisch werden könnte; ich habe keinen Ausländer in Schweden so großen Ruhm um eines Aufsatzes willen gewinnen sehen“ ${ }^{3}$ ).

I) Brief von 1753 .

2) „Daß dieses Gebiet der Erkenntnis von mir glücklich bearbeitet worden ist, erkennt der berïhmte schwedische Archiater Linnaeus in seinen Amoenitates academicae, Vol. VI, an; daß er in seinen Briefen in schmeichelhaften Ausdrücken die Nosologie beurteilt, schreibe ich seinem Wohlwollen zu. 'Da er aber in vielen Hinsichten und besonders in der Beurteilung von Methoden der hervorragendste Mann ist, schätze ich mich glücklich, daß diese "meine Methode seinen Beifall erlangt hat". Vorrede zu Nosologia methodica, I. S. 90 .
3) Brief von 1747 . 
Die eigentliche Abhandlung, die Sauvages über diesen Gegenstand herausgegeben, „Mémoire sur la Maladie des Boeufs du Vivarais" (Montpell. I 745), wurde dann auf Linnés Fürsorge ins Schwedische übersetzt ${ }^{1}$ ).

In den Abhandlungen der Akademie der Wissenschaften I75I kommt ferner ein Aufsatz von Sauvages, „Anmärkningar om refbensmusklernas fibrers ställning" („Bemerkungen über die Stellung der Rippenmuskelfasern") vor, in welchem er die Gesetze der Mechanik anwendet, und den er mit den Worten beschließt: „Wird nicht auch hierdurch bestätigt, daß Gott alles nach Maß, Zahl und Gewicht geschaffen hat?"

Es waren nicht nur Fragen betreffs der systematischen Nosologie und der medizinischen Theorie, in denen Linnè und Sauvages ihre Ansichten und Erfahrungen austauschten. Einerseits lieferte Lin né dem Forscher im Süden wichtige und wertvolle Auskünfte über die nordischen Krankheitsverhältnisse ${ }^{2}$ ), andererseits kommen ständig gegenseitige Mitteilungen über die Natur und Behandlung einzelner Krankheiten vor. Durch Sauvages erhielt Lin né Kenntnis von der Behandlung gewisser Krankheiten mittelst Elektrizität. Es scheint, daß $\mathrm{S}$ auvages sich eine längere Zeit mit dieser Frage beschäftigt hat, da er zum Beweis für den Wert seiner Kurmethode Linné eine Menge von ihm gemachter Beobachtungen mitteilt ${ }^{3}$ ).

Diese Mitteilung interessierte Linné aufs allerhöchste und er antwortet Sauvages:

„Was Sie von der Elektrisation schreiben, ist in hohem Grade merkwürdig. Noch hat niemand bei uns begonnen, sie anzuwenden, ich werde aber sogleich damit Versuche anstellen"4). "Thre Beobachtungen über die Elektrisation sind ausgezeichnet und sind in der Societät verlesen worden. Alle preisen Sie, da Sie bisweilen uns Ihre Untersuchungen mitteilen, während viele andere das nie tun" ${ }^{5}$ ).

1) Unter dem Titel „Anmärkningar öfver boskapssjukan uti Vivarais af Herr de Sauvages", Stockholm 1748,32 S. in $8^{\circ}$ (mit einem kurzen Vorwort von Linné, der die Uebersetzung der Arbeit durch Mag. Stecksenius hatte besorgen lassen).

2) Briefe vom 21 . Jan. I 740 , I744, I753, vom 20. Dez. 1754 , vom 24. Febr. 1756.

3) Brief vom 12. April 1749 .

4) Brief vom 22. Aug. 1749 .

5) Brief vom 21. Aug. 1750. Diese Bemcrkung bezieht sich auf eine kurz vorher von Sauvages der Sozietät der Wissenschaften in Upsala eingereichtc Abhandlung, "Usus electricitatis in rheumatismo", abgedruckt in Acta Soc. reg. Scient. Upsal. 17421750, Stockholm 1751, S. I-8. In den Abhandlungen der Sozietät 1742, gedruckt in Stockholm 1748, findet sich ein Aufsatz von Sauvages „Observationes physicae", Beobachtungen übcr Catalepsis delirans und Acr lethalis enthaltend. 
Im Anschluß an diese Mitteilungen über die Einwirkungen der Elektrizität auf gewisse Krankheiten scheint die medizinische Fakultät in Upsala bei der Regierung angefragt zu haben, ob nicht der Studiosus der Medizin, der für die Anstellung dahingehender Untersuchungen angenommen werden sollte, ein höheres Stipendium erhalten könnte. Eine Königl. Verfügung vom 28. Sept. 1752 bestimmte,

„daß das doppelte stipendium regium dem studiosus medicinae zu erteilen ist, der zur Vornalme von Elektrisierungsversuchen an Kranken angenommen wird und bei den Observationen darüber gehörige Kontrolle anstellt und Aufzeichnungen macht".

Bevor wir das innige Freundschaftsverhältnis verlassen, das sich zwischen Linné und Sauvages durch ihren Briefwechsel über medizinische Fragen entwickelt hatte, wollen wir hinzufügen, daß dieser Briefwechsel ebensosehr auch die Botanik berührte. Linné schrieb oft seinem Freund in besonderen botanischen Fragen und bat ihn um seinen Rat, und der Austausch von Pflanzen zwischen den beiden Gelehrten war sehr lebhaft. Sie beschränkten sich nicht nur auf wissenschaftliche Mitteilungen, sondern sie interessierten sich auch für die gegenseitigen Familienverhältnisse. Auler detaillierten Angaben über einzelne häusliche Vorfälle findet man in Linnés Briefen warme Grüße von seiner Frau und seinen Kindern an Sauvages' Gattin Jeanne Yolande und ihre Kinder. Als Sauvages sich vermählte, schrieb Linné an ihn: „Von Gottes Segnungen ist eine liebe Hausfrau die vornehmste. Glücklich ist der $\mathrm{zu}$ erachten, dem er eine frohe, liebende, freundliche Gattin gegeben" ${ }^{1}$ ).

Das offene und aufrichtige Freundschaftsverhältnis zwischen Linné und Sauvages gewährt uns auch in eine andere Seite von Linnés Charakter einen Einblick, in seine Auffassung von literarischen Gegnern und Neidern. Sie verrät dieselbe naive, treuherzige, gutmütig scherzende Anschauung in Rede und Schrift, wie sie Literaturkenner in neuester Zeit dazu geführt hat, Linné zu den prosaischen Dichtern Schwedens zu rechnen. „Sie brauchen sich nicht“, schreibt er, „darüber zu wundern, daß Sie Feinde haben. Da Sie nicht Ebenbürtige haben können, ist es nötig, daß Sie Feinde haben. Ich bitte Sie, prüfen Sie alle die Aerzte, welche ihrer Zeit die größten gewesen sind, und zeigen Sie mir einen einzigen, der nicht Gegner gehabt hat. Ich wenigstens kenne keinen solchen“ ${ }^{2}$ ). „Wenn ich beginnen wollte, auf die Bemerkungen meiner Krittler zu

1) Brief vom 1I. Nov. 1748 .

2) Brief vom I4. Juni 1743 . 
antworten, so wäre es bald aus mit mir (dudum de me actum fuisset), und es bliebe mir nichts anderes übrig, als Verteidigungsschriften zu schreiben. Den Urteilen meiner Nachfolger würde ich dennoch nicht entgehen können“ 1). Als La Mettrie in seinem Buch "Penelope“ (1748) Linné heftig angriff und ihn mit Schmähungen überhäufte, antwortete er nicht darauf, schrieb aber an Sauvages, „daß er, nachdem Materia medica fertig geworden, sich nicht weiter mit Schriftstellerei befassen, sondern seiner Bequemlichkeit und seinem Vergnügen leben wolle, wie seine Freunde und Kollegen" 2). Es ist bekannt, daß, als La Mettrie fälschlicherweise Linné vorwarf, er habe den Menschen zu den Säugetieren in dieselbe Klasse mit dem Pferd und Schwein gestellt, Voltaire zu ihm äußerte: „Oui, mais vous conviendrez que, si M. Linnaeus est un cheval, c'est le premier de tous les chevaux."

Man hat die Vorstellung gehabt, daß Linné, nachdem er den Lehrstuhl der Botanik übernommen, ganz und gar mit seiner Tätigkeit als Arzt aufgehört hätte. Zwar bemerkt er selbst, „entweder mußte die Professur oder die Praxis vernachlässigt werden, bediente also hiernach niemals andere als Freunde und Arme" 3 ), wir besitzen aber eine Menge Beweise dafür, daß Linné sich dennoch nicht vollständig der Ausübung des ärztlichen Berufes entzogen hat. Besonders seinen Freunden diente er mit seiner Erfahrung. Es ist rührend zu sehen, mit welcher Unruhe Linné, als er von der Krankheit des Kanzlers, Grafen C. Gyllenborg, erfuhr, sich beeilte, sich mit dessen Arzt, seinem Freunde Abr. Bäck, in Verbindung zu setzen.

„Ich höre, daß Sie täglich bei Sr. Excellenz, meinem eigenen Apollo, sind. Ich habe zu meinem großen Leidwesen erfahren, daß Sr. Excellenz noch immer täglich von seinem schrecklichen Leiden gepeinigt wird; ich habe in diesem Sommer an das Leiden sehr viel gedacht, es wird sicher ein ulcus internum sein. Ist dem nun so, so wird es kaum ein Mittel für dieses Leiden geben, wenn nicht Radix herbae Britannicae, dieses bitte ich Sie um alles in der Welt nicht zu vergessen. Ich wage es, sie so hoch zu rekommandieren, daß ich niemals mit gutem Gewissen sterben kann, wenn ich hören sollte, daß Sr. Excellenz stürbe, ohne dieses Mittel versucht zu haben; ich weiß von Wirkungen, die es bei allen ulcera interna gehabt hat, woselbst die ossa angegriffen waren, wie sie niemals ein anderes Mittel hätte prästieren können. Aber es muß einige Zeit hindurch gebraucht werden. Das Pulver zu $3^{i}$ pro Dosis jeden Tag. Mein lieber Präses (B ̈̈ck war jetzt Vorsitzender der Akademie der Wissenschaften), wenn Sie mich lieben, probieren Sie alles, und wenn nichts anderes möglich

I) Brief vom 14. April 1754 .

2) Brief von 1748 .

3) Egenhändigra Anteckningar, S. 201. 
ist, verlingern Sie ihm wenigstens die Zeit, denn wenn er seine Augen schließt, dann öffnen andere Fata die Augen bei der Akademie. Lassen Sie mich wissen und überzeugt sein, daß Sie radicem britannicae brauchen" 1 ). "Es dürfte wohıl nichts schaden, mit infuso juniperi die Kraft der Rd. Britannicae mehr nach den vias urinarias zu determinieren, nur darf es nicht zu stark genommen werclen, da es andere Kraft hat, als Rd. Brit. Seien Sie nicht zu sparsam in der Dosis und Zeit, mit einem Medikamente zu continuieren, das so gar keine Gefahr besitzt, und denken Sie daran, daß medicastri oft die größten Kuren machen mit sufficienti dosi und diuturno usu" 2 ).

In Linnés Schriften finden wir im übrigen zahlreiche Spuren davon, daß er sich andauernd für die praktische Heilwissenschaft interessierte und ihre Fortschritte verfolgte, wovon iwir uns weiter unten in der speziellen Darstellung seines medizinischen Systems überzeugen werden. In seinen Briefen teilt er nicht selten die Erfahrungen mit, die er am Krankenbett gewonnen, und befragt in schweren und verwickelteren Fällen seine medizinischen Freunde um ihre Ansicht. Groß war jedoch Linnés Praxis nicht, und noch weniger war sie einträglich. In einem schwachen Augenblick schreibt er an Abr. Bäck:

„Es war eine unglückliche Stunde, als ich die Professur annahm. Hätte ich mich an auream praxin gehalten, wäre ich wohl zu dieser Zeit etwas weiter gekommen und wäre wohl versorgt" ${ }^{3}$ ). „Du klagst, lieber Freund, darüber, daß Du auream praxin für einige Tage verlierst, was soll ich aber sagen, der ich so viele Jahre lang sie total um der Wissenschaft willen aufgegeben habe. Hätte ich den achten Teil meiner Arbcit darauf verwandt, so wäre ich vielleicht practicus gewesen und hätte mich wohlbefunden. Sed sero sapiunt Phryges': ${ }^{4}$ ).

Dieser kurze geschichtliche Ueberblick über Linnés Beschäftigung mit der Systematik der Krankheiten zeigt schon das lebhafte Interesse, das er dem Studium der Medizin widmete. Eine eingehendere Darlegung des pathologischen Systems Linnés und der ihm zugrunde liegenden Theorien, wie wir sie im folgenden geben werden, wird nebst der spezialisierenden Darstellung seiner praktischen medizinischen Erfahrungen erkennen lassen, welch mächtigen Einfluß seine Tätigkeit als Lehrer und Schriftsteller auf lange Zeit hinaus, ja in gewisser Hinsicht bis auf unsere Zeit auf die ärztliche Bildung in Schweden ausgeübt hat.

I) Brief vom 5. Sept. 1746 .

2) Brief vom 19. Sept. 1746.

3) Briel vom 10. Febr. 1756.

4) Brief vom 22. Dez. $176 r$. 
Noch andere Gebiete der medizinischen Wissenschaft sind es aber, auf die Linnés Genie, Kenntnisse und rastlosen Fleilo befruchtend gewirkt haben. Vor allem läßt sich dies von der sog. Materia medica oder der Arzneimittellehre sagen, die er nicht nur mit zahlreichen Beobachtungen von bleibendem Wert bereicherte, sondern deren leitende Grundsätze er auf eine originelle und geistvolle Weise entwickelte. Diese unentbehrliche Helferin der praktischen Medizin schuf überall, wo man mit der Einführung eines geordneten Medizinalwesens begonnen hatte, besondere, den jeweiligen Verhältnissen in den verschiedenen Ländern angepaßte Pharmakopöen. Sogar einige größere Städte eiferten zu jener Zeit danach, einen solchen Kodex zu besitzen. So kam die erste Pharmakopöe Schwedens, „Pharmacopoeja Holmiensis" r686 (auf Kosten des Magistrats) heraus. Da man im Pflanzenreiche die wichtigsten und wirksamsten Arzneimittel suchte und zu finden glaubte, so bildete, bevor die Chemie in der Herstellung derselben ein neues gewinnbringendes Feld industriellen Erwerbs gefunden hatte, die pharmazeutische Botanik die Grundlage für die Pharmakopöe, deren hauptsächlichsten Teil die Pflanzen einnahmen, deren medizinischer Nutzen mehr oder weniger allgemein anerkannt war. Daß Linné sich besonders mit der Materia medica beschäftigte und in ständig wiederkehrenden Vorlesungen darüber die jungen Aerzte mit pharmakodynamischen Ansichten, auf die seine ganze Therapie sich stützte, vertraut machte, versteht sich von selbst. Aus dieser Zeit stammen das allgemeine Interesse und die Spezialkenntnisse in Fragen der Materia medica her, wie sie seitdem bei den schwedischen Aerzten und Apothekern lebendig geblieben sind. Aber nicht nur der Unterricht gewann hierdurch. Auch die praktische Medizin hatte hiervon unschätzbaren Nutzen, wie das weiter unten eingehender dargelegt werden soll.

Daß Linné sich bereits frühzeitig mit dem beschäftigte, was er später „Materia medica“ nannte, und spezielle Studien auf diesem Gebiete trieb, ersieht man daraus, daß er während seiner Studienzeit dahingehörige Angaben in einer noch erhaltenen Handschrift "C a roli Lin na e i Pharmacopoea Holmiensis, in qua Medicamenta simplicia, quae in officinis Pharmaceutis Sueciae prostent, Systematice secundum Regna 3 Naturae recensentur" sammelte ${ }^{1}$ ). Die Mängel der geltenden schwedischen Pharmakopöe waren indessen immer augenfälliger geworden, sowohl in Ermangelung neuerer, in Aufnahme gekommener Arzneimittel als durch die Beibehaltung einer großen

I) Th. M. Fries, Linné, II, S. I74. 
Menge unnützer, geradezu abergläubischer Stoffe. Während Li nné seine „Materia medica" (I749) ausarbeitete, worüber mehr weiter unten, traten diese Mängel stärker und stärker zutage. Er lenkte A br. Bäcks Aufmerksamkeit darauf und fügte hinzu: „,Du, der Du der einzige im Collegium medicum bist, der etwas tun kann, solltest die Pharmacopöen raffinieren" 1 ).

Durch Königl. Erlaß vom i 3. Okt. I $75^{2}$ erhielt das Collegium medicum die Weisung, ,für die Einrichtung eines neuen Apothekerbuches oder Dispensatoriums Sorge zu tragen, wie es in allen anderen wohlbestellten Reichen und Staaten geschehen ist, seitdem die Wissenschaften aus ihrem früheren Dunkel herausgetreten sind“. Zunächst kam 1757 nur des Collegium medicum „Nachricht von einigen Aenderungen in der Stockholmischen Pharmacopöe" heraus, während die eigentliche Umarbeitung sich mehr und mehr in die Länge zog. Aus einem Briefe an Abr. Bäck ersieht man, daß Linné sehr tätigen Anteil an der Ausarbeitung der neuen Pharmakopöe nahm und kräftig zu der ausgezeichneten Form beitrug, in der sie schließlich 1775 herauskam $\left.{ }^{2}\right)$.

Zwei für Linnés Ansichten bezeichnende Briefe an A br. Bäck seien hier mitgeteilt :

„Zwei Nächte habe ich auf das Papier verwendet, denn ich hatte tagsüber nicht Zeit, daher wurde es so schnell geschrieben. Willst Du es deutlich reinschreiben lassen und es mir in den Ferien auf ein paar Tage senden, so würde ich es genauer durchsehen und zusehen, daß nichts weggelassen wird, denn man darf nichts Essentielles vergessen. Meinst Du nun, daß etwas weggelassen werden könne, so laß uns zeitig darüber korrespondieren" 3 ).

Weiter heilt es in einem Briefe vom 23. Nov. 1773:

„Es giebt nichts, was das Publikum (totaque res medica) heißer vom Collegium medicum ersehnt, als eine neue Ordination der Simplicia, worauf das andere sich stützt, denn jetzt ist es eine schreckliche, weitläuftige, zu mehr als der Hälfte unnötige Sammlung, und wir gehen mit Absicht am hellen Tage mit der Laterne. Was die Simplicia angeht, so ist die Sache nun ziemlich leicht auszuarbeiten, aber ich möchte geme hören, was das Königl. Collegium aus einem großen Teil der Praeparata und noch mehr aus den Composita macht.

Ich habe einmal selbst unter Aufopferung einiger Näclite die Simplicia zusammengeschrieben; vielleicht könnte ich noch zwei Stellen raffinieren, aber

1) Brief vom 23. Okt. 1749.

2) O. E. A. Hjelt, Svenska och Finska Med. Verkets Hist. I/Geschichte des Schwedischen und Finnländischen Medizinalwesens), III, S. 491-497.

3) Brief vom 22. Dez. 1761 . 
Prof. B ergius hat mir- geschrieben und mich gebeten, mitzuteilen, woran noch weiter zu erinnern wäre. Darum bitte ich nun, daß, nachdem Herr Prof. Bergius sie durchgelesen und zum Druck approbiert hat, ich sie zuletzt noch einmal durchzublättern bekomme, dann will ich ehrlich sagen, ob ich noch mehr weib.

Es kann wohl angehen, auszumustern, aber neue medicamenta simplicia anzugeben, die für souverän ausgegeben werden, dürfte schwerer sein. Denn die Apotheker, die sie nicht bei den Materialisten erhalten, würden sagen, daß das Collegium etwas befiehlt, was nicht zu erhalten ist; sie werden die Medicos bitten, sic zu verschaffen, wo sie dann bezahlen wollen, et sexcentas difficultates. Ich wünschte hierüber ein paar Stunden mit Dir und den hauptsächlichsten der Herren mündlich zu sprechen, da dürfte alles leichter gehen. Sonst fürchte ich, daß es beim Kochen sauer wird. Komme ich im Januario, wenn G. will, zur Bibelcommission, so dürfte es am zweckmäßigsten durchzuführen sein, oder es geht niemals; dann wäre es auch unnötig, sie mir zu schicken."

Die allgemeine Aufmerksankeit und die lebhafte Teilnahme, die Linnés wissenschaftlichen Arbeiten zuteil wurde, findet zum Teil ihre Erklärung in der praktischen Richtung jener Zeit. In jeder naturwissenschaftlichen Entdeckung wollte man eine neue ergiebige Quelle für die Hebung des allgemeinen Wohlstandes und die ökonomische Entwicklung des Landes finden. Es war natürlich, daß auch Linné, so hoch er auch die freie Forschung stellte, den Bestrebungen der Zeit seinen Tribut zollte, die nicht selten den Wert der Wissenschaft nach den „Tonnen Gold“ einschätzte, die das Land der Berechnung nach dabei ernten würde. Der Hauptzweck der Reisen, welche Lin né auf Staatskosten nach iverschiedenen Provinzen des Reiches unternahm, war die Erforschung ihrer Naturprodukte, ihrer Erwerbsquellen und übrigen ökonomischen Verhältnisse. Bei diesen Forschungen wandte Linné unter anderem seine Aufmerksamkeit auch der Pflege und Ernährung der Haustiere in verschiedenen Teilen des Landes zu. Man findet in seinen Reiseschilderungen eine Menge Beobachtungen über für die Haustiere nützliche und schädliche Pflanzen, wie auch bezüglich ihrer Krankheiten und der gegen diese benutzten Arzneimittel. Auf Linnés Aufforderung wurden dann an verschiedenen Orten Untersuchungen darüber angestellt, welche Pflanzen sich für die eine oder andere Art von Haustieren eigneten, und infolge dieser Beobachtungen erhielt man eine Menge höchst wichtiger und bedeutsamer Beiträge zur Kenntnis ihrer Lebensweise und Krankheiten. Linné schreibt selbst an Sauvages: „Ich habe diesen Sommer meine Untersuchungen darüber fortgesetzt, welche Pflanzen das Rindvieh frißt, und welche es verschmäht oder meidet, eine Arbeit, die, wie ich glaube, grund- 
legende Bedeutung sowohl für die Privatökonomie als für die Viehzucht selbst besitzt" 1 ).

Linné behandelte diesen Gegenstand kurz darauf in einer akademischen Abhandlung "Pan suecicus" (1749) ${ }^{2}$ ). Mehrere von seinen Schülern führten diese Untersuchungen fort und erweiterten sie. Zahlreiche Beobachtungen auf diesem Felde wurden von ihnen in verschiedenen Schriften und in den Abhandlungen der Schwedischen Akademie der Wissenschaften veröffentlicht. Es sei hier nur an J. O. Hagströms : bemerkenswerte, von ider Akademie herausgegebene Schrift über „Pan apum eller afluandling om de örter, af livilka bien hämta deras Honung och vax" („Pan apum oder Abhandlung über die Kräuter, aus denen die Bienen ihren Honig und Wachs holen“, I768) erinnert ${ }^{3}$ ).

Wegen der Erfahrung, die Lin n é sich auf seinen ausgedehnten Reisen erworben hatte, wurde er in Fragen bezüglich der Veterinärkunst Inicht selten von Behörden um seinen Rat angegangen, und sein Ausspruch wurde gewöhnlich für die Wahl der zu treffenden Maßnahmen entscheidend. In einem Briefe ian den Sekretär der Akademie der Wissenschaften P. E1vius schreibt Linné:

"Ich schicke Ihnen die ,Gedanken betreffend Rinderpest' zurück; ich möchte wohl wissen, wer sie geschrieben hat. Das heißt alles a priori verstehen oder ex cathedra gelehrt sein, das heißt gelehrt über das räsonieren, was man nicht versteht. Er hat nie gelesen, was der alte Celsus einstmals gesagt hat, nämlich: non post rationem medicina inventa est, sed post inventam medicinam ratio quaesita est.

Keineswegs ist die Rinderpest mit der Pferdeseuche verwandt, sondern so different wie Pferd und Kuh.

Doch gestehe ich, ich würde dafür sein, daß Baron Cederhjelms Beschreibung der Pferdeseuche gedruckt würde, sofern man sie nur nicht

I) Brief vom I I. Nov. I748.

2) Eine Bearbeitung davon ist gedruckt in Linnés Amoen. acad. II, Holmiae I 762 , S. 203, 24I und ferner (von P. G. T engmalm) in K. Patriotiska Sällskapets Hushailsjournal I779-I780, sowie auch von J. Chr. Schreber in Amoen. acad. X, Erlangen I790, aufgenommen.

3) Von dieser Schrift war Linné so entzückt, daß er am 28. Okt. 1768 an den Verfasser schrieb: „Ich habe achtmal Ihr Pan apum, das Sie mir freundlichst übersandt haben, durchgelesen: ich darf ohne Prahlerei gestehen, daß es ein Juwel ist. Ihre ganz neuen Beobachtungen, die kurze und geistreiche Schreibweise, Ihre klaren Gedanken und Schlüsse machen, daß der ein Herz von Stein haben muß, der nicht gerührt wird und eine Affeltion für das Buch bekommt, wie grob auch der Leser sei. Sie haben, Herr Doctor, mit dieser einzigen Schrift Ihren Namen so tief in den Fels der Zeit gegraben, daß kein Wechsel der Zeit ihn auslöschen kann. Icl gratuliere Ihnen, Herr Doctor, zur Unsterblichkeit." Ew. A ehrling, C. von Linnés Svenska arbeten (C. von Linnés schwedische Arbeiten), I, 1879 , S. 403. 
auf die Rinderpest anzuwenden versuchte, die von der anderen so verschieden ist wic Tag und Nacht. Baron Cederhjelm beschreibt aber hübsch die Pferdeseuche, die eine angina contagiosa ist.

Was die von einem Mitglied des Collegium medicum eingelieferte Observation des Dr. Hegart betrifft, so ist es eine febris contagiosa, ganz different von der des Barons Cederhjelm.

Lassen Sie sie um Gotteswillen nicht drucken, auf daß nicht die Akademie zum Gelächter für die ganze Welt werde.

Herr Hegart hat bei dem Pferd nach der Gallenblase gesucht und sie nicht gefunden, wie achtsam er dabei auch zu Werke gegangen; jedes Kind weiß, daß Pferd und Renntier nebst ihrer Gattung (species) keine Gallenblase haben. Du lieber Himmel, welche Barbaries scientiae historiae naturalis in hac amicissima patria" 1 ).

Li nné schrieb auch selbst einige für das größere Publikum bestimmte Aufsätze bezüglich der Krankheiten der Haustiere ${ }^{2}$, und in seinen Schriften befinden sich eine Menge Notizen, die sich mehr oder weniger auf die Veterinärwissenschaft beziehen und zum Teil auch in derselben Aufnahme gefunden haben ${ }^{3}$ ). Je weiter die Kenntnisse in diesen Dingen sich verbreiteten, um so mehr wurde die Aufmerksamkeit darauf gelenkt, wie wichtig es war, das Veterinärwesen des Landes zu ordnen, um so klarer zeigte sich die Notwendigkeit, eine besondere Unterrichtsanstalt für diese Zwecke einzurichten. Es

I) Brief von I746. Ew. A ehrling, C. v. Linnés Svenska arbeten, I, S. I7I.

2) Diese Aufsätze sind, soweit Verf. hat finden können, folgende: Arch. Linnaez Svar uppå L. Salvï bref angaende boskapssjukan dat. $\sigma$ Julz 1750 (Arch. Linnaei Antwort auf L. Salvius' Brief hezüglich der Rinderpest vom 6. Juli I750), abgedruckt in Salvius' Lärda Tidningar (Gelehrte Zeitungen) 1750, S. 2 Iо. Utdrag af Hr Archiatern och Riddarens Linnaei bref (om farsjukan) (Auszug aus Herrn Archiater und Ritter Linnaeus' Brief [über die Schafseuche]) vom I4. April I 756, nebst Oekonomielektor Karl Dahlmans „Berättelse öfver Färsjukan $i$ Länghındra härad och Stockholms län " (Bericht über die Schafseuche im Bezirk Långhundra und im Stockholmer Län) von der Gesundheitskommission herausgegeben, Stockholm I756. Beide später neu abgedruckt in Modees Werk, VI, 4408. Archiatern och Riddarens Herr Carl Linnaei till Upsala Lands Canzlie den I4 Juli 1761 aflämnade utlatande om den i länet försporda boskapssjukan (Des Herrn Archiater und Ritter Carl Linnaeus' an die Landeskanzlei in Upsala am I4. Juli I76I erstattetes Gutachten über die aufgetretene Rinderpest) in Inrikes Tidningar $176 \mathrm{I}$, No. 6I. Linné hat außerdem ein Vorwort zu Landeshauptnann G. Falkenbergs ,Anledning till en Mulo-Medicina, Tryckt till innevanarenas tjenst och nytta i Wästmanlands Höfdingdöme“ (,Anlcitung zu einer Mulo-Medicina, Gedruckt zu Nutz und Frommen der Einwohner der Landeshauptmannschaft Wästmanland"), Westerås $1763,8^{\circ}$.

3) J. K. K inberg, Linné och Veterinär-Vetenskapen. Föredrag vid K. VeterinärInstitutets i Stockholm femtioiriga jubileum (Liuné und die Veterinärwissenschaft, Vortrag bei dem 50-jährigen Jubiläum des Kgl. Veterinärinstituts in Stockholm), Stockholn I 872. Enthält ein Verzeichnis dessen, was in Linnés Schriften betreffend veterinäre Fragen vorkommt. 
geschah auf Linnés Aufforderung und Vorschlag, daß der Begründer des schwedischen Veterinärwesens, der so hoch verdiente Petter Hernquistl, sich dem Studium desselben widmete. In einem Briefe an den Vorsitzenden des Collegium medicum, Abr. Bäck, empfiehlt ihn Linné mit folgenden warmen Worten:

„In meinem vorigen Briefe erwähnte ich, daß für Professionem veterinariam nur vier Personen im Reiche seien, die meines Wissens dazu vorzuschlagen wären, daß ich aber nicht wüßte, ob einer von ihnen Lust hätte, sie anzunehmen. In Deinem letzten Briefe bittest Du mich, mit den hier Anwesenden darüber zu sprechen, was ich auch getan.

Magister Hernquist wäre der, der meines Erachtens am zweckmäßigsten zu gewinnen wäre. Das ist ein Mann, der nie eine Wissenschaft losgelassen hat, es sei denn, er habe sie penetriert, wenn er einmal angefangen. Du kannst mit ilım räsonieren, in welcher Wissenschaft $\mathrm{Du}$ willst, so wirst Du stets hören, daß er seinen Mann steht und Professorsstudien hat. Er hat einige Jahre lang Diätetik, Chemie, Materia medica, Naturwissenschaft in ihrem ganzen Umfang, Botanik, Systema morborum etc. gehört. Ich muß gestehen, ich habe keinen gesehen, der wie er durch die härteste Wissenschaft hindurchdringt; so daß ich sicher bin, er wäre der Mann, das zu lernen, was schon gefunden ist, und dann die ganze Wissenschaft auf reinem Grunde aufzubauen. Alle lobten ihn mir zuerst, aber sein Exterieur und seine Schweigsamkeit machten, daß ich ihn nicht für einen solchen hielt, bis ich ihn ein Jahr lang bei mir gehabt hatte. Sprich mit ihm, so wirst Du finden, daß ich viel zu wenig von seinem Merit gesagt habe"1).

Die schwedische Veterinärkunst hat demnach Linné nicht nur für viele wertvolle Beiträge zu ihrer Entwicklung zu danken, sondern vor allem für das Interesse, das er durch seine Untersuchungen und Beobachtungen für ihre Ausübung zu erwecken verstand, und die Anerkennung, zu der er ihr im praktischen Leben verhalf. Von dieser Zeit an begann die Veterinärwissenschaft in Schweden ihren Platz als ein wichtiges Glied im Wirtschaftsbetrieb des Staates und des Einzelnen $z u$ behaupten.

Die Medizin hat mehr als die anderen Wissenschaften nahe Berührungspunkte mit vielen Bedürfnissen des bürgerlichen, ja täglichen Lebens. Die ärztliche Wissenschaft ist dazu berufen, veredelnd und aufklärend in das Verhältnis der Menschheit zu der äußeren Natur und ihre Abhängigkeit von ihr einzugreifen, sie in dem Kampf gegen die Herrschaft der rohen Naturtriebe zu unterstützen und das Gefühl

1) Brief vom I. März $\mathrm{I}_{7} 6_{3}$, abgednuckt in J. E. Wikström, Conspectus Litteraturae Botanicae in Suecia, Stockholm 183I, S. 97. Ein weiterer Brief von Linné über Hernquist vom 29. März desselben Jahres findet sich bei Wikström, S. 99, und in Svenska och Finska Med. Verk. Hist., II, S. 597. 
von der Macht der Vergänglichkeit für sie zu mildern. Der medizinischen Wissenschaft fehlte es nie an Gelegenheit und Anlalu, sich in den von Zeit zu Zeit auftauchenden Fragen innerhalb der menschlichen Kulturarbeit und des istaatlichen Lebens auszusprechen. Die Geschichte der Wissenschaft zeigt uns auch, daß ihre Meister sich nicht gescheut haben, sich an die grole Masse des Volkes mit Ratschlägen und Aufklärungen zu wenden, ihre Erfahrung und die Ergebnisse ihrer Forschungen zu popularisieren. Auch Linné interessierte sich in hohem Grade für allgemeine hygienische Fragen. Mit Vorliebe 'hielt er Vorlesungen über die Bedingungen einer gesunden Lebensweise in ihren Einzelheiten, entsprechend den Forderungen der Gesundheitslehre und dem Wohlbefinden des Einzelnen. In zahlreichen Schriften sowohl wissenschaftlichen wie populären Inhalts suchte er unter den Aerzten und der Bevölkerung des Landes Kenntnis von den Wahrheiten der Diätetik zu verbreiten und ihnen Freunde im täglichen Leben und in der häuslichen Wirtschaft zu gewinnen.!

\section{Er schreibt hierüber selbst:}

„Linnaeus liest nun publice über Experimental-Diätetik mit Erfahrungen und Observationen; in welchen Dingen er mehr Erfahrungen durch Reisen und seine Lektüre gesammelt hat, als sie irgend ein Autor vorher besessen, weshalb auch sein Auditorium das größte ward“ "1). „Oeffentlich lese ich über Diätetik vor; kein Professor in Upsala hat während der letzten sechzig Jahre mehr Zuhörer gehabt als ich jetzt; die Diätetik trage ich vollständig auf Grund von Beobachtungen vor, und wenn es mir vergönnt wird, meine Arbeit zu veröffentlichen, zweifle ich nicht daran, daß sie vielen zu Nutze sein und Beifall gewinnen wird“"2).

Die Diätetik war übrigens ein Gegenstand, der Linné seit seiner Jugend aufs höchste interessiert, wozu er seit lange Materialien gesammelt hatte und woran er andauernd weiter arbeitete. Er schreibt an Albr. von Haller:

„Ich gehe nun mit größtem Eifer Ihren Kommentar zu Boerha ave durch. Ich bitte Sie, geben Sie uns die folgenden Teile betreffs der Diätetik. Das ist ein Gegenstand, an welchem ich meine Freude habe, und worin ich mehr gesammelt habe als, soviel ich weiß, irgend jemand anders. Neue Beiträge werde ich in Ihrem Buch finden. Was ich gesammelt, werden Sie einmal zu sehen bekommen, ich habe daran zehn Jahre lang gearbeitet" ${ }^{\prime 3}$ ).

1) Egenhändiga Anteckningar, S. 42.

2) Brief an Sauvages vorn 3. April 1743. „Der große Zulauf von Studenten zu meinen Vorlesungen hat bercits Neid bei mcinen (Kollegen) erweckt; ich muß diese Vorlesungen einige Jahre aufschieben, bis er sich gelegt hat.“

3) Brief an A. v. Haller vom 15. Scpt. 1770 und 29. Mai 1744. 
Im Zusammenhang mit dieser Popularisierung der Wissenschaft finden wir Linnés Namen auch auf dem Gebiet der medizinischen Volksschriften wieder. Zu Beginn seiner akademischen Tätigkeit schrieb Linné 'in den von O1. P. Hjorter herausgegebenen Kalendern leicht verständliche Aufsätze über medizinische Fragen 1). Seine „Anmärkningar om brännvin" (,Bemerkungen über den Branntwein"), welche ernste, höchst beherzigenswerte Warnungen gegen den überhandnehmenden Mißbrauch des Branntweins enthielten, erregten seinerzcit große Aufmerksamkeit, und das Gewicht von Linnés Namen verlieh dieser Aeuperung eine besondere Bedeutung. Diese Schrift hat noch in unseren Tagen eine Neuauflage erlebt. Im folgenden werden wir uns im Anschlub an die Darstellungen von Linnés medizinischem System näher mit seiner Tätigkeit auf dem Gebiet der Hygiene beschäftigen.

Es erübrigt noch, mit einigen Worten den Einfluß zu berühren, den Linné auf die allgemeinen medizinischen Angelegenheiten in seinem Vaterlande ausübte. Sein Rat und seine Erfahrung wurde sowohl von der Regierung wie von anderen Behörden oft zu Gutachten in öffentlichen Fragen in Anspruch genommen, auf die im einzelnen einzugehen, hier unmöglich wäre. Sie fallen zum großen Teil in den Rahmen einer speziellen Biographie. Wir haben bereits oben den Anteil erwähnt, den er an der Umarbeitung der schwedischen Pharmakopöe nahm, und seine Bestrebungen um die Einführung eines geordneten Veterinärwesens in Schweden. Hier wollen wir nur noch die Aufmerksamkeit darauf lenken, daß L in né während seiner tätigsten Lebensperiode durch seine Verbindung mit dem Collegium medicum einen sehr großen Einfluß auch in medizinischadministrativer Hinsicht ausübte.

Zu jener Zeit, wo es an öffentlichen Krankenhäusern noch fehlte, und die Militärärzte oder Chirurgen unter unmittelbarer A ufsicht der Militärbehörden standen, waren die Provinzial- oder Bezirksärzte eigentlich die einzigen aus Staatsmitteln besoldeten ärztlichen Beamten im Lande. Die Besetzung dieser Stellen mit geeigneten Personen war oft Gegen-

I) In den (von Hjorter herausgegebenen) Kalendern finden sich Abhandlungen von Linné: 1742 "Huscurer för frossan" („Hauskuren für das Wechselfieber"), 1745 "Contmuation of huscurerna för de gangbara sjukdomar" (,Kontinuation der Hauskuren für die grassierenden Krankheiten“), eine Anweisung zur Heilung der Ruhr, 1746, „Anmärkningar om Thee och theedrickande" („Bemerkungen über den Tee und das Teetrinken") 1747, "Anmärkningar on Caffe", I 748, "Anmärkningar om brännvin" (Bemerkungen über den Branntwein"), und im Stockholmer Kalender 1749 „Beskrifning om öl" (,Beschreibung des Biers"). 
stand des Briefwechsels zwischen Linné und dem „Praeses“ des Collegium medicum, seinem langjährigen Freunde A br. Bäck. Um genauere Kenntnis bezüglich der künftigen Acrzte und ihrer Anstellung im Amte zu erlangen, ersuchte das Collegium in einem Schreiben vom 24. April I 756 die medizinischen Fakultäten um regelmäßige jährliche Verzeichnisse von denjenigen, die das Licentiatexamen bestanden hatten und bald promoviert werden sollten, „weil durch Erlangung genauerer Kenntnis von der Kapazität eines jeden das Collegium fortan besser in der Lage sein dürfte, bei der Besetzung von Aemtern nicht einen weniger Geschickten einem Geschickteren, einen Jüngeren einem Aelteren usw. vorzuziehen, was aus Unkenntnis sonst leicht geschehen könnte, entgegen dem Recht und der Billigkeit, die das Collegium gegen einen jeden auszuüben aufrichtig wünscht und die Absicht hat". Zugleich wünschte das Collegium, durch Fürsorge der Fakultät Io-I2 Exemplare von allen sowohl pro exercitio als gradu herauskommenden medizinischen Disputationen zu erhalten, nebst den Programmata, „zugleich mit einer Abschrift der casus, die pro licentia von solchen Doctorandis ausgearbeitet worden, ferner auch die Doctoralquestion selbst und die darauf erfolgende Antwort, auf daß das Collegium, abgesehen von dem Vergnügen des Durchlesens solcher Arbeiten, Kenntnis von der Qualifikation der Bewerber zur Beförderung bei vorkommenden Vakanzen in den Provinzen erhalten möge".

Linné, der oft allein die Fakultät in Upsala repräsentierte, sandte am 24. Aug. desselben Jahres folgende Antwort ab:

„Die Facultät sieht sehr wohl ein, daß, wenn die Provinzen und Städte des Vaterlandes mit zuverlässigen und je nach den Umständen geeigneten Medici versehen werden sollen, das Königl. Collegium bei der Abgabe von Vorschlägen zur Wiederbesetzung erledigter Medicinalämter soviel Kenntnis wie möglich von der Qualification der Personen braucht, um sie mit gutem Gewissen der Königl. Regierung vorschlagen zu können. Die Facultät kann sich daher keinesfalls der Pflicht entziehen, dem Königl. Collegium in derartigen Angelegenheiten, und wann es nötig ist, alle die Nachrichten zu erteilen, welche sie zu geben im Stande sein kann. Will sich auch nicht weigem, dem Begehren des Königl. Collegii gemäß die Namen derjenigen einzureichen, die sich dem Licentiatexamen unterzogen haben, wie auch das Zeugnis hinzuzufügen, das die Naturgaben eines jeden, sein angewandter Fleiß und bekanntes Betragen verdienen, indem die Facultät wünscht, daß das Königl. Collegium dadurch in die Lage käme, die Bewerber hinreichend zu kennen. Außerdem wird die Facultät es nicht versäumen, die Betreffenden an ihre Pflicht zu erimnern, den Herren Mitgliedern des Königl. Collegii Exemplare ihrer im Druck herauskommenden specimina academica, zugleich mit dem Promotionsprogramm zuzusenden, um so weniger, als die 
Facnltäit sich in dem Glauben befunden, daß solches bisher beobachtet worden ist."

Linnés Briefwechsel mit A br. Bäck zeigt zur Genüge, wie oft er persönlich bei der Besetzung erledigter Stellen befragt wurde und welche entscheidende Bedeutung sein Ausspruch hatte. Daß Linné einerseits ein lebhaftes Bedürfnis fühlte, sich über die medizinischen Verhältnisse auszusprechen und die darauf bezüglichen Angelegenheiten $\mathrm{zu}$ diskutieren, geht auch aus diesen Briefen hervor. So schreibt er (in lateinischer Sprache) am I3. Dez. I 757 : „Möge Dein Gesundheitszustand mir das Vergnügen schenken, Dich in Upsala während der Ferien zu sehen, solange der Winter so milde ist. Oder könntest $\mathrm{Du}$ mich vielleicht für eine Nacht auf halbem Wege treffen? Sonst muß ich nach Stockholm reisen, um mit Dir über cine Sache von höchster Wichtigkeit und über den Zustand unseres Medizinalwesens und unsere Medizinstudierenden zu sprechen."

Wie warm Linné das Ansehen der Fakultät und die Förderung des medizinischen Unterrichts am Herzen lag, ersieht man gleichfalls aus diesem privaten Briefwechsel mit A b r. Bä ck, dem gegenüber er seine Unruhe und herzliche Sorge aussprach, so oft etwas darauf hindeutete, daß die Forderungen an die wissenschaftliche Ausbildung der Aerzte beiseitegesetzt oder nicht völlig anerkannt würden. Die Bedingungen für die Erwerbung des medizinischen Grades müßten stets hoch gestellt werden. Wir werden aus dem Folgenden ersehen, daß es die Sache der Wissenschaft und ihre Verteidigung war, die ihn in den Kampf gegen die aufdringliche Routine und Oberflächlichkeit trieb. So schrieb er an Abr. Bäck:

„Eine neue Nachricht von Göttingen ist die, daß Herr A urivillius, der dem Vernehmen nach der Schwiegersohn des Archiaters Rosén werden wird, nun dort promovieren soll; er reiste vor einem Jahre aus, hatte bis dahin wenig Chemie studiert, nichts aber sonst in der Medizin. Ja, so treiben ausländische warme Klimate rohe Burschen zur Frucht. Wohin soll es bei einem solchen Mißbrauch kommen, ich wundere mich, daß nicht ein jeder Studiosus medicinae ausrcist, um sogleich zu promovieren. Dann kommt mein Herr Doctor heim und wird sofort Professor, Archiater usw. Ja, so reist man per Wagen zur höchsten Spitze der Gelehrsamkeit" 1 ). „Wir wollen schon ehrlich examinieren, sofern nur das Königl. Collegium darauf hinwirken will, daß die Ungelehrten nicht deshalb ins Ausland reisen und sich den Grad kaufen, denn dann ist alles umsonst; es ist möglich, Euch Leute zu schaffen, die Ihr selber beneiden würdet, wenn die Herren Collegae in Stockholm mit uns gemeinsame Sache machen wollen" 2 ). "Wenn

1) Brief vom 28. Okt. 1749 .

2) Brief vom 3I. Mai 1757 .

Hjelt, Carl von Linné. 
kein Unterschied zwischen wirklichen und Pseudodoctores gemacht wird, dann ist es aus mit dem Ruf und dem Vertrauen unserer Doctoren" 1 ).

Allmählich bildete sich jedoch zwischen der Fakultät in Upsala und mehreren der Mitglieder des Collegium medicum ein kühles, ja sogar gespanntes Verhältnis heraus. Die nächste Ursache hierfür scheint gegenseitige Unzufriedenheit bezüglich angestellter Examina gewesen zu sein. Linné klagt über die schwankenden und geringen Forderungen medizinischer Kenntnisse, mit welchen das Collegium bei der Besetzung ärztlicher Stellen sich manchmal begnügte.

Er beklagt sich in einem Briefe an A b r. Bäck, dalo das

„Königl. Collegium solche als Licentiaten annimmt und anerkennt, die kaum medicinae alumni sind, auch vor der Regierung, als solche sie tituliert und ihnen Aemter hoc nomine überträgt. Wir müssen dann entwẹder promovieren oder das Collegium verletzen, wenn wir sie improbieren, und Ursache zur Feindschaft geben. Das Collegium recommandiert solche zu Provinciales, die auf keine Weise candidati sein können. Dennoch klagt man darüber, daß wir nicht alle gleich prästieren können. Dies sage ich im Vertrauen zu meinem lieben und vertrauten Freunde" ${ }^{2}$ ).

Besonders während des Krieges in Pommern (1757-1762) gab die Fakultät in Greifswald Anlaß zu Klagen durch die leichtfertige Weise, in welcher an der dortigen Universität der medizinische Grad erlangt werden konnte. Mehrere von den in der schwedischen Armee angestellten Chirurgen machten sich die Gelegenheit zunutze, ohne besondere Beschwerden sich diesen Grad zu erwerben. Linné, der mit Kummer von dieser bequemen Weise, die Examensforderungen der übrigen schwedischen medizinischen Fakultäten zu umgehen, erfuhr, schrieb aus diesem Anlaß an Abr. Bäck:

„Als junge Medici nach Pommern sollten, nahmen die Herren Collegii assessores Knaben und Burschen, die kaum in ein medizinisches Buch geguckt, solche, die meines Bedünkens nie mit gutem Gewissen die Behandlung von Menschen und christlichen Menschen übernehmen können, während sie gute und fleißige Leute übergingen, weil sie nicht bei ihnen gewesen waren (d. h. nicht in Stockholm studiert hatten). Diese haben sie nun zu Doctores promoviert, per quod quis peccat? In früheren Zeiten schrieb man an die Fakultäten, daß sie solche junge Leute aussuchen sollten, nun aber geht es in der kleinen Welt wie in der großen. Transeat etiam hoc cum caeteris erroribus. Ich schaudere, wenn ich höre, daß ein Haufe Burschen in Greifswald promoviert worden sind, von denen ich sicher weiß, daß sie von der Medizin nichts verstehen. Ihresgleichen hat wohl Schweden nie

I) Brief vom 2. März I76I. „Nisi distinguantur doctores a pseudodoctoribus, res acta erit de fama et fide doctorum nostratum."

2) Brief vom 17. Febr. $175^{8}$. 
gehabt, obwohl es mit vielen schwach genug bestellt ist. Es tut mir leid, dab unter Deinem Regiment solche existicren sollen"1).

Infolge dieser Klagen über die Leichtigkeit, womit der medizinische Doktorgrad in Greifswald erlangt werden konnte, sal sich das Collegium am 13. Jan. 1763 veranlaßt, der Regierung mitzuteilen, daß das Collegium beschlossen habe, „diejenigen, die hinfort an der Akademie zu Greifswald promoviert werden, einem solchen Examen zu unterziehen, wie es zuvor mit den doctores medicinae angestellt worden", die an ausländischen Universitäten promoviert worden waren. Auch Linné forderte eifrig das Collegium auf, ein Examen mit den Greifswalder Doktoren anzustellen, und schrieb an Abr. Bäck am 27. März 1764:

"Alle die, welche bei uns nicht Doctores werden, gehen nach Greifswald, wie Petersen, Ramström etc., und drei, die wir nicht durchlassen können, sind daran, denselben Umweg zu gehen; schließlich gehen alle. Das einfachste Mittel wäre das, wenn das Collegium sieht, daß es unwürdige Doctoren bekommt, die von Greifswald alle zu examinieren; die Geschickten approbieren, die anderen improbieren. Wenn man seine Sache zum Nutzen des Publikums und zur Sicherheit der Einwohner tut, was dienlich ist, so ist man nicht so leicht anzugreifen und hat das Publikum auf seiner Seite."

Auch Dispens von vorgeschriebenen Prüfungen oder wenigstens eine Umgehung der betreffenden Bestimmungen scheint sogar später vorgekommen "zu sein, nach einer Aeußerung Linnés an Abr. Bäck in einem Briefe vom 5. Juni 1772 zu urteilen: „Man hat mir gesagt, daß Se. Majestät eine Menge zu Doctores ernannt hat, sei so gut und laß mich dies wissen, wenn irgend möglich mit nächster Post. Es heißt, daß es Feldscherer und Feldschergesellen sind. Laß mich wissen welche?" Tatsächliche Beweise dafür dürften jedoch, soweit dem Verf. bekannt, nicht vorliegen.

Obwohl das Collegium medicum bereits in seiner an den Reichstag 1765 abgegebenen „Relation“ über die Leichtigkeit klagte, womit der medizinische Grad in Greifswald erlangt werden könnte, und über die Schlaffheit, welche die dortige medizinische Fakultät bei der Anstellung der vorgeschriebenen Prüfungen zeigte, scheint der oben angeführte] Beschluß des Collegiums nicht allgemeine Nachachtung Igefunden $\mathrm{zu}$ haben, was man daraus ersieht, daß mehrere schwedische Aerzte, die dort den medizinischen Grad erlangt hatten, es auch weiter unterließen, sich beim Collegium zur Erlangung völliger Approbation anzumelden \%).

I) Briefe vom 29. Mai 1760 und vom 2. Okt. 1762 .

2) Siehe O. ${ }^{\wedge}$ E. A. H jelt, Svenska och Finska Medicinalverkets Hist., I, S. $477-485$. 
Eine andere Ursache zu Mißhelligkeiten zwischen Linné und dem Collegium war das unklare Verhältnis, das zu jener Zeit noch zwischen den Ausübern der verschiedenen Teile der praktischen Heilkunde herrschte. Wir müssen uns daran erinnern, daßo man in Uebereinstimmung mit dem, was in anderen Ländern der Fall war, auch in Schweden einen scharfen Unterschied zwischen Aerzten und Chirurgen machte. Diejenigen, welche den operativen Teil der Heilkunde ausübten, die sog. Bartscherer (bardskärarne), bildeten eine eigene privilegierte Zunft, aus einer Anzahl Meisterfeldscherer nebst ihnen unterstehenden Gesellen und Lehrlingen bestehend, welche letztere von je ihren Meistern Unterricht erhielten. In Stockholm hatte sich, hauptsächlich nach französischem Muster, eine solche Korporation gebildet, die schließlich als staatliche Institution anerkannt wurde und I7I7 den Namen Chirurgische Sozietät erhielt ${ }^{1}$ ). Dieser Verein von Chirurgen hatte das Recht, innerhalb seines Gebietes den Unterricht zu regeln, und er verlangte daher als unerläßliche Bedingung von einem jeden, der als Mitglied des Vereins anerkannt werden und dessen Privilegien genießen wollte, daß er die vorgeschriebenen Lehrjahre und die einzelnen Grade durchgemacht hatte. Der Oberdirektor der Chirurgie im Reiche war Vorsteher dieser Korporation, welche im übrigen sich nicht als dem Collegium medicum unterstehend betrachtete. Um die Mitte des vorigen Jahrhunderts steht die Chirurgische Sozietät in Stockholm auf der Höhe ihres Ansehens, dank den hervorragenden Männern, die an der Spitze derselben standen und ihre Angelegenheiten leiteten: Ewald Ribe, S. Schützer, H. Schützer (geadelt Schützercrantz) und N. Ramström. Unter dem Einfluß mehrerer der Chirurgischen Sozietät angehörender Männer, welche nicht selten eine sehr ausgedelınte Praxis in Stockholm ausübten, und von denen auch einige Sitz und Stimme im Collegium medicum erhielten, wurden die rein praktischen, empirischen Studien im Gegensatz zu den akademischen begünstigt. Diese „chirurgorum turba“ wollte Linné niemals anerkennen. Sogar die Auszeichnungen, die diesem und jenem der hervorragendsten Männer der chirurgischen Schule zuteil wurden, verstimmten ihn aufs tiefste. Er schreibt darüber an Abr. $\mathrm{Bäck}$ :

„Gott verzeihe dem, der unseren gnädigsten König dazu verleitet hat, einen Chirurgus zum Archiater zu machen ${ }^{2}$ ). Er hat nie dem König treu

I) Ihre Geschichte findet der Leser in der eben angeführten Arbeit, I, S. 215-338.

2) Diese Auszeichnung war nämlich kurz vorher dem damaligen Oberdirektor der Chinurgic, Herman Schützer, zuteil geworden. 
gedient, und ich habe nie gehört, daß Aehnliches in der Welt geschehen, nicht einmal in Frankreich, wo die Chirurgi bei ihrem König so gesiegt haben. Der Zweck bei dem, der dem König hierzu geraten, kann, soweit ich sehe, kein anderer sein, als auf eimmal bei allen Medici die Sympathien für den König zu ertöten, und die haben bei den meisten im Reiche Influence. Kannst Du nicht dem König raten, ihn zum Kammerherrn zu machen, so hat er dasselbe, die Regierung aber entgeht den Folgen? Ich liege krank im Bette und schreibe dies 1 ). - Gebe Gott, der König hätte Schytzer zum Ritter, ja, Seraphimer gemacht, so hätte das nie so sehr der Medizin geschadet, nun haben die Chirurgi die Ehre bekommen, die sie noch nie bekommen haben, und die Comparation mit den Medicis. Mit einem Wort, die Medicin hat bei uns ihren stärksten Stoß erhalten, der vielleicht nie repariert werden kann. Ich hätte gewünscht, daß Ihre Majestäten dies nicht in Ihrer Historia hätten, denn alle Nationen wundern sich darüber" $\left.{ }^{2}\right)$.

Die Chirurgen jener Zeit (Meisterfeldscherer und Feldschergesellen) waren und verblieben für Linné eine Zunft von ausschließlich Männern der Empirie, manuellen Assistenten für den wissenschaftlichen Arzt. Er schreibt darüber an A br. Bäck:

„Die ganze Lage des gegenwärtigen Status medicus ist verfitzt und hat unendliche Confusion bewirkt. Die Herren Assessoren raten davon ab, academice zu studieren, es sei am sichersten, nur in das Nosocomium Holmiense zu gehen und solche Medici zu werden, wie die Geistlichen in einem Stift, die, sobald sie Studenten geworden, Stellen als Hausgeistliche annehmen, sich meritieren und Avancement suchen, so daß die Pfarrer dort schlimmer sind als Mönche. Lieber Freund, Du hast academice studiert und weißt selbst, wie die Wissenschaften einander die Hand reichen. Die Sache ist aber vielfältig verfitzt, so daß sie nicht aufgelöst werden kann, außer in der Weise, wie Alexander gordium auflöste; daher stammt nun die Verwirrung mit den Chirurgis und Pharmacopaeis und dem ganzen medizinischen Wesen. Chirurgi und Pharmacopaei werden Leibmedici, die Doctoren müssen das Maul aufsperren und zusehen. Was soll die Facultät tun, wenn sie gegen sich ein ganzes System angelegt sieht, sie zu untergraben. Wir suchen unseren Dienst nach bestem Vermögen zu verrichten, so daß wir ein gutes Gewissen haben, im übrigen müssen wir es gehen lassen, wie es geht" 3 ).

Der Unterricht an den Universitäten hatte sich indessen zunächst infolge der Tätigkeit Rosensteins, Linnés und Eberhard Rosenblads (in Lund) eine so allgemeine Anerkennung erworben, daß die weitgehenden Pläne der Chirurgischen Sozietät, durch überall im Lande verbreitete, staatlich besoldete und von den Feldscherern selbst ausgebildete sog. Chirurgen die Krankenpflege auf dem Lande

I) Brief vom 20. Nov. 1753 .

2) Brief vom 23. Nov. 1753 .

3) Brief vom 27. März 1764 . 
zu übernehmen, mifoglückte. Hätten diese Pläne Erfolg gehabt, so würden sie für eine lange Zeit die Wissenschaft der Heilkunde in Schweden und Finnland gehemmt und sie damit auf eine gewerbsmäßige Routine hinabgedrückt haben. Lin né unterstützte daher aufs wärmste das Collegium medicum in seinem beharrlichen Kampfe um eine wissenschaftliche Ausbildung der Aerzte und ihre Berechtigung ${ }^{1}$.

Weitschauender als irgendeiner seiner Zeitgenossen unter den Universitätslehrern und Mitgliedern des Collegium medicum sah Linné ein, daß das Studium der Chirurgie, um Früchte zu tragen, auf wissenschaftlichem Grund ruhen mußte. Nachdem P. Hamnerin bei der Regierung I74I eine vielbesprochene, von verschiedenen Seiten scharf kritisierte Schrift über die Einführung des Unterrichts in der Chirurgie an den Universitäten ${ }^{2}$ ) eingereicht hatte, hielt Linné bei einer Promotionsfeier am 30. Okt. 1747 eine Rede „de chirurgiae fundamento ex medicina" (über die medizinische Wissenschaft als Grundlage der Chirurgie). Ja, als es sich $175^{8} \mathrm{um}$ die Umgestaltung des akademischen Krankenhauses in Upsala handelte, machte er den Vorschlag (welchem jedoch der damalige Professor der betreffenden Disziplin, Sa m u el A u rivilli us, widersprach), daß die Chirurgie von der Professur der praktischen Medizin getrennt werden und einen besonderen Lehrer erhalten sollte, „auf daß auch die Chirurgie dort [im Nosocomium] demonstriert und mit den medicinae alumnis praktiziert werden könnte." "Dazu müßte ein solcher ausgesucht werden, der nicht die Kunst als ein Handwerk gelernt hätte, sondern die Chirurgie von Grund aus, auf Anatomie und andere nötige Teile gebaut, verstehe." Dieser Lehrer könnte auch über Verbandlehre (die zu jener Zeit durch ihre kunstvoll zusammengesetzten Binden eine große Rolle in der Chirurgie spielte), Obstetrik und gerichtliche Medizin vorlesen ${ }^{3}$ ). L in né wollte daher, daß jüngere, begabte Chirurgen akademische Bildung erhalten und an den Universitäten zugleich Medizin studieren sollten. Auf seine Fürsprache wurde später J. G. Acrel, der in Stockholm studiert hatte, 1767 zum Adjunkten der Medizin in Upsala ernannt, „denn ich finde, daß vor allem die Chirurgie hier in der Fakultät fehlt“.

I) Eine ausführliche Schilderung des langwierigen, bitteren Kampfes zwischen dem Collegium medicum und der chirurgischen Sozietät um die Mitte des I8. Jahrhunderts findet sich in der oben angeführten Arbeit: O. E. A. Hjelt, Svenska och Finska Medicinalverkets Historia, I, S. 285-3I5.

2) Eben angeführte Arbeit, I, S. 487-496: „Förening af medicinska och kirurgiska studier."

3) Th. M. Fries, Linné, II, S. I44. 
Man darf jedoch nicht glauben, daß Li nné das Verdienst nicht auch bei anderen als denen, welche den akademischen Grad erworben, geschätzt hätte. Es ist eine interessante Episode in der ärztlichen Geschichte Schwedens, als der berühmte, hochangesehene Ol of Acrel nicht ohne Examen die Doktorwürde empfing, die die Fakultät I 760 als Ausdruck ihrer Anerkennung ihm, dem wissenschaftlichen Chirurgen und dem bedeutendsten praktizierenden Arzte in Stockholm, erteilen wollte. Das von Lin né aufgesetzte Protokoll der Fakultät verdient $\mathrm{zu}$ ehrendem Gedächtnis an diese beiden um die Wissenschaft der Heilkunde in Schweden so hochverdienten Männer hier angeführt zu werden.

„Da Herr Professor Acrel sich so bemerkenswert von allen anderen Chirurgis durch solide Erudition in allen Teilen der Medicin und eine weitläufige Praxis medica in der Residenz, vornehmlichst aber durch sein schönes Buch über Kuren im Lazarett, das ein Juwel voll so vieler herrlicher Observationen und anderem ist, distinguiert hat, hielt es die Facultät für angemessen, ihn von den Ungelehrten und Schlechteren durch Offerierung des Doctorgrades zu distinguieren. Da sie aber fürchtete, daß ein solches Präjudicat zu Mißbrauch Anlaß geben möchte, ward er von dem Decanus der Facultät ersucht, hier in loco durch einen Discurs seine Kenntnisse zu zeigen, weshalb er von uns Anwesenden in allerhand, was zur Medicin gehört, verhört wurde, besonders in allen den Teilen, die essentiell einen Medicus constituieren, wobei er überall eine solche Geschicklichkeit zeigte, daß die Facultät nicht viele von solcher Experience und Gelehrsamkeit be$\mathrm{sa}$, und fand die Facultät, daß er mit allen gebührenden Elogen bei Illustrissimum zu recommandieren sei, mit dem wahrhaftigen Bericht, da $\beta$ er in allen Teilen der Facultät bewiesen habe, daß er die Kenntnisse besitze, wie sie jemals zuvor nur irgend ein Promovendus habe prästieren

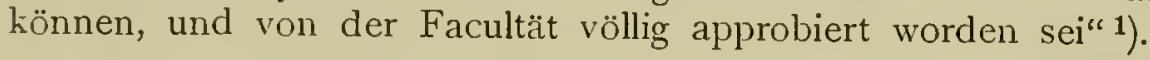

Als schließlich eine medizinisch-chirurgische Unterrichtsanstalt im engen Anschluß an das Seraphimerlazarett um die Mitte des I8. Jahrhunderts, von tüchtigen Lehrern und mit reichen materiellen Hilfsmitteln zur Erlernung der praktischen Heilkunde unterstützt, in Stockholm rasch aufblühte, kann es nicht wundernehmen, wenn sie

I) Protokoll der medizin. Fakultät vom 20. Mai 1760 . Der durch seine Praxis sehr in Anspruch genommene Acrel reiste um 3 Uhr morgens von Stockholm ab, war um 8 Uhr in Upsala: um sich der Prüfung vor der Fakultät zu unterziehen, und kehrte um 7 Uhr abends nach der Hauptstadt zurück, um einige seiner Patienten zu besuchen. Acrel hatte alle ihm vorgelegten Fragen beantwortet, erzählte aber seinen Freunden, daß er auf Linnés Frage, "welches das beste Emmenagogum sei“, wohl die in dieser Hinsicht gebräuchlichen Mittel aufgezählt habe, nicht aber auf die von dem Examinator als kräftigst angesehene Aristolochia rotunda gekommen sei. Aminnelse-Tal över Olof af Acrel, den 29. Okt. 1806 (Gedächtnisrede auf Olof af Acrel) von David Schulz von Schulzenheim, S. 2 I. 
allmählich als eine Nebenbuhlerin der medizinischen Fakultät in Upsala auftrat und Anspruch darauf erheben wollte, als ihr gleichberechtigt anerkannt zu werden. Durch das Hinzutreten dieser für die praktische Medizin wichtigen Lehrinstitute bewahrheitete sich, was Linné einstmals bezüglich der bis dahin unbestrittenen Autorität der Fakultät geäußert hatte: „Es geht mit der Wissenschaft wie mit Cynosurus coeruleus [Sesleria coerulea]. Sie welkt, wenn sie begonnen hat, verbreitet sich aber ringsumher" "1). Ganz zufrieden, wenigstens mit einigen der neuen Kollegen, war jedoch Linné nicht. Er schreibt darüber:

„Nachdem Dr. Bergius Botanices, Historiae naturalis et Diaetetices Professor regius Holmiensis geworden ist, bin ich es müde, Upsaliensis zu sein, und bin dabei colligere sarcinas meas (meine Sachen zu packen). Die Ausfertigung Sr. Majestät ist bereits gekommen, ich soll mich in obscuro setzen, unum coelum non fert duos soles" " $)$ ). „Wenn die Herren Stockholmer Professoren glauben, daß es ihnen gegolten habe, als ich die Gnade erfuhr, meine untertänigste Aufwartung machen zu dürfen [Linné war vor kurzem bei König Gustav III. auf Ekolsund gewesen], so tun sie mir Unrecht. Ich greife nie einen anderen an, wenn er mich nicht zuerst angegriffen hat. Niemals dränge ich mich in anderer Territorium. Nie spreche ich übel von jemandem vor meiner hohen Obrigkeit. Ich bin gewiß, daß sie nicht wider mich andringen, zumal sie meine ehrlichen Schüler gewesen sind. Ich gebrauche niemals Schliche oder Intrigen“ ${ }^{3}$ ).

Der lange, hitzige Streit zwischen Aerzten und Feldscherern, der lange erstrebte und schließlich erlangte Eintritt der Chirurgen in das Collegium medicum, die gegenseitigen Anklagen und Intriguen bei den Reichstagen, die verschiedenen politischen Parteigesichtspunkte (die Aerzte gehörten gewöhnlich der Partei der Hüte, die Chirurgen der Partei der Mützen an) hatten einen Rückschritt in Unterricht und Wissenschaft hervorgerufen. Die dadurch veranlasste Herabsetzung des Ansehens und Einflusses der Aerzte in der bürgerlichen Gesellschaft, die Zersplitterung und die Lockerung der gegenseitigen Beziehungen zwischen ihnen wurde $z u$ einer Gefahr für das ganze Medizinalkorps. Nachdem eine Instruktion sowohl für das Collegium medicum wie für die Provinzialärzte 1774 erlassen worden war, nahm das Collegium Anlaß, in einem Schreiben an den König vom 8. Juni desselben Jahres seiner Besorgnis wegen des Mangels an geeigneten Personen zur Besetzung von ärztlichen Stellen Ausdruck zu geben und über den Verfall des medizinischen Unterrichts Klage zu führen.

I) Carl Linna ei Öländska resa (Öländische Reise), Stockholm I745, S. 66.

2) Brief vom 2. Okt. 1762 .

3) Brief rom 3. Aug. 1773 . 
„Indem Ew. Maj. Collegium medicum mit allen Einwohnern des Reiches Ursache hat, sich über die unvergleichlichen Anstalten zu freuen, welche Ew. Maj. bezüglich des Medicinalwesens sowie der zur Conservation der Volksmenge zu ergreifenden Mittel in Gnaden getroffen haben, sicht sich das Collegium genütigt, untertänigst seine Besorgnis über einen allem Anschein nach bevorstehenden Mangel an guten und wohlqualificierten Kräften zur Besetzung der medicinischen Aemter zu vermelden. Das Collegium wagt es nicht, Ew. Maj. mit der Aufzählung verschiedener Umstände zu belästigen, die in den letztverflossenen Jahren zum Niedergang der Medicin wie anderer nützlicher Wissenschaft hier im Reiche beigetragen haben, denn das würde in einen an sich vielleicht fremden Gegenstand hineinführen. Das Collegium glaubt aber, nicht verbergen zu dürfen, daß es an einigen der öffentlichen Hochschulen für weniger Kenntnisreiche und Geschickte nicht schwer gewesen ist, den Doctorgrad zu erlangen und damit die Berechtigung, sich um Aemter zu bewerben, die reife und mit großem Geschick und tüchtigen Kenntnissen ausgestattete Männer verlangen.

Um einem für das allgemeine Wohl so schädlichen Mißbrauch vorzubeugen und in untertänigster Befolgung der gnädigen Weisung Ew. Maj. an das Collegium medicum, sich alles höchst angelegen scin zu lassen, was zur Förderung des Medicinalwesens irgendwie beitragen kann, wagt es das Collegium untertänigst die Bitte auszusprechen, Ew. Maj. wolle den gnädigsten Befehl an die Academie zu Greifswald erneuern, bei Strafe nicht zu Doctoren andere als solche zu promovieren, welche gemäß den academischen Constitutionen hinreichende Proben des erforderlichen Wissens und Geschicks abgelegt haben. Das Collegium erlaubt sich auch untertänigst darauf hinzuweisen, daß, wenn alle medicinischen Facultäten verpflichtet werden, gegen Ende jedes Jahres an das Collegium ein Verzeichnis derjenigen einzusenden, welche Medicin studieren, zugleich mit ihren academischen Specimina, das Collegium in der Lage sein könnte, bei der Abgabe der Vorschläge das Geschick und Verdienst der Bewerber genauer zu kennen, als es bisher möglich gewesen."

$\mathrm{Ob}$ das Collegium medicum mit diesem Schreiben nur seine Klagen über die Greifswalder Universität wiederholen wollte, oder dabei vielleicht auch die übrigen medizinischen Fakultäten des Reiches im Auge hatte, dürfte nunmehr schwer zu entscheiden sein. Soviel ist sicher, daß, da mehrere der bei Hof diensttuenden Aerzte nicht besondere Freunde der Fakultäten oder ihrer Mitglieder waren und zugleich als Mitglieder des Collegium medicum in die Entwicklung der Medizinalverhältnisse des Landes eingreifen konnten, der Einfluß, der sich allmählich neben den medizinischen Lehrstühlen herausgebildet hatte, ziemlich bedenklich wurde. Dunkle Gerüchte gingen von einem Plane um, das Recht der medizinischen Fakultäten, Doktoren zu promovieren, aufzuheben und es dem Collegium medicum $\mathrm{zu}$ übertragen.

Anläßlich des oben angeführten Schreibens des Collegium medicum und der ständigen Klagen über die Verhältnisse in Greifs- 
wald wurde schließlich die nachstehende Königl. Verfügung vom I4. Juni I 774 erlassen, in welcher „einigen“ der Universitätsfakultäten der Vorwurf gemacht wurde, infolge der Leichtigkeit, womit der Doktorgrad bei ihnen erlangt werden könnte, in ihrer Weise zu dem Verfall der medizinischen Studien beigetragen $\mathrm{zu}$ haben.

„Da uns die untertänigste Mitteilung zugegangen ist, daß es in den verflossenen Jahren sehr zum Verfall der Medicin wie auch anderer nützlicher Wissenschaften hier im Reiche beigetragen hat, daß es an einigen der öffentlichen Hochschulen für weniger Kenntnisreiche und Ungeschickte nicht sonderlich schwer gewesen ist, den Doctorgrad und damit die Berechtigung zu erlangen, sich um Aemter zu bewerben, welche reife und mit großem Geschick und tüchtigen Kenntnissen ausgestattete Männer verlangen; demnach einem für die allgemeine Wohlfahrt so schädlichen Mißbrauch vorzubeugen, sehen Wir uns nun veranlaßt, den hierfür in Gnaden ergangenen Befehl zu erneuern, wonach keine anderen an unseren Academien zu Doctoren der Medicin promoviert werden sollen als die, welche gemäß den Academischen Constitutionen eine genügende Probe des erforderlichen Wissens und Geschickes abgelegt haben: und sollen außerdem alle medicinischen Facultäten gegen Ende jedes Jahres an unser Collegium medicum ein Verzeichnis derjenigen einsenden, welche Medicin studieren, zugleich mit ihren academischen Specimina, wodurch bemeldetes Collegium in den Stand gesetzt werden kann, bei der Abgabe untertänigster Vorschläge bessere Gelegenheit zu haben, Geschicklichkeit und Verdienst der Bewerber zu kennen, als es bisher möglich gewesen" 1 ).

Bald darauf, nämlich im Jahre 1776 , scheint man wirklich den Plan entworfen $z u$ haben, die medizinischen Fakultäten dieses ihres Rechtes, Doktoren zu promovieren, zu berauben und es dem Collegium medicum zu übertragen. Man glaubte, daß sogar der König geneigt sei, auf diesen Vorschlag einzugehen. Als Prof. Jonas Sidrén von diesen Gerüchten Kenntnis erhielt, überredete er den greisen, kranken Linné, dem König auf Drottningholm aufzuwarten und um eine Privataudienz zu bitten. Kaum in das Zimmer des Königs hineingekommen, stammelte Linné in größter Erregung, die Forderungen der Etikette vergessend, diese Worte hervor:

„Das geht nimmer an, Euer Majestät. Das zerstört die Academie und die Wissenschaft. Ich kann nimmer dieses Unglück überleben."

Der König, der nicht begreifen konnte, was Linné meinte, verlangte von Sidrén näheren Aufschluß und soll dann mit lächelnder Miene an Linné herangetreten sein, ihn auf die Schulter geklopft und gesagt haben:

I) Dieser Königl. Erlaß findet sich im Archiv der medizinischen Fakultät in Upsala aufbewahrt. 
„Das wird nicht geschehen, mein lieber Linné. Reisen Sie in Frieden heim und seien Sie ruhig." ${ }^{1}$ ).

Es war dies der letzte öffentliche Schritt, den Linné für die Hochschule tat, deren Wohlergehen ihm stets so sehr am Herzen gelegen; es war sein Testament an die Fakultät, über die er soviel Glanz und Ehre verbreitet hatte. Am Io. Jan. 1778 gehörte er nicht mehr der Hochschule in Upsala an.

\section{III.}

Wenn wir nun zu einer Darstellung der medizinischen Ansichten Linnés übergehen, wie man sie in den zahlreichen akademischen Abhandlungen, die seinen Namen tragen, findet, und von ihnen ein zusammenhängendes Bild zu geben versuchen, werden wir notgedrungen auf eine Menge bedeutender Schwierigkeiten stoßen. Li n né hat nicht, wie einige seiner Zeitgenossen, selbst seine Ansichten und seine Erfahrungen in größeren, umfassenden Arbeiten zusammengestellt, sondern sich damit begnügt, sie vor dem zahlreichen Kreise von Schülern auszusprechen, die er um sich sammelte, und die dann, im Anschluß an seine Vorlesungen, eine Menge wissenschaftlicher Fragen bearbeiteten. Wer sein medizinisches Lehrgebäude zu einem Ganzen vereinen will, muß daher in seinen zahlreichen Schriften die verschiedenen Teile aufsuchen und sammeln, die dieses System bilden. Zwar hat Linné selbst zwei medizinisch-systematische Abhandlungen, Genera morborum und Clavis medicinae, herausgegeben. Aber die kompendiöse, ja, aphoristische Kürze, die er seinen Arbeiten gegeben hat, verrät zur Genüge, daß sie nur als Grundlage für die mündlichen Vorträge bestimmt waren, denen er jene praktische, anziehende Form zu geben verstand, die für ihn so kennzeichnend war.

Linné setzte der medizinischen Wissenschaft ein hohes Ziel. Ihm, dem unermüdlichen Forscher, dem scharfen Beobachter der Erscheinungen in der Natur, war es klar, daß die Medizin, wenn sie auf einen Platz im Kreise der Naturwissenschaften Anspruch machen wollte, zu ihrer Entwicklung dieselben Methoden wählen mußte wie jene. Lin né verlangte, daß, wie der Physiker seine Sätze auf Experimente stützt, so auch der Arzt seine Ansichten auf Beobachtungen und Versuche gründen muß ${ }^{2}$ ), denn „die Heilwissenschaft hat mit verwandten Zweigen der Erkenntnis das traurige Los gehabt, durch

1) Egenhändiga Anteckningar, S. 230.

2) Inebriantia ( 1762 ). 
leichtsinnige Hypothesen und Vorurteile erniedrigt zu werden (deturpari)“ 1). Die rein empirische Medizin verwendet durch die Erfahrung erprobte Heilmittel, ohne sich auf eine Erklärung ihrer Wirkungsweise einzulassen, die rationelle Heilwissenschaft dagegen strebt danach, wenn Störungen innerhalb der mechanischen Gesetze für den Bau und die Funktion des Körpers auftreten, sie unter dieselben Gesetze wieder zurückzuführen ${ }^{2}$ ). Durch die Verbindung anatomischer, botanischer, physiologischer, chemischer und mechanischer Wahrheiten mit den Lehrsätzen der Medizin ist die rationelle Heilwissenschaft entstanden. Die wirklichen wissenschaftlichen Beobachtungen selbst bleiben bestehen und verändern sich niemals, während die Erklärungen ihrer Ursache und Natur dem Wechsel unterworfen sind und sich je nach der in verschiedenen Zeiten geltenden Auffassung verändern. Die Theorie der Medizin bildet gleichsam den Schlüssel zu den praktischen Beobachtungen. Diese aber sind der lydische Stein, an welchem diese Theorie geprüft werden muß. Denn wenn die Wissenschaft richtige Indikationen aufgestellt hat, kann der Arzt sich stets in dunklen und zweifelhaften Fällen zurechtfinden. Vermißt man dagegen eine Methode, die sich der Grundwahrheiten der Wissenschaft bedienen (disponere) kann, eines verläßlichen und festen Grundes, so wird die ganze medizinische Praxis unsicher und schwankend ${ }^{3)}$. Man hat zwar behauptet, die Zeit sei noch nicht reif für ein medizinisches System. Die medizinischen Lehrwahrheiten müssen aber gleichwohl in die Ordnung, wie ihre Natur es erlaubt, gebracht und aufgestellt, und danach durch neue und ständig wiederholte Beobachtungen verbessert und vervollkommnet werden. Denn wo kein Anfang vorhanden ist, läßt sich auch keine Entrvicklung erwarten. Theorie und Erfahrung bleiben demnach der gemeinsame Grund, auf welchem das medizinische System aufgebaut werden mulo ${ }^{4}$ ). Der rationelle Arzt, der diesen Namen verdienen will, muß daher lieber Eklektiker sein, als blind und einseitig den Ansichten einer bestimmten Schule zu huldigen. Auch Lin né mußte in seiner Stellung und von seinem Standpunkte aus dies sein, wenn er auch viele originelle Ideen auf dem Gebiete der Heilwissenschaft hegte und aussprach.

1) Circa fervidorum et gelidorum usum paraenesis ( 1765 ).

2) „Corporis nostri machina ad leges mechanicas atque hydraulicas, quo structuram et operationes, est efficta, ita etiam quandoque turbata eadem erit ad regulas emendanda." Purgantia indigena (I766).

3) Sapor medicameniorum (I75 I).

4) De effectu et cura vitiorum diaeteticorum (1766). 
Was die pathologische Anschauungsweise betrifft, die zur Zeit der unbestrittenen Herrschaft der Boerhaaveschen Schule sich innerhalb der Medizin geltend machte, und die auch merklich auf Linnés wissenschaftliche Theorie einwirkte, so sei hier zum Verständnis der Ansichten, die wir weiter unten in seinen Schriften ausgesprochen finden, mit einigen Worten der Grundgedanke der Boerha a veschen Krankheitslehre angedeutet. Was ist Krankheit? Sie ist derjenige Zustand des Organismus, welcher entsteht, wenn die innerhalb des Körpers mittels der Fasern vor sich gehenden Bewegungen nicht dem gegenseitigen Bedürfnis der Organe und der gleichmäßigen Verteilung der Flüssigkeiten, entweder in den Blutgefäßen oder den serösen Gefäßuen, entsprechen, oder wenn das Blut selbst der Eigenschaften ermangelt, die zu dieser Verteilung erforderlich sind ${ }^{1}$ ). $\mathrm{Zu}$ den wichtigsten Folgen einer Unregelmäßigkeit in den zur normalen Tätigkeit des Körpers notwendigen Lebensbewegungen gehören das Fieber und die Entzündung, ersteres auf einer Veränderung des auf das Herz wirkenden Nervenfluidums, letztere auf einer Reibung (attritus) zwischen der Wand des Gefäßes und dem in den kleineren Gefäßen stockenden arteriellen Blute beruhend ${ }^{2}$. Diese Anschauungsweise von dem innersten Grunde der Krankheit erhält seine Erklärung weiter unten bei der Frage nach den konstituierenden Elementarteilen des Körpers, wo auch Linn és in mehreren Hinsichten abweichende Auffassung von dem Krankheitsprozeß deutlich zutage treten wird.

In der Pathologie hat die Frage nach den Krankheitsursachen stets eine wichtige Rolle gespielt, und sie waren für Linné von noch größerer Bedeutung, weil die Krankheitsart (species morbi), d. h. die Form, in welcher eine Krankheit in dem einzelnen F a1le auftritt, seiner Ansicht nach von der Ursache derselben abhängig ist oder mit ihr zusammenfällt ${ }^{3}$ ). Da verschiedene Ursachen demgemäß verschiedene Formen (species) einer und derselben Krankheitsgattung (genus) hervorrufen können, so müssen „ratio morbi“ und "medendi methodus" sich nach der richtigen Kenntnis der ursächlichen Verhältnisse richten. Die Krankheitscharaktere sind für die Bestimmung wichtig, welcher Gattung eine Krankheit angehört. Zur Bestimmung der Krankheitsform (species) in einem

I) „Aequabili fluidorum per vasa propulsioni sufficientes fibrae.“ „Humores vasorum aequabili dilatationi sufficientes."

2) „Inflammatio est sangvinis rubri arteriosi in minimis canalibus stagnantis attritus a motu reliqui sanguinis moti.“

3) Siehe weiter unten S. 73 . 
gegebenen Falle ist dagegen die Ursache festzustellen. Denn bevor wir nicht die Ursache einer Krankheit kennen, ist jene Gewißheit ausgeschlossen. So muß man Lin n és Satz verstehen: medicamentum curat speciem, raro genus morbi. Die Aetiologie erhielt dadurch einen hervorragenden Platz in der älteren Pathologie und wurde oft für die Diagnose und Behandlung bestimmend. Es ist daher nicht genügend, sagt Linné, nur die Genera morborum zu kennen, die Kenntnis der Species aber gering zu achten, „zumal da die Species in einem und demselben Genus oft und meistenteils differenter sind als die Genera selbst und oft von konträren Ursachen herrühren, also auch konträre Kuren erfordern. Ohne genus et species morborum zu kennen, kuriere ich nur aufs Geratewohl und expectando" 1 ).

In Uebereinstimmung mit den älteren Aerzten nahm auch Lin né zwei ursächliche Verhältnisse für die Krankheit an, nämlich eine nähere und eine entferntere (proxima et remota). Die nächste Ursache für die Entstehung einer Krankheit ist eine Störung, sei es in der Zusammensetzung, den Spannungs- und Dichtigkeitsverhältnissen der festen Teile, sei es in der Beschaffenheit der Flüssigkeit. d. h., wie wir sagen würden, in einer pathologisch-anatomischen Veränderung der Gewebe und Organe des Körpers. Ist diese Störung aufgehoben, hört auch die Krankheit als solche auf. Die entferntere Ursache hat gewöhnlich ihre Wurzel und Quelle in der Diät oder Lebensweise, in Alter, Körperkonstitution oder Ansteckung (contagium). Die fernerliegende Grundursache (principium morbi) läßt sich oft auf einen äußeren, vermittelnden Anlaß zurückführen ${ }^{2}$ ).

Dem Arzte liegt es ob, genau die vorliegende Krankheitsart zu bestimmen und unter Vermeidung zusammengesetzter Medikamente am liebsten sich sog. einfacher Heilmittel zu bedienen (.,nec nisi simplicia praescribenda medicamenta") ${ }^{3}$ ). $\mathrm{Zu}$ diesem Zweck sind, wie es bei wohlgeordneten Lehranstalten, wo das Studium der Medizin mit Ernst und Erfolg betrieben wird, der Fall ist, Krankenhäuser und botanische Gärten für die Bedürfnisse des Unterrichts einzurichten. Die medizinische Wissenschaft wird hiervon herrliche Früchte erhalten und eine bemerkenswerte Förderung erfahren, denn da in ihnen eine Menge Kranke derselben Art behandelt werden, wird

I) „Genus est similitudo seu convenientia specierum, sic diarrhoea genus est, quippe continet sub se diversas species, ut serosam, biliosam etc. Classis est sinilitudo vel conniventia generum; sic febris, quae classis est, continet synochum, ephemeram, quartanan, etc; ordo est velut exigna classis." Sauvages, Nosologia methodica (I768) I, p. 9I.

2) Medicamenta graveolentia (1758).

3) Hortus Upsaliensis (1745). 
nicht nur die Natur der Krankheit genau beobachtet und beschrieben, sondern auch die Wirkung der Heilmittel erforscht und, wenn der Tod erfolgt, die Einwirkung der Krankheit auf die Organe festgestellt werden können (effectus internus morbi inclagari oportet). Hierbei wird jedoch nicht an ein unvorsichtiges und kühnes Experimentieren mit neuen und unbekannten Heilmitteln (in vili anima experimentum captare) gedacht, da jeder fürsorgliche Arzt zur Genüge versteht, wie und auf welche Weise solche Medikamente, ohne den Kranken zu schaden, angewendet werden können, indem man mit kleinen Dosen beginnt und danach zu großen übergeht, bis ihre Wirkung festgestellt worden ist ${ }^{1}$ ). Alles Aussprüche Linnés, die noch für den heutigen Tag Geltung haben, und die erst weit später anerkannt und praktisch ausgeführt worden sind.

Die Krankheitsbehandlung selbst ist entweder eine palliative oder rationelle. Während erstere nur die Symptome und ihre Behandlung ins Auge faßt, sucht letztere den eigentlichen Grund und die Ursache der Krankheit zu bekämpfen. Ist die erstere leicht zu erlernen, so ist es die letztere, welche den wirklichen Arzt von dem Quacksalber und Charlatan unterscheidet. Weder muß jedes Bemühen der Natur, die Krankheitseinflüsse zu entfernen, bekämpft werden, noch ist es die Hauptsache, einzelne Symptome zu mildern. Eine schädliche Pflanze verschwindet nicht damit, daß Blätter und Stacheln entfernt werden, sondern dadurch, daß sie mit den Wurzeln herausgerissen wird. Nicht der Rauch, sondern das Feuer ist es, welches gelöscht werden muß. Und ist erst einmal der Anführer gefallen, so fliehen auch die Trabanten. Wenigstens muß der Arzt, nachdem die Diagnose gestellt und die Krankheitsursachen festgestellt worden sind, diese $z u$. entfernen oder zu vermindern suchen, da die ärztliche Kunst ziemlich oft nicht mehr vermag, als das Wachstum des Uebels zu verhindern und die Krankheit erträglicher zu machell ${ }^{2}$.

Bevor wir nun zu einer genaueren Darstellung des pathologischen Systems Linnés übergehen, ist es notwendig festzustellen, wie er sich die innere Zusammensetzung des menschlichen Körpers und sein Verhalten bei verschiedenen Krankheitszuständen dachte. Einer der wichtigsten Grundgedanken in Linnés Pathologie, worauf ebenso sehr die Auffassung von dem inneren Wesen des Krankheitsprozesses als die Erklärung der Wirkung der Medikamente und die Aufstellung der Indikationen zu ihrer Anwendung teilweise beruht, ist seine An-

I) Purgantia indigena (1766).

2) Medicamenta graveolentia (I758). 
sicht, daß der menschliche oder tierische Körper aus einer Kortikalund einer Medullarsubstanz zusammengesetzt ist. Unter der Medullarsubstanz (medullare animale, systema nervosum medullare) versteht Linné das Nervensystem (Gehirn, Rückenmark und Nerven) im Gegensatz zu den übrigen festen und flüssigen Bestandteilen des Körpers (corticale vitale, systema corticale corporis, systema fibrosum et vasculosum). Der menschliche Organismus wird mit einem Gewebe verglichen, aus doppelten Fäden zusammengesetzt, in welchem die Nerven die Kette (texturae stamen) darstellen, während die verschiedenen Arten von Fasern nebst Flüssigkeiten den Einschlag (intertextum, inter stamina implicatum) bilden. Die flüssigen und festen Bestandteile ernähren und unterhalten das Nervensystem, das seinerseits ihnen Spannkraft, Bewegung und Tätigkeit verleiht (vigorem, motum et actionem subministrat) ${ }^{1}$ ).

Auch die Pflanze besteht nach Lin nés Ansicht aus Medullarund Kortikalsubstanz. Seine Auffassung von diesen konstituierenden Teilen der Pflanze spricht er in folgenden Worten aus: „Die Medulla, die das eigentliche I.eben der Pflanze ausmacht, hat einen wunderbaren Charakter und ein Vermögen der Vervielfältigung ins Unendliche, wächst und vermehrt sich bis in die Spitzen der Zweige hinein, wo die Möglichkeit zum fortgesetzten Bestande schon beim Ursprung am geringsten ist. Die kleinen Zweige, welche durch fortgesetztes Wachsen die Pflanze vervielfältigen, können nicht gänzlich der Medulla entbehren. Diese wird gleichsam in der Kortikalsubstanz eingesperrt, die mit aller Macht sie festzuhalten sucht, solange die Bedingungen dazu fortbestehen. Wo die Kortikalsubstanz nicht stark genug ist, drängt sich die Medulla nach oben, durchbricht die Corticalis, und die Pflanze erfährt eine Metamorphose, die Fruktifikation tritt ein, und die Medulla geht in Samen über (granulatur). Der zweite konstituierende Teil der Pflanze ist die Kortikalsubstanz, welche Nährstoffe an sich zieht, die Säfte verarbeitet und die Medulla unterhält, die auf keine andere Weise ernährt werden kann. Da die Medulla bei dem Fortpflanzungsprozesse eine von der Korticalis verschiedene Aufgabe hat, so dal die erstere bei der Pflanze deutlich aus dem weiblichen (femininen) Teile, die letztere dagegen aus dem männlichen hervorgeht, so können wir nicht umhin, auch bei den Tieren bei einer gleichförmigen Entwicklung dasselbe Gesetz der Natur zu finden“" 2).

I) Fundamenta valetudinis (I759); Inebriantia (176I).

2) „In dissert. ,De Generatione ambigena“ (I759) demonstrare volo quod substantia cerebri, medulla spinalis et systema nervosum a matre prodeat; corpus vero vasculosum et 
Auf Grund vergleichender Beobachtungen über die Entwicklung des Pflanzenlebens und im Hinblick auf das Verhëltnis bei hybriden Pflanzen glaubt daher Linué den Gedauken aussprechen zu können, daß die Bildung der Medullarsubstanz der weiblichen Pflanze und die der Kortikalsubstanz der männlichen zukommt. Bei der hybriden Pflanzenbildung gibt nämlich die neue Pflanze Stamm und Blätter der männlichen Pflanze wieder, d. h. das äußere Aussehen der Pflanze (larva plantae), während die Fruktifikation die Form der weiblichen Pflanze aufweist. Das gleiche Verhältnis glaubt Linné bei Tieren (zunächst bei Bastarden, gekreuzten Tieren) wiederzufinden, indem die äußeren Teile des Körpers, wie Gestalt, Haar, Farbe usw., an den Vater (systema corticale a patre), Gemütsart und Neigung dagegen an die Mutter erinnern (systema nervosum a matre), „obwohl“ fügt er hinzu, ,ich nicht verstehe, wie diese Verbindungen entstehen" ${ }^{1}$ ).

Diese originelle Auffassung Linnés von der Zusammensetzung des Organismus aus einer Medullar- und einer Kortikalsubstanz ist für ihn ganz eigentümlich und dürfte meines Wissens von keinem zeitgenössischen Forscher ausgesprochen sein. In der akademischen Abhandlung "Generatio ambigena" (1759), wo er diesen seinen Gedanken näher entwickelt, wird auch kein anderer Schriftsteller zur Stütze für denselben angeführt ${ }^{2}$ ). Daß diese geistreiche, gänzlich spekulative Annahme des gleichartigen Baues des Pflanzen- und Tierorganismus nicht größere Aufmerksamkeit erweckte oder zu fortgesetzter Forschung anregte, kann nur durch den damaligen niedrigen Standpunkt der mikroskopischen Anatomie und der Entwicklungslehre erklärt werden. Erst nachdem das Mikroskop, mit dem Lin né

fibrosum a patre; et quod idem est in regno vegetabili, substantia medullaris a planta femina, corticalis a planta mare." Brief an Sauvages vom 22. Nov. 1759.

1) „A posteriori hoc manifestum est, sed quomodo hoc fiat, altioris indaginis est, quod nullus hodie explicet, si non summus Sauvagesius". Mit Bezug auf sich selbst bemerkt er bei der Behandlung dieser Frage: Ego interim fungar vice cotis, qui acuit, exsors ipse secandi (ich selbst will nur als ein Wetzstein dienen, der scharf macht, nicht aber selbst schneideu kann). Vgl. L in nés Egenhändiga Anteckningar, S. 201.

2) In Commentarii de rebus in Scientia Naturali et Medicina gestis, secundae decadis suppl. I ( 1772$),$ p. 3 beginnt der einzige Bericht über Linnés in dieser Abhandlung ausgesprochene Ansichten bezüglich des Generationsprozesses, den Verf. in der Literatur gefunden hat, mit folgenden Worten: "Cum cl. auctori non placuerit ob difficultatem rei et veterum generationem aequivocan, et recentiorum univocam sic dictam, assumendi ac defendendi, ad novam planeque singularem theorian hujus rei cogitando pervenit. Cum enim analogiam summam certe inter vegetabilia et animalia inveniret, summo cum studio disquisivit, annon ex comparatione structurae utriusque ad originem vitae seu generations negotium concludere liceat".

H jelt. Carl von Linné. 
sich ebensowenig wie andere Aerzte jener Zeit befaßte, zu allgemeiner Anwendung gekommen war, wurde diese Frage durch M. J. Schleidens und Th. Schwanns Arbeiten der Ausgangspunkt zu einer vollständigen Umwälzung der Wissenschaft ${ }^{1}$ ).

Bewegung und Gefüh1 des Lebens, sagt Linné, haben ihren Sitz in der Medullarsubstanz, die das Ursprüngliche und zuerst Gebildete im Körper ist. Unter ihrer Einwirkung entstehen dann aus dem Nährsafte sowohl die flüssigen als die festen Teile (corticale solidum ac liquidum). Die Ernährung der Medullarsubstanz geschieht mittelst der feinsten Stoffe des flüssigen Kortikalteiles und wird von der Elektrizität unterhalten, welche die Lungen aus der Luft aufnehmen 2). Wenn das Verhältnis zwischen diesen konstituierenden Teilen gestört wird, kommt es zur Krankheit. Man kann hierbei zwischen den Krankheiten unterscheiden, welche ihren Grund in einer veränderten Beschaffenheit der Flüssigkeiten des Körpers haben, und den Krankheiten, welche den festen Teilen angehören. Das Fieber deutet auf eine Störung in der Zusammensetzung der Flüssigkeiten (des Blutes), und Linnés Fiebertheorie ruht auf der Vor-

I) Zum Vergleich mit den naturphilosophischen Betrachtungen einer späteren Zeit sei hier mit Linnés eigenen Worten mitgeteilt, wie er sich die Uebereinstimmung zwischen dem Bau der Pflanzen und der Tiere dachte: „Gleichwie die Bäume die Medulla ganz innen haben, bedeckt mit Lignum und Cortex, so hat es sich auch die Natur angelegen sein lassen, die Medulla i. e. Cerebrum et medulla spinalis bei den Tieren in einer dicken Knochenkruste zu soignieren. Die Natur hat auch der Medulla einen Cortex gegeben, der sie ernähren soll, die Wurzeln (vasa lactea) saugen den Saft aus dem Mistbeet (intestina), und die Medulla würde vertrocknen, wie das auch geschieht, wenn man die Rinde am Baum ringsumher abschneidet, wenn die Vasa lactea nicht dem Körper Nährsaft zusaugten. Aristoteles hat daher recht, wenn er sagt, der Mensch sei eine inversa planta." Linné spricht den eigentümlichen Gedanken aus, daß, wenn nicht das Gehirn und die Mcdulla spinalis in ihrem Wachstum durch die Knochenkruste gehindert würden, wir weiter wachsen würden, solange wir leben, ,gleichwie die Bäume nnd gewisse niedere Ticre, z. B. die Würmer, Medusa u. a. Auch Polypen und Taenia wachsen, solange sie leben, und ihre Brut wächst immediate aus ihrer Medulla. Daß die Medulla in infinitum wächst, ersieht man aus der Propagation aller Dinge, die durch sie geschieht. Daher wächst auch ein Zweig von einem Baum, wenn er in die Erde eingesetat wird.“ L in nés Vorlesungen über Clavis medicinae.

2) Linné schreibt hierüber in Egenhändiga Anteckningar, S. 201: „Was die Respiration betrifft, so war er der erste, welcher glaubte, daß die Lunge Electricum aus der Luft ziehe und es an das Medullare weitergebe, dicses demnach dasselbe sei wie spiritus animalis, und daß die hauptsächlichste Funktion der Lunge daher nicht die sei, das Blut zu accelerieren. Viele Ausländer haben dies als eine Hypothese angesehen; Linnaeus aber erachtetc es für ein Axionn." Es sei hier an Linnés Bemerkung erinnert, „daß das Licht, das Feucr (die Wärme) und die Elektrizität nicht viel voneinander verschieden sein dürften" (Vorlesungen über Clavis mcdicinae). 
stellung, daß, „wenn eine Schärfe in den Körper eindringt“, das Fieber entsteht, um dieselbe, gleichwie andere widrige Stoffe, abzusondern oder zu entfernen. Die flüssige Kortikalsubstanz, aus welcher die festen Teile entstehen, wird nämlich von in Säuerung oder Verwesung begriffenen Stoffen, welche in den Körper eindringen, aufgelöst und zerstört. Während des vom Nervensystem ausgehenden Kampfes gegen diese für den Bestand des Lebens schädlichen Einflüsse entstehen die verschiedensten Arten von Fieber, das kritische Fieber von säurebildenden und das phlogistische von septischen Stoffen her, während das exanthematische Fieber vielleicht auf einem lebenden Kontagium beruht. Alle diese Stoffe sind dem Körper fremd, feindlich und besitzen die Fähigkeit schneller Vermehrung. Die Natur entfernt aus den Flüssigkeiten schädliche Stoffe auf natürlichem oder künstlichem Wege; je schädlicher sie sind, um so schneller geht es, gleichzeitig aber werden gewöhnlich nicht zwei Wege benutzt. Andererseits wird täglich die feste Kortikalsubstanz zerstört und verschlechtert sich und muß daher täglich unter Beobachtung ider Vorschriften der Diätetik erneuert und wieder hergestellt werden. Werden diese vernachlässigt, oder entspricht die Lebensweise im übrigen nicht den Anforderungen des Körpers, so entsteht ein Mangel im Organismus, d. h. es kommt zur Krankheit.

Wollen wir nun nach diesen allgemeinen Betrachrtungen eine genauere Darstellung von Linnés pathologischem System geben, so findet man dasselbe in seinen Genera morborum ${ }^{1}$ ) ausgeführt. In dieser Arbeit sind die Krankheiten in Ordnungen, Klassen und Gattungen unter Beifügung ihrer wichtigsten diagnostischen Symptome aufgestellt. Schon im vorhergehenden ist der überwiegende Einfluß, den Sauvages auf Linnés medizinische Ansichten ausgeübt hat, angedeutet worden, und in seinen Genera morborum finden wir zallreiche Spuren davon. Linné sagt selbst:

„daß ein wirkliches medizinisches System fehlte, bis Sauvages ein solches erdachte (absolutum edidit systema), das meines Erachtens in natürlicher Aufstellung, Charakteren und innerer Vollendung bis zu dem Grade alle früheren übertrifft, daß nichts anderes damit verglichen werden kann. Ueber 20 Jahre lang habe ich es an der Akademie in Upsala vorgetragen und auf Grund neuerer Beobachtungen fortgesetzt zu verbessern gesucht."

Obwohl, wie bereits oben erwähnt, Sauvages' Nosologie bei Linné das lebhafteste Interesse für die systematische Krankheitslehre erweckte, und er während der ersten Jahre seiner Lehrtätiglieit

I) Genera morborum in auditorum usum edita, Upsaliae 1763,32 S., kl. $8^{0}$. 
diese Arbeit seinen Vorlesungen zugrunde legte, scheint Linné dennoch allmählich sich mehr oder weniger davon unabhängig gemacht zu haben. Es entstand in ihm der Gedanke, selbst ein nosologisches System auszuarbeiten, das er dann später im einzelnen entwickelte. Da es ihm oblag, über diesen Gegenstand Vorlesungen zu halten, hielt er es für seine Pflicht, auch Beiträge zu der pathologischen Systematik zu liefern, mit deren Bearbeitung die Wissenschaft besonders zu jener Zeit sich eifrig beschäftigte, und deren sie bei der ständig anwachsenden Menge der einzelnen Beobachtungen vor allem bedurfte. Von den einzelnen Teilen der Pathologie war die Symptomatologie am meisten bearbeitet worden, und es lag daher am nächsten, sie als Grundlage für die Klassifikation der Krankheiten zu verwerten. Da Lin né bei der Aufstellung der Krankheitsgruppen infolge des unentwickelten Standes der Wissenschaft ebensowenig wie die übrigen Systematiker jener Zeit ein allgemein gültiges anatomisches oder physiologisches Prinzip finden konnte, war er gezwungen, die symptomatologische Methode zu wählen.

Man findet wesentliche Unterschiede zwischen Sauvages' und Linnés System ebensosehr in der Gruppierung der Krankheitsklassen als in ihrer Benennung. Die Krankheitsgattungen sind ihnen dagegen in groler Zahl gemeinsam, obgleich in jedem der beiden Systeme anders geordnet und an andere Stellen gesetzt. Sauvages nahm später selbst eine Menge von Linnés Krankheitsgattungen an und führte sie in die späteren Auflagen seiner Arbeit ein. Auch die nächstfolgenden Systematiker, wie Vogel, Selle, Cullen u. a., erkennen Linné als solchen an. Mir scheint, daß Linnés Klassifikation sich durch größere Klarheit der Anordnung auszeichnet und in gewisser Hinsicht mehr physiologische Färbung zeigt, während Sauvages auch weiterhin die exklusiv symptomatische Grundlage für sein System beibehielt. Während Sauva'ges' Arbeit „Nosologia methodica“ (1763) eine für jene Zeit vollständige Pathologie war und damit die damals herrschende Auffassung von den Krankheitserscheinungen mitteilte, war dagegen Linnés "Genera morborum" nur eine für seine Schüler bestimmte Uebersicht der Krankheitsnomenklatur in systematischer Folge, deren Inhalt bei den Vorlesungen näher erklärt, ausgeführt und ergänzt werden sollte. Deshalb eben, weil diese grundlegende systematische Arbeit Linnés in so unvollständiger, fast skelettartiger Form ohne Anführung spezieller Krankheitsarten, Diagnosen und sonstiger den Gegenstand beleuchtenden Angaben hervortrat, ist es !begreiflich, weshalb seine pathologischen Schriften bisher nicht dieselbe Be- 
achtung in der Geschichte der Medizin gefunden haben, wie andere zeitgenössische Arbeiten in derselben Richtung.

Die Einteilung der Krankheiten, wie sie Linné in der angefülırten Arbeit liefert, ist folgende:

\section{Morbi.}

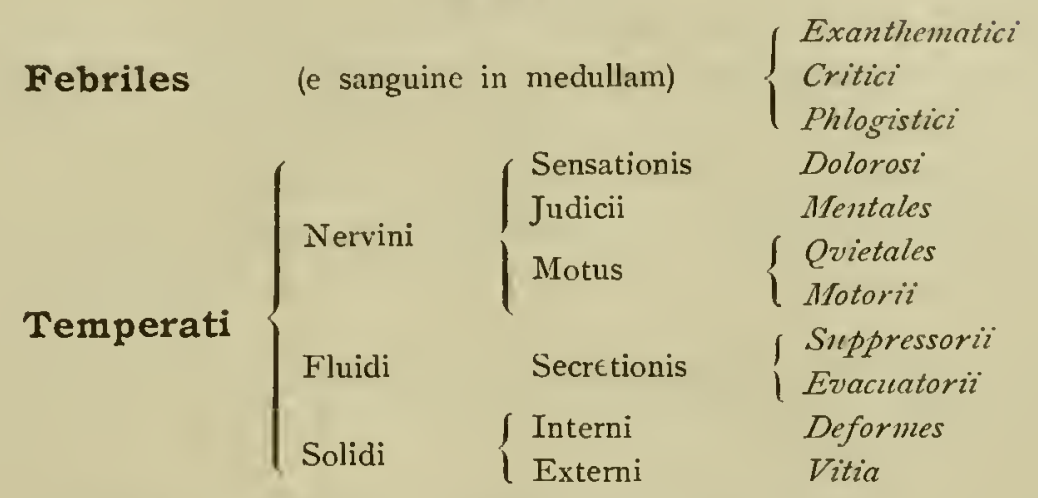

Exanthematici Febris cum efflorescentia cutis maculata.

Critici Febris cum Urinae hypostasi lateritia.

Phlogistici Febris cum Pulsu duro, Dolore topico.

Dolorosi Doloris sensatio.

Mentales Judicii alienatio.

Quietales Motus abolitio.

Motorii Motus involuntarius.

Suppressorii Meatuum impeditio.

Evacuatorii Fluidorum evacuatio.

Deformes Solidorum facies mutata.

Vitia Externa palpabilia.

Aus dem Folgenden geht hervor, daß Linnés System im Verhältnis zu Sauvages' Anordnung der Krankheiten unleugbar eine selbständige Stellung einnimmt. Wenn man, wie Haeser, die Wichtigkeit von Sauvages' Klassifikationsversuchen anerkennt, muß es mehr als unberechtigt erscheinen, wenn ersterer Linnés Genera morborum ,einen vollständig mißlungenen Versuch zu einem künstlichen Systeme der Krankheiten" nennt. Jedem der beiden Systeme liegen die allgemeinen und gemeinsamen Symptome der Krankheiten zugrunde, und beide leiden in demselben Grade an den Konsequenzen, die eine solche einseitige, schwankende Grundlage notwendig mit sich bringen mußte. Für jeden dieser Forscher galt es, nach dem Vorbilde der Botaniker die Krankheitsformen in wissenschaftlicher Ordnung aufzustellen, an der es bis dahin gefehlt hatte, d. h. mit anderen Worten, eine systematische Pathologie zu begründen. In jedem dieser beiden Systeme können wir einen Anfang zu den Krankheitsklassifikationen sehen, mit denen sich dann die medizinische Wissenschaft unter größerem oder geringerem Bei- 
fall nahezu ein Jahrhundert lang abgemüht hat, bis sie mit der naturhistorischen Schule um die Mitte des vergangenen Jahrhunderts zum Abschluß gelangten ${ }^{1}$.

Das pathologische System, nach welchem Lin né die verschiedenen Krankheitsformen aufstellte, ist, wie man leicht sieht, auch von ausgesprochen symptomatologischer Natur. Nur die Fieber, deren verschiedene Entstehungsweise soeben angedeutet wurde, und für die ein anderer Einteilungsgrund gewählt worden ist, sind teils nach ihrer Verbreitungsweise, teils nach dem besonderen Charakter, den sie in ihrem Verlaufe annehmen, angeordnet. Die exanthematischen Fieber (I) werden so in contagiosi (pestis, variola, petechia oder Fleck-

I) Zum Beweis für die Selbständigkeit von Linnés System sei hier 'eine Uebersicht über Sauvages' Arbeit nebst den Charakteren für seine Krankheitsklassen nach „Nosologia methodica" (I 768) mitgeteilt:

I. Vitia. Symptomata cutanea levidensia, vel mechanicis Chirurgiae auxiliis curanda.

II. Febres. Pulsus frequens, fortisve viribis artuum imminutis.?

III. Phlegmasiae. Concurrit, pyrexia continua vel remittens cum interna inflammatione, vel cum exanthematis.

IV. Spasmi. Contractio invita, constans vel interpolata, musculorum organis loco motivis, non vitalibus, inservientium.

V. Anhelationes. Agitatio invita, defatigans, musculonum pectoris, unde respiratio difficilis, frequens, sine febre acuta.

VI. Debilitates. Impotentia clare et distincte sentiendi, appetendi, consueta vi artus organave movendi, nec non imaginandi, vigilandi etc.

VII. Dolores. Cujusvis experientia cognoscendi, nulla definitione distincte explicabiles sunt.

VIII. Vesaniae. Character est imaginationis, judicii, voluntatis, etc. depravatio.

IX. Fluxus. Character est ejectio fluidorum aut contentorum, quae quantitate, qualitate, desuetudine notabilis est.

$\mathrm{X}$. Cachexiae. Coloris, figurae, molis in corporis habitu depravatio.

Diese zelın Klassen zerfielen in 44 Ordnungen und 3 I4 Gattungen oder Krankheitsnamen. Linné hat I I Klassen, 37 Ordnungen und 325 Krankheitsnamen.

In Sauvages' Nosologia methodica finden sich noch zwei andere Vorschläge zur Ordnung der systematischen Krankheitslehre, nämlich "Classes morbonm aetiologicae" in 25 Gruppen und "Methodus anatomica morbonum" in 9 Klassen. Weder Sauvages noch $\mathrm{L}$ inné brachten indessen das anatomische Prinzip zu praktischer Anwendung.

Bei der Frage nach dem gegenseitigen Verhältnis zwischen Sauvages' und Linnès pathologischen Systemen kann Verf. nicht unterlassen, an Prof. Johan Haartmans Arbeit "Sciagraphia morborm", in akademischen Disputationen herausgegeben, Ảbo I779-I781, $483 \mathrm{~S}$. in $8^{\circ}$, zu crinnern, welche Arbeit gleichfalls einen Versuch zur systematischen Aufstellung der Krankheiten enthält. Haartman sucht in dieser Schrift die zu weit gehende Systematisierung der Krankheitsgruppen wie auch Spezialisierung von Krankheitsgattıngen und Arten einzuschränken. Haartman hat sich unter Benutzung von Sauvages', Linnés, Vogels, Cullens und Sagars Schriften mit nur 8 Fílassen, 24 Ordnungen und 205 Gattungen begnügt und teilt zugleich Diagnosen, Synonymik und Krankheitsbehandlung mit. 
fieber usw.), sporadici (miliaria, aphta) und solitarii eingeteilt, während die krutischen Fieber (II) nach ihrem Typus in continentes (synocha, lenta), intermittentes (quotidiana, tertiana, quartana, duplicana, errana) und exacerbantes (amphimerina, tritaea, hemitritaea usw.) zerfallen. $\mathrm{Zu}$ den Fiebern werden auch die akuten Entzündungen gezählt, und in dieser Gruppe findet man aber einen Versuch, die betreffenden Krankheiten nach den verschiedenen Organen zu ordnen, in denen sie auftreten. Linné teilte nämlich die phlogistischen Fieber (III, die Entzündungen) in membranacei ein, d. h. solche, welche die serösen oder mukösen Häute angreifen, wie Phrenitis oder Meningitis, Pleuritis, Enteritis usw., und parenchymatici, die sich innerhalb der Organe entwickeln, wie Peripneumonia, Hepatitis, Nephritis usw. Auch die Phlegmone rechnete er zu dieser Gruppe.

Nachdem er somit die Fieber als eine große besondere Gruppe abgesondert hatte, wandte Linné als Einteilungsgrund für alle übrigen Krankheiten die drei Hauptkategorien an, unter welche er, wie schon oben dargestellt ist, die pathologischen Erscheinungen einordnete, nämlich das Nervensystem, die flüssigen (fluida) und die festen (solida) Bestandteile des Körpers. Dem Nervensystem gehören IV. morbi dolorosi, V. mentales, VI. quietales und VII. motorii an. Die Flüssigkeiten werden entweder vermindert, hören eventuell auf (VIII. morbi suppressorii) oder werden vermehrt (IX. morbi evacuatorii). Die Krankheiten der festen Teile sind entweder innere (X. morbi deformes) oder äußere (XI. vitia).

Diese eben angeführten Krankheitsgruppen umfassen eine Menge symptomatischer Leiden, die als selbständige Krankheitsformen aufgenommen werden. So enthält die vierte Klasse „Morbi dolorosi“ „diejenigen Krankheiten, die einen eigenartigen Schmerz haben ohne Fieber, ohne Evakuationen, Zuckungen oder Konvulsionen“1). Sie

I) Diese Definitionen sind handschriftlichen Aufzeichnungen nach Lin nés Vorlesungen 1752 und $175^{8}$, die in der Bibliothek der Schwed. Akad. der Wissenschaften aufbewahrt sind, entnommen. - In den schwcdischen Bibliotheken finden sich noch andere von Linnés Schülern hinterlassene, mehr oder weniger zuverlässige Notizen aus seinen Vorlesungen über Pathologie, und Th. M. Fries teilt (a. a. O., II, S. 218) mit, daß sieh unter den Manuskripten in der Linnean Society ein sehr weitläufiges originales Werk von Linné findet, genannt "Systema morborum", wozu der Grund bereits während der ersten Zeit seiner Lehrtätigkeit gelegt wurdc, und in das er dann bis in sein spätes Alter seine Beobachtungen und Ideen hineinschrieb. Die Umarbeitung der von Zeit zu Zeit wiederkehrenden Vorlesungskurse erklärt, weshalb Linné im Laufe der Jahre in sein pathologisches System so viele Veränderungen hinsichtlieh des Umfangs und der Begrenzung der Krankheitsklasscn, wie auch bezüglich dcr Anzahl, Einteilung und Anordnung der Krankheitsgattungen einführte. 
sind „intrinseci“, wie Cephalalgia, Hemicrania, Odontalgia, Dolor pleuriticus usw., oder „extrinseci“, wie Arthritis, Rheumatismus, Pruritus. In der fünften Klasse „Morbi mentales" „ist die Perzeption angegriffen und lädiert, worunter alle Krankheiten einbegriffen sind, wo animae functiones, judicium, imaginatio et voluntas depravatae sind“. Die Ordnungen sind „ideales“ (Delirium, Mania, Melancholia), „imaginarii“ (Phantasma, Hypochondriasis), „pathetici“ (Satyriasis, Erotomania, Rabies, Hydrophobia, Anxietas).

Die sechste Klasse wird von den „Morbi quiẹtales" (früher von Linné soporosi genannt) gebildet. Sie sind durch eine ,imminutio, resolutio, cessatio et privatio virium sensationum vel motuum, aut in toto corpore "v. in aliqua ejus parte" gekennzeichnet. „Die Nerven sind in unserem Körper als Custodes bestellt, ihn vor zufälligen Feindlichkeiten zu retten und der Seele Rapport über das Allergeringste zu erstatten, was zustoßen mag. Wenn nun gewisse Nerven dem Befehl, den die Seele ihnen gibt, nicht gehorchen, so haben wir eine Krankheit unter sopores; wenn keine Nerven den Befehlen der Seele gehorchen, so haben wir den Tod. Sopor und Mors differieren nur gradu. Diese Krankheiten bilden den Beginn unseres Todes."

Die Ordnungen sind „defectivi“ (Lipothymia, Syncope), „soporosi“ (Carus oder Schlafkrankheit, Apoplexia, Paraplegia, Paralysis), „privativi" (Oblivio, Amblyopia, Cophosis oder Taubheit, Anesthesia).

Zur siebenten Klasse „Morbi motorii" (oder spastici) rechnet L i n né diejenigen Krankheiten, in welchen stärkere oder schwächere unfreiwillige Muskelbewegungen vorkommen, wie Sardiasis, Hysteria, Tetanus, Catalepsis, Tremor, Chorea, Epilepsia usw. Von dieser Gruppe zweigte er später die achte Klasse "Morbi suppressorii" $\mathrm{ab}$ und wies ihr, außer rein physiologischen Zuständen, wie Risus, Fletus, Oscitatio, Singultus, Sternutatio (ad sinum frontis evacuandum), auch Tussis, Anhelatio (Atemnot), Dyspnoea, Asthma, Obstipatio, Ischuria usw. zu. Die n eunte Klasse „Morbi evacuatoriz" umfaßt diejenigen Krankheiten, „bei welchen eine Flüssigkeit dem menschlichen Körper entgegen dem ordinären Gang der Natur entzogen wird, so dalo er dadurch geschwächt wird“. Diese Klasse ist nach den Körperteilen eingeteilt, von welchen aus die Entleerung geschicht. Wir haben demnach morbi evacuatorii capitis, thoracis, abdominis, genitalium et corporis externi (Galactia, Sudor). Die zehnte Klasse "Morbi deformes" (vel cachectici) hat drei Ordnungen: „emaciantes" (Phthisis, Tabes, Atrophia, Rhachitis), „tumidosi" (Anasarca, Hydrocephalus, Ascites) und „decolores" (Cachexia, Chlorosis, Scorbutus, 
Icterus, Plethora). Die elf te und letzte Klasse wird „Vitia“ benannt und umfaßt an der äußeren Körperoberfläche hervortretende Krankheiten, wie Gangraena, Sphacelus, Ulcera, Carcinoma, Caries, Fistula, Geschwülste und andere chirurgische Fälle sowie Hautkrankheiten.

In den angeführten elf Klassen werden insgesamt 325 Krankheitsgattungen mit beigefügten kurzen Diagnosen aufgezählt. Ein großer Teil dieser Gattungen bildet jedoch, wie schon ein flüchtiger Blick zeigt, nicht voneinander charakteristisch verschiedene Krankheiten, sondern nur mehr oder weniger in die Augen fallende, verschiedenen Leiden gemeinsame Symptome. Die Gattungen selbst sind wieder vin sog. Krankheitsarten (oder Formen) eingeteilt, je nach den Ursachen, die sie im einzelnen Falle hervorgerufen haben. Diese Krankheitsarten finden sich nicht in der gedruckten Ausgabe der Genera morborum angeführt, sondern wurden bei den Vorlesungen über diesen Gegenstand beschrieben und erklärt ${ }^{1}$ ). Die Darstellung dieser Arten, ihrer verschiedenen Entstehungsweise, Erkennung und Behandlung bildete den eigentlichen Inhalt des Vortrags, entsprechend der speziellen Pathologie unserer Zeit. Eine Folge davon, daß eine große Anzahl oft untergeordneter Symptome auf diese Weise als selbständige Krankheiten betrachtet wurden, war die, daß der physiologische Zusammenhang zwischen den Symptomen eines und desselben Krankheitsprozesses verloren ging, während die Anzahl „Gattungen“ über die Maßen vermehrt wurde. Diese Betrachtungsweise hing einerseits aufs engste mit dem allgemeinen medizinischen Standpunkt jener Zeit zusammen, und andererseits konnte eine solche symptomatische, übersichtliche und leichtfaßliche Aufstellung der Krankheiten um so mehr die Bedürfnisse des praktischen Arztes befriedigen, als die Krankheitsbehandlung dadurch in wesentlichem Grade erleichtert wurde.

Untersucht man näher die theoretischen Vorstellungen, von denen Linné bei der Betrachtung des Krankheitsprozesses ausging, und von denen viele unter anderer Form und anderem Gewande sich noch in der Pathologie erhalten haben, so läßt sich als kennzeichnend

I) Zur Erklärung hierfür sei erwähnt, daß, soweit Verf. weiß, Sauvages der erste war, der in die Pathologie schematische Uebersichten möglicher Ursachen für die Entstehung von Krankheitszuständen einführte. Linné folgte seinem Beispiele. So z. B. führte er in seinen Vorlesungen über "Pathologia nosologica" (1756-1758) folgende Arten von Phrenitis (Meningitis), durch verschiedene Ursachen hervorgerufen, an: a) Phrenitis idiopathica a structura, b) Phren. symptomatica, c) Phren. ebriosa, d) Phren. phanatica a meditatione, e) Phren. aphrodisiaca, f) Phren. puerperans, g) Phren. a retropulsis exanthematicis, h) Phren. ab hectica, i) Phren. a morsu venenato, k) Phren. a febre, l) Phren. a pervigilio, $\mathrm{m}$ ) Phren. a laeso cranio. 
für ihn feststellen, daß er mit Leichtigkeit das Gleichartige und das Ungleichartige, das Wesentliche und das Unwesentliche in den wechselnden Phänomenen unterscheiden konnte, gleichwie er es auch verstand, unter allgemeinen Gesichtspunkten die Mannigfaltigkeit der Erscheinungen zu ordnen. Die Grundlagen, von denen er ausging und auf die er ständig zurückkam, sind, wie bereits im vorhergehenden angedeutet wurde, teils gewisse theoretische Voraussetzungen, teils wirkliche Erfahrungswahrheiten, obwohl man zugeben muß, daß auch L in né der Neigung seiner Zeit, des 18. Jahrhunderts, zur Aufstellung mehr oder weniger apodiktischer Lehrsätze auf dem Gebiet der medizinischen Wissenschaft seinen Tribut entrichtete. Wir erinnern hier an Hoffmanns, Stah1s, Boerhaaves, Gaubs, Gorters u. a. fast gleichzeitige Schriften.

Bekanntlich legte Boerhaave seiner pathologischen Theorie die Vorstellung zugrunde, dab die Elementarteile des Organismus, in welchen der Krankheitsprozeß vor sich geht, Gefäle und Fasern seien. Alle, auch die kleinsten Gefäße seien geschlossene mit flüssigem Inhalt angefüllte Kanäle (Hohlräume), die, von einer Ursprungsquelle, dem Herzen, herkommend, in wunderbarer Verflechtung und zusammenhängender Ausdehnung (uno continuo filo) wieder dahin zurückkehren. Durch sie werden die für die Ernährung des Körpers nötigen und geeigneten Flüssigkeiten zusammengehalten und in ihrer Bewegung bestimmt, welche Flüssigkeiten auch für die kleinsten Gefäße und deren gleichförmige Erweiterung abgepaßt sind (humores proportionati suis vasis etiam exilissimis). Die zwischenliegenden Fasern entstehen dadurch, daß die Wandungen der obengenannten Kanäle miteinander verschmelzen. Diese Um- und Neubildung stellt die ständig fortgehende Entwicklung innerhalb der Organe des Körpers dar. Die Fasern können stärker oder schwächer sein hinsichtlich der Kohäsion der konstitutiven Teile, des Zusammenziehungsvermögens, der Elastizität, der Einwirkung auf die Gefäße usw. Alle Bewegung und Tätigkeit im Körper beruht demnach auf den gegenseitigen Verhältnissen der festen Teile und den Eigenschaften der in ihnen fließenden Flüssigkeiten. Veränderungen in Gefäßen und Fasern rufen daher allgemeine und lokale pathologische Erscheinungen im Körper hervor.

Boerhaave führte demnach die krankhaften Störungen in Organismus auf mechanisch-physikalische Veränderungen in den Grundelementen des Körpers (Vasa et Fibrae) zurück, ließ aber auch seinen Flüssigkeiten und deren chemischen Verhältnissen gebührenden Raum in der Pathologie. Das Vertrauen zu der krassen Fermen- 
tationslehre der älteren Aerzte hatte er erschüttert und einer gereinigten Humoralpathologie den Weg gebahnt. Obwohl sich Linné im wesentlichen Boerhaves Ansichten anschloß, gab er doch seiner medizinischen Theorie hinsichtlich der Natur und des inneren Wesens der Krankheiten einen mehr entwickelten, man kann sagen, spezialisierteren Inhalt ${ }^{1}$ ). Die verschiedenen Spannungs- und Dichtigkeitsverhältnisse innerhalb der festen und flüssigen Bestandteile des Körpers bilden zwar den Kernpunkt, um welchen herum sich auch L in nés pathologische Ideen und Vorstellungen bewegten, er legte aber, gleich F. Hof $\mathrm{fmann}$, größeres Gewicht auf die ständige und gegenseitige Wechselwirkung, in welcher diese Bestandteile zueinander stehen, als Boerhaave es tat. In dieser lebhaften Wechselwirkung zwischen den Organen des Körpers suchte er die Erklärung für die pathologischen Erscheinungen ${ }^{2}$ ). Wir werden im folgenden sehen, daß es zum Teil Linnés pharmakodynamische Ansichten waren, die ihn zu dieser Auffassung führten und sie vertieften. Daß auch Linnés botanische Anschauung in ihrer Weise mehr oder weniger bestimmten Einfluß auf diese seine medizinischen Theorien gehabt hat, mag gern zugegeben werden. Bei der Aufstellung seiner "Fibrillarpathologie" suchte Boerhaave den Grund zu den meisten Krankheitszuständen in der Spannung oder Erschlaffung, denen die Faser, der gemeinsame Bestandteil des Organismus, unterworfen ist ${ }^{3}$ ), und die sich auch bei Krankheiten sowohl in den großen als in den kleinen Gefäßen zeigen. L inné begnügt sich dagegen nicht mit diesem allgemeinen Satz, sondern sucht ihn in seinen Einzelheiten zu verfolgen und will auch innerhalb der Flüssigkeiten des Körpers mehr oder weniger entsprechende Kategorien nachweisen ${ }^{4}$ ).

I) „Boerhaave baute die Fehler der Fibrarum nur auf zwei Zufälligkeiten, laxum et strictum, das war aber nur die erste Harfensaite, es variiert jedoch mehr, als daß man dadurch alle morbi fibrarum komprehendieren könnte." (Linnés Vorlesungen über Clavis.)

2) "Qualis chylus, talis sanguis, qualis sanguis, tales fibrae, quales fibrae, tales oriuntur morbi." (L innés Vorlesungen über Clavis.) Diese Unstellung von F. H of fmanns bekannten Worten kommt oft in Linnés Abhandlungen vor.

3) „Morbi fibrae debilis et laxae, rigidae et elasticae" (B oerha a ve).

4) Es ist vielleicht angebracht, hier in der Originalsprache die Grundgedanken mitzuteilen, die $\mathrm{L}$ in né ausgesprochen hat, und die sich wie ein roter Faden durch sein medizinisches System hindurchziehen.

a) Solida ceu alterae partis humani corporis ex fibris et fibrillis constant et quidem pro Medicorum laxo et stricto quinque modis differunt, I) prout siccae vel humectatae, 2) ut crassae v. graciles, 3) ut tenaces aut tenerae, 4) ut durae vel molles, atque denique 5) ut exsuccae vel ipingues. Singulas hasce qualitates partium medicus a signis percipit easque medicamentis suis corrigit et inmutat, dum modo affectum sapidorum in fluida et solida satis sibi perspectum habet. 
Diese Kategorien sind mit Rücksicht sowohl auf die augenfälligsten Eigenschaften der Fasern als auf die Zusammensetzung der Flüssigkeiten aufgestellt. Eigentliche Gründe für ihre Aufstellung gibt Linné nicht an. Er hat weder in seinen medizinischen Schriften ausführlicher die fraglichen Kategorien beschrieben, noch eine nähere Erklärung seiner Auffassung von ihren diagnostischen Eigenheiten geliefert. In Anbetracht des wissenschaftlichen Standpunktes jener Zeit war ihm das ja auch nicht möglich. Die spezielle Diagnostik der einzelnen Kategorien und ihrer wesentlichen Kennzeichen beschränkt sich daher auf gewisse allgemeine Ausdrücke oder Erfahrungssätze, wie man sie noch in unseren Tagen in der populären medizinischen Sprache findet. Wahrscheinlich hat Linné seine Ansichten näher ausgeführt, wenn er über Pathologie vorlas. Verf. hat in seinen Vorlesungen über "Clavis medicinae" (wahrscheinlich aus dem Jahre 1771) einige Andeutungen in dieser Hinsicht gefunden und teilt sie im folgenden, so kurz und unvollständig sie auch sind, mit 1 ).

Die festen Bestandteile des Körpers können, nach Linnés Ansicht, in ihren feinsten Fibrillen nicht nur im allgemeinen gespannt oder erschlafft sein (fibrae strictae vel laxae), sondern sie zeigen dies in fünf verschiedenen Modifikationen. Sie sind:

a) feucht (fibrae humidae); „wenn die Flüssigkeiten die Fasern erweichen, werden sie relachiert und verlieren ihren Tonus. Im Gegensatz hierzu sind die Fasern trocken (fibrae torridae), „wenn die Flüssigkeiten dick sind und starke Entleerungen stattgefunden haben";

b) spröde (tenerae); „dieser Zustand kommt von acido humorum, denn man weiß, daß z. B. zähes Fleisch, wenn es einige Zeit in Ersig liegt, ziemlich mürbe wird und moleculae fibrarum weniger zusammenhängen, indem das Gluten weggenommen wird";

$z \ddot{a} h$ (tenaces); „so werden fibrae von humores phlogistici, und diese werden phlogistici, wenn das Blut dick wird, was a motu geschieht";

Morbosae istae qvinque fluidorum solidonumque affectiones diaetae potissinum erroribus originem debent; ita quoque in viis chylopoeticis seu primis, ventriculum puta ac intestina, plerumque incipiunt. Purgantia indigena (1 766 ).

b) Fluida ceu verae solidorum matrices etiam sanguineam massam ex rubro sanguine et seroso compositam sub se comprehendunt, quae rursus bifariam differre potest, scilicet, qua crasin et diathesin: ratione craseos, cum vel abundat vel deficit, nimium seri copia, diatheseos, cum massa sanguinea peregrino quodam vel acri vel viscido fuerit permixta.

I) Aufzeichnungen nach diesen Vorlesungen werden in der Bibliothek des Kgl. Karolinischen Institus in Stockholm aufbewahrt. 
c) fett (pingues); ,von fetter und oleoser Speise“; „fette Personen sind müde, torpentes et stupidi“;

mager (macrae); „wenn fibrae nicht hinreichend lubricatae mit Flüssigkeit sind";

d) dick (turgidae); ,fibrae grobfaserig, oder wenn nimia sanguinis copia sie ausdehnt"; je dicker die Fasern, um so mehr Stärke, "gleichwie großes Gehirn auch großen Verstand markiert, doch müssen beide exerciert werden, sonst geschieht es nicht. Feminae robustae sind gewöhnlich steriles";

dïnn (graciles); ,fibrae feinfaserig, kommt von Mangel an succus“;

e) weich (fluxae), „fibrae schlottrig, kommt von humores glutinosi“,

steif (rigidae); "so werden fibrae von Salz". Alle Fische in der Salzsee haben festeres Fleisch als frische Binnenseefische.

Die flüssigen Bestandteile des Körpers, zu denen auch das Blut gehört, und die die eigentliche Bildungsquelle für die festen Gewebe abgeben, können auf zwiefache Weise verändert sein, nämlich ihrer Zusammensetzung (crasis) und ihrer Mischung (diathesis) nach. Die Flüssigkeiten (humores) können nämlich werden:

a) tenues, „wenn Serum in Proportion zu viel gegenüber cruor sanguinis ist". Mißbrauch starker Getränke, Mangel an Bewegung in der freien Luft usw. befördern einen solchern Zustand. Davon rühren Leucophlegmasie, Scorbut und Hydrops her, „welche nicht kuriert werden, sofern man nicht ihr contrarium hervorruft, welches humores densi ist";

densi, ,wenn Serum fehlt, welches das Blut verdünnen müßte, wird so in hitzigen Fiebern und bei Alten, entsteht auch durch seri evacuatio. Nimis labor macht das Blut dicker, ebenso Wachen, weil es das Serum dissipiert. Alte Personen werden schließlich exsucci, besonders wenn sie hart arbeiten. Marasmus rührt von zu wenig Serum her."

b) aciduli. „Daß das Serum acesciert (sauer wird), beruht auf seiner Aehnlichkeit mit Milch und Eiweiß. Säure im Blut bringt ängstliches Gemüt, Unruhe, Schwäche, saures Aufstoßen (ructus acidi) mit sich, besonders wenn malum in primis viis liegt." Ferner entstehen Hypochondrie, Stein, Podagra, Migraine, weshalb starke Weintrinker selten diesen Krankheiten entgehen. "Qvies" befördert auch Säure, während ihr Kontrast, „motus“, die davon herrührenden Krankheiten kuriert. „Mineralsäuren koagulieren das Blut, vegetabilische dagegen resolvieren es." 
phlogistici. „In der phlogistischen, putriden Discrasie wird das Blut angegriffen; wenn es stagniert, wird es scharf (acris fit), und eine Entzündung entsteht; falls nicht eine Resolution eintritt, verdirbt das Blut, und die infolgedessen irritierten Nerven rufen Fieber hervor. Die gleiche Ursache haben alle sog. Wundfieber, die daher nicht früher kommen, als bis sich die Materie gesetzt hat. Das Herz bestrebt sich, dieses Heterogeneum durch Fieber zu evakuieren. Medici pflegen auch bei sangv. phlogist. einen Teil des koagulierten zu evakuieren. Acida, als Contraria, werden hierbei benutzt, den geronnenen Cruor zu resolvieren, die Hitze und das Fieber zu dämpfen. Humores phlogistici et putredinosi infizieren bald solida, besonders das Fleisch, das seiner Natur nach sehr ad putredinem geneigt ist."

c) oleosi. „Der Chylus besteht aus mit Wasser zur Emulsion gemischten partes oleosae. Man weiß daher, daß, wenn jemand hungert, die Flüssigkeiten scharf werden; der Speichel, der Harn, die Milch bei Menschen und Tieren zeugen davon. Erhält der Körper genügend oleosum, so ist er flink und munter, erhält er es aber im Ueberflulu, so sammelt die Natur es in eine Truhe, welches die tunica cellulosa ist, bis sie es braucht. Das Blut, das auch eine ansehnliche Menge in sich hat, disponiert, wenn es Ueberfluß daran hat, zu Carus und Cataphora (soporösen Zuständen), denn man weiß, daß man besser schläft, wenn man fette Speisen abends gegessen hat. Fett kann sich im übrigen nur bei qvies setzen, daher werden diejenigen niemals fett, welche viel Bewegung haben. Die Galle nimmt auch durch Fett sehr zu, denn keine Flüssigkeit im Körper braucht mehr davon als sie. Die Oleosa verändern ganz ihre Natur, wenn sie ranzig werden, und werden dann acria."

Acres sind von zweierlei Art: scharfe, fressende Stoffe, wie Ingwer, Capsicum usw., und salzige; die ersteren sind den Oleosa und die letzteren den Mucilaginosa entgegengesetzt. Linné sagt, er habe die Erklärung für dieses Verhältnis durch seine Beobachtung gefunden, „daß alles, was in der Salzsee sich aufhält, mit Schleim überzogen und dadurch konserviert wird. Mucilago und Salz müssen daher untereinander konträr sein; Oleosa und Acria kontrabalancieren einander."

d) plethorici, „wenn die Flüssigkeiten, besonders das Blut, im Körper im Ueberflul vorhanden ist". Das Gesicht wird dabei florisant, rot und fröhlich, bei starker Bewegung errötend. Die Palpebrae sind auf der Innenseite gerötet und geben stets das sicherste Zeichen für Plethora ab. Unter Ursachen: zu vieles Essen von loser Speise, die bald in Gelatina umgewandelt wird, besonders von süßen Sachen; 
Mangel an Bewegung bei otiosi und sedentarii; evacuatio sangvinis suppressa (gehemmter Blutabgang). Plethorici können bald Apoplexie infolge des Berstens eines Blutgefäßes im Gehirn und Haemoptysis bekommen, wenn in den Lungen etwas zerreißt. Kinder haben daher Nasenbluten, welches das überflüssige Blut evakuiert.

pauperati, „wenn die Flüssigkeit schwach und in geringer Menge vorhanden ist. Entsteht durch Hunger oder infolge ungeeigneter Nahrung, die die Natur nicht in Blut umwandeln kann. Ebenso wenn man nicht Speise anwendet, welche Chylus in derselben Proportion fourniert, wie der Körper durch Arbeit abgenutzt wird; kommt daher bei armen Arbeitsleuten vor."

e) glutinosi, pituitosi. „Durch stilles Verhalten wird zu viel Schleim im Körper gebildet. Wenn Milch zum Sauerwerden lange stehen bleibt, wird sie so schleimig, daß sie lang ausgezogen werden kann. Auf dieselbe Weise wird durch stilles Verhalten Schleim im Körper generiert, durch Motus der Schleim zerstört. Mund, Schlund, Magen und Därme müssen stets inwendig mit etwas Schleim bekleidet sein, um diese Teile vor Acria zu schützen, er darf aber nicht excessu generiert werden, was stets infolge von Erschlaffung geschieht. Viscidum ut tardum tarde abit ideoque post consumta viscosa diutius saturi sumus qvam alias. Oleum und Glutinosum scheinen einander zu ähneln, indem beide Schärfe aufheben, sie sind aber wohlverschieden, denn aus Oleum wird Resina, aus Gluten aber wird Gummi.“

muriatici. „Salz dient im Körper dazu, den Schleim zu lösen, vermehrt gleichzeitig den Appetit; starke Salzesser werden steif in allen Gliedern; Salz ist dem Schleim entgegengesetzt" und wirkt digestiv durch seine schleimlösende Kraft. Alles Salz ist aber unerträglich für die Natur und muß daher wieder heraus, was durch den Harn geschieht, der daher Sal commune beim Menschen enthält, was er nicht bei Tieren tut, welche nicht Salz verzehren. Ein Sedentarius, der nicht durch Motion das Salz wieder herausschaffen kann, darf es nicht in größerer Menge anwenden. Die Lappen, die nicht viel Salz gebrauchen, sind sehr biegsam in den Gelenken und geschmeidig."

Wirft man einen Blick auf alle diese verschiedenen Kategorien, die Linné hinsichtlich der Beschaffenheit der Flüssigkeiten aufstellt, so wird man unwillkürlich an die Krasislehre erinnert, wie sie noch vor einigen Jahrzehnten eine wichtige Rolle in der Wissenschaft spielte, und man fragt sich, ob der Unterschied in dieser Hinsicht wirklich so sehr groß ist. Da zwischen den festen und flüssigen 
Teilen im menschlichen Körper ständig ein lebhaftes Wechselverhältnis stattfindet, war es die Aufgabe des praktischen Arztes, zu entscheiden, ob die festen Teile durch ihre verschiedene Spannung die Zusammensetzung der Flüssigkeiten verändert hatten, oder ob es die Flüssigkeiten waren, die einen größeren oder geringeren Grad von Spannung und Erschlaffung in den festen Teilen, indem sie auf ihre Bildung einwirkten, hervorgerufen hatten $\left.{ }^{1}\right)$.

Es war die Aufgabe des Arztes, alle diese Verschiedenheiten in den Geweben und Flüssigkeiten des Körpers aufzufassen und zu versuchen, sie durch seine Arzneimittel zu verändern oder zu bessern. So wird nach Linnés Ansicht die schlaffe Faser durch bittere Mittel gestärkt und durch zusammenziehende Stoffe fester. Die zu stark gespannte Faser wird unter Anwendung wasserhaltiger (aquosa) Mittel feucht, durch saure verdünnt und durch fette Stoffe erweicht. Die saure Diathese wird durch bittere Stoffe vermindert, und der septischen kann man durch balsamische Arzneimittel entgegenarbeiten. Sind die Flüssigkeiten scharf, so werden sie durch süße Stoffe gemildert, durch wasserhaltige gereinigt und durch klebrige (viscosa) erweicht. Die dünne Flüssigkeit wird von trocknenden Mitteln aufgesaugt und durch zusammenziehende Mittel verdickt. Die Arzneimittel wirken demnach dadurch, daß sie den kleinsten Partikeln der festen Teile einen größeren oder geringeren Zusammenhang (majorem vel minorem adunationem) verleihen, und auf die Flüssigkeiten des Körpers dadurch, daß sie entweder dieselben verbessern, wenn sie ihrer Zusammensetzung und Schärfe nach (crasis ac acrimonia) verändert sind, oder sie auf geeigneten Wegen von schädlichen Stoffen befreien ${ }^{2}$ ).

Diese obenerwähnten Annahmen Linnés oder, wie man sie auch nennen könnte, allgemeinen pathologischen Ideen über die verschiedene Beschaffenheit sowohl des Blutes und der Flüssigkeiten wie der organischen Fasern spiegeln das Bedürfnis jener Zeit nach einer wissenschaftlichen Einsicht in die Natur und das innere Wesen der Krankheiten wieder. Der damalige unentwickelte Standpunkt der Wissenschaft und der Mangel an exakten Untersuchungsmethoden machte jedoch die volle Anwendung dieser theoretischen Betrachtungsweise auf das Gebiet der praktischen Medizin unmöglich. Der speziellen Krankheitslehre blieben diese Spekulationen fremd. Zwischen Theorie und Praxis bestand eine Kluft, die man vergebens auszu-

I) "Quemadmodum vero fluida solidas partes progenerant, ita etiam solida vicissim in fluida agunt eaque modificant." (L innés Vorlesungen über Clavis.)

2) Sapor medicamentorum (I75I). 
füllen versuchte. Da Linné kein allgemein gültiges Prinzip für die systematische Gruppierung der Krankheiten fand, war er, wie wir es oben bereits erwähnt haben, gezwungen, die Symptomatologie ihrer Klassifizierung zugrunde zu legen.

Ein Gebiet fand sich jedoch, wo Lin n és allgemeine medizinische Ideen sich geltend machen konnten, und das war die Therapie. Da es vom praktischen Gesichtspunkt aus wichtig war, die allgemeinen, soeben geschilderten pathologischen Störungen in den Elementarteilen des Körpers in engsten Zusammenhang mit ihrer medizinischen Behandlung zu bringen, so erwachte bei Linné der Gedanke, auch die vegetabilischen Arzneimittel in Uebereinstimmung damit in entsprechenden therapeutischen Gruppen aufzustellen. Um die zu stark gespannte oder erschlaffte Faser und das seiner Krasis oder Diathese nach veränderte Blut in den normalen Zustand zurückbringen zu können, muß es Klassen von Arzneimitteln geben, welche ein entgegengesetztes Verhalten zu bewirken vermögen. Hierin liegt auch die Erklärung für die Entstehung von Linnés pharmakodynamischer Aufstellung der vegetabilischen Drogen. Ein derartig pathologischpharmakodynamisches System ist fïr Linné originell und findet sich meines Wissens bei keinem anderen zeitgenössischen Forscher in so ausgesprochener und allgemein gültiger Form $\left.{ }^{1}\right)$.

Auf Grund seiner Auffassung von der Einwirkung, welche die Pflanzen infolge ihres Geschmacks oder Greruchs auf den Organismus, seine Funktionen und verschiedenen Zustände ausüben, ordnete Linné in Analogie mit seiner oben mitgeteilten Vorstellung von den Flüssigkeiten und der pathologischen Beschaffenheit der organischen Fasern die medizinischen Pflanzen mit ihren Gegensätzen in folgende weiter im einzelnen zu beschreibende Gruppen ${ }^{2}$. Diese Ansicht Linnés von der verschiedenen Einwirkung der Pflanzen auf den menschlichen Körper je nach ihrem Geschmack und Geruch ist der Fundamentalsatz, auf welchen er sein pharmakodynamisches System griindet, und das zugleich einen entscheidenden Einfluß auf seine ganze pathologische Anschauungsweise ausgeübt hat. Die vitalen Funktionen, zu welchen Linné die Viscera, Muskeln, Gefäße usw. rechnete, „werden nur von Sapida influiert, welche man ja auch in dem Geschmack des Fleisches der Tiere je nach der ver-

I) In dieser Kombination scheint mir das Verdienst von Lin nés sog. medizinischen System oder seinen pathologischen Ideen eigentlich zu liegen, da es für den praktischen Arzt von Wichtigkeit war, seine zerstreuten Beobachtungen unter gewisse Gruppen $z u$ sammeln und einen Ausgangspunkt für seine Krankheitsbehandlung zu gewinnen.

2) Genera morborum, S. 32. Philosophia botanica, S. 363. Clavis medicinae, S. 913. $\mathrm{H}$ jelt, Carl von Linné. 
schiedenen Pflanzennahrung wiederfindet, denn was, wenn es aufgelöst wird, nicht schmeckt, kann nicht auf functiones vitales agieren". Stark riechende Pflanzen (olida), sei es grata oder tetra, wirken dagegen nur auf die animalen Funktionen ein ${ }^{1}$.

\section{Sapida.}

Agunt in Corticale vitale

$$
\text { in Flutidis in Solidis }
$$

I. Aquosa Mundificantia, Humectantia

2. Acida Absorbcntia, Exsiccantia

Balsanica, Tonica

Sicca.

3. Dulcia

Edulcorantia, Impinguantia

Incidentia, Corrodentia

Amara.

4. Viscosa

Inviscantia,

Lubricantia

Penetrantia,

Abstergentia

5. Pinguia

Obtundentia

Emollientia

Inspissantia

Adstringentia

Acria.

Salsa.

Stiptica.

\section{Olida.}

Agunt in Medullare animale:

$\begin{array}{lllll}\text { Sensum } & \text { Excitant } & \text { Aromatica, } & \text { Sopiunt } & \text { Virosa. } \\ \text { Motum } & \text { Spasticant } & \text { Orgastica, } & \text { Evacuant } & \text { Nauseosa. } \\ \text { Judicium } & \text { Acuunt } & \text { Spirituosa, } & \text { Confundunt } & \text { Tetra. } \\ \text { Libidinem } & \text { Provocant } & \text { Ambrosiaca, } & \text { Suffocant } & \text { Hircina }{ }^{2} \text { ). }\end{array}$

I) Linné erinnert oft daran, „daß die Natur in Zunge und Nase Organe“ oder, wie er sich auch ausdrückt, "Wächter bei der Wahl von sapida und olida erhalten hat. Wie kräftig olida Igrata auf das Gehirn wirken, sehen wir bei Ohnmachtsanfällen, und mit einem einzigen Tropfen von Oleum Cinnamomi kann das Leben bei einem Halbtoten aufgehalten werden".

2) Deutsch dürften dicsc Termini technici auf folgende Weise wiederzugeben sein:

I. Heilmittel, die durch ihren Geschmack auf die flüssigen und festen Elementarteile des Körpers (corticale vitale) eimwirken: auf die flüssigen
1. Aquosa reinigend aufsaugend
2. Acida liühlend balsamisch
3. Dulcia süßend schneidend
4. Viscosa klebend stcchend
5. Pinguia verdickend verdichtend

auf die festen

anfeuchtend

austrocknend

Sicca. verdünnend stärkend

Amara. anhaftend anfressend Acria. schlüpfrigmachend troclinend Salsa. erweichend zusammmenziehcnd Stiptica 
Um eine Krankheit zu heben, ist es, nach Linnés Ansicht, erforderlich, eine Veränderung in den Flüssigkeiten oder festen Teilen des Körpers hervorzurufen, die dem Zustande entgegengesetzt ist, bei welchem sich die Krankheit entwickelt hat. In dieser Absicht werden Medikamente gebraucht. Dieses ihr Vermögen, in Körper solche entgegengesetzte Zustände hervorzurufen, kann man aus der Wirkung erkenmen, die sie durch ihren Geschmack auf die flüssigen und festen Elementarteile in Körper oder durch ihren Geruch auf das Nervensystem (die Medullarsubstanz) ausüben. Die wichtigsten Arzneimittel werden gewöhnlich Pflanzen entnommen, die einander an Geschmack und Geruch (sapida et olida) entgegengesetzt sind. Darin liegt auch der Schlüssel zur Materia medica.

Aus dieser Theorie der Gegensätze, wie man sie nennen kann, wird das pathologische und pharmakodynamische System ${ }^{1}$ ) entwickelt, das mehr oder weniger klar durch Linnés medizinische Schriften hindurchgeht, und ohne dessen Kenntnis sie nicht verstanden werden können. Daß Linné das Nervensystem in einen gewissen Gegensatz zu den übrigen Geweben des Körpers stellte, scheint mir darauf zu beruhen, daß auch sein pharmakodynamisches System eine solche Scheidung erforderte. Wenn Linné den allgemeinen Satz aussprach, daß die Pflanzen, die sich durch ihren Geschmack auszeichnen, die festen und flüssigen Bestandteile des Körpers verändern, während die riechenden und flüchtigen Stoffe auf das Gehirn einwirken, so mußte es ein organisches Substrat in Körper geben, das allein für die Eigenschaften der Arzneimittel empfänglich ist, welche die große Gruppe der Olida, Odorata. Volatilia, Spirantia ${ }^{2}$ ) usw. bilden. Auch

II. Heilmittel, die durch ihren Geruch auf das Nervensystem

(medullare animatum) einwirken:

Die Empfindlichkeit wird gereizt durch

Die Bewegung wird angeregt durch

Das Urteil wird geschärft durch

Die Begierde wird angefacht durch

$\begin{array}{ll}\text { Aromatica, } & \text { eingeschläfert durch } \\ \text { Orgastica, } & \text { erschöpft durch } \\ \text { Spirituosa, } & \text { verwirrt durch } \\ \text { Amurosiaca, } & \text { erstickt durch }\end{array}$

Aromatica, eingeschläfert durch

Spirituos $\alpha$,

Ambrosiaca, erstickt durch
Virosa.

Nauseosa.

Tetra.

Hircina.

I) Es ist, sagt $\mathrm{L}$ inné, besonders $z u$ beobachten, daß, gleichwie fünf abnorme $\mathrm{Zu}$ stände des Organismus mit ihren Gegensätzen (vitia cum suis oppositis) Ausgangspunkte für die meisten Krankheiten bilden, sie ebenso durch gleich viele schon von der Natur selbst angedeutete Mittel mit ihren Gegensätzen geheilt werden. Hieraus ergibt sich die Wahrheit des alten, auch von Boerha ave angewandten, in der Literatur oft angeführten Satzes: „Contraria contrariis curantur". Mehr als alle anderen führte Li nné diese "Theorie der Gegensätze" sowohl in der Pathologie als in der Pharmakodynanilk durch. De effectu et cura vitionum diaeteticorum generali (1;66).

2) "Sapida agunt in fluida et solida, eaque variant, non vero systema cerebri. Odorata volatilia agunt in cerebrum, sed solida et fluida ceteris paribus non mutant, nisi mediate ciendo motum in systemate nervoso." Inebriantia (1;61). 
Boerhaave nahm ein fluidum nervosum an, erkannte aber den Nerven nur das Vermögen der Spannung und Erschlaffung zu.

Linné stellte daher die Regel auf, daß man bei der Benutzung eines Arzneimittels stets ein solches verwenden müsse, das einen $\mathrm{Zu}$ stand im Gewebe mit sich bringe oder hervorrufe, der dem zu bekämpfenden entgegengesetzt sei (contrariorum e contrariis curatio) ${ }^{1}$ ). Es ist überhaupt ein in seinen Schriften oft wiederkehrender Gedanke, daß die Arbeit der Natur unter Gegensätzen vor sich geht (nam contrariis fere sua omnia natura operatur). Ja, es ist eine Grundansicht in Linnés ganzer Naturanschauung, daß das Gleichgewicht der Natur auf dem Kampfe zwischen Verschiedenheiten beruht (universum luctâ discordium aequilibratur) ${ }^{2}$ \% Damit hängt die Vorstellung zusammen, daß die eine Krankheit die andere verdrängt, oder daß durch das Vorhandensein eines Krankheitszustandes der Organismus gegen einen anderen gleichsam geschützt oder immun wird (hinc morbi contrariis morbis saepius curantur) ${ }^{3}$ \%. Eine Ansicht, der übrigens bekanntlich bis vor noch nicht langer Zeit in der Medizin gehuldigt wurde.

Die Bedingungen für das Wohlbefinden des Menschen oder die Diät im weiteren Sinne sind, nach Li nnés Darstellung, frische Luft, geeignete Nahrung, hinreichende körperliche Bewegung und Ruhe, der ungestörte Gang der natürlichen Entleerungen und die Beschaffenheit der Gemütsbewegungen. Man versucht vergebens, die nächste Krankheitsursache aufzuheben, wenn eine ungeeignete Diät sie noch weiter unterhält. Es ist daher eine der wichtigsten Obliegenheiten des Arztes, mit gröliter Sorgfalt die vorhandenen Mängel oder Mißgriffe in der Lebensweise zu erforschen, und dies ist nicht möglich ohne eine genaue Kenntnis der Forderungen der Diätetik. Diese beruhen gänzlich auf den Wahrheiten der Naturwissenschaft, und in dieser Hinsicht werden Medizin und Naturwissenschaft durch ein gemeinsames Band zusammengehalten (utraque veluti lapides muri firmo nititur vinculo). Hat der Arzt diese Krankheitsursache festgestellt, oder ihre Quelle (indicantia) gefunden, so wird ihm auch klar, was er $\mathrm{zu}$ tun hat (certior evadit de suo indicato), und er kann mit Leichtigkeit zu den Indikationen für die Behandlung gelangen. Kennt er die Arzneimittel, die dem Geschmack und Geruch nach

I) Purgantia indigena (1766).

2) Der Körper des Menschen kann ,als eine Balance consideriert werden; wenn sie äquilibriert, befinden wir uns wohl, sobald aber auf einer Seite ein Uebergewicht da ist, sind wir krank" (Linnés Vorlesungen über Clavis).

3) Vires plantarum ( 1747$)$. 
miteinander übereinstimmen, so kann er die kräftigsten und wirksamsten auswählen und sie auf eine mit ihrer Natur übereinstimmende Weise ordinieren. Hiermit wird er wohl in vielen Fällen die Krankheit zum Verschwinden gebracht haben, er kann aber nicht verhindern, daß sie wiederkehrt, sofern er es unterläßt, unter sorgfältiger Beobachtung der erwähnten, in der Lebensweise liegenden Ursachen dem Kranken eine entgegengesetzte oder veränderte Lebensweise vorzuschreiben. Erst dadurch heilt er die Krankheit vollständig ${ }^{1}$ ).

$\mathrm{Zu}$ den bemerkenswertesten Ansichten in Linnés Lehre von den Krankheitsursachen gehört seine Hypothese von den „Exanthemata viva" oder die Vorstellung davon, daß die ansteckenden Krankheiten durch die Einwanderung kleiner Tierchen in den menschlichen Körper, ein „contagium ex animalculis“, hervorgerufen werden und auf ihr beruhen. Er war durch eine Mitteilung von Freiherrn O. von Münchhausen in Göttingen auf das Vorkommen kleiner, lebender, beweglicher Körperchen in Pilzen usw. und anderen leicht verwesenden Stoffen aufmerksam gemacht worden. Diese Mitteilung erweckte bei Linné den Gedanken, die Erklärung für die grol3e, unerklärlich schnelle Verbreitung gewisser ansteckender Krankheiten in der Mitwirkung kleiner, in den Körper eindringender "vermiculi“" zu suchen, in nächster Analogie mit Leeuwenhoecks „vermiculi spermatici“. Linné meint, daß man sowohl durch ihre Analogie wie auf Grund der Erfahrung zu der Annahme dieser Entstehungsweise für verschiedene ansteckende Seuchen berechtigt ist, und findet Stützen für diese Annahme sowohl in eigenen als von anderen gemachten Beobachtungen am Krankenbett. $\mathrm{Zu}$ diesen Krankheiten werden Krätze und epidemische Ruhr (Dysenterie), von Linné „scabies intestinorum interna“ genannt, Keuchhusten (tussis ferina), Pocken, Masern, Syphilis und Pest gerechnet $\left.{ }^{2}\right)$. Später werden in diese Kategorie auch Aussatz (Lepra), Lungenschwindsucht ${ }^{3}$ ) (Phthisis) und wechselfieberartige Krankheiten aufgenommen ${ }^{4}$ ).

Obwohl die fraglichen kleinen Tierchen noch nicht entdeckt und beschrieben worden waren, meinte L,inné, daß die Ausbreitung der ansteckenden Krankheiten eine bemerkenswerte Aehnlichkeit mit der Art und Weise habe, wie eine Menge Tiere, besonders Insekten sich fortpflanzen und vermehren. Er führt die oft plötzliche und furchtbare Entwicklung der Ansteckungsstoffe hierauf zurück. Je kleiner

I) De effectu et cura vitionum diaeteticonm generali 1766 ).

2) Exanthemata viva (1757).

3) Lepra (1765), De Viola Ipecacuanha (1774), De Ledo paluestri (1775).

4) Mundus inviszbilis ( 1767 ). 
ein Tier im allgemeinen ist, um so zahlreichere Nachkommen kann es hervorbringen, und daher dürfte man sich wohl denken können, daf schon eines oder einige von diesen kleinen tierischen Wesen durch ihre unerhörte Vermehrung in kurzem den ganzen menschlichen Körper zu erfüllen vermögen. Dieses Verhältnis kommt auch darin zum Vorschein, daß es bei der Pockenimpfung nicht auf die größere oder geringere Menge von Eiter ankommt, die zur Hervorrufung von Pockenpusteln angewandt wird. Als Beweis für die Ansicht von dem parasitären Ursprung der ansteckenden Krankheiten führt Linné auch an, daß der Ansteckungsstoff durch Kälte zerstört wird, in Wärme sich aber vermehrt $\left.{ }^{1}\right)$. Linn é spricht die Vermutung aus, daß, wenn auch diese „lebenden Ursachen“ der exanthematischen Krankheiten noch nicht gefunden und entdeckt worden sind, künftige genaue Forschungen ihren Bau weit kunstreicher und zusammengesetzter finden werden, als man es jetzt noch ahnen kann, denn die Wahrheit steht fest, „daß die Natur nirgends vollkommener, kunstreicher ist, als in ihren kleinsten Erscheinungen“ "2). Diese Tierchen haben sicherlich der Menschheit größere Verluste zugefügt, als die größten Kriege. Wer entscheidet, ruft Linné aus, wo die im Großen und Kleinen gleichermaßen bewundernswerte Entwicklung der Natur beginnt oder endet, derın die Natur schreitet gradweise vorwärts, nicht sprungweise! Im Pflanzenreiche findet sich eine bemerkenswerte Analogie zu einem solchen Ansteckungsstoff, näm-

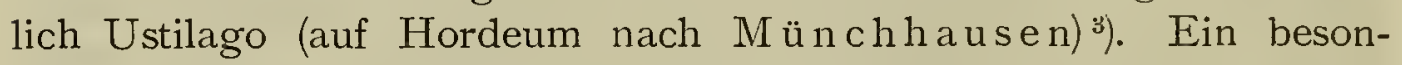
deres Gewicht legte er darauf, daß die Arzneimittel, die sich als gegen die Insekten und gegen die Krätzmilbe wirksam erweisen, sich auch bei der Behandlung ansteckender Krankheiten als wohltuend erwiesen haben, wie z. B. Moschus, Kampfer, Mercurialia, Schwefel usiv. So ließ Linné während einer heftigen Pockenepidemie seine Kinder am Halse Moschusbeutel (wie es in Norrland üblich war) tragen und glaubte, daß sie dadurch vor Ansteckung bewahrt blieben ${ }^{4}$ ). Bei schwerem Masernhusten fand Linné kleine und oft wiederholte Dosen von Flor. sulphuris sehr wirksam. In einer späteren Abhandlung „De mundo invisibili" ( $\left.{ }_{7} 6_{7}\right)$ entwickelt Linné noch weiter seine Auffassung von der Entstehungsweise der

I) Lepra (1765).

2) Exanthemata viza (I 757 ).

3) „Qvi perpendit unicam farimae ustilaginis particulam per omnes ejusdem radicis triticeae ant hordaceae spicas multiplicari, analogiam haud minimam inveniet." Mundus invisibilis ( 1767$)$.

4) Exanthemata viza (1757). 
ansteckenden und exanthematischen Krankheiten durch cin ,contagium vivum" und stellt zuletzt die Frage auf: „anne animalculis infusoriis debcantur morbi contagiosi et exanthematici plerique?" 1 ). In Zusammenhang mit Lin nés Annahme cines „contagium animatum“ als Ursache gewisser organischer Prozesse kann man auch an seine im Anschluß daran gefällte Aeußerung crinnern: „Wollen schen, ob nicht schließlich alles Gären zu lauter lebenden Partikeln wird." Es läßt sich daher sagen, daß Linné früher als irgend ein anderer die Ueberzeugung von cinem "contagium animatum" als Krankheitsursache gewonnen hat. Freilich waren es nur theoretische Gründe, auf die er sich stützte, als er anspruchslos seine Ansicht darlegte. Seine Schlußsätzc aber, die er aussprach, waren doch Folgerungen, die das divinatorische Vermögen des Genies dem Naturforscher schenkt. Ohne größere Aufmerksamkeit erregt zu haben, ward dieser für die künftige Entwicklung der Pathologic so inhaltsreiche und Iruchtbare Gedanke vergessen und beiseite geschoben, bis die Zeit reif war, ihn zu allseitiger emsiger Forschung wieder aufzunchmen. Schon Linné bemerkte: „Erit hic certe campus ad ingenia, donec omnia haec explorata fuerint, experimentis exercenda patentissimis“ 2 ).

Unter Plethora verstand L in né den Zustand, wobei die Menge des Blutes zu groß ist, als daß das Herz und die Blutgefäße es in sich aufnehmen oder es in regelmäßiger Bewegung halten können. Man muß diese Zustände voneinander unterscheiden. Bei der wirklichen Plethora oder Vollblütigkcit wird mehr Blut gebildet, als der Körper

r) "Quam hypothesin quasi ex tripode dictam alii avide arripuerunt, verum alii ut inscitiae involucrum repudiarunt. Saltem in plurimis exanthematicis morbis illam valere, valde videtur probabile." De Ledo palustri (1775).

2) $\mathrm{DaB}$ diese Ideen Linnés von ihm nahestehenden Aerzten anerkannt und angenommen worden, ersieht man aus Rosén von $\mathrm{R}$ osensteins sehr verbreiteter „Underrättelse om Barns sjukdomar och deras botemedel" ("Nachricht von den Krankheiten der Kinder und ihren Heilmitteln") ( $77 / 1$ ), worin er von dem Keuchhusten auf S. 278 schreibt: „Die rechte Ursache dieser Krankheit ist demnach eine frende Materia oder Samen, der das Vermögen hat sich zu vermehren, gleichwie der Pockensamen. Hieraus folgt, daß der, welcher den Ǩeuchhusten heilen will, solche Mittel anwenden muß, die den Samen töten oder kraftlos machen." Auch andere von Linné ausgesprochene Ansichten findet man hier und da in Rosensteins Schriften wieder.

Obwohl Linné in seinen Disputationen "Exanthemata viva" und "Mundus invisibilis" sich deutlich für die mikroskopische Natur seines „,contagium animatum" ausgesprochen und Guettard in seinen Mémoires sur différentes parties des Sciences et Arts, II, Paris 1770 , S. 473 die letztere Abhandlung auch der ausländischen Literatur einverleibt hatte, findet man bei medizinischen Geschichtsschreibern die unerwartete Angabe, Linné habe Insekten als die Ursache für die Entstehung gewisser exanthematischer Krankheiten angesehen, eine Angabe, die gleich anderen von einer Unbekanntschaft mit seinen Schriften zeugt. 
braucht oder anwenden kann. Dem letzteren Zustand liegt dagegen eine gewisse Schwäche des Herzens und der Blutgefäße zugrunde („Atonie“, F. Hoffmann), und dadurch entsteht eine scheinbare Blutüberfüllung. Eine solche Erweiterung der Blutgefäße ist für schwerkranke Personen während Fieberanfällen, wie auch für kachektische Individuen eigentümlich ${ }^{1}$. Kongestion ist ein reichlicheres Zuströmen von Blut zu einem Teil des Körpers als zu den übrigen. Sie deutet nicht nur auf eine Ungleichmäßigkeit in der Zirkulation des Blutes hin, sondern kann außerdem auf einer Schwäche oder auf einer Reizung (Irritation) in dem Teil des Körpers beruhen, wohin der Blutstrom nach mechanischen Gesetzen hingeht. Kongestion kann ferner durch Verengung der Blutgefäße in einem angrenzenden Teil hervorgerufen werden, oder kann auch infolge von Krämpfen in den Gefäßen entstehen. Wenn nun aus einem zufälligen Anlaß die Bewegung des Blutes zunimmt, kann es zu einem Bluterguß (Haemorrhagia) kommen ${ }^{2}$ ).

Unter den Hilfsmitteln zur Aufstellung von Krankheitsdiagnosen war der Puls und seine wechselnde Beschaffenheit für die älteren Aerzte von der größten und wichtigsten Bedeutung. Man muß wahrlich den Scharfsinn und die Sorgfalt bewundern, die die älteren Aerzte, mangels anderer objektiver Symptome, auf das Studium des Pulses verwandten. Wenn man nicht, bemerkt $\mathrm{L}$ inné, in jedem einzelnen Falle die Stärke und Beschaffenheit dieses Messers und Aufrechterhalters des Lebens (de humanae vitae indice illa et conservatrice) beurteilen kann, so kann man auch nicht den größeren oder geringeren Grad von Störungen in den vitalen, natürlichen und animalischen Funktionen und die dadurch bedingten Gefahren für die Gesundheit des Menschen schätzen. Es gibt in diagnostischer und prognostischer Hinsicht weder eine bedeutsamere noch notwendigere Lehre als die von der Bewegung des Blutes, dem Pulse. Man kann daher nicht umhin, den Leichtsinn der Aerzte zu tadeln, welche den Kranken mit so leichter, flüchtiger Hand untersuchen, daß sie kaum zwei Pulsschläge abwarten, und sobald der Kranke dieses oder jenes Symptom angegeben, oder sie auch nur den Namen der Krankheit gehört haben, bereit sind, Medikamente zu verschreiben. Im Gegenteil muß der Arzt in jedem Fall die genaueste Prüfung aller Krankheitszeichen anstellen und sich daraus ein mehr oder weniger sicheres oder wenigstens wahrscheinliches Urteil

I) De haemorrhagiis ex plethora (1772).

2) De haemorrhagiis uteri sub statu graviditatis (1749). 
bilden $\left.{ }^{1}\right)$. In einer besonderen Abhandlung, „Ueber den intermittenten Puls", finden sich die Ursachen seiner Entstehung angegeben, und man ersieht daraus, dal3 die Heilkunde schon zu jener Zeit nicht eines Einblicks in die Krankheitsprozesse ermangelte, die diese UnregelmäßBigkeiten bewirken. Die Ursachen für den intermittenten Puls liegen vor allem im Herzen, z. B. in einer Entzündung desselben, in einer zu starken Erweiterung seines Muskels, in Aneurysmen, Polypen, Geschwülsten und Abszessen im Herzen, in der Verknöcherung der Klappen, in der Verwachsung des Herzbeutels und anderen perikardialen Leiden sowie unregelmäßiger Tätigkeit der Herznerven. Demnächst beruht der intermittente Puls auf Ursachen, die in den Artcrien liegen, z. B. einem paralytischen Zustand oder spasmodischen Kontraktionen der Gefäße, Stase bei Entzündung ${ }^{2}$ ), Verknöcherung der Arterien ${ }^{3}$ ), Aneurysmen und polypösen Konkretionen. Schließlich können die Ursachen des intermittenten Pulses in der Beschaffenheit des Blutes liegen. Bei der phlogistischen Diathese in akuten und entzündlichen Fiebern wird der dünne Bestandteil des Blutes vorwärts getrieben, während die festen an den Wänden des Gefäßes kleben bleiben und somit ein Stillstehen des Pulses entstehen kann. Findet sich Blut in zu großer Menge, oder werden die Gefäße übermäßig erweitert, so wird ihre Tätigkeit gelähmt, und die Gefäßwände können den Widerstand nicht überwinden. Bei Blutmangel werden dagegen die Ventrikel nicht mit so viel Blut gefüllt, daß das Herz zu voller Systole stimuliert werden kann, wie das bei der Ohnmacht und nach reichlicherem Blutverlust der Fall ist, ein Umstand, der mit Leichtigkeit auch bei starken Aderlässen zu beobachten ist. Die Zeichen, auf Grund deren diese verschiedenen Ursachen diagnostiziert werden, sind jedoch so mannigfaltig und für die verschiedenen Herzkrankheiten so gemeinsam, daß man sich noch nicht mit Sicherheit für das eine oder andere Leiden entscheiden kann. Ein bemerkenswerter Gedanke ist der, daß fibrinöse Ablagerungen innerhalb der Gefäße („Polypen“), von ihrem Ursprungsorte losgerissen, plötzlich Erstickung bewirken können, weshalb Ruhe für alle die notwendig ist. die daran leiden. Die Vorstellung liegt nahe, daß man vielleicht in Zukunft Arzneimittel finden wird, die das Vermögen besitzen, derartige Ablagerungen aufzulösen. - Die bei kachektischen

1) De pulsu intermittente ( 1756$)$.

2) „Durities in tunicas arteriarum inducta, a stagnante liquido is in vasis, per quae ei exitus denegatur, binc minus flectuntur latera, sicque non cedunt motui, sed diametrum eandem internae superficiei vasis conservant, uti in inflammationibus earum evenit."

3) "Succus hic osseus effunditur in interiorem arteriarum cellulosam." 
und kränklichen Personen auftretende Blässe soll darauf beruhen, daß3 das Blut entweder an und für sich schwach und wässerig ist, oder daß es nicht mit der nötigen Kraft in den Kapillargefäßen vorwärtsgetrieben wird. Eine lange fortfahrende Abmagerung, wie sie nicht selten nach schweren Fieberkrankheiten entsteht, wird der Anstrengung zugeschrieben, welcher das Herz ausgesetzt gewesen ist ${ }^{1}$. Bezüglich der Entstehung der sog. entzündlichen Fieber wird der Gedanke ausgesprochen, daß, wenn das Blut aus irgendeinem Anlaß stockt, eine Verstopfung der kleinsten Gefäße (obstructio vasorum) und infolge davon phlogistische Fieber, Pleuritis, Peripneumonia usw. entstehen ${ }^{2}$. Lin né geht von der Vorstellung aus, daß die kleinen Gefäße, die von Nerven umsponnen werden, bei einer Entzündung so stark erweitert werden, daß sie infolge des heftigen Andringens des Bluts a tergo leicht bersten, und die Entzündung in Gangrän übergeht. Sind die resorbierenden Gefäbe untätig, so entsteht Hydrops, und entleeren die Filtrierapparate (colatoria) des Körpers nicht in hinreichender Menge die Flüssigkeit, so hat man Anasarca $z u$ befürchten ${ }^{3}$ ).

Linné schrieb eine Abhandlung über die Notwendigkeit für Mütter, ihre Kinder zu säugen und betonte die Wichtigkeit hiervon für ihre ganze Entwicklung $\left.{ }^{4}\right)$. Bei Frauen von verschiedener Körperkonstitution ist die Beschaffenheit der Milch verschieden, da die Brüste außer den Milchpartikeln aus der Blutmasse auch andere Bestandteile an sich ziehen, welche die Natur der Milch verändern können. Wenn das Kind einer fremden Frau zum Säugen übergeben wird, verändert sich seine Nahrung, und ein besonderer Einfluß auf den Neugeborenen wird sich unfehlbar bald zeigen. Es wird hier nicht nur der Grund für die Gesundheit des Kindes (stamina valetudinis) gelegt ${ }^{5}$, sondern auch für sein Temperament, das später kaum mehr zu verändern ist $\left.{ }^{6}\right)$. Kein Wunder daher, wenn das Kind gleichsam als Erbschaft von der Amme gewisse Eigentümlichkeiten des Gemütes und des Charakters empfängt. Li nné meint. daß die Milch einer Amme nicht selten durch die diesen Frauen fremde Lebensart und die oft stillsitzende Lebensweise, zu der sie gezwungen

1) Motus polyclirestus (1763).

2) Spiritus frumenti ( 1764$)$.

3) De effectu et cura vitionum diacteticomm generali (1766).

4) Natrix noverca (1752). Diese Abhandlung findet sich in französischer Ueber-

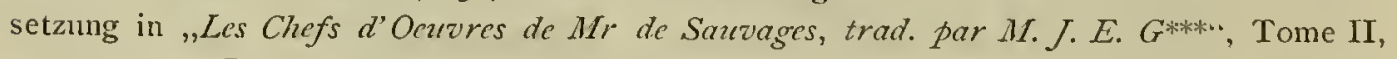
p. 213-244, Lyon 1770.

5) Liberi cum a utero, tum ab uberibus stamina valetudinis repetunt.

6) Derselbe Gedanke wird auch in "Fundamenta valetudinis". (1756) ausgesprochen. 
werden, verschlechtert wird. Er sagt, nützlicher als alle Arzneimittel habe es sich ihm erwiesen, eine Amme sich jeden Tag draußen in der frischen Luft bewegen oder andere körperliche Arbeit vor der Mahlzeit vornehmen zu lassen. In der in Västerbotten üblichen Sitte, kleine Kinder "bubulo" (mittelst eines Horns) aufzuziehen, sieht Li in né eine wichtige Ursache sowohl für die ungewöhnliche Fruchtbarkeit bei den Frauen wie für 'die große Sterblichkeit unter den Kindern in diesem Teile des Landes. In der bei den höheren Ständen herrschenden Neigung, seine Kinder von Ammen nähren zu lassen, sucht Li n né eine Erklärung dafür, daß viele Familien entarten und die sie auszeichnenden körperlichen und seelischen Eigenschaften verlieren 1). Ohne zwingende Gründe soll sich daher nie eine Mutter der Pflicht entziehen, ihr Kind selbst zu nähren. Doch kann es gleichwohl wirkliche Hindernisse in dieser Hinsicht geben. Was die Syphilis betrifft, so gibt es Beispiele dafür, daß Mütter, obwohl während der Schwangerschaft angesteckt, dennoch gesunde Kinder geboren haben. es gibt aber keinen einzigen Beweis dafür, daß eine syphilitische Frau ein Kind hat säugen können, ohne daß dasselbe angesteckt worden ist ${ }^{2}$. Nur diese Krankheit, allgemeine Schwäche (Atrophie) und Lungenschwindsucht können als Hindernis für das Nähren angesehen werden. Im Zusammenhang hiermit sei erwähnt, daß Linné die Erblichkeit gewisser Krankheiten und die Bedingungen, unter denen dieselbe eintritt, andeutet. Lungenschwindsucht, Gicht und Neigung zur Steinbildung gehen von Eltern auf Kinder über $\left.{ }^{3}\right)$.

Nach dieser Darstellung von Linnés allgemein medizinischen Ideen erübrigt es noch, in Kürze seine Ansichten betreffs einzelner Krankheiten zu berühren, soweit sie aus seinen Schriften zu erschließen sind. Das intermittente Fieber, seine Natur, Ursachen und Behandlung ist eine Frage, die Linn é mit besonderer Vorliebe behandelt hat. Er hatte Gelegenheit gehabt, dieser Krankheit schon während seines ersten Aufenthaltes in Upsala, in dessen Umgebung die Wechselfieber endemisch waren, seine Aufmerksamkeit zu widmen, und als er nach Holland kam, fand er sie auf den feuchten Ebenen dieses Landes wieder. Er wählte das intermittente Fieber zum Gegenstand für seine in Harderwyk I 735 herausgegebene Doktordissertation,

I) „Hic causa, cur nobiles degenerent, acutissimi hebescant, temperamentumque corporis optimum plures amittant, nec non quod plurimi infantes, dum primum esse inceperunt, esse desierint."

2) Nutrix noverca (I 752).

3) Fundanenta valetudinis (I756). 
und nicht ohne Interesse liest man die klare, von warmer Ueberzeugung durchdrungene Sprache, mit welcher der junge nordische Arzt sich über eine erst in unseren Tagen gelöste Frage der Pathologie ausspricht ${ }^{1}$ ).

Im südöstlichen Teile Schwedens, sagt Li n né, ist das Wechselfieber sehr gemein. In Upland findet sich keine Krankheit, die verbreiteter wäre. In der Gegend um Ảbo grassiert sie gleichfalls oft. In ganz Västerbotten dagegen kommt Wechselfieber nur bei den Kaufleuten und Seeleuten vor, die in Stockholm sich aufgehalten haben. In Lappland fehlt es ganz. Das intermittente Fieber wird in den Teilen des Landes angetroffen, wo der Erdboden Lehm in größerer Menge enthält. Linnés Ansicht geht dahin, daß die im Wasser gelösten Lehmpartikeln (intimae solutae particulae argillaceae) in das Blut eindringen und in den feinen arteriellen Gefäßen haften bleiben, wodurch eine Störung der Hauttätigkeit entsteht. Man muß daraus den Schluß ziehen, daß die Stoffe, die durch die Hautausdünstung entfernt werden sollen, auf gewaltsame Weise bei dem intermittenten Fieber zurückgehalten werden, und daß man von diesem ergriffen wird, wenn die Hautabsonderung gehindert wurde und in dem Körper zugleich eine schon zuvor dort befindliche Ursache vorhanden ist, sonst nicht. Die Indikationen für die Behandlung des Wechselfiebers sind demnach: I) Internum expellens s. vasa intendi debent, 2) Pori cutis calore aperiendi sunt. Uebergießungen mit kaltem Wasser nach vorhergehender Erwärmung sind daher wohltuend. Im übrigen ist starke körperliche Bewegung, sparsame Diät und hinreichender Schlaf vorzuschreiben. Amara, Austera und Graveolentia sind als Arzneimittel zu benutzen.

Während Linné in seiner medizinischen Erstlingsarbeit die Quelle des intermittenten Fiebers in der unreinen Beschaffenheit des Wassers suchte, stellte er in späteren Schriften eine neue Theorie für ihre Entstehung auf und glaubte ihre Ursache in der Luft und dadurch hervorgerufenen Störungen der Hautausdünstung (perspiratio insensibilis) zu finden ${ }^{2}$ ). In der Attraktion, wodurch der Körper mittelst seiner geöffneten Poren die mit schädlichen Ausdünstungen vermischte Feuchtigkeit der Luft aufnimmt, suchte er die Ursache

1) Hypothesis nova de fibrium intermittentinn canesa, Harderwyk 1735, 40.

2) De varia febrium intermittentium curatione (I77I). In dieser Abhandlung bemerkt der Respondent auf S. I2: „Palmam facile omnibus praeripit haec ingeniosissima tanti viri opinio, quae intricatissimam, in origine harum febrium indaganda, acu quasi, rem tetigisse merito videtur. Indefesso enim studio et indagatione consummatissima, illius substituit loco, quam amplexus fuit, noviorem theoriam." 
zu den Störungen. Es ist nicht nur die vereinigte Wirkung der Kälte und der Feuchtigkeit an und für sich, welche Krankheit hervorruft. In den Ausdünstungen, welche von stillstehendem Wasser, aus verschlossenen Kellerräumen, verwesenden Tier- und Pflanzenteilen, Gräbern usw. in die Luft aufsteigen, kommen zahlreiche in Fäulnis begriffene Teile vor. Dal3 die Luft eine Art eigentümlicher Säure oder in Ansäuerung begriffene Stoffe enthalten muß, kann man daraus schließen, daß nicht nur tierische, sondern fast alle vegetabilischen Flüssigkeiten unter ihrer Einwirkung sauer werden. Die nächste Ursache der intermittenten Fieber dürfte daher, nach Lin n és Auffassung, in einer Gerinnung der serösen Bestandteile des Blutes zu suchen sein, wie sie unter der Einwirkung angesäuerter, aus der Luft aufgenommener Stoffe zustande kommt. Schon oben ist angedeutet worden, daß Linné die Erklärung für die Entstehung einer Menge Seuchen in dem Vorhandensein kleiner, in verdorbener Luft lebender Wesen suchte. Ist man nicht, fragt Linné, berechtigt, die Ursache der intermittenten exacerbierenden Krankheiten, die vorzugsweise während des Herbstes herrschen, wenn die Luft feucht und neblig ist, in derartigen äußerst kleinen Tierchen (animalcula infinite parva) zu suchen, welche ein „acre“ der eben erwähnten Art enthalten. Man könnte daher wohl annehmen, daß die Entstehung der intermittenten Fieber darauf beruht, daß ein in Ansäuerung begriffener Stoff (acre) in größeren Mengen sich in der Luft ansammelt und von dem Körper aufgenommen wird, gleichwie es auch nicht zu bestreiten sein dürfte, daß Luft, welche Dünste enthält, die mit verdorbenen Pflanzen- oder Tierteilen gemischt sind, zu ihrer Bildung beiträgt.

Diese Theorie Linnés stützt sich der Hauptsache nach auf folgende Gründe:

I) Die intermittenten Fieber herrschen vorzugsweise im Herbst und Frühling, wenn die Witterung feucht und kühl ist.

2) Diese Fieber kommen endemisch an feuchten und schattenreichen, dem Luftwechsel weniger zugänglichen Orten vor, wo die Erde hauptsächlich aus Lehm besteht, welcher, wie bekannt, hartnäckig Wasser zurückhält. Trockene, höher gelegene Gegenden sind dagegen nahezu von diesen Fiebern frei ${ }^{1}$ ). Als Beweis für Linnés Furcht vor stillstehender feuchter Luft wird angeführt, daß er seine Zuhörer warnte, an der nach Norden liegenden, nicht mit Fenstern versehenen Wand des „Frigidariums“ des Botanischen Gartens, wo

I) Respiratio diactetica (1772). 
die Vorlesungen gehalten wurden, zu sitzen, weil die Luft dort mehr unbeweglich sei. Besonders warnte er diejenigen, welche blasse Gesichtsfarbe besaßen und zuvor schon anTertianfieber gelitten hatten, diesen Platz zu wählen. Die, welche seinen Rat unbeachtet ließen, wurden nicht selten von Wechselfieber befallen ${ }^{1}$ ).

3) Diejenigen Personen werden vorzugsweise von diesen Krankheiten ergriffen, welche in mit Pilz oder Schimmel erfüllter Luft leben, niedrig liegende Räume zu ebener Erde bewohnen oder im Frühling ihre Winterkleider zu früh ablegen oder sich sonst unvorsichtig in erhitztem Zustande kalter, nebliger Luft aussetzen. Nach starker Transpiration ist der Körper mehr als sonst für eine solche feuchte und unreine Luft empfänglich (magis quam alias bibulum), und daher sind besonders die Personen diesen Krankheiten ausgesetzt, die sich lange und oft in solcher Atmosphäre aufhalten ${ }^{2}$ ). Schon Li in n é hatte beobachtet, daß Personen, welche Kellerwohnungen oder Erdgeschosse in Häusern bewohnen, mehr Krankheiten ausgesetzt sind, und fragt: „Cur Querquerae et Hemitritiae frequentiores vere et autumno, et pejores in intima concameratione? Cur autumno morbi endemii frequentiores?" 3 ).

4) Bei denen, die an dieser Art Fieber leiden, bemerkt man oft einen Schweiß von so eigentümlichem, säuerlichem Geruch, daß man schon daran die Natur der Krankheit erkennen kann.

5) Da bittere Stoffe im allgemeinen Säurebildung im Körper verhindern oder ihr entgegenwirken, so sind derartige Arzneimittel zugleich die wirksamsten bei diesen Krankheiten, wie z. B. Cinchona, Gentiana, Centaurium, Faba Ignatii. Nux vomica usw.

Die Wechselfieber werden nicht selten von Linné erwähnt. Hierher ist das sog. Upsalaer Fieber zu rechnen, das in der Mitte der 1750 er Jahre dort und auch an anderen Orten grassierte und in der Disputation „Febris Upsaliensis" (I 757) beschrieben wird. Der Name dürfte wohl dadurch entstanden sein, daß die Krankheit durch die von ihr befallenen und heimreisenden Studenten allgemein bekannt und im Lande besprochen wurde. Der Typus war der, daß das Fieber sich plötzlich zwischen 3 und 4 Uhr nachmittags, ohne Schüttelfrost, einstellte und nach $3-4$ Stunden fast aufhörte, dann aber gegen Mitternacht unvermutet exacerbierte, um bis $7 \mathrm{Uhr}$ morgens anzudauern und nach eingetretenem Schweiß den Kranken äußerst geschwächt zu verlassen. Die Krankheit verhielt sich dem-

1) Feuris Upsaliensis (1757).

2) Morti expeditionis classicae 1756 (1757).

3) Mundus invisibilis ( 1767 ). 
nach wie ein Febris quotidiana duplicata oder Amphimerina duplex, jeden zweiten Tag aber kehrte der Paroxysmus, der in der Nacht begonnen hatte, ungefähr um 10 Uhr vormittags mit starkem Schüttelfrost wieder, wie es beim Quotidian- oder Tertianfieber der Fall ist. Im Frühling sich feuchter Luft auszusetzen, warm zu werden und darnach sich zu erkälten, wurde als für die Krankheit disponierend angesehen, deren eigentümliche Entstehungsquelle man in clem mit Verunreinigungen angefüllten sog. Kamphaf (sentina malorum sordium plenissima Kamphaf) und dem sog. Stadtgraben (fossa in altera parte urbis, sordibus etiam abundans) suchte. Die Stadtbehörde wurde aufgefordert, eiligst diese Krankheitsherde zu beseitigen. Von einer solchen Amphimerina duplicata petechizans, an welcher auch Linnés Gattin erkrankte, liefert er in einem Brief an seinen Freund Sa uvages folgende Beschreibung:

„Das Fieber exacerbierte jeden Abend 5 Uhr, der Paroxysmus dauerte 2 Stunden an bis 7 Uhr, der zweite Paroxysmus traf am selben Abend um 1 I Uhr ein und dauerte bis 7 Uhr morgens oder gar bis gegen Mittag. Jeden zweiten Tag waren die Anfälle doppelt so heftig. Die Krankheit löste sich endlich mit Erbrechen und reichlichem Auswurf von zähem Schleim. Die Kranken, welche nicht Diarrhöe hatten, bekamen Petechien. Ueber dreihundert Personen erkrankten in Upsala während der Monate Oktober, November und Dezember I 754, und besonders diejenigen wurden von ihr ergegriffen, die sich nebliger Luft aussetzten" 1 ). - Ueber seine Behandlung des Upsalaer Fiebers teilte Linné mit: „Ich habe Unzählige von dieser Krankheit wiederhergestellt. Am ersten Tage gab ich Ipecacuanha zum Brechen, danach Infusum Chinae vinosum (denn die Rinde in Substanz hilft nicht) und zu jeder Nacht Laudanum liquidum“ "2).

Einige Jahre später erwähnt Lin né in einem Briefe an S a uvag es vom Io. März ${ }_{1764}$, daß er acht Tage zuvor an einer "tritaea maligna saepius petechizante“, die während des Herbstes 1763 viele von den Einwohnern der Stadt dahingerafft hatte, erkrankt sei, und beschreibt seine Krankheit folgendermaßen:

„Schwach wie ich war und außerstande, eine schwere Krankheit durchzumachen, faßte ich meinen Entschluß zu dem zu beginnenden Kampfe

I) Brief an Sauvages vom 20. März I 755.

2) Brief vom 22. April 1756. - Die von Linné benutzten Rezepte, die in einigen Exemplaren noch erhalten sind, waren folgende:

Rec. Aqv. fontanae unc. ijj, pulv. Ipecacuanh. gr. xii, Tartari tartarisat. gr. vjjj, Oxymel. scillit. drach. iii. M. Dr. in vitro S. Einen Löffel alle acht Minuten zu nehmen, bis man sich erbricht.

Rec. Cort. Chinae unc. j, Vin. rubri unc. v, digere per 4 horas, express. filtretur, resid. coque in Aqv. font. q. s. Colaturae unc. vjjj, adde priori Syr. aurant. unc. jjj M. D. S. Eine Teetasse jede Stundc zu nehmen, wonach das Fieber nachläßt.

Schlaftropfen werden 12 genommen, initten in der Nacht. 
(sumpsi consilium in arena); wie bei der Pest oder dem englischen Schweiß nahm ich sofort ein schweißtreibendes Mittel und schwitzte ro Stunden lang, ohne etwas anderes zu mir zu nehmen als sommerlaues Quellwasser; nach 24 Stunden hörten die Kopfschmerzen auf, und der Schweiß war sauer, das Fieber verschwand ganz und gar; ich bin ziemlich schwach und habe noch nicht meine Kräfte wiedererlangt."

Ueber den Skorbut findet sich eine besondere Abhandlung von Linné ${ }^{1}$. Diese Krankheit kommt seines Erachtens eigentlich nicht im Norden endemisch vor, er gibt aber zu, dalo sie sporadisch auftritt und vielleicht auch ofter in kaltem als in warmem Klima. Daß der Skorbut epidemisch auftritt und besonders auf Seeexpeditionen großes Unglück hervorgerufen hat, ist bekannt. Die nächste Ursache seiner Entstehung ist nach Linné in allgemeinen diätetischen und äußeren Verhältnissen zu suchen. Vorzugsweise werden von dieser Krankheit Personen ergriffen, die ein stillsitzendes und untätiges Leben führen, wie auch solche, die an intermittenten oder anderen Fieberkrankheiten gelitten haben. Die kalte Luft macht die Flüssigkeiten des Körpers geeigneter zur Bildung salzartiger Bestandteile (ad muriaticam dissolutionem disponit), auch seine festen Teile werden dadurch zu starr und steif ${ }^{2}$ ). Wenn außerdem infolge der Feuchtigkeit der Luft die Poren verschlossen werden, wird die Ausdünstung gehindert. Von der Beschaffenheit der Nahrungsstoffe und der Getränke hängt zu einem wesentlichen Teil die Zusammensetzung der Flüssigkeiten des Körpers ab. In den Gegenden, wo nur Vegetabilien oder frisches Fleisch benutzt werden, ist der Skorbut selten, wo aber salzige Nahrung gewöhnlich ist, kommt er oft vor, denn solche Nahrungsmittel wirken auflösend auf das Blut und das Leimartige in den festen Teilen. Wenn solche Nahrung oft und lange in größeren Mengen benutzt wird, wird seine Einwirkung sogar fressend (vis ejus abstergens in corrodentem mutatur). Was die körperliche Bewegung betrifft, so ist sie ebenso notwendig für die Erhaltung der Gesundheit, wie die Nahrungsstoffe unentbehrlich für den Fortbestand des Lebens sind. Alle Körperübungen vermehren die Bewegung der Flüssigkeiten, erhöhen die Wärme und erleichtern besonders die Hautausdünstung. Die im Blut angesammelten scharfen und salzartigen oder sonst zum Verderben geneigten Partikeln werden durch Körperbewegung aus dem Organismus ausgeschieden. Die, welche in größerer Menge salzige Speisen verzehren, bedürfen daher starker körperlicher Arbeit. Die nächste Ursache des Skorbuts muß

I) De scorbuto (1775).

2) Clavis medicinae, S. 8. 
daher in Diathese gesucht werden, die auf „acrimonia salina“ beruht. Unter den Arzneimitteln gegen Skorbut spielen die Pflanzen, die der Klasse der Tetradynamisten angehören, eine hervorragende Rolle, desgleichen auch vegetabilische Säuren, Cider, Chinarinde, Infusion von Trifolium aquaticum usw. Besonders wird die Benutzung von Sauerkohl zur Verhütung von Skorbut auf Schiffen empfohlen,


Lin n é dedizierte ${ }^{1}$ ), eingeführt wurde, und dessen wohltuenden Einfluß auf die Gesundheit der Mannschaften in einem Briefe an ihn (1775) von dem bekannten Forschungsreisenden Forster geschildert wird. Daneben wird auf den außerordentlichen Nutzen von Malzinfusion nach der Zubereitungsmethode des englischen Arztes Macbride hingewiesen. - Schon früher hatte $\mathrm{L}$ inné in einem Brief an Sauvages mitgeteilt, daß im Jahre 1740 nach einem sehr kalten Winter eine größere Menge Menschen an Skorbut gestorben waren: als es in fünfzig Jahren der Fall gewesen war. Besonders war die Sterblichkeit groß unter den Soldaten und Seeleuten. Alle dem Trunk ergebenen Personen waren verloren ${ }^{2}$ ).

Rhachitis beruht nach Linné auf exzessiver Säurebildung im Körper, wobei die Knochen ihre Feuchtigkeit verlieren und die Muskeln nebst den Bändern schlaff werden. Rhachitische Kinder werden am sichersten durch Reiben, Bewegung und solche Mittel geheilt, die der Entstehung von Säuren in den ersten Wegen entgegenwirken. - Was man eine Zeitlang bei Kindern Tabes mesenterica nannte, heißt bei Linné: „hectica puerilis Sydenhamii, Febris lenta infantum Junkeri". An dieser Krankheit, die durch stark angeschwollene Mesenterialdrüsen, Geschwürbildung im Darme (intestina inflammata) und Zerstörung der Lungen gekennzeichnet ist, sterben nach $\mathrm{L}$ innés Angabe eine größere Menge Kinder in Schweden als an irgendeiner anderen Krankheit, ausgenommen Pocken. Linné berichtet, er habe in einer sehr großen Anzahl von Fällen (plusquam centies) ein wirksames Heilmittel in Rhabarbertinktur (anima rhei) zu einer Drachme des Tages gefunden, und erachtet dieses Mittel für spezifisch ${ }^{3}$ ). Gegen Ruhr erklärt Linné kein sichereres Heilmittel zu kennen als ein Eigelb, mit einem Teelöffel Branntwein verrührt, zwei- bis dreimal täglich genommen. So sehr er im übrigen gegen den Mißbrauch des Branntweins eiferte, hält Linné ihn doch für ein Schutzmittel gegen die Ruhr und be-

1) Traité sur le scorbut, Edinb. $1761,8^{\circ}$.

2) Brief vom 20. Sept. 1740 .

3) Rhabarbarum (1752).

Hjelt, Carl von Linné. 
richtet, daß bei einer Epidemie alle die Mitglieder in drei Familien, welche Branntwein zu sich nahmen, gesund blieben ${ }^{1}$ ). . Die Ruhr steckt nach Linnés Ansicht mittelst der Entleerungen an.

Unter den Ursachen der Lungenschwindsucht betont Linné an mehreren Stellen seiner Schriften die Einatmung feiner Staubpartikeln. Bei den Personen, welche sich mit Steinhauen beschäftigen oder sich längere Zeit in stauberfüllter Luft aufhalten, dringen die Staubpartikeln in die Lungen ein und werden daselbst durch Schleim miteinander verklebt. Ein trockner Husten entsteht, wodurch der Staub freilich oft entfernt wird (tussis calculosa), nicht selten aber bleiben die Partikeln in den Lungen zurück und bewirken Lungenschwindsucht. Sprechende Beweise hierfür liefern besonders die Steinhauer in Orsa in Dalarne, welche in großer Anzahl und gewöhnlich vor dem 30. Lebensjahr an dieser Krankheit sterben ${ }^{2}$ ). Eine wie grole Fähigkeit ein solcher feiner Staub beṣitzt, Gegenstände, mit denen er in Berührung kommt, zu durchdringen, ersieht man daraus, daß, wenn man in einer Steinhauerwerkstätte eine wohlverschlossene und umbundene Tierblase aufhängt, man sie bald mit Staub gefüllt finden wird. Die Luft ist überhaupt durchaus nicht frei von fremden Beimischungen, sie enthält im Gegenteil, wie das Mikroskop zeigt, eine große Menge kleiner, in ihr schwebender Körper, seien es Sandpartikeln, Haare, Staub, Flaumfedern usw., die mit den Atemzügen in die Lungen eindringen und den ersten Anlaß zur Entstehung der Lungenschwindsucht geben. Man soll es daher vermeiden, mit offenem Munde zu atmen, denn nach Linnés Auffassung werden diejenigen, die sich daran gewöhnt haben, nicht selten schwindsüchtig. Hierauf beruht zu einem Teil die Schädlichkeit des Gebrauchs von Federbetten oder Kissen, weil sie soviel Staub verbreiten ${ }^{3}$ ). Die Auffassung von der Lungenschwindsucht als einer ansteckenden Krankheit ist Linnés Pathologie nicht ganz fremd. Man findet Spuren davon an mehreren Stellen seiner Schriften. So erwähnt er einen Fall von Ansteckung durch einen Lederhandschuh (manica ex pelle confecta), der von einer älteren schwindsüchtigen Frau nacheinander in den Besitz von 7 anderen Personen überging. Alle starben an Lungenschwindsucht. Ein zuvor völlig gesunder Student aus Gotenburg, der in eine Wohnung nach einer schwindsüchtigen Person eingezogen war, starb selbst innerhalb eines Jahres danach an dieser Krankheit ${ }^{4}$.

I) Brief an Sauvages vom 20. Sept. I740.

2) De generatione calculi (1749), Morbi Artificum (1765).

3) Respiratio diaetetica (1772).

4) De Lepra (1765). 
Die Ursachen zu Blutungen von den Luftwegen her sind entweder prädisponierend, wie z. B. natürliche oder erbliche Anlagen, zuviel Fleischessen, stillsitzende Lebensweise, Mißbrauch von geistigen Getränken usw., oder zufällig, wie plötzliche Unterbrechung hämorrhoidaler und menstrualer Blutungen, Anstrengung der Lungen durch Fall, Schreien, Tanz, Laufen und Husten, krankhafte Veränderungen in ihnen oder auch Gemütsbewegungen. Wenn eine Lungenblutung nicht stark ist und rotschäumendes Blut nebst koaguliertem ausgeworfen wird, entsteht selten Gefahr für das Leben, wenn aber das extravasierte Blut in den Luftröhren zurückbleibt, wird es durch die Wärme des Körpers aufgelöst und geht in Eiter über, der allmählich das Lungengewebe zerfrißt und zerstört; Phthisis entsteht, und ständige Neigung zu Blutungen bleibt bestehen 1). Um die Blutung zu stillen, wird Aderlaß am Fuß vorgeschlagen, und dieser ist zu wiederholen, wenn der Puls und die Körperwärme hoch ist. Linné teilte mit, daß Schwämme, in kaltes Wasser getaucht und auf den Hodensack gelegt, mit großem Erfolg angewendet worden sind, um Blutungen aus den Lungen $\mathrm{zu}$ stillen ${ }^{2}$ ). Als besonders wirksames Mittel gegen Lungenschwindsucht wird, nach Sydenham, Reiten angegeben, „nam in phthisi incipiente tam certa est medicina, quam cortex peruvianus in febribus intermittentibus“, und Linné erwähnt, daß er zwei Asthmatikern zu einem Ritt von Stockholm nach Ystad geraten habe, und daß sie gesund zurückgekommen seien ${ }^{3}$ ). Auf Grund gewonnener Erfahrung preist Linné den Gebrauch von Hypericum bei gewissen Arten von Lungenschwindsucht ${ }^{4}$ ).

Im Anschluß hieran sei mitgeteilt, was $L$ in né früher über ein von den älteren Aerzten sog. rheumatisch-katarrhalisches Leiden äußerte. „Bei unseren vornehmen Damen ist der Katarrh eine endemische Krankheit, die sie sich in ihren warmen Zimmern des Winters zuziehen, wenn die kalte Luft durch die Fensterspalten den Hals trifft, infolge dessen ein heftiger Schmerz und eine kaum sichtbare Anschwellung der Hautbedeckung auf den Armen auftritt. Unsere Aerzte suchen vergebens die Krankheit mit resolvierenden, diluierenden und schweißtreibenden Dekokten zu bekämpfen. Sie wird jedoch glücklich wie Frostschaden sofort durch ein Mittel ge-

I) De haemoptysi (1767), De haemorrhagiis ex plethora (1772).

2) De haemoptysi ( 1767 ).

3) Motus polychrestus ( 1763 ).

4) Hypericum (I776). Siehe weiter unten S. 133. 
heilt, das außer mir kaum jemand anders in Schweden kennt, nämlich Spiritus salis acidus" 1 ).

Es ist bereits erwähnt worden, daß Linné den Keuchhusten (tussis ferina) $\mathrm{zu}$ den Krankheiten zählte, deren Ursprung in einem animalischen Ansteckungsstoff (animalcula viva) zu suchen wäre. Nur dadurch glaubte er seine epidemische Verbreitung (contagium suum quasi ipsa pestis dispergens) erklären zu können. Es dürfte überflüssig sein, daran $\mathrm{zu}$ erinnern, daß diese Ansicht der Auffassung unserer Zeit von der Pathogenese des Keuchhustens sich nähert. Als eines der kräftigsten Mittel gegen diese Krankheit empfahl Linné die Anwendung von Ledum palustre in Infusion oder Dekokt ${ }^{2}$ ).

Auch bei der sehr ansteckenden, epidemisch auftretenden sog. „Angina strangulatoria“ (Diphtherie?), die in späteren Jahren vorkam und besonders jüngere Personen angriff, wobei die Halsdrüsen plötzlich unter gelindem Fieber, heftigen Schmerzen im Hals und ständigem Räuspern (screatus) anschwellen, wurden mit Erfolg Gurgelwasser und Kataplasmen von Ledum angewandt. Bemerkenswert ist, was Linné im übrigen über Ledum schreibt:

„Sonst hat hier ein allgemeiner Husten grassiert. Ich versuchte allerlei, auch Extr. Nicotianae, das in Stockholm I 740 half, als alles andere versagte, es hatte aber keine Wirkung. Endlich ließ ich die Meinen und andere Infusum foliorum Ledi trinken, wonach alle innerhalb dreier Tage kuriert waren" 3 ).

Der wesentliche Unterschied zwischen Gehirnhämorrhagie und Gehirnkongestion entging Linné nicht. Er weist darauf hin, daß die apoplektischen Anfälle, die in vollständige Genesung übergehen (ut ne minimi dein percipiat aeger molestiam), auf einer Blutkongestion nach den Gefäßen des Gehirns beruhen, oder auch durch einen serösen Erguß in die Höhlungen desselben bedingt werden ${ }^{4}$ ). - Hemikranie ist ein Leiden, das nach Linnés Ansicht oft bei Gelehrten und Personen, die eine stillsitzende Lebensweise führen, angetroffen wird. Er erzählt von sich selbst, daß er I6 Jahre lang an Migräne gelitten und vergebens bei allen seinen medizinischen Freunden in Europa Hilfe gesucht habe ${ }^{5}$ ). Die Anfälle dauerten

I) Brief an Sauvages 1748 .

2) De Ledo palustri (1775).

3) Brief an A br. Bäck vom 19. Febr. I751.

4) De haemorrhagiis ex plethora (1772).

5) „Hemicrania multoties me excruciat, unde hic morbus? Au novisti medicinan, quaeso, communices." Brief an Sauvages vom 22. April 1756. - Schon früher schreibt 
24 Stunden lang und zeichneten sich zugleich durch ein reichliches Entströmen heißer Tränen aus dem Auge auf der kranken Seite aus. Selten vergingen acht Tage ohne einen Anfall; je länger die Zeit war, um so schwerer waren die Paroxysmen. Durch Trinken von gutem Quellwasser früh morgens und körperliche Bewegung vor dem Mittagessen glaubt er geheilt worden zu sein ${ }^{1}$ ). - Aus seiner Praxis teilte Linné einen Fall von Aphasie mit, wo der Kranke während eines halben Jahres ,alle Substantiva vergessen hatte, so daß er sich nicht eines einzigen erinnerte, ja nicht einmal der Namen seiner Kinder, seiner Frau oder seines eigenen, viel weniger denn des Namens anderer. Wenn man ihn bat, nachzusprechen, antwortete er: Ich kann nicht. Wollte er einen seiner Kollegen nennen, so zeigte er auf das Vorlesungsverzeichnis, wo dessen Name stand“" 2).

In verschiedenen Teilen von Schweden trat während der Jahre 1746-1747 und 1754-1755 die „Kriebelkrankheit" („Krampfsucht“) auf, die durch ihre eigentümlichen Symptome und die starken Schmerzen, an denen alle von ihr befallenen Personen litten, allgemeine Teilnahme erweckte. Eberhard Rosén (geadelt Rosenblad) in Lund war der erste, der in Schweden diese Krankheit in einer 1749 herausgekommenen Abhandlung „De morbo spasmodico convulsivo epidemico" beschrieb, für welche J. B. Heiligtag Respondent war. Die späteren Epidemieen in Småland und Blekinge, 1754-1755, wurden auf Grund der Amtsberichte der Provinzialärzte von P. J. Bergius in "Försök till de uti Sverige gångbara sjukdomars utrönande för år I754-1756" (,Versuch zur Erforschung der in Schweden grassierenden Krankheiten in den Jahren $1754-175^{6 /)}$ beschrieben. L in né widmete dieser Krankheit große Aufmerksamkeit und faßte seine Beobachtungen in folgenden Sätzen zusammen: Die

Linné an C. G. Tessin in einem Brief vom 27. Sept. I75I: „Eine rare Krankheir, die ich lieber in eines anderen Körper examinierte, hat das Fett aus mir herausgesponnen, seitdem ich in Stockholm war; sie ist abends und morgens immer wieder gekommen, hat mich 5 Stunden hintereinander gepeinigt, wie ein Nagel sich mir durch die linke Schläfe gebohrt, gleich den schlimmsten Kindswehen, dann hat sie mich losgelassen, so daß ich meine publiquen Geschäfte erledigen konnte, aber sehr matt; ich bin alle praedicamenta medicamentorum durchgegangen, ohne Affekt, bis ich fand, daß es ein partikuläres Quartanfieber in den Schläfen war, wonach ich begann ihr mit China zuzusetzen, so dah ich heute Nacht zum ersten Male gelinde davongekommen bin." E. A ehrling, Carl von Linnés svenska arbeten (Carl von Linnés schwedische Arbeiten), I (1878), S. I3.

I) Motus polychrestius ( 1763 ).

2) Linnés Aufsatz "Glömska af alla substantiva och isynnerhet namn" ("Gedächtnisschwund aller Substantiva und besonders Namen"), in Svenska Vetensk. Akad. Handl. 1742, S. I 16 . 
Krankheit greift 1) nur das gemeine Volk an, 2) nie Kinder, 3) tritt nur während des Herbstes nach einem regnerischen Sommer auf, 4) zeigt sich ausnahmsweise bei Haustieren, 5) dauert oft 2-3 Monate hindurch an, 6) wenn eine Person im Hause erkrankt, werden die meisten, wenn nicht alle Mitbewohner davon befallen, 7) kommt nur in Schonen, Blekinge, Halland, Småland und Västergötland vor, nie aber in den nördlichen Gegenden Schwedens, 8) ist nicht ansteckend ${ }^{1}$ ). Durch seine Untersuchungen der Verhältnisse, unter denen die Krankheit auftrat, fand Linné, daß die Ursache ihres Auftretens in dem Getreide zu suchen' sein mußte, welches die Kranken verzehrten ${ }^{2}$ ). Linné fand zugleich, daß es eben eingebrachtes Getreide war, das hauptsächlich die Krankheit hervorrief, daß es aber, je länger es lagerte und trocknete, um so mehr diese seine Eigenschaft verlor (ejus acre avolasset). Da die arbeitende Bevölkerung besonders in Småland in jener Zeit Gerste zum Brotbacken benutzte, meinte Linné, daß die Krankheitsursache in dieser Getreideart läge. Er hatte außerdem beobachtet, daß nasse und regnerische Sommer dem Auftreten der Krankheit vorhergegangen waren, und zog daraus den Schluß, daß ein solches unreines Getreide zugleich stark mit Unkraut vermischt war. Unter diesem Unkraut hielt er Raphanus raphanistrum, das in nassen Sommern besonders scharf wird und sehr gemein auf Gerstenfeldern wächst, für die eigentliche Ursache der Krampfsucht. Diese Pflanze erhielt daher den Namen „krampfrö“ (Krampfsamen) "). Die Samen sollten in dieser Hinsicht am wirksamsten sein, und Linné hatte sogar Versuche an Truthähnen mit den Hülsen von diesem Kraut, die in ihr Futter gemischt wurden, angestellt und gefunden, daß eines von den Versuchstieren Krampf in den Füßen bekam (uni gallopavonum maxime contracti sunt pedes). Auch wurden Hühner und Schweine, die mit derartiger verunreinigter Gerste gefüttert wurden, von der Krankheit befallen. Weshalb die Krankheit in Paroxysmen auftrat, glaubte Linné ebensowenig erklären zu können wie die periodischen Anfälle des intermittenten Fiebers, „wobei die Blutmasse von einer Säure infiziert ist". Die allgemeinen Erscheinungen des Nervensystems sind, wie Linné bemerkt, noch nicht „völlig klargestellt worden“. Auf Grund dieser Beobachtungen führte er den Namen „Raphania" als Bezeichnung für die sog. Krampfsucht (articulorum

I) Brief an Sauvages vom 22. Nov. 1759, worin er schreibt: quo hunc morbum refers? An vobis etiam innotuit?"

2) De raphania (1763).

3) Flora Svecica, Ed. altera, p. 6I2, Holmiae 1755 . 
contractio spastica cum agitatione convulsiva, dolore violentissimo, periodico) ein, eine Benennung, die sich bis in die jüngste Zeit in der Pathologie erhalten hat, bis eine richtigere Einsicht in die Ursache der Krankheit zu einem anderen Namen (Ergotismus) führte ${ }^{1}$ ). $\mathrm{Daß}$ es aber Linné war, der in dem medizinischen System dieser Krankheitsform einen bestimmten Platz anwies, obwohl ihr Vorkommen bereits in älteren Schriften erwähnt worden ist, dürfte, wie auch der eigentliche Anlaß zu der ursprünglichen Benennung, allmählich in Vergessenheit geraten sein. Unter den wirksamsten Heilmitteln werden Rad. Valerian. minor. und Angel. sylvestris, Kampfer, Chinarinde und besonders Tra Alchemillae vulgaris, in Småland „dragblad" (Krampfblatt) genannt, angeführt.

Wie sehr die Frage der sog. Krampfsucht Linn é interessierte, ersieht man daraus, daß er I 755 im Collegium medicum vorschlug, es sollte eine Belohnung von 50 Dukaten demjenigen zuerkannt werden, der die Ursache der furchtbaren Krankheit entdeckte. Der Vorschlag wurde abgelehnt ${ }^{2}$ ). Noch einige Jahre später schrieb er an den Sekretär der Akademie der Wissenschaften, P. W. Wargentin:

„Unter den ökonomischen Fragen dürfte eine ihren Platz verdienen, nämlich woher die Krampfsucht herrührt? Diese Krankheit hat in den südlichen Teilen des Reiches, soweit die Leute sich erinnern können, 4-5mal grassiert. Ganze Dörfer, ja, Kirchspiele sind davon befallen worden; viele sind elend gestorben. Sie grassierte vor einigen Jahren schrecklich in Smáland, Blekinge etc., wo die Leute unter den größten Schmerzen zusammengezogen wurden, bis sie endlich das Leben aufgaben. Sie muß auf irgend einem Fehler in der Oekonomie beruhen, denn, obwohl viele Hunderte, ja Tausende von ihr ergriffen wurden, steckte sie doch niemals an. Wird diese Frage aufgestellt, so will ich mich daranhalten und mich bemühen, die Nuß zu knacken, und glaube ich niemals, daß ein praemium nützlicher für das Reich angewandt werden kann, denn sicherlich kehrt diese Krankheit nach einigen Jahren wieder, sofern man ihr nicht durch ökonomische Maßregeln zuvorkommt. Die Krankheit hat auch mehrmals in Deutschland grassiert, ohne daß ein Sterblicher die Ursache hat entdecken können“3).

I) In Deutschland, wo auch die Krankheit vorgekommen war, erklärten bereits verschiedene Aerzte die Entstehung der „Kriebelkrankheit" „ex esu secalis cornuti vel ex alia frumenti corruptione“.

2) Weit später wurde von der Akademie der Wissenschaften die Frage aufgestellt: Was kann die Ursache ider in gewissen Provinzen oft auftretenden Krampfsucht sein? und von dem Pfarrer, Hofprediger Jör an Oeller beantwortet. Die preisgekrönte Schrift ist 1806 in Stockholm gedruckt.

3) Brief vom 15. Jan. I761. E. A ehrling, a. a. O., S. 344. 
Ebenso dürfte es nunmehr nahezu vergessen oder wenigstens nicht sehr bekannt sein, daß Linné eine genaue Kenntnis von der Krätzmilbe besaß. Während die Aerzte jener Zeit in den verschiedenartigsten Umständen die Erklärung für die Entstehung von Hautausschlägen suchten, deren Ursache man in der Schärfe der Flüssigkeiten zu finden glaubte, sprach Linné mit Bestimmtheit aus, daß das Eindringen der Krätzmilbe in die Haut den Ausschlag hervorruft, der diese Krankheit begleitet. Diesen „Acarus humanus subcutaneus" stellt Linné als eine Abart von "Acarus Siro" auf und schreibt darüber: „habitat sub cute hominis scabiem caussans, ubi vesiculam excitavit, parum recedit, corporis rugas secutus, quiescit iterum et titillationem excitat; nudis oculis sub cuticula delitescens observatur ab adsueto, acu facile eximitur, ungui impositus vix movetur, si vero oris calido halitu affletur, agilis in ungue cursitat" ${ }^{1}$ ).

Während man bis dahin verschiedenartige Formen von Hautkrankheiten miteinander vermengt und in der Voraussetzung, daß sie auf allgemeinen Störungen in den Flüssigkeiten des Körpers beruhten, alle mit innerlich zu nehmenden Mitteln behandelt hatte, sonderte Linné die Krätze als eine eigenartige Krankheit aus, und man findet in seinen Schriften mehr oder weniger spezifische Mittel gegen dieselbe vorgeschlagen, darunter z. B. Ledum palustre. In dieser Frage schreibt Linné an Sauvages:

Ich habe zwar Ihr Hilfsmittel gegen die Krätze versucht, aber ich bin mit der gewöhnlichen Salbe nebst Unguent. rosatum zufrieden gewesen. Sie hilft stets, ohne daß Rückfall eintritt" 2 ).

Im Zusammenhang hiermit kann bemerkt werden, daß Linné die Vermutung aussprach, daß die Eier von Ascaris durch Vermittlung des Trinkwassers oder anderen im Haushalt gebrauchten Wassers, in das sie aus der Erde hineingekommen seien, in den menschlichen Körper gelangten ${ }^{3}$ ). Dagegen hat die Ansicht, die um die Mitte des i8. Jahrhunderts ausgesprochen wurde, daß die Entstehung des Aussatzes auf dem Eindringen eines Wurmes in die Haut beruhte, keine Bestätigung gefunden. Da man fand, daß der Aussatz hauptsächlich an der Meeresküste vorkam, so glaubte man die Erklärung dafür in dem Umstande suchen zu müssen, daß die Einwohner in diesen Gegenden sich fast ausschließlich von Fischen ernährten, und man nahm an, daß ein Wurm, Gordius fluviatilis, der

I) Carl Linné, Fauna Svecica, ed. alt., Stockholm 1761, S. $4^{82 .}$

2) Brief an Sauvages, 1762 .

3) De Spigelia Anthelmia (1758). 
in verschiedenen Fischarten angetroffen wird, in den Körper eindringt und die Knoten in der Haut und den inneren Teilen bildet, welche diese Krankheit kennzeichnen ${ }^{1}$ ). Hierzu bemerkt jedoch Linné, daßo, wenn sich die Gelegenheit böte, einen an Aussatz Gestorbenen zu untersuchen, es wichtig wäre, wenn ein Arzt die erwähnten Knoten eröffnete und nachsähe, ob sie einen solchen Wurm enthielten ${ }^{2}$ ). Diese Knoten (tubercula) werden als beweglich, schmerzfrei, blaurot, hauptsächlich auf Stirn, Wangen, Armen, Händen und Schenkeln vorkommend beschricben. Knoten von mehr gelblicher oder schwach livider Färbung kommen auch in Mund, Gaumen, Rachen und an der Zungenwurzel vor; Geschwüre entstehen an der Nase, die Lippen sind dick, die Hände und Füße angeschwollen. In einigen Fällen kommen Hautgeschwüre oder Risse mit angeschwollenen, harten, manchmal blutenden Rändern vor. Bei allen davon befallenen Personen ermangeln die leprösen Knoten des Gefühls, ihre Umgebung verursacht jedoch starkes Jucken ${ }^{3}$ ). Linné berichtet, daß die Lepra in den Küstengegenden des bottnischen Meerbusens vorkomnt, und daß die Finnen ihre Ursache darin erblicken, daß sie während der Zeit, wo sie des Fischfanges wegen auf der See sind, von altem Seehundsfleisch leben. In Upsala hat Linné Fälle von Aussatz gesehen. Die von dieser Krankheit Befallenen wurden von der Gemeinschaft mit anderen Menschen ausgeschlossen ${ }^{4}$ ). - Als ein Tribut an die Vorstellungsweise jener Zeit ist der Ausspruch Linnés aufzufassen, daß Kinder kränklich werden, wenn ein ulcerierender Ausschlag auf ihrem Kopf mit kaltem Wasser gewaschen wird, und daß das allgemeine Vorkommen der Epilepsie im südlichen Småland seine Ursache in dieser Sitte hat $\left.{ }^{5}\right)$.

Bezüglich des Panaritiums (Paronychia) hegte Linné die Vorstellung, daß dieses Leiden entsteht, wenn die Hände starkem Tem-

I) Anton R. Martin sprach zuerst diese Ansicht in Svenska Vetensk. Akad. Handl. I760, S. 307 aus. In Linnés Abhandlung De Ledo palustri (I775) wird angegeben, daß dieses Kraut in Form einer Infusion mit großem Erfolg von den Kamtschadalen gegen Lepra gebraucht wird, die bei ihnen sehr gemein ist. Auch J. L. Odhelius preist in Vetensk. Akad. Handl. I774:266; I779: 218; 1783:222 die Wirkungen von Ledum palustre gegen Lepra, die seiner Ansicht nach durch überwiegend salzige Nahrung hervorgerufen wird.

2) De Lepra (1765).

3) De Lepra (1765).

4) Brief an Sauvages vom 20. Sept. I740.

5) Brief an Sauvages vom 2. Dez. I74 I und von 1744. Diese Ansicht findet sich weiterhin ausgesprochen in $\mathrm{L}$ inn és Aufsatz ,Rön om orsaken till fallandesoten $i$ Skione och Werns-härad $i$ Småland" (,Erfahrungen über die Ursache der Fallsucht in Schonen und dem Bezirk Wern in Småland"), in Svenska Vetensk. Akad. Handl. I742, S. 279. 
peraturwechsel ausgesetzt werden, und er erzählt von sich selbst, daß er davon befallen wurde, als seine Hände auf der Heimreise von Frankreich naß wurden, nachdem sie sehr warm gewesen waren 1 ). - Gegen nicht ulcerierende Frostschäden (perniones) will Li n né mit großem Erfolg Spiritus salis acidus (Salzsäure) angewandt haben, womit der Frostschaden bestrichen wird, bis er verschwunden ist. Li nné sagt, er habe damit mehr als roo Fälle behandelt ${ }^{2}$ ). - Übelriechende und bösartige Geschwüre (ulcera cacoëthica) werden, nach Linn és Erfahrung, nicht selten glücklich mit Feigensaft oder auch mit Rad. Hb. britannicae (Rumex aquaticus) behandelt ${ }^{3}$ ). Er berichtet, daß er mit glücklichem Ausgang Rumex aquaticus auch bei Ulcus palati phagedaenicum, wo das Gaumenbein angefressen war, angewandt habe, indem er das Geschwür mit Dekokt von der Wurzel wusch. Ebenso kann Actaea racemosa bei scirrhösen Tumoren in Form von Kataplasmen unter Zusatz ihrer Wurzeln benutzt werden. Solche Geschwüre heilen oft nicht anders als unter Anwendung eines Zugpflasters von Canthariden, das die verdorbenen Stoffe zerstört und die Wunde reinigt $\left.{ }^{4}\right)$. In der Heilkunde müssen nämlich zwei Umstände beachtet werden, welche die Wirkung äußerer Reizmittel erklären, der eine, daß ein Schmerz den anderen vertreibe (,,dolor dolorem trahit“), und der andere, daß zwei Entleerungen nicht nebeneinander bestehen können.

Die Zusammensetzung von Gu y s berühmtem Mittel gegen Krebs, dessen Bestandteile nicht bekannt waren, behauptet Linné entdeckt zu haben. Er glaubte, daß Guys Pulver gegen diese Krankheit aus pulvis foliorum Actaeae bestand. Die Haut in der nächsten Umgebung der Wunde muß auf geeignete Weise bloßgelegt und das Pulver dort eingestreut werden, das Kranke wird dadurch von dem Gesunden abgeschieden und fällt schließlich ab. Linné berichtet, daß viele auf diese Weise geheilt worden seien ${ }^{5}$ ). -- Folia Uvae ursi,

I) De morbis ex hyeme ( 1752$)$.

2) Brief an Sauvages I753.

3) Linné hegte großes Vertrauen zu dieser Pflanze. In einem Brief an Prof. E. G. Lidbeck vom 7. Sept. 1756 , jetzt in der Universitätsbibliothek in Lund aufbewahrt, bemerkt Linné: „Es ist uns berichtet worden, daß Sie, Herr Professor, ein ulcus oris malignum bekommen hätten. Ist es cariosum oder fistulosum, muß rad. Britannicae gebraucht werden, ist es cancrosum, nuß unverzüglich infusum Belladonnae in Anwendung kommen." Vergl. oben S. 38.

4) De Meloë vesicatorio ( 1762 ).

5) Brief an Sauvages vom 26. Jan. I76I. Siehe O. E. A. Hjelt, Svenska Statens inköp af hemliga läkemedel och särskilat kinurgen Guys medel mot kräfta (Einkäufe von geheimen Heilmitteln und besonders des Guy schen Mittels gegen Krebs durch den schwedischen Staat), in Finska Vetensk. Societ. Bidrag 47, (I888). 
von Sauvages bei Krankheiten der Harnwege empfohlen, wurde von Linné in die Praxis der schwedischen Aerzte eingeführt ${ }^{1}$ ). Von der Benutzung von Conium gegen chronische Anschwellung der lymphatischen Drüsen schreibt er: „Der bisher angepriesene Gebrauch von Conium und Cicuta beginnt abzunehmen" ${ }^{2}$ ).

Gegen Gangrän, kalten Brand und Skorbutwunden wandte Linné ein Rezept an, auf das er großen Wert legte, und das, aus der damaligen Zeichensprache in technische Termini übertragen, folgendermaßen lautet. Rec. Ciner. Clavell (-potass. venal.) to , Salis ammoniaci to I $\beta$, Calc. vivae $16 \mathrm{IV}$, Urina $\$ 6$ I 20. M. Distilles per vesicam cupream, evadat aqua coerulea; pro usu externo ${ }^{3}$ ). - Die Ursache der Steinbildung liegt nach Linné in der Anwendung von Nahrungsstoffen, welche Säure im Körper bilden. Gleichwie Wermut, zu einem säuerlichen Trank gemischt, im Sommer den sauren Geschmack vermindert, so, sagt er, habe er während seiner praktischen Tätigkeit Essentia Absinthii, längere Zeit angewendet, als ein ausgezeichnetes Mittel gegen Stein befunden. Wein und andere säuerliche Getränke müssen gleichzeitig gemieden werden ${ }^{4}$ ).

Gerötete und entzündete Augen werden vom gemeinen Volk, nach Linnés Angaben, mit einem Dekokt von Pyrola uniflora behandelt, womit die Augen gewaschen werden, oder die Pflanze wird gekaut und die Augen dann mit dem Speichel befeuchtet; „ich habe davon wunderbare Wirkungen gesehen“5). Aus seinen eigenen Mitteilungen ersieht man, daß Linné außer seiner anderen Praxis auch Augenpatienten behandelte. Schon früher hatte er Sa u vages wegen seiner Augenkrankheit Rat gegeben und schreibt: „Ich bedauere innigst, daß Ihre Augen krank sind. Sicherlich kennen Sie das Rezept, womit ich und manch anderer eine Menge kranker Augen geheilt haben, und das niemals zu versagen pflegt. Obwohl ich nicht bezweifle, daß Sie das Rezept, wie alle anderen, kennen, bitte ich Sie doch, es versuchen zu wollen. Ich habe fast Blinde damit geheilt" "6).

1) Brief an Sauvages vom 25. Aug. 1761.

2) Ebenda.

3) „Dieses Rezept schätze ich sehr hoch und will es Ihnen mitteilen, bitte Sie aber, es selbst zu versuchen, und keinem anderen zu entdecken." Brief an Sauvages vom 20. Aug. 1753 .

4) De generatione calculi (1749).

5) Brief an Sauvages vom 22. Aug. 1754.

6) Dieses Rezept lautet in der Originalsprache folgendermaßen:

„R. a. Albumina ovorum n:o 3, ad duritiem cocta, et a membranis omnibus decorticata, eaque ad minutissima frusta dissecta: 
Von den verschiedenen medizinischen Wissenschaften waren es die Drogenkenntnis und die Pharmakodynamik oder, wie die älteren Aerzte sie nannten, Materia medica, die Linné vor allem mit Vorliebe bearbeitete. Der enge Zusammenhang, in dem die Botanik und die Pharmakognosie miteinander stehen, macht es erklärlich, weshalb die Mehrzahl seiner medizinischen Arbeiten sich gerade auf diese Seite der Wissenschaft bezieht. Die meisten seiner Abhandlungen auf dem Gebiete der Pharmakologie enthalten genaue botanische Beschreibungen der Pflanzen, deren Anwendung in der Medizin den Gegenstand der Abhandlung bildet. Zugleich werden nicht selten Angaben der chemischen Bestandteile der fraglichen Drogen, soweit sie bekannt waren, sowie der verschiedenen pharmazeutischen Präparate, die entweder bereits in den Apotheken vorkamen oder von ihnen bereitet werden konnten, geliefert. Eine Frage, die fast stets, wo sich die Gelegenheit dazu bietet, in diesen Abhandlungen wiederkehrt, ist die, ob die teuren ausländischen Arzneimittel durch ebenso kräftige, in Schweden wachsende Kräuter ersetzt werden können. Als Fingerzeig für die Entdeckung und Anwendung dieser Succedanea werden die wildwachsenden Pflanzen angeführt, die mit den betreffenden ausländischen nächstverwandt sind, und man muß zugeben, daß infolge dieser Arbeiten Linnés viele einheimische Drogen in allgemeinen Gebrauch gekommen und mit in die nordischen Pharmakopöen aufgenommen worden sind, wie z. B. Rhamnus frangula, Solanum Dulcamara, Pimpinella saxifraga, Arctostaphylos uva ursi, Cetraria Islandica usw. Die Therapie oder die Lehre :von den Wirkungen und der Verwendung der Arzneimittel in den verschiedenen Krankheiten wird daneben ausführlich behandelt. Es war im übrigen Sitte der Zeit, in botanischen Schriften den medizinischen Nutzen der Pflanzen anzugeben, und man findet, daß die älteren Botaniker in ihren Arbeiten selten es versäumten, längere oder kürzere Ausflüge in das Gebiet der Heilkunde zu machen.

Es ist im allgemeinen ein charakteristischer Zug in Linnés medizinischen Schriften, daß er in kurzen, bestimmten Sätzen solche Wahrheiten, besonders in der Pharmakodynamik, zusammenzufassen

C. dein, Larg. Syll. (s. Eyll) anmatic., n:o XVIII, ope mortarii redacta in pulveren pastacaeum: G. tum vitrioli albi $3 ; ;$

Misce haec omnia (a'. c. z.), ope mortarii, in pastam; stent dein per horam $1 / 2$ intacta; exprimentur demum per linteum, collectus liquor servetur, qui collyrium nostrum est.

Immergas oculos, aliquoties de die." Brief an Sauvages vom 8. Dez. 1747. Später schreibt Linné in seinen Egenhändiga Anteckningar, S. 204: ,Sauvagesium paucis ante obitum annis lippum, ut vix legeret librum, curavit Lin né infuso Caryophyllorum, ut ipse in literis fatetur: Tibi debeo oculos meos." 
oder auszusprechen versucht, die er für allgemeingültig ansah. Seine Abhandlungen bezüglich der medizinischen Eigenschaften und Wirkungen der Pflanzen haben daher in ihrer Aufstellung große Aehnlichkeit mit dem, was er in seiner Philosophia botanica betreffs der reinen Botanik aussprach. Es ist nämlich ein von Linné ausgesprochener und besonders betonter Satz, daß die Pflanzen, die zu derselben Gattung gehören, auch den Eigenschaften nach übereinstimmen, und daß die Pflanzen, die zu derselben natürlichen Familie gezählt werden, auch hinsichtlich ihrer medizinischen Wirkungen einander nahestehen 1). Dieser Satz hat sich, wenn auch viele Ausnahmen existieren, in der Pharmakodynamik bis in unsere Zeit erhalten ${ }^{2}$ ). Die Eigenschaften werden daher am sichersten nach den natürlichen Familien, denen sie angehören, bestimmt, sofern man nur zuvor durch die Erfahrung den medizinischen Nutzen der einen oder anderen der dahingehörigen Pflanzen kennen gelernt hat. So enthält die Familie Stellatae Pflanzen mit diuretischen Eigenschaften; zur Fanilie Luridae gehören eine Menge verdächtiger Pflanzen, wie Solanum, Hyoscyamus, Nicotiana, Atropa, Datura; die Pflanzen aus der Familie Umbellatae sind, wenn sie auf trockenen Lokalitäten wachsen, aromaticae, calefacientes et pellentes, werden aber an feuchten Oertlichkeiten giftig, die Wurzel und die Samen enthalten die wirksamen Bestandteile; die zu den Polyandria gehörigen Pflanzen sind im allgemeinen giftig, wie auch die Gewächse, deren Blüten einen von den Blumenblättern getrennten Honigbehälter besitzen; Verticillatae sind „fragrantes, nervinae, resolventes et pellentes, folia virtute pollent"; die Pflanzen in der Familie siliquosae sind, so lange sie frisch sind, ,acres, incidentes, abstergentes et diureticae", beim Trocknen nimmt aber ihre Kraft ab; Compositae besitzen im allgemeinen einen bitteren Geschmack, die Orchideen sind aphrodisiacae; Coniferae sind ,resiniferae et diureticae". Kräuter, die an trockenen Stellen wachsen, sind aromatisch und besitzen einen bestimmten Geschmack, wie z. B. Thymus, Salvia, Origanum, Hyssopus, Lavandula u. a. Saftige Erde bringt geschmacklose Pflanzen (olera pleraque) hervor, und an nassen Oertlichkeiten werden die Pflanzen nicht selten scharf und fressend

I) Philosophia botanica, Stockholm I751, § 337 .

2) „Aber zuerst war es Linné, dieser seltne Genius der Naturwissenschaften, der auch diesen Gegenstand näher ins Auge faßte (in seiner Abh. Vires plantarum, Upsala 1747): "Quaecunque plantae genere conveniunt, etiam virtute conveniunt; quae ordine naturali continentur, etiam virtute proprius accedunt, quaeque classe naturali congruunt, etiam viribus quodammodo congruunt." K. F. Marx, Geschichtl. Darstellung d. Giftlehre, II, Gött. 1829 , S. 95. 
(corrosivae), wie Ranunculus, Calla, Nymphaea, Phellandrium, Cicuta u. a.; die Frühlingspflanzen besitzen meistens scharfen Geschmack, und die medizinischen Kräuter weisen in frischem Zustande bei weitem nicht den Geschmack auf, den sie erhalten, wenn sie getrocknet sind. Alle aromatischen Pflanzen sind in getrocknetem Zustande am kräftigsten ${ }^{1}$ ).

Obwohl demnach, wie aus dem Obigen hervorgeht, die botanische Intuition in hohem Grade für Linnés Auffassung von den pharmakodynamischen Eigenschaften der Pflanzen bestimmend war, erkannte er jedoch auch die Bedeutung der Chemie in dieser Hinsicht an. Er gab zu, daß ebenso, wie man auf Grund von Analogieen, die teils der Uebereinstimmung der Fruchtbildung, teils dem Verhalten der Pflanze in bezug auf Geschmack und Geruch entnommen waren, sich über ihre Eigenschaften aussprechen kann, es auch möglich ist, auf Grund einer qualitativ und quantitativ ausgeführten chemischen Analyse ohne direkte Versuche Einsicht in die entsprechende gleichförmige oder proportionierte Wirkung der medizinischen Kräfte der Pflanzen zu gewinnen 2).

Als Linné seine von den Zeitgenossen so hochgepriesene $M a$ teria medica herausgab, die eine längere Reihe von Jahren hindurch anderen Verfassern zum Vorbild diente, ordnete er die pharmazeutischen Pflanzen nach seinem botanischen System $\left.{ }^{3}\right)$. Linnés systematisierendes Genie trat hier wie überall in seinen Schriften zutage. Man dürfte in keiner pharmakologischen Arbeit der medizinischen Literatur der vorhergehenden oder nächstfolgenden Zeit eine solche Klarheit und Uebersichtlichkeit finden, wie sie uns in seiner „Materia medica" begegnet. Diese Arbeit trägt zwar den Stempel ihrer Zeit

I) Philosophia botanica, Holmiae I75 I: $\$ \$ 339-356$.

2) De methodo investigandi vires medicanzentorum chemica (I 754).

3) Caroli Linnaei Materia medica, Liber I. de Plantis. Secundum Genera, Differentias, Synonyma, Loca, Durationes, Culturas, Nomina, Simplicia, Pracparata, Qualitates, Modos, Potentias, Vires, Usus, Composita Digestus, Holmiae 1749, 252 pp., $8^{0}$. Die Arbeit enthält unter anderem ein Verzeichnis der in Schweden angewandten offizinellen Pflanzen, nach ihrer pharmazeutischen Verwendung, als radices, herbae, flores usw., zusammengestellt, Angaben über einheimische und ausländische Medizinalpflanzen, ein alphabetisches Verzeichnis von Krankheiten mit Angabe der gegen sie gebrauchten Pflanzen und schließlich, ,index virium" oder die Medizinalpflanzen, nach ihren medizinischen Eigenschaften in 103 Gruppen geordnet. An diese botanische Arbeit Linnés schließen sich seine akademischen Abhandlungen "Materia medica in Regno animali" (1750) und "Materia medica in Regno lapideo" (1752) an, wie auch die Abhandlung "Observationes in Materiam medicam" (1772), welche eine Liste der Pflanzen, die später in die Pharmakologie eingeführt worden sind, und außerdem ein Verzeichnis von ,incognita et dubia" enthält. 
und teilt ihre Neigung zur Aufnahme einer Menge Pflanzen, deren Bedeutung und Wert für die praktische Medizin illusorisch ist, denn je weniger entwickelt die Wissenschaft war, um so größer war auch die Mannigfaltigkeit von Heilmitteln, die man der leidenden Menschheit darbieten zu müssen glaubte. Das Kindesalter der Wissenschaft hatte ihren Vertretern einen Ueberfluß an Stoffen, Arcana und Drogen hinterlassen, denen sie ratlos und erstaunt gegenüberstanden ${ }^{1}$ ). Linné warnte mit überzeugender und kräftiger Stimme vor diesem Mißbrauch und drang darauf, daß, da wir auf experimentellem Wege zu keiner wirklichen Kenntnis von den Eigenschaften der Pflanzen gelangen können, wenn sie gleichzeitig oder gemischt mit anderen Pflanzen angewendet werden, man lieber die Wirkungen der einfachen Heilmittel (Simplicia) kennen lernen sollte, als die zu jener Zeit so gewöhnlichen zusammengesetzten Rezepte fortwährend zu benutzen. Ebenso sollte der Arzt niemals in seinem Rezepte Pflanzen mit verschiedenen Eigenschaften verschreiben. L i n n é äußert sich hierüber :

„Gerade große Rezepte șind es, die die ganze Medizin verdorben haben. Es wundert mich, wie so viele ohne Hilfe des Effektes von Simplicia andere curieren können. Ich lehre nun die Sache und, wie ich meine, mit Nutzen für meine Studiosi, daß sie erfahren sollen, was demonstriert ist und was nicht" 2).

Er schloß daher eine Menge unnötiger „offizineller Kräuter" aus und strich andere, die seit Jahrhunderten mit abergläubischer Verehrung angewendet worden waren. Dadurch wurden in wesentlichem Grade die Drogen verringert, welche die Apotheker der Pharmakopöe gemäß verpflichtet waren zum Verkauf vorrätig zu halten, statt dessen empfahl er neue wirksame Mittel, von denen viele bis auf den heutigen Tag in Gebrauch geblieben sind ${ }^{3}$ ). So schloß er bei seiner Prüfung der vorgeschriebenen pharmazeutischen Pflanzen nicht weniger als 130 aus, schlug dafür aber die Aufnahme neuer vegetabilischer Mittel, teils nach der Erfahrung anderer Aerzte, teils auf Grund eigener Erfahrung, vor, so unter anderem radices Ceanothi und Lobeliae (Syphilis), Diervilla (Gonorrhoea), Dulcamarae stipites, Elaterium album, Faba Ignatii, Fungus melitensis, Linum catharticum,

I) "Tanta enim hodierna medicina superbit virium medicinalium copia, ut non arcto libello copiatur, sed potius proprio pondere ruat." Linné, Materia medica.

2) Brief an A br. Bäck vom 30. Okt. 1749.

3) „Nostrates medici in eo sunt, ut dispensatorium reformetur, secundum quod pharmacopolae tenentur medicamenta praestare. Dedi itaque dissertationem de simplicibus I. excludendis, 2. de introducendis." Brief an Sauvages vom 15. Jan. 1754. 
Linnaea borealis, Rhamnus frargula, Ribes nigrum (medicina boum), Senegae radix, Folia uvae ursi usw. ${ }^{1}$ ).

„Wir können sehr wohl in unseren Apotheken entbehren:

Rd. Pastinacae, Saxifr. alb., rubr., Herb. Adianthi, agerati, beccabungae, Hb. perfoliatae, ptarmicae, pulsatillae, Flores Bellid. minor., endiviae, Sem. brassicae, calend. etc." - „Ich arbeite tagsüber an der Materia medica, um die Simplicia für das Königl. Collegium gut aufzustellen, eine Menge schließe ich aus und viele werden neu aufgenommen" ${ }^{2}$ ).

„Materia medica“ ist unbestreitbar eine der wichtigsten medizinischen Schriften Linnés und wurde von den Zeitgenossen mit allgemeiner Anerkennung aufgenommen, worüber er selber schreibt:

"Ich erhielt heute Briefe von Gronovius und van Royen und habe von ihnen mehr Flatessen für meine Materia medica bekommen, als ich jemals von der ganzen Welt zu bekommen gehofft habe" ${ }^{3}$ ).

Sogar A. von Hall er nennt diese Arbeit „commodissimum praelectionibus compendium, inter optima auctoris". Bei ihrer Ausarbeitung befragte er seine gelehrten Freunde um ihre Ansicht bezüglich mehrerer in sie aufgenommener Pflanzen, deren Platz im System und richtige Bestimmung nicht sicher war. An Bernhard de Jussieu schreibt Linné:

„Nachdem Flora Zeylanica nunmehr abgeschlossen worden, beabsichtige ich, eine kurze Materia medica herauszugeben, in welcher ich alles vermeiden will, was nicht durch die Erfahrung oder durch Beobachtung anderer bestätigt worden ist. Ich bitte Sie nun, dessen Urteil in diesen Fragen so hoch gilt, mir diese oder jene Beobachtung mitteilen zu wollen, damit ich mit aller gebührenden Ehrenbezeugung Thren Namen anführen könne. Ich weiß nicht, zu welchen Gattungen folgende Pflanzen $\mathrm{zu}$ rechnen sind: Myrobalani Indae, Chebulae, Belliorcae, Citrinae; Anisum stellatum; Gum. elemi, Sagapenum, Carannae, Bdellii, Myrrhae, Olibani, Ammoniac., Opobalsamum, Balsam. peruvianum, Copaivae, Lignum Aloes; sang. Draconis, Lign. Rhodii, Simarubae. Wenn Sie eine von diesen Pflanzen kennen, lassen Sie es mich freundlichst (candide et amice) wissen, zu welcher Gattung sie gehört, und ich will Thnen öffentlich danken" $\left.{ }^{4}\right)$.

Auch an A. von Haller stellt Linné fast dieselben Fragen.

„Ich habe nahezu meine Materia medica abgeschlossen, ich kenne aber nicht die Pflanzen, von denen man Agallochum, Lignum Rhodium, Caran-

I) Censura medicamentorum simplicium vegetabilium (1753).

2) Briefe vom 23. Okt. I749 und 24. Sept. I753.

3) Brief an Abr. Bäck vom ro. Nov. 1749.

4) Brief an Bernh. de Jussieu vom 24. April 1747, abgedruckt in Menoirs of the American Academy of arts and sciences, N. Ser. Vol. V, Cambridge and Boston 1855, S. 200 . 
nam, Elemi, Sagapenum, s. Ammonicum, Myrrham, Thus, Balsamum peruvianum, Anisum stellatum, Myrobalanus Chebulae, Belliric., Citrináe erhålt. Wenn Sie eine von diesen Pflanzen kennen, bitte ich Sie, es mir mitteilen zu wollen"1),

Linné las an der Universität oft über „Materia medica“, und die dabei gemachten Aufzeichnungen, wie man sie in Bibliotheken angetroffen hat, lassen erkennen, mit welch großer Sorgfalt er seinen Vorträgen einen so vollständigen Inhalt wie möglich zu geben versuchte. Jede Pflanze, die in der Medizin Verwendung fand, wird bezüglich ihrer Heimat, der Teile (Wurzel, Stengel, Blätter, Blüten), die in den Apotheken benutzt werden, ihrer Präparate (Oel, Tinktur, Dekokt, Pulver), ihrer chemischen Eigenschaften, ihrer physiologischen und therapeutischen Einwirkung auf den Körper (Stimulans, Cardiacum, Stomachicum, Soporificum usw.), sowie der Krankheitszustände, in denen sie gewöhnlich benutzt wurde, und der dabei verwendeten Dosis geschildert. Alle für nötig befundenen Verbesserungen und Zusätze zur Materia medica teilte Linné nur in seinen Vorlesungen oder in besonderen medizinischen Abhandlungen mit, obwohl er auch daran dachte, eine neue Auflage herauszugeben, „die, hoffe ich, anders werden wird als die erste“"). Man hat bezweifelt, daß Linné die Absicht gehabt hat, seine Materia medica umzuarbeiten, daß dieses aber der Fall war, ersieht man unter anderem aus dem Protokoll des Consistorium academicum vom 6. Okt. i768, das anläßlich eines von Li nné eingereichten Gesuches, zum Zwecke der Herausgabe einer neuen Auflage dieser Arbeit von konsistoriellen Geschäften entbunden zu werden, folgenden Bescheid des Kanzlers enthält:

„Da der Fleiß und die Lust, mit welcher der Herr Archiater und Ritter Linné stets der gelehrten Welt neue Erkenntnisse mitzuteilen gesucht hat, so beliannt ist, glaubt Seine Königl. Hoheit Allergnädigst nicht besser ihre Liebe zur Förderung der Wissenschaften zeigen zu können, als daß Seine Königl. Hoheit in Berücksichtigung der von dem Herrn Archiater und Ritter angeführten Gründe ihm Zeit gewährt, dem Publikum neue Wahrheiten vorzulegen; demnach Herrn Archiater und Ritter hiermit die gnädigste Erlaubnis zuteil wird, die Beratungen des Konsistoriums während dieses Semesters nicht zu besuchen, soll sich jedoch nicht der Pflicht entziehen, die Jugend zu informieren."

I) Brief vom 23. Okt. I747 (bei Stoever, S. 65).

2) Brief an J. A. Murray vom 24. Jan. 1765. (Egenhändiga Anteckningar, S. I 90.) - P. D. Giseke erzählt, daß Linné i77 I ilım gegenüber bemerkte: „Ich habe keinen, der mir bei der Herausgabe einer neuen Auflage hilft. Wenn Sie bci mir den Winter über bleiben wollen, will ich sie herausgcben und sie Ihnen vorlesen, so daß Sie schreiben und das Buch in Ordnung bringen können." „Dies konnte aber nicht geschehen.“ Stoever, II, 8.

Hjelt, Carl von Linné. 
Unter Benutzung der hinterlassenen Sammlungen seines Vaters beabsichtigte später Linné d. J., aufs neue die "Materia medica“ herauszugeben, dieser Plan wurde aber durch seinen frühen Tod zunichte gemacht ${ }^{1}$ ).

Lin nés Materia medica gewährt uns einen tiefen Einblick in seine Auffassung von den praktischen Zielen der Heilkunde, und sie besitzt für uns ein umso größeres Interesse, als sie in wesentlichem Grade dazu beigetragen hat, die Liebe zur medizinischen Naturwissenschaft und zur Pharmakologie und die tüchtigen Kenntnisse in diesen Wissenschaften zu begründen, die seit langen Zeiten die schwedischen Aerzte und Apotheker in so hervorragender Weise auszeichnen. Wenn man die Entwicklung der medizinischen Wissenschaft in Schweden von der Mitte des 18. Jahrhunderts an näher betrachtet, so gelangt man unwillkürlich zu der Ueberzeugung, daß es Linnés überwältigender, in medizinischer Hinsicht nicht hoch genug einzuschätzender Einfluß war, der ihr das naturwissenschaftliche Gepräge gab, das seitdem fortgelebt und in vielfältiger Weise der ärztlichen Bildung in Schweden bis in unsere Zeit hinein seinen Stempel aufgedrückt hat. Infolge der Richtung, die Linné der Wissenschaft gab, hat sich die Jahrhunderte alte Verbindung zwischen Naturwissenschaft und Medizin in Schweden länger erhalten als in irgend einem anderen Lande und zu ihrem gemeinsamen Heil die herrlichsten Früchte getragen.

Linnés Materia medica wurde, wie er selbst sagt, „in gratiam discipulorum studiosorum Upsaliensium" herausgegeben und sollte, da sie für schwedische Aerzte bestimmt war, hauptsächlich die offizinellen Pflanzen umfassen, die in die vom Collegium medicum $174 \mathrm{I}$ herausgegebene Medizinaltaxe aufgenommen warer, „et eas quidem omnes nulla exclusa, quamvis multae et excludi possent et deberent". Jedoch hat Linné gemeint, auch einige solche Pflanzen aufnehmen zu müssen, deren wirksame Eigenschaften zwar anerkannt waren, die aber die Aerzte in den Apotheken nicht vorauszusetzen berechtigt waren, da sie in der eben erwähnten Medizinaltaxe fehlten. Von diesen wird ein besonderes Verzeichnis geliefert, in welchem u. a. angeführt werden: rad. Saleb, stipites Dulcamarae, herba Linnaei, Uvae ursi, Musc. Islandic., semina Daturae, herba Laurocerasi, bacc. Belladonnae, rad. Senegae, cort. Simarubae. Linné hat mit der ihm eigenen Klarheit und Kürze bei jeder offizinellen Pflanze alles

I) „Materiam medicam postea edam, sed exspecto adhuc proxima aestate varia ex America, quae eruenda commisi Botanicis meis ibi degentibus; vellem quoad ortum ut botanicus nullius pharmaci originem ignoraret." Brief an P. D. G is eke vom I. Nov. 1779 (bei Stoever, S. II6). 
angegeben, was sich von derselben in pharmakologisch-therapeutischer Hinsicht sagen läßt. Von größter Wichtigkeit in dieser Beziehung war, daß die offizinellen Pflanzen sorgfältig botanisch der Gattung und Art nach bestimmt wurden, wodurch der bis dahin so gewöhnlichen Verwechslung mit anderen mehr oder weniger nahestehenden Pflanzen vorgebeugt wurde. Dadurch wurde Linnés „Materia medica" ein wirkliches Handbuch ebenso für die schwedischen Aerzte wie für die Apotheker, das die wichtigsten und zuverlässigsten Auskünfte bot. Durch die Herausgabe der „Flora Suecica“ erhielten die Apotheker zugleich Kenntnis von den Drogen, die im eigenen Lande erhältlich waren. Linné verlangte daher, daß einheimische Gewächse soviel wie mögiich von den Apothekern verwandt werden sollten, „nicht nur damit das Geld im eigenen Lande bleibt, sondern, was noch wichtiger ist, damit die offizinellen Pflanzen frisch und unter größerer Kontrolle (majori cautione) erhalten werden könnten" 1 ). Der Hinweis auf „Hortus Upsaliensis" gab zugleich Aufschlüsse über die offizinellen Pflanzen, welche L in né mit größerem oder geringerem Erfolg einzuführen und zu kultivieren versucht hatte, „damit nicht die Apotheker entweder vergebens die von mir angestellten Versuche wiederholen oder aus fremden Ländern verschreiben, was in unseren Gärten, ebenso gut wie in den ausländischen wächst und gedeiht". Durch Li nn nes lebhaftes Interesse für die Einführung ausländischer Medizinalpflanzen und ihren Anbau in Schweden wie auch seine beharrlichen Versuche, durch sorgfältige Kultur die Eigenschaften der einheimischen pharmazeutischen Pflanzen gleichsam zu erhöhen und zu veredeln, wurde der Gedanke an die Anlegung sog. Medizinalgärten in den Städten erweckt und gefördert ${ }^{2}$ ). Linné schlug daher vor, daß wenigstens im südlichen Schweden, z. B. in Helsingborg und Ystad, ein pharmazeutischer Garten angelegt werden sollte, der, wie er hoffte, gewinnbringend sein würde, und teilte in „Plantae officinales" (I753) ein Verzeichnis der Medizinalpflanzen mit, deren Anbau in diesen Gärten zu betreiben wäre ${ }^{5}$ ). Zugleich

I) Auf Ersuchen der Schwedischen Akademie der Wissenschaften schrieb Linné einen "Upsats po̊ de medicinalväxter, som i apothequen bevaras och hos oss $i$ fäderneslandet växa" (,Aufsatz über die Medizinalpflanzen, die in den Apotheken erhältlich sind und bei uns im Lande wachsen"), in Abhandl. d. Akad. I74I, S. 81 ff. Hierher gehört auch die Abhandlung Plantae officinales (1753). S. A. Hedin hebt in seiner Disputation "Quid Linnaeo Patri debeat medicina", Ups. 1784, der einzigen Abhandlung, die sich bisher mit Linné als medizinischem Schriftsteller beschäftigt hat, seine Verdienste um die Pharmakologie hervor.

2) Hortus Upsaliensis, I. Ups. I748. Horticultura academica (I75I).

3) Vergl. das Kapitel über Medizinalgärten an einzelnen Orten in Schweden in O. E. A. Hjelt, Svenska och Finska Med.-Verk. Hist. III, 537-540. 
stellte er eine Liste solcher Medizinalpflanzen auf, welche, da sie das Klima in Schweden nicht ertragen, aus südlichen Gegenden bezogen werden müßten. In „Specifica Canadensium" (1756) schlägt er weitere Pflanzen vor, die angebaut zu werden verdienten, unter ihnen Aralia nudicaulis et racemosa (als Ersatz für Sarsaparilla), Lobelia syphilitica, Spigelia anthelminthica, Polygala senega, Phytolacca americana u. a.

Auf Grund seiner eigenen Erfahrung teilt Linné viele wichtige Aufschlüsse darüber mit, wie und wann die offizinellen Pflanzen einzusammeln und aufzubewahren wären, damit sie ihre Eigenschaften erhielten oder bewahrten $\left.{ }^{1}\right)$. Er lehrte so z. B. die Apotheker, daß die Art der technischen Anwendung der Medizinalpflanzen von besonderer Wichtigkeit sei. Die Eigenschaften der getrockneten Pflanze oder des aus ihr bereiteten Dekoktes sind nicht dieselben wie bei der frischen Pflanze oder ihrem Saft. Die Apotheker sollten daher selbst Medizinalpflanzen ziehen, um sie je nach der Entwicklungszeit, in der sie am besten verwendbar sind, erhalten zu können, ferner sollte genau untersucht werden, welcher Teil der Pflanze (Wurzel, Blätter, Blüten oder Samen) die wirksamen Bestandteile enthält. Das Einsammeln soll gleichfalls zur rechten Zeit und ihre Aufbewahrung in rechter Weise geschehen. Li in é hat beobachtet, daß einige offizinelle Pflanzen ihre Kraft bei zu starker Blätterentwicklung, andere bei der Fruchtbildung verlieren. Von den medizinischen Pflanzen, welche noch nicht genau botanisch bestinmmt worden waren, gibt Linné in "Materia medica“" ein besonderes Verzeichnis, und darunter kommen Namen vor, deren Feststellung erst der Forschung einer späteren Zeit vorbehalten gewesen ist. Für jede Pflanze wird kurz ihre Heimat, Synonyme, ihre Kultur und ihr Wachstum sowie ihr pharmazeutischer Name, ferner die Pflanzenteile und Präparate davon, die in den Apotheken benutzt werden, wie radix, lignum, cortex, folia, flos, fructus, semina et aqua destillata, oleum stillatitium, oleum empyreumaticum, spiritus, extracta usw. angegeben. Natur und Eigenschaften (qualitates) werden nach ihrem Geruch, Geschmack und äußeren Aussehen bestimmt. Ihr größerer oder geringerer offizineller Wert wird mit den Worten dubia, infida, eximia, heroica, trita, usitata, exoleta usw. bezeichnet. Schließlich werden die verschiedenen Krankheiten angegeben, bei welchen die pharmazeutischen Pflanzen zur Verwendung kommen. Lin né bemerkt jedoch, daß er nur solche aufgenommen hat, welche anerkannte Autoren oder er selbst als wirklich nützlich befunden, und berichtet, daß er als Arzt im Marine-

I) Obstacula medicinae ( $\left.175^{2}\right)$. 
krankenhaus soviel wie möglich alle Heilmittel prüfte, „et infida atro carbone, tuta albo calculo notavi“. Bisweilen sah er sich jedoch gezwungen, in zweifelhaften Fällen ein Fragezeichen hinzuzufügen. War er von der spezifischen Wirkung des Mittels überzeugt, so pflegte er ein Ausrufezeichen hinzuzusetzen. Ueber alle zusammengesetzten Heilmittel erklärt Linné seine besondere Meinung (peculiaris sententia) zu haben, und er tadelt die Sitte der Aerzte, solche zu verschreiben, „denn derjenige, der lange Rezepte verschreibt (longas praescribit receptorum formulas), tut es entweder in betrügerischer Absicht oder aus Unwissenheit“. Was Linné im übrigen über die medizinischen Eigenschaften (vires) der Pflanzen bemerkt, ist außerordentlich charakteristisch für den hohen Standpunkt, den er auf dem Gebiete des Wissens jener Zeit einnahm.

In seiner "Materia medica“ hat Linné eine Aufstellung der Pflanzen aus therapeutischem Gesichtspunkt in gewissen durch die Erfahrung bestätigten und für die Bedürfnisse der praktischen Heilkunde angeordneten Klassen gegeben. Verf. teilt hier eine Uebersicht über dieses sein früheres pharmakodynamisches System mit, wie er es in der genannten Arbeit ausführlich dargestellt hat ${ }^{1}$ ).

Classes.

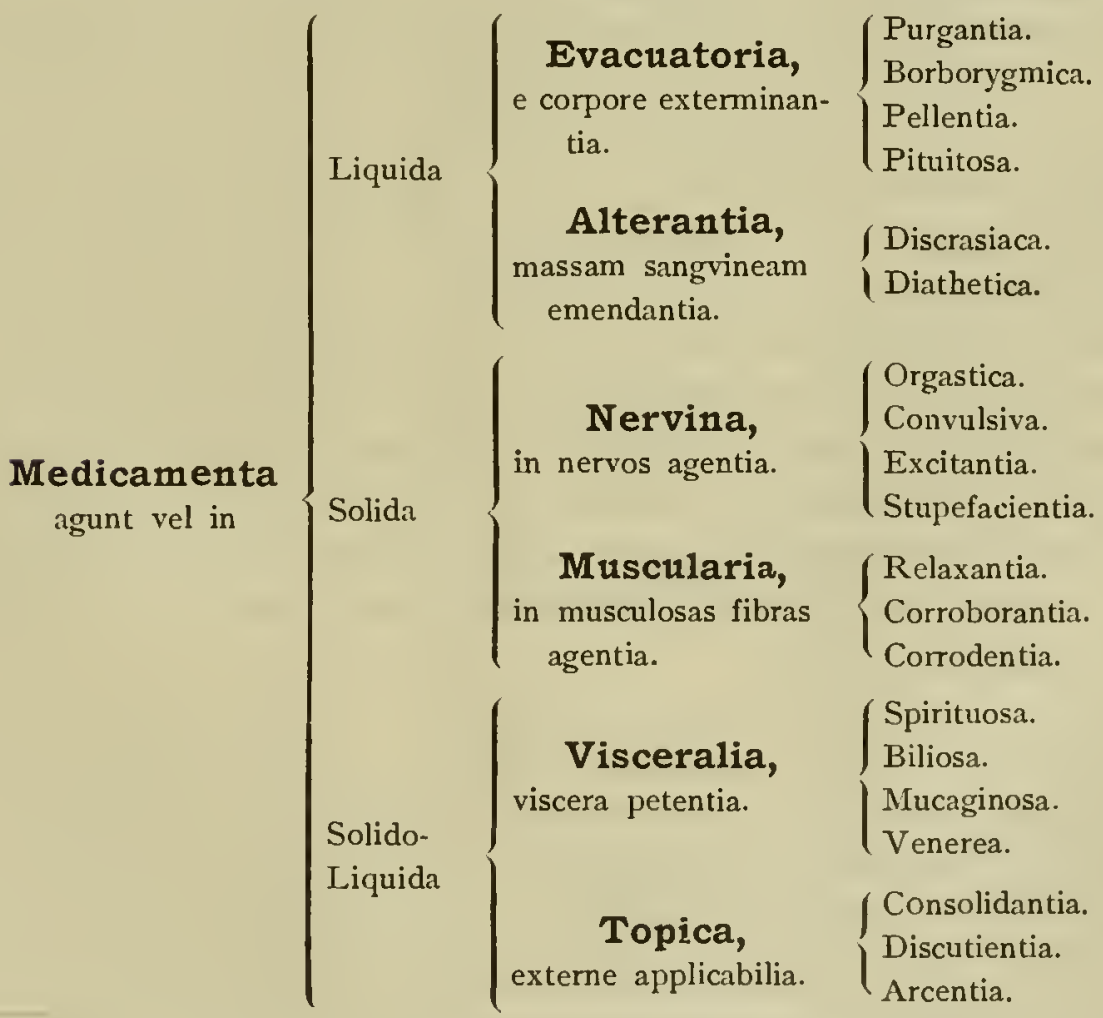

I) „Dieses allgemein gepriesene und zu den academischen Vorlesungen sehr bequeme Buch, wodurch man zuerst die Arzneyen nach ihren Gattungen bestimmen gelernt hat." Gött. gel. Anz. 1772, S. 1287. 
Dieser rein empirische Einteilungsgrund für ein pharmakodynamisches Pflanzensystem wurde jedoch später von Lin né aufgegeben, je mehr er in der Bildung und den Eigenschaften der Pflanzen eine Erklärung für ihre verschiedene Einwirkung auf den menschlichen Körper zu finden glaubte. Unter anderem lenkte er die Aufmerksamkeit auf die eigentümliche Tatsache (mirum naturae phaenomenon), daß gewisse Stoffe, seien sie nun süß oder sauer, scharf, bitter, salzig, fett usw., keine Veränderung (variatio) unseres Gedankenganges oder Auffassungsvermögens herbeiführen, während dagegen die Benutzung stark riechender Stoffe, wohlriechender oder widerlicher, und Spirituosen auf das Denk- und Urteilsvermögen einwirkt (de omnibus fere aliter quam antea judicamus). Dieser Gedanke ist für Li n né charakteristisch und erklärt die große Bedeutung, die er dem Geruch der Pflanzen in ihrem Verhältnis zum Nervensystem beilegte, dessen Tätigkeit unter dem Einfluß dieses Geruches eine Veränderung nicht nur bezüglich des Bewegungsvermögens, sondern auch der Gefühlsstimmung erfährt. Es geschieht dieses durch die äußerst feinen, flüchtigen Stoffe, die teils von den Pflanzen gleichsam ausgeatmet werden, teils auch auf chemischem Wege hergestellt werden können (inebriantia nativa et artificialia 1 ). Linné suchte daher mehr oder weniger konsequent den von ihm ausgesprochenen, bereits angeführten Satz durchzuführen: „Was Geschmack hat, wirkt auf die festen und flüssigen Teile des Körpers ein, was Geruch hat, wirkt auf die Nerven ein“ (,sapida in fibras, olida in nervos agunt“ 2). Es liegt in diesem Satz eine unbewußte Vorstellung von der notwendigen und engen Beziehung zwischen den medizinischen Wirkungen (vires) der Pflanzen und ihren chemischen Bestandteilen. Es war, kann man sagen, eine dunkle Ahnung von dem Ziel, dem die Pharmakodynamik zustreben muß. Infolge des unentwickelten Standpunktes, auf dem die Chemie sich damals noch befand, konnte Linné jedoch keine bestimmten Kriterien für die verschiedenen Gruppen aufstellen, in die er seinem Prinzip gemäß die Pflanzen hinsichtlich ihrer medizinischen Eigenschaften einteilen wollte.

1) Inebriantia (I761). Zu den nativa gehören unter anderen Opium, Datura, Hyoscyamus, Atropa, plantae ambrosiacae, fragrantes usw. $Z u$ den artificialia werden gewisse Bestandteile in Bier, Wein, Spiritus vini usw. gerechnet.

2) „Medicamenta agunt odore in maternam (seu internam et nerveam) partem corporis, sapore in paternam (seu externam et fibrosam)", heißt es in der Abhandlung "De Menthae usu" ( 1767$)$. „Linna eus medicamentorum vires solo sapore et odore dijudicandas primus rite intellexit, evicit ac erudito aperuit orbi“, lautet eine Stelle in der Abhandlung „Medicamenta graveolentia" (1758). 
Auf Grund praktischer Erfahrung hatten die älteren Aerzte ihre Pflanzendrogen in einer großen Menge von Spezialgruppen aufgestellt, die sie nach ihren symptomatisch-pharmakodynamischen Eigenheiten benannten. Man hatte Emetica, Cathartica, Eccoprotica, Carminativa, Diaphoretica, Diuretica, Antispasmodica, Abortiva, Expectorantia, Hypnotica usw. Hier fand sich demnach kein anderer Einteilungsgrund als die Erfahrung bezüglich der einzelnen Drogen und eine sozusagen instinktive Auffassung von ihren Eigenschaften. Durch Vereinigung von Heilmitteln aus verschiedenen Gruppen glaubte man sogar auf verschiedene Weise je nach Bedarf diese ihre Wirkung modifizieren zu können. In dieser Ansicht liegt die Erklärung für die langen und bunten Rezepte der älteren Aerzte. Linné wollte dagegen, wie schon oben angedeutet wurde, seiner Einteilung der Pflanzendrogen ihren Einfluß auf den jeweilig verschieden pathologischen Zustand der Gewebe gemäß der Auffassung, die er hiervon hegte, zugrunde legen. Er ging dabei von der Voraussetzung aus, daß gewisse Heilmittel auf die festen Gewebe dadurch einwirken könnten, daß sie den Zusammenhang zwischen ihren kleinsten Teilen erhöhten oder verminderten, während andere das Vermögen besäßen, teils die Beschaffenheit der Flüssigkeiten hinsichtlich ihrer Zusammensetzung und Schärfe zu verbessern, teils auf geeigneten Wegen solche Flüssigkeiten aus dem Körper auszutreiben, deren Menge für den Organismus schädlich sei ${ }^{1}$ ).

Diese Voraussetzung von den heilbringenden Eigenschaften der Heilmittel und besonders der Pflanzen, über die, wie Linné meinte, der Arzt durch die Anwendung des einen oder anderen Mittels oder seines Gegensatzes verfügen konnte, barg den Anfang zu einer therapeutischen Erklärung des Problems der Pharmakodynamik in sich. Diese Betrachtungsweise setzte eine bestimmte Beobachtung wie auch Erfahrung voraus, indem sie gleichzeitig den Bedürfnissen des praktischen Arztes entgegenkam. Die ihr zugrunde liegenden theoretischen Voraussetzungen waren für ihre Zeit ebenso bedeutungsvoll wie in einer späteren Periode die verwickelten Gedankenoperationen der Aerzte mit Indikationen und Kontraindikationen, mit Indicans und Indicatum bei der Behandlung der Krankheiten, die. eine Erbschaft der Schule Boerhaaves, noch um die Mitte des letztverflossenen Jahrhunderts eine so wichtige Rolle in der Pathologie spielten. Da für Linné, wie oben bereits erwähnt, fünf verschiedene pathologische Zustände sowohl in den Spannungsverhält-

1) Sapor medicamentorum (1751). Vergl. oben S. $76 \mathrm{ff}$. 
nissen der festen Teile als in der chemischen Zusammensetzung der Flüssigkeiten existierten, so stellte er mit Rücksicht auf die medizinischen Eigenschaften der Pflanzen auch fünf verschiedene Arten von Geschmack und Geruch nebst ihren Gegensätzen auf. Lin né betrachtete überhaupt die Fünfzahl als einen Ausdruck der Vollendung der organischen Form, und gleichwie die Pflanzen, deren einzelne Blütenteile auf diese Zahl zurückgeführt werden konnten, seiner Auffassung nach die in der Entwicklung am meisten vorgeschrittenen waren, so suchte er auch in der Welt der Krankheiten und in den gegen sie verwendeten Heilmitteln diese bedeutungsvolle Zahl wiederzufinden. Besonders tritt in seinem "Clavis medicinae" dieser Versuch hervor, die Heilmittel und besonders die medizinischen Pflanzen hinsichtlich ihres Geschmacks und Geruchs unter die Fünfzahl einzuordnen.

Lin né nahm fünf verschiedene Arten von Geschmack an, nämlich den wässerigen, sauren, fetten, süßen und schleimigen Geschmack, sowie ihre Gegensätze, den trockenen, bitteren, zusammenziehenden, scharfen und salzigen Geschmack. Sapida wirken nur auf das Corticale vitale ein. Nach diesem Prinzip verteilen sich die Heilmittel und besonders die Pflanzen auf folgende Gruppen ${ }^{1}$ ):

I) Aquosa, welche die Flüssigkeiten verdünnen und reinigen und die festen Teile feuchter machen. $\mathrm{Zu}$ diesen Heilmitteln gehören die säuerlichen Getränke (acetaria), die „ex oleribus et fructibus horaeis“, wie z. B. Melone, Chamaemorus, Fraga, Cerasus, Prunus alba, bereitet werden, sowie ausgepreßte Kräutersäfte, ferner unter den Pflanzen rad. Rapae, Brassicae, Pastinacae, Daucus, Portulaca, Spinachia, Taraxacum usw.

2) Sicca stärken die Fasern des Körpers und saugen Flüssigkeiten auf, sind Diuretica und werden blutreinigend genannt, wie z. B. Dulcamara, lign. Guajacum, Sassafras, Juniperus, rad. Sarsaparillae, China, semina Pisi, Fabae, Phaseoli, Ervi. Werden auch äußerlich bei bösartigen Geschwüren angewandt, wie z. B. semina Lycopodii, Herbae capillares.

3) Acida wirken vermindernd auf die festen Teile. Wenn saure Mittel im Uebermaß angewandt werden, so wird dadurch Bleichsucht, Leukorrhöe, Hydrops und allgemeiner kachektischer Zustand hervorgerufen. Auf die flüssigen Bestandteile des Körpers wirken sie kühlend. Oppositum ist Amarum, „daher wird Hopfen ins Bier ge-

I) Eine ausführliche, ins einzelne gehende Erklärung dieser Gruppen findet sich in "Diss. med. de effectu et cura vitionum diaeteticorum generali" (1769), S. I6-22. 
legt, damit es nicht süuern soll". Zu clieser Gruppe gehören unter den Pflanzen Citrus, Berberis, Oxycoccus, Vitis idaea, Rubus, Tamarindus, Acetosa usw.

4) Amara wirken auf die festen Teile stärkend und werden daher Tonica genannt. Sie erhöhen den Appetit, die Verdauung, die Diaphorese und die Körperwärme und stimulieren das Gefäßsystem. Durch ihre balsamischen Eigenschaften wirken sie dem Verderben und der Säurebildung in den Flüssigkeiten entgegen, denn auf diese Weise werden alle Pflanzen und Tiere aufgelöst und zerstört ${ }^{1}$ ). Hierhin gehören (außer Fel tauri) Aloe, Myrrha, Faba St. Ignatii, Nux vomica, Quassia, China, Pareira, Gentiana, Centaurium, Trifolium aquaticum, Carduus benedictus, Tanacetum, Artemisia, Absinthium usw.

5) Pinguia wirken auf die festen Teile erweichend und auf die Flüssigkeiten einhüllend. Durch diese ihre Eigenschaft sondern sie Wundschorf (escara) ab und lindern die Schmerzen in Wunden, sind von Nutzen bei Brandwunden und mildern Kolikschmerzen und Husten. Fette Menschen sind gewöhnlich frohen Gemütes, während ältere, magere und dürre Personen (rigidi) milzsüchtig und von unruhiger Natur sind. „Uterum comprimendo foeminas steriles reddant pinguia“. Hierhin gehören Oele, Sperma ceti, Vitellus, Balsamum copaivae, tolu, opobalsamum, peruvianum, Terebinthina.

6) Stiptica sind zusammenziehend (adstringentia) und den Pinguia entgegengesetzt. Zu ihnen gehören Quercus, Acacia, folia Uvae urs i Tamarix, Catechu, rad. Bistortae, Tormentillae, Caryophyllatae, Pimpinellae, Fructus granatum, Cydonia. Sind nicht bei stillsitzender Lebensweise und Anlage zu Steinbildung zu gebrauchen.

7) Dulcia machen die festen Gewebe nachgiebig (relaxando) und süßen die Flüssigkeiten (edulcorando) ${ }^{2}$ ), „Kein Chylus ist nutriens, sofern er nicht sül0 ist." Alte Personen und diejenigen, deren Fasern starr sind, haben Nutzen vom Zuckeressen, während Kinder und solche, bei denen die Gewebe weich und nachgiebig sind, Schaden

1) Balsamisch werden diejenigen Stoffe genannt, die durch ihre bitteren Eigenschaften sowohl Ansäuerung als Verwesung verhindern. Diese beiden Wege sind es, auf denen alle vegetabilischen wie animalischen Bestandteile nach $L$ innés Ansicht aufgelöst und zerstört werden. Die Verwesung verändert die Körper zu „alcali volatile“ und hebt den Zusammenhang der Teile auf. $\mathrm{Da}$ saure und verdorbene Stoffe durch bittere Mittel gebrochen werden (franguntur), lehrt uns ja die tägliche Erfahrung. $\mathrm{Zu}$ ihnen gehören unter andercn vor allem Absinthium, Lupulus, Teucrium (Scordium), Aloe, Myrrha. Siehe "Lignum Qvassiae" ( 1763 ).

2) "Solida incrassant non eodem modo ac stiptica et amara, crassiores quidem reddendo fibras, sed simul laxas." 
leiden, wenn sie davon im Uebermaß genießen. Je milder die Flüssigkeiten des Körpers sind, um so gesunder ist das Individuum und auf um so längere Lebenszeit kann es hoffen ${ }^{1}$ ). $\mathrm{Zu}$ den Dulcia.gehören Lac dulc., Emulsiones, Saccharum, Syrupi, Konserven, Confectiones, Mel, rad. Liquiritiae, Polypodium, Cacao, Amygdala usw.

8) Acria reizen die festen Gewebe und machen die Flüssigkeiten scharf (corrodunt solida et incidunt humores). Sie kommen zur Verwendung, wo die Absonderung träge und die Flüssigkeiten klebrig sind, wie z. B. „in gewissen morbi soporosi und Kachexien, bei Hydrops, bei schleinigem Asthma und Skorbut". In großer Menge benutzt, wirken sie wärmend, irritierend und sogar zerstörend auf die kleinsten Fasern. Aeußerlich angewandt, rufen sie Rötung hervor, und bei innerem Gebrauch werden sie aus dem Körper durch seine Ausführwege entfernt. „Will man die Entleerungen des Körpers befördern, so muß man Acria hinzufügen, wobei man dann ebensoviel von dem Purgiermittel weglassen kann." $\mathrm{Zu}$ dieser Gruppe rechnet Linné Euphorbia, Arum, Capsicum, Cicuta, Ledum, Ranunculus, Sinapis, Armoracia, Raphanus, Allium, Porrum, Cepa, Scilla, eine Menge Umbellaten usw.

9) Mucosa wirken auf die festen Teile einhüllend und vermindern die Schärfe in den Flüssigkeiten (agunt in solida lubricando et in fluida acria involvendo, inviscando). Sie finden daher bei Schmerzen infolge von Stein, bei Kolik, Dysenterie, Strangurie, Heiserkeit und Husten Verwendung und werden als Emulsionen, Gargarisma, Augenwasser usw. benutzt. Zu diesen Mitteln gehören nach Li nn é semina Ocymi, Psyllii, Cydonii, Gmi arabicum, Cerasi, Tragacanthae, radix Pulmonariae, herb. Malvae, Althaeae, Meliloti, fructus caricae.

г) Salsa irritieren die Gewebe und durchdringen die Flüssigkeiten (agunt in solida irritando et fluida penetrando). Sie befördern die Absonderungen und sind schleimlösend; im Uebermaß gebraucht, wirken sie auf das Blut ein, wie z. B. bei Skorbut, 'so daß es aus den Gefäßen herausdringt. Sie sind den Mucosa entgegengesetzt. $\mathrm{Zu}$ dieser Gruppe von Heilmitteln gehören „Sauerbrunnen“ (acidulae), Meerwasser, pisces salsi, Salicornia, Salsola, Chenopodium marit. usw.

Es sei hier noch bemerkt, daß Linné außer den eigentlichen Geschmacksarten auch „sapores mixti“ zugab, die durch Vereinigung von Pflanzen mit verschiedenem Geschmack entstanden waren. Derartige Verbindungen können jedoch nicht nach Belieben erhalten werden, denn die eine Geschmacksform läßt sich nicht ohne weiteres

I) Dulcia nutriunt, si simul mucosa s. pinguia. 
mit der anderen verbinden. Darauf beruht $L$ in n és in therapeutischer Bezichung eigentümliche Bemerkung, daß gewisse Heilmittel, wenn sie je für sich gebraucht werden, ihre gewöhnliche Wirkung zeigen, wenn sie aber mit anderen verbunden werden, vollkommen unwirksam sind. Vegetabilische Heilmittel, die hinsichtlich des Geschmacks vereinigt werden können (conformia medicamenta) sind Aquosa et Viscosa, Dulcia et Pinguia, Acria et Amara, Acida et Stiptica 1).

Wie der Geschmack der Heilmittel, nach Linnés Auffassung, einen Fingerzeig für die Beurteilung ihrer Eigenschaften gab, so war auch der Geruch von großer Bedeutung für die Entscheidung bezüglich ihrer therapeutischen Verwendung. Es ist bereits erwähnt worden, daß Linné den allgemeinen Satz aufstellte, daß die Heilmittel, die Geruch besitzen, ihre besondere eigentümliche Wirkung auf und durch die Nerven ausüben (olida in nervos agunt). Wenn er diesen für ihn originellen und in seinen Konsequenzen für sein pharmakodynamisches System grundlegenden Gedanken aussprach, ging Linné von der physiologischen Vorstellung aus, daß der Einfluß des Geruchs auf der Hervorrufung einer bestimmten Bewegung in den Nerven (motus tremulus) beruht, in Uebereinstimmung mit Boerhaaves Annahme eines "fluidum nervosum" 2). Analog den verschiedenen Geschmacksarten stellte Linné auch zehn Geruchskategorien auf, nämlich :

I) Ambrosiaca verbreiten einen starken, erstickenden Geruch, wie z. B. Ambra, Moschus, Vanilla, Orchideen, Abelmoschus moschatus, Matrisylva (Asperula odorata), Balsama pleraque ${ }^{3}$ ). Sie sollen vor Ansteckung schützen und antikontagiösa und aphrodisiaca sein. Linné führte in Schweden den Gebrauch von Moschus bei der Behandlung kontagiöser und exanthematischer Fieber ein, und seiner Angabe gemäß wurde dieses Mittel später von allen Aerzten mit größtem Erfolg angewandt ${ }^{4}$ ).

2) Hircosa oder Felina besitzen einen stinkenden Geruch, sind "discutientia“ (abtreibend), wie z. B. Geranium, Vulvaria, Linaria, Valeriana, Mentha, Salvia, Hypericum hircinum. Excitant venerem und sind repellentia. Werden bald ausgetrieben, weil sie für den Körper widerlich sind.

1) Sapor medicamentorum (175 I).

2) Odores medicamentom (I752).

3) Ambrosiaca (1759). In dieser Abhandlung wird erwähnt, daß im Kirchspiel Ilmola (Österbotten) einige Personen 1752 von einem tollwütigen Wolf gebissen wurden und danach an Hydrophobie starben.

4) Brief an Sauvages vom 15. Jan. I754. 
3) Fragrantia verbreiten einen würzigen Geruch, wie z. B. Flores citri, Aurantiorum, Tiliae, Rosae flor., Santali lign., Sassafras lign., Crocus, Iris florent. rad., Caryophyllat. rad., Herb. Meliloti usiv. Sie wirken beruhigend und schlaffördernd. Li n n é fordert Sauvages auf, zu untersuchen, ob die Elektrizität einen Einfluß auf die Fragrantia und Suaveolentia hat, welche die Nerventätigkeit steigern, wie auch auf die Foetida, welche sie aufheben, wie z. B. Datura, Belladonna, Actaea, Tagetes usw. „Wenn diese Pflanzen in einer Beziehung zur Elektrizität stehen, so ist die Sache klar"1).

4) Nidorosa haben einen strengen, herben Geruch, wie z. B. Humulus, Rosmarinus sylv., Vitex, Ledum, Absinthium, Tanacetum, Matricaria, Hyssopus, Coffea usw. Sie sind zum größten Teil Bitterstoffe und rufen, im Uebermal angewandt, Rausch, Schwindel und Kopfschmerzen hervor.

5) Spirantia verbreiten einen würzigen Geruch, wie z. B. Marum, Thymus, Salvia, Melissa, Mentha nobilis (Herzensfreude), nebst einer Menge Verticillatae, Fermentata dosi refracta oder Vina, Spiritus distillatus, Spiritus salis ammon. Spirantia werden sowohl innerlich wie äußerlich bei allen Schwächezuständen verwandt. Sie wirken durch die Erzeugung von Wärme (analeptica) bei Krankheiten belebend und vermehren gewisse Absonderungen, außerdem besitzen die hierhergehörigen Pflanzen verteilende Eigenschaften. Diese Wirkung liegt nicht in ihrem Saft oder ihrer Substanz, sondern darin, daß sie durch ihren Duft (halitus) auf die Nerven einwirken. So z. B. leiten sie die Aufsaugung in angeschwollenen Teilen ein \%). Durch die vermehrte Nerventätigkeit (per oscillationem nervorum) entsteht in den festen Teilen eine Bewegung hin und her, wodurch die entzündliche Stase gleichsam zerschüttelt und verdünnt wird ${ }^{3}$ ).

6) Tetra zeichnen sich durch einen „verdrießlichen, abstoßenden und übel stinkenden Geruch" aus ${ }^{4}$ ) und sind die besten Repellentia,

I) Brief an Sauvages vom I 4. Okt. I 755. Bei seinen medizinischen Vorlesungen erzählte Linné bisweilen von den Krankheiten, die er selbst durchgemacht hatte, und teilte Erfahrungen aus seinem eigenen Leben mit. Er sagte, er sei daran gewöhnt, um 3 Uhr morgens aufzuwachen, und könne dann nicht mehr schlafen, wenn er nicht einige Herbae fragrantes neben sein Bett stellte, wo er dann noch zwei bis drei Stunden weiter schlafen könne. Er habe nie in seinem Leben vor dem Mittagessen geschlafen außer einem einzigen Mal, als er in seiner Jugend sich neben einige Gartenbeete gesetzt hatte, wo die Bohnen eben in Blühen begriffen waren. (Vorlesungen über Clavis).

2) De Menthae usu ( 1767$)$.

3) De Maro (1774).

4) „Omnia tetra sunt narcotica nervosam actionem suffocantia et spirantibus analepticis seu incitentibus opposita." 
wie z. B. Papaver, Opium, Cimicifuga, Paeonia, Sambucus, umbellatae wie Coriandrum, Anethum, Conium, Cicuta; Castoreum. Werden sie in größeren Dosen angewandt, so erweitert sich die Pupille, und die Iris wird paralytisch, wodurch eine Herabsetzung des Sehvermögens (scotomia) entsteht. Oefters benutzt, wirken sie lähmend, in geeigneter Dosis stillen sie jedoch Schmerzen und Spasmen. Linné macht die wichtige Bemerkung, daß man die Dosis für Narcotica nicht vermehren oder mit ihrem Gebrauch nicht fortfahren soll, wenn die Pupille sich erweitert und die Augen einen ungewöhnlichen Glanz annehmen ${ }^{1}$. Schon Raij hatte auf die Wirkung von Belladonna auf die Pupille aufmerksam gemacht. Was im besonderen das Opium betrifft, so ist bei der Bestimmung der Krankheitsformen, in welchen es benutzt werden kann, stets auf die Krankheitsursachen Rücksicht zu nehmen.

i) Aromatica besitzen einen sog. „Spezereigeruch“, wie z. B. Cinnamomum, Cassia lign., Canella alb., Laurus, Camphora, Caryophyllus, Myrtus, Piper, Cardamomum, Zingiber, Acorus, Angelica, Gentiana alba, Carum, Cyminum, Petrosel. mac., Cerefolium, Foeniculum, Anisum stellatum usw. Sie erhöhen den Blutumlauf und sind stimulantia, calefacientia, bei schwacher Herztätigkeit zu verwenden. Acorus Calamus ist nach Lin né die einzige zuverlässige aromatische Pflanze in Schweden.

8) Nauseosa verbreiten einen widerlichen Geruch \%). Sie sind teils amara, wie z. B. Aloe, Elaterium, Colocynthis extr., Bryonia, Scammonium, Senna, Gratiola, teils acria, wie z. B. Veratrum, Helleborus, Jalapa, Ipecacuanha, Sambucus, teils stiptica, wie z. B. Rheum, Lapathum, teils acida, wie z. B. Tamarindus, teils dulcia, wie z. B. Cassia fist., Polypodium, Dulcamara. Die hierher gehörigen Mittel sind emetica, cathartica, diuretica, emmenagoga. sudorifera, errhina.

9) Orgastica sind spastica und haben einen stickigen Geruch, wie z. B. Scilla, Allium, Cepa, Porrum, Scordium, Alliaria, Thlaspi. Armoracia, Sinapis, Raphanus, Nasturtium, Erysimum, Assa foetida, Ammoniacum.

10) Virosa sind fatuantia und zeichnen sich durch barschen Geruch aus, wie z. B. Datura, Hyoscyamus, Belladonna, Solanum, Tabacum, Arnica, Cannabis. "Sie machen einen toll, wenn sie viel benutzt werden, und haben denselben Effekt wie Branntwein."

I) Oprum (1775).

2) Was die "Nauseosa" oder Ekel erregenden Mittel an sich sind, können wir nicht erklären oder in Worten ausdrückèn, ebensowenig wie wir erörtern können, was der salzige, süße, saure Geschmack ist. Ail das, was unmittelbar von unseren Sinnen erfaßt wird, kann der inenschliche Verstand nicht definieren. Medicamenta graveolentza ( 1775$)$. 
In seinem „Clavis medicinae", worüber mehr weiter unten, gibt Linné eine schematische Zusammenfassung seiner Ansichten über die Einwirkung des Geruchs der Pflanzen auf das Nervensystem ${ }^{1}$. $\mathrm{Da}$ diese Aufstellung ein außerordentlich klares Bild von seinem Vermögen gibt, die, wenn man so sagen darf, physiologische Wirksamkeit der von ihm rücksichtlich ihres Geruchs zusammengestellten Pflanzengruppen zu gruppieren und durch einen einzigen Ausdruck anzugeben, so sei sie hier zur Veranschaulichung des eben Gesagten mitgeteilt.

Suaveolentes
Ambrosiaca
Fragrantia
Spirantia
Aromatica
Orgastica
XI. Ambrosiaca
XIII. Fragrantia
XV. Spirantia
XVII. Aromatica
XIX. Orgastica

Odores.

Pandentia

\section{Oppositi}

Libidini

Somno

Vigori

Actui

Sensui

A phrodisiaca

Discutientia

Pacantia

Paregorica

Temulenta

Incitantia

Stimulantia

Stringentia
Analeptica

Narcotica

Calefacientia

Evacuantia Convulsiva Nauseosa XVIII.

Spastica

Fatuantia

Suffocantia Tetra

XVI.

Relaxantia Virosa

$\mathrm{Xx}$.

\section{Graveolentes}

Hircosa.

$\mathrm{Nidoros}$.

Tetra.

$\mathrm{N}$ auseosa.

Virosa.

Exspirantia Hircosa

Roborantia Nidorosa XIV.

Außer dieser mit Rücksicht auf Geschmack und Geruch vorgenommenen Gruppierung der in der Heilkunde verwendeten Pflanzen findet man noch weiter in Linnés pharmakodynamischem System oder eigentlich im "Clavis medicinae" zehn Abteilungen, die zum großen Teil viele der bereits angeführten Pflanzennamen enthalten. Teils nach äußeren Kennzeichen geordnet, teils auf Grund gemeinsamer medizinischer Eigenschaften zusammengestellt, können diese Abteilungen als das schillernde Gedankenspiel eines systematisierenden Geistes betrachtet werden. Schon in "Philosophia botanica" hatte Lin n é bemerkt, daß neben dem Geschmack und Geruch der Pflanzen auch die Farbe nicht aller Bedeutung bei der Beurteilung ihrer medizinischen Verwendung entbehrt. Wir treffen daher unter diesen Abteilungen eine Gruppe, welche Linné Colorata nennt, und bei welcher er bemerkt, daß die roten Pflanzen (rubra) gewöhnlich stiptica

I) Natura secundum Qvalitates sensuum Olidas seligit fvires Diaeteticas et medicas. Clavis, S. 13. 
sind und die Entleerungen des Körpers hindern, wie z. B. Catechu, Rubia, Bistorta, Tormentilla, Rosae rubr. fl., daß die gelben (lutea) auf die Galle einwirken, wie z. B. Berberis, Frangula, Gummi gutta, Crocus, Rheum, Lapathum u. a., und daß die schwarzen Pflanzen (nigra) Blutfluß stillen, z. B. Hypocistis, Fungus melitensis (Cynomorium coccineum), Orobus niger, Anacardium. Mit diesen Bemerkungen scheint Lin né auf die Signaturlehre der Alten anspielen zu wollen. Diese in früheren Jahrhunderten allgemeine Wahnvorstellung wird an mehreren Stellen in Linnés Schriften bekämpft.

Als Toxica, die hinsichtlich des Geschmacks zu den Acria oder Corrosiva und hinsichtlich ihres Geruchs zu den Tetra, Nauseosa und Virosa gehören, werden angeführt lactescentia pleraque (Euphorbia, Chelidonium, Lobelia, Convolvulus, Lactuca virosa), polyandrae polygynae (ord. natur. XXVI), luridae omnes (ord. natur. XXVIII), contortae omnes (ord. natur. XXX, ord. natur. XXXI), tricoccae omnes (ord. natur. XXXVIII), umbellatae aquaticae und gewisse Liliaceen (z. B. Corona imperialis, Gloriosa, Hyacinthus). Derartige pharmakodynamisch zusammengestellte Gruppen sind ferner Lactariae, „die, welche die Milch in der Brust färben oder ändern", Urinariae, Anthelminthica, Phthiriaca und Exanthematica. Die Ordnung Cansaria vereinigt sogar eine Menge medizinischer Pflanzen nach den verschiedenen Krankheitszuständen, in denen sie benutzt werden. Crepitantia und Lactescentia beziehen sich teilweise auf die äußeren Eigenschaften der Pflanzen ${ }^{1}$.

Linn és Materia medica wurde in mehreren Auflagen in Deutschland von seinem Schüler J. Chr. D. Schreber herausgegeben, wobei er nicht nur Ausdrücke und Ratschläge von Linné selbst, der „seine Aufmerksamkeit auf die Umstände lenkte, die vorzugsweise zu beachten wären", sondern auch Aufzeichnungen nach seinen Vorlesungen benutzte, „von denen er von verschiedenen Freunden eine Menge sorgfältig hergestellter Handschriften erhalten hatte". Schrebers Ausgabe (I772) enthält außerdem sowohl die offizinellen Stoffe, die dem Tier- und Steinreich entnommen werden, und die Linné in zwei bereits erwähnten Abhandlungen ${ }^{2}$ ) beschrieben hatte, wie auch die Pflanzen, die nach Linnés Ansicht unter die Venalia aufzunehmen waren, alle nach Species plantarum, Systema naturae und Mantissae geordnet. Betreffs der Eigenschaften und der Anwendung der Pflanzen hat Schreber zahlreiche Zusätze bei-

I) Alle diese dreißig Abteilungen mit den zu ihnen gehörigen Pflanzen finden sich in "Clavis medicinae interior", S. 15-29 aufgezählt.

2) Materia medica in regno animali (1750). - Materia medica in regno lapideo (1752)- 
gefügt, dabei aber seinen eigenen Worten nach alles weggelassen, was Linné vermutlich nicht gebilligt haben würde. Dieser scheint jedoch nicht ganz mit der von Schreber besorgten Auflage zufrieden gewesen zu sein, da er an Abr. Bäck schrieb:

„Neulich habe ich Materiam medicam, die in Leipzig aufgelegt ist, erhalten, mit sehr wenigen, ja, fast gar keinen Aenderungen. Hätte ich die Auflage besorgt, wäre sie sicherlich anders geworden ${ }^{1}$ ).

An seinen Schüler und Freund, Prof. Andr. Murray in Göttingen, schreibt Linné:

„Ich habe gehört, daß Prof. Schreber meine Materia medica herausgegeben hat; ich wundere mich, daß er mir kein Exemplar zugesandt hat. Hat er darin etwas Neues hinzugefügt?" ${ }^{2}$ ). - „Ich höre, daß Herr Prof. Schreber meine Materia medica herausgegeben hat, ich habe sie aber nie zu sehen belommen, was von ihm irräsonabel ist ${ }^{3}$ ).

Die von Linné eingeführte Richtung und Methode der Bearbeitung der „Materia medica" wurde dann in der nächstfolgenden Zeit von mehreren Autoren aufgenommen, die alle mehr oder weniger seinen Spuren folgten. Von ihnen seien genannt J. G. Gleditsch, J. R. Spielmann, J. Andr. Murray und P. J. Bergius u. a. ${ }^{4}$. Obwohl Linné demnach in ausgezeichneter und vielseitiger Weise zur Entwicklung der Pharmakologie beigetragen hat, hat er doch bisher nicht den hervorragenden Platz in ihrer Geschichte erhalten, der ihm mit Fug zukommt und für den mehr als hinreichende Beweise im vorhergehenden beigebracht worden sind. Es kann dieses Uebersehen nur auf Unkenntnis der Geschichte der älteren Wissenschaft beruhen.

Aus der obigen Darstellung dürfte man ersehen, daß die Pharmakodynamik oder genauer die Lehre von der Anwendung der medizinischen Pflanzen in der praktischen Heilkunde ein Lieblingsgegenstand von Linné war, mit dem er sich gerne befaßte, und auf

1) Brief vom 12. März 1773 .

2) Brief vom 26. Okt. 1772 .

3) Brief vom 15. Febr. 1773 .

4) Die zum großen Teile unbefugten Einwände, die Vicq d'A zyr in seiner ,Eloge de Mr Linne" gegen seine Materia medica (und Genera morbonum) erhebt, widerlegt C. M. Blom in ,Samling af rön och wppläckter gjorde i senare tider uti physik, medicin, chirurgie" (,,Sammlung von Erfahrungen und Entdeckungen, wie sie in letzteren Zeiten in der Physik, Medizin, Chirurgie gemacht worden sind"), I. Götheborg 1781, S. 257-284, und Murray schreibt: „Wer selbst über die Materia medıca Linnés gelesen hat, wird am besten den unvergleichlichen Wert derselben einsehen." Med. prakt. Bıbl. I. Gött. 1775 , S. 307 . 
den er ständig zurückkam ${ }^{1}$. Wenn man die medizinische Literatur überblickt, kann man ohne Uebertreibung behaupten, daß es Li n nés Verdienst ist, nicht nur diesen wichtigen Teil der medizinischen Wissenschaft geordnet und bereichert, sondern auch durch seine systematische Behandlung den Grund zu seiner selbständigen Entwicklung und Bearbeitung gelegt zu haben.

Das Interesse, das Li nn é für die Pharmakologie hegte, verrät sich in der großen Menge von Abhandlungen, in denen er zahlreiche in ihr Gebiet fallende Fragen behandelt. In diesen Schriften bearbeitete er ausführlich teils größere Abteilungen seines pharmakologischen Systems, teils stellte er die Naturgeschichte und medizinische Eigenschaft einzelner wichtiger Pflanzen dar. Von ihnen sei die Abhandlung "Medicamenta graveolentia" (1758) erwähnt, in welcher er die dahin gehörigen Pflanzen in subinsipida, acria und amara einteilte; eine jede dieser Gruppen zerfällt wieder in zwei Ordnungen, fortiora und debiliora. $\mathrm{Zu}$ den graveolentia subinsipida fortiora werden Pflanzen gerechnet wie Datura, Hyoscyamus, Tabacum, Mandragora, Belladonna, Dulcamara, Cannabis, während Orobus, 'Calendula, Nerium, Viola und Tilia die Ordnung debiliora bilden. $\mathrm{Zu}$ den graveolentia acria fortiora gehören Valeriana major et minor, Iris, Jalapa, Colchicum, Paeonia, Aconitum usw., zu den debiliora Assa foetida, Coriandrum, Anethum, Allia u. a. Die graveolentia amara fortiora bestehen unter anderen aus Nux vomica, Aloe, Rhabarbarum, Senna, Colocynthis usiv.; zu den debiliora gehören Tanacetum vulgare, Absinthium, Lupulus, Laurocerasus u. a. Ein großer Teil der graveolentia sind soporifera, narcotica, anodyna, während andere repellentia und purificantia sind. Sie wirken teils auf die Gefühls-, teils auf die Bewegungsnerven.

In einer späteren Arbeit, „Medicamenta purgantia“ (1775), werden ferner die verschiedenen Gruppen der Graveolentia behandelt, welche zunächst angewendet werden, um die Entleerungen des Körpers zu befördern. Zum größten Teil gehören sie der Ordnung nauseosa an und werden nach ihren physiologischen Wirkungen in Vomitoria, Purgantia proprie sic dicta, Diaphoretica, Diuretica, Emmenagoga, Sialagoga und Sternutatoria eingeteilt. Die eigentlich abführenden Heilmittel werden am besten als Drastica, Eccoprotica und Purgantia proprie sic dicta unterschieden. Drastica sind nur in schweren Fällen zu verwenden, wie bei Geisteskranken, Konvulsionen usw., wo

I) „Deberent vestrates medici Wiennenses, qui omnia tentant in morbis desperatis, et imprinis tentare, quid hae duae plantae (Cleome gigantea et Lobelia longzlora) valerent", schrieb Linné an N. J. Jacquin in einem Brief vom 9. Okt. 1769.

Hjelt, Carl von Linné. 
nur starke Mittel wirken, und auch hier nur vorsichtig von einem erfahrenen Arzte (suspensa manu atque a peritissimis artis magistris). Dahin gehören Veratrum, Colocynthis, Elaterium. Eccoprotica sind die gelindesten, geeignetsten lösenden Mittel, besonders für kleine Kinder, Wöchnerinnen und schwache Personen, z. B. Polypodium, Pruna, Agaricus, Tamarindus, Manna. Von den eigentlichen Purgiermitteln gibt es eine große Menge. In dieser Abhandlung wird die Ansicht ausgesprochen, daß abführende Mittel nicht nur zu benutzen sind, um aus dem Darmkanal unverdaute Sammlungen (saburra), durch deren Gärung und Verderben Krankheiten entstehen, zu entfernen, sondern auch um das Streben der Natur, den Körper und besonders die Blutmasse von schädlichen und überflüssigen Stoffen zu befreien, zu unterstützen. Die Natur führt es um so leichter durch, wenn ihr dabei die Kunst zu Hilfe kommt, und wenn ihr ein Ausweg geöffnet worden ist, scheidet sie ohne Schwierigkeit alles das ab, was für sie nicht geeignet ist. Die Natur strebt stets danach, den Krankheitsstoff nach einer angegriffenen Stelle zu transportieren ${ }^{1}$. Rhamnus Frangula wird besonders gepriesen, obwohl diese Rinde zu jener Zeit mehr vom Publikum als von den Aerzten gebraucht wurde; ihre Wirkung sei zuverlässig, und sie könne ohne alle Vorsichtsmaßregeln verwendet werden. Der Rhabarber ist ein Tonicum bei Schwächezuständen im Magen und Darmkanal und wirkt auf die Leber ein, weshalb Tinctura (anima) rhei von den älteren Aerzten "anima hepatis“ benannt wurde. Von einheimischen Pflanzen, welche lösende Eigenschaften besitzen und als Ersatz für die viel teuereren ausländischen Heilmittel dienen können, werden außer Rhamnus Frangula auch Rh. catharticus, Linum catharticum, Eupatorium cannabinum, Genista tinctoria, Prunus spinosa, Berberis vulgaris, Convolvulus sepium, Valeriana officinalis, Bryonia alba, Sambucus ebulus (purgans hydragogum), Lichen aphthosus (Flor. Svec. 1098) 2) usw. angeführt. Von kultivierten Pflanzen, welche das Klima vertragen, werden erwähnt Gratiola officinalis, Asarum europaeum, Rheum palmatum, Mirabilis longiflora, Momordica elaterium.

Die therapeutische Anwendung von Mentha (zunächst crispa, piperita, sylvestris und pulegium) ist Gegenstand einer besonderen Abhandlung (1767). In dieser Arbeit entwickelt $L$ in né noch weiterhin seine Ansicht über den Geruch der Pflanzen. Mentha, die zu den Resolventia und Antaphrodisiaca gerechnet wird, findet mit

1) "Qua data porta, incongrua ista felicius exterminat natura. Illa enim ad locum affectum materiam deducere studet morbosam."

2) Purgantia indigena (1766). 
Nutzen bei entzündlichen Krankheiten und besonders bei verschiedenen nervösen Zuständen Verwendung. Jede Entzündung ist von einem schmerzhaften Gefühl begleitet, denn „die gespannte, beinahe reißende Faser schmerzt". In entzündlichen Krankheiten wird daher Mentha verwendet, un die Tätigkeit der Nerven zu belcben, welch letztere die Entzündung löst und den Schmerz aufhebt. Auch die Fasern, welche ihre Elastizität verlieren, wenn sie nicht unter dem Einfluß der Nerven stehen (nisi a nervis animatae), erhalten bei Benutzung von Mentha ihre Spannkraft wieder. Auf diese Weise kann man die Wirkung der Carminativa, unter denen Mentha einen hervorragenden Platz einnimmt, bei Kolikschmerzen und Blähungen im Darmkanal, besonders bei kleinen Kindern, wenn die Fasern in den Wandungen des Darmkanals erschlafft sind, erklären. Mentha beugt der Säurebildung bei Ammen vor und soll die Milch- und Käsebildung vermindern, sowie mit Nutzen bei Hysterie, die oft auf Störungen in den Geschlechtsorganen beruht, bei unterdrückten Lochien usw. zu verwenden sein, entweder zum Waschen des Bauches oder als Infusion oder Klystier, bei Brustgeschwüren usw. Mentha soll auch Unfruchtbarkeit verursachen, weshalb Aristoteles den Rat gab: „mentham tempore belli nec edito nec bibito", „denn was libido vernichtet, vernichtet auch courage".

Nachdem Linné von Oberstleutnant Carl Gustav Dahlberg (in Surinam ansässig) die Quassia-Rinde erhalten hatte, führte er sie in die Therapie unter den bitteren tonizierenden Mitteln bei der Behandlung intermittenter und exacerbierender Fieber ein, welch letztere nach Linnés Ansicht nichts anderes als intermittente Fieber sind, obgleich bei den verlängerten und ständigen Paroxysmen der eine Anfall endet, wenn der andere beginnt. Remittente oder exacerbierende Fieber nehmen oft zu Anfang des Frühlings und im späteren Teil des Sommers den intermittenten Typus an. Linné schlug vor, daß die Apotheker sich Quassia aus ihrem Heimatlande kommen lassen sollten und schrieb darüber:

„Ich habe radix Quassiae gegen das Upsalaer Fieber versucht; sie hat nicht ihresgleichen" ${ }^{1}$ ).

Mehrere andere Pflanzen wurden zu Linnés Zeiten unter die Anzahl der Arzneimittel aufgenommen. So empfahl er Folia uvae ursi, Cortex frangulae, Elaterium und Gummi gutta auf Grund seiner

1) Brief an Abr. Bäck vom 22. März 1763. Liggnum Quassiae (1763). Der Quassiabaum erhielt seinen Namen nach einem Neger Kwassi, der Dablberg seine medizinische Eigenschaft entdeckte. 
Erfahrung im Marine-Krankenhaus. Eine Infusion von den Blättern von Linnaea begann gegen Rheumatismus angewendet zu werden, und L in né sagt, er habe diese Pflanze gegen die genannte Krankheit ebenso spezifisch gefunden, wie Chinarinde gegen Wechselfieber, worüber er schreibt: „In nosocomiis classis navalis, quorum medicus primarius sum, innumeris casibus expertus sum vires plantae, quam $L$ in n a eae nomine indigitavit Gronovius, eamque certo Rheumatismum tollere, si per octiduum propinetur foliorum infusum, ac China in febribus“" ${ }^{1}$.

Schon in älteren Zeiten spielten bekanntlich die bei Menschen vorkommenden Eingeweidewürmer eine große Rolle in der Pathologie, weil man in ihnen eine wichtige Ursache von allerhand krankhaften Störungen und die Quelle mancher Leiden erblickte. Besonders während des 18 . Jahrhunderts wurde eifrig nach Wurmmitteln gesucht, und das eine Mittel nach dem anderen kam in Gebrauch. So z. B. kam das teuer bezahlte $\mathrm{Nuffer}$ sche Mittel (Filix mas) allgemeiner erst ungefähr in den 1770-er Jahren in Aufnahme. Etwas früher stellte Linné Versuche mit der von Brown auf Jamaika gefundenen "Spigelia Anthelmia" an, die er in dem Upsalaer botanischen Garten kultivierte. Da diese Pflanze eine sorgfältige und mühevolle Behandlung erfordert, rät er jedoch, sie aus den Gegenden $z u$ beziehen, wo sie einheimisch ist. Lin né verwandte sie als Dekokt und beschreibt ihre Anwendung und Zubereitung ${ }^{2} \%$. Gegen welche Art von Würmern Spigelia sich wirksam erwiesen hat, wird nicht erwähnt, wohl aber heißt es: „Würmer werden damit in großer Menge ausgetrieben. Wenn nicht sofort, so wenigstens nach Anwendung

I) Brief an Bernh. de Jussieu vom 5. Febr. 1740, abgedruckt in Memoirs of the American Academy etc., Vol. V, S. I90. Dieseiben Bemerkungen kommen in einem Brief an Sauvages vom 21. Jan. 1740 und in einem von 1762 vor, worin erwähnt wird, daß Linnaea in allen dänischen Apotheken vorrätig gehallen wird. Die von Gronovius nach Linné benannte Pflanze erhielt gleichzeitig den Namen Obolaria von dem Petersburger Professor Si egesbeck, der gleichfalls gefunden hatte, daß sie eine neue Gattung bilden müßte.

2) Spigelia Anthelmia (1758). Das Rezept war folgendes: Rec. Herb. Spigeliae manip. ii coque in Aq. font. lib. ii, colaturae exhibe lib. i, cui adde sacch. f. Limon. q. s. pro grato sapore. S. Dosis unc. IV (pro adulto), repetenda 6 s. I 2 quavis hora, per triduum. - An Sauvages schriel, Linné über Spigelia am 22. April 1756 und ferner 1762: „Ich habe von London echte Spigelia in trockenem Zustande für meine Töchter bekommen, die an Würmern leiden." Auch unter dem Publıkum verbreitete sich die Kenntnis der Spigelia und das Vertrauen zu ihr. In Inrikes Tidningar 1768 , No. 85 findet man eine Bitte an die Herren Aerzte um Angabe der rechten Art und Weise, das Kraut Spigelia als Mittel gegen Würmer zu gebrauchen. Antworten auf diese Anfrage finden sich in No. 87 (zwei Antworten) und in No. 88, sowie ferner in derselben Zeitung 1770 , No. 70 . 
eines Abführmittels. Oft gehen ungefähr einhundert auf einmal ab." - In den oben erwähnten Aufzeichnungen über Clavis medicinae wird berichtet, daß Linné „stets mit Vorteil semina Hyperici (perforati) zu seinen Wurmpulvern hinzugemischt hat".

Den Gebrauch von Senega, als ein gutes Expectorans bei der Behandlung von Brustkrankheiten, führte Linné in Schweden ein und teilte besondere Fälle aus der Praxis mit, in denen dieses Heilmittel eine augenfällige Wirkung gehabt hat. Bemerkenswert ist, daß er auf Grund von in Amerika gemachten Erfahrungen Senega gegen Schlangenbiß empfiehlt. Als entsprechende Pflanze in der schwedischen Flora wird Polygala vorgeschlagen ${ }^{1}$.

Als Volksmittel gegen Lungenschwindsucht und andere Brustkrankheiten stand Hypericum (perforatum) in älteren Zeiten in sehr hohem Ansehen. In seiner Abhandlung "Hypericum" berichtet C. N. Hellenius, Linné selbst habe erzählt, wie bei einem Besuch auf Drottningholm gelegentlich einer Diskussion über die Krankheiten, gegen welche die Bemühungen des Arztes vergeblich sind, alle darin einig waren, daß die Lungenschwindsucht zu ihnen gehörte. Nur einer der Anwesenden war anderer Meinung und erzählte, daßo seine Mutter mittelst eines von ihr aufbewahrten Rezeptes mehr als hundert Schwindsüchtige von ihrem Tode errettet habe (ultra centum phthisicos ex orci faucibus eripuisse). Er versprach, bei Gelegenheit das Rezept zu zeigen. Und es stellte sich heraus, daß es ein von Linné während seiner Reise in Wästergötland ausgefertigtes, sorgfältig aufbewahrtes und vielbenutztes Rezept war. Es lautete folgendermaßen: Summit. Hyperici (perf.) manip.; coque in Vin. hisp. libr. IV ad tert. part. remanentiam. Cola, Dr. Sr. Hiervon ein halbes Quartier morgens und abends einzunehmen ${ }^{2}$ ).

Es ist bekannt, daß Linné großes Vertrauen zu Walderdbeeren als Heilmittel gegen Podagra hegte. In biographischen Arbeiten über ihn werden sogar einzelne, mit dieser seiner Neigung zusammenhängende Episoden berichtet. Interessant ist es zu lesen, was er

1) Radix Senega (1749). Brief an Sauvages vom 24. Febr. 1756. In der Abhandlung "Specifica Canadensizım" (1756), S. 28 schreibt Linné es denı Gebrauch von Senega $z \mathbf{u}$, daß er von einer Peripneumonie wiederhergestellt wurde, und in der Disputation "De Morsura Serpentum" (I762) wird S. I7 erwähnt, daß er eine Frau vor den Folgen eines Schlangenbisses durch die Anwendung von Senega in Pulverform gerettet habe.

2) Hypericum (I776). Diese akademische Abhandlung ist die letzte, die Linnés Namen trägt, und wurde von dem Finnländer Carl Niclas Hellenius (af Hellens) zur Erlangung des medizinischen Doktorgrades verteidigt. Linné konnte aus Gesundheitsrücksichten nicht mehr bei dem Alite anwesend sein. 
selbst über seine jährlich wiederkehrende Erdbeerkur mitteilt. Er schreibt darüber:

Als ich zum ersten Mal (I750) von Podagra geplagt wurde und seit I3 Tagen nicht geschlafen hatte, erhielt ich zwei Pfund (libra) Walderdbeeren; ich kostete davon und sie schmeckten gut (gustavi et sapiebant); ich verzehrte sie und schlief sechs Stunden; als ich erwachte, fühlte ich nicht den geringsten Schmerz, ausgenommen eine gewisse Steifheit im Fußgelenk; ich verzehrte wieder dieselbe Dosis, schlief wieder ein und war frei von jedem Schmerz. Ich verzehrte nun täglich acht liber Erdbeeren während eines ganzen Monats, und nie sind meine Füße besser gewesen. Als ich im folgenden Jahre infolge eines Irrtums in meiner Diät ein liber nicht allzu besten Wein trank, begannen meine Füße wieder zu schmerzen; an folgenden Tage war ich meine Schmerzen los, nachdem ich Erdbeeren gegessen hatte." - „Jeden Sommer habe ich 24 Tage lang Walderdbeeren mit etwas Zucker oder frischer, nicht gekochter Milch zu essen gepflegt, und zwar viermal täglich, fast ohne während dieser Zeit eine andere Speise $\mathrm{zu}$ genießen. So habe ich täglich mindestens ein bis zwei Kannen (cantharus?) verzehrt. Es ist dies meine hauptsächlichste Medizin gewesen, mit Erstaunen habe ich gesehen, wie bei dieser Ernährung der "tartarus"1) sich von den Zähnen löste, wie dieselben rein werden, die Haltung des Körpers aufrechter wird, die Gesichtsfarbe wiederkehrt und alle Verhärtungen im Körper aufgelöst werden. Der Duft der Walderdbeeren belebt die Nerven. Ihr wasserhaltiger und leicht saurer Saft verdünnt das Blut und löst den "tartarus", nicht aber die Fasern, wie sonstiges Obst es durch seine Säure tut, was ja allen Säuren eigentümlich ist. Wenn Sie Walderdbeeren in hinreichender Menge in Ihrem Vaterlande erhalten können, verzehren Sie dieselben nach gleicher Methode, und ich verspreche Ihnen, daß Ihre Kräfte wieder hergestellt werden, und daß aller "tartarus" in Ihrem Körper aufgelöst werden wird.

Ich habe auf verschiedene Weisen diese Beeren für den Winter zu konservieren gesucht, aber vergebens, weder als Konserven, Syrup oder eingemacht (condita) behalten sie ihren Geschmack und Geruch; sie entbehren nämlich der feinen Haut, welche andere Früchte umgibt.

Walderdbeeren wurden früher in Upsala für ein viertel Taler verkauft. Nun wollen alle Arthritici sie haben, und ich muß sie achtmal teuerer, mit drei Talern bezahlen" ${ }^{2}$ ).

Unter den Drogen, deren Einführung in die Medizin Linné sich als ein besonderes Verdienst zurechnet, befindet sich Solanum Dulcamara. Diese bereits von Boerhaave benutzte Pflanze gewann Linnés besonderes Vertrauen während seiner Dienstleistung am Admiralitätskrankenhaus in Stockholm. Es gibt keine Pflanze in der ganzen Materia medica, bemerkt er, die diesen Mittel bei der Behandlung von Gicht, Skorbut, Gelbsucht und Rheumatismus gleich-

I) Ein in der älteren Chemie verwendeter Ausdruck für den Rückstand bei gewissen chemischen Prozessen, eine Art Schlacke.

2 Brief an Sa uvages 1753, vom 15. Jan. I754 und 1762. 
gestellt, viel weniger denn vorgezogen werden kann ${ }^{1}$. Linné gebrauchte Dulcamara mit großem Erfolg bei Syphilis und ihren Folgen und berichtet selbst, wie ein schwedischer Edelmann, welcher meinte, er könnte in seinem eigenen Lande von dieser Krankheit nicht befreit werden, nach Südfrankreich reiste, um sich bei Sauvages Rats zu erholen, und von diesem die Weisung erhielt, Dulcamara zu benutzen, in Uebereinstimmung mit dem, was Linné ihn gelehrt hatte und er selbst aus seiner eigenen Erfahrung bestätigen konnte. Die Behandlung von Syphilis mit vegetabilischen Heilmitteln war überhaupt eine Frage, die in hohem Grade Linné interessierte. Er schreibt an Bernhard de Jussieu:

„Nächstes Jahr wird Kalm von Amerilka zurückkehren. Er hat bei den Indianern ein höchst merkwürdiges Heilmittel entdeckt, nämlich ein Spezifikum gegen die venerische Krankheit, das er als ein nie versagendes Mittel preist. Kranke, die von dieser Krankheit fast aufgefressen waren, wurden innerhalb IO-I6 Tagen vollständig geheilt, und zwar ohne jede Beschwerde oder Schmerz, während viele, die mit der gewöhnlichen Quecksilberkur behandelt werden, während der Kur sterben. Dieses neue Heilmittel heilt dagegen die Krankheit ohne Rezidiv, ohne jede Schwierigkeiten und fast ohne Beobachtung einer besonderen Diät. Wenn Ihr Helvetius diese Medizin entdeckt hätte, hätte er sicher von Ihrem König ganze Berge Gold erhalten ${ }^{2}$ ). Dieses Heilmittel ist eine Infusion von den Wurzeln von Ceanothus americanus, zu welcher man, wenn die Krankheit sehr eingewurzelt ist, die Wurzel von Ranunculus fol. subrotundo virginicus, flore parvo Herm. Lugdh. 5 I4 (Ranunculus abortivus L.) hinzufügen muß. Diese Infusion oder ein schwaches Dekokt verzehrt man am Morgen auf nüchtemen Magen; sollte das Mittel stark abführend wirken, so benutze man es an den folgenden Tagen in kleinerer Dosis und schwächerer Infusion. Da die Wurzel von genanntem Ranunculus den Magen angreift, muß man sie in sehr kleiner Dosis anwenden. In gelinderer Form der Krankheit verschlagen die Wurzeln von Lobelia secunda Hort. Cliff. (Lobelia syphilitica) in Infusion oder schwachem Dekokt, täglich getrunken" " ${ }^{3}$.

I) De Dulcamara (177I). „Dulcamara ist erfahrungsgemäß besonders (spezifisch) wirksam in Lochiis retentis, Arthritide vaga, Rheumatismus; nur besteht der Uebelstand, daß sie den Magen belästigt und Ekel erregt, etwas laxiert und den Appetit benimmt, besonders im Anfang, ehe man sich daran gewöhnt hat; mit Milch getrunken, belästigt sie weniger." Brief an Abr. Bäck vom 21. Nov. 1746. Vgl, auch Linnés Bemerkung über Dulcanara in Egenhändiga Anteckningar, S. 204.

2) Bezieht sich auf die Belohnung von 1000 Louisdor, die der Holländer Joh Hadrian Helvetius 1686 von $\mathrm{Ludwig}$ XIV. für die Einführung der Ipecacuanlawurzel in die Pharmazie erhielt.

3) Brief aus Upsala 1750 (ohne Datum), abgedruckt in Memoirs of the American Academy etc. - In den Abhandlungen der Schwedischen Akademie der Wissenschaften 1750 findet sich von P. Kalm ein Aufsatz: ,Lobelia såsom ett säkert botemedel mot veneriska sjukan" ("Lobelia als ein sicheres Heilmittel gegen die venerische Seuche"), S. 280. 
Hierauf antwortete Jussieu:

„Kalmius alter discipulus pretiosam ex America mercedem tibi renuntiavit, specificum Indorum sylvestrium adversus luem veneream, medicamentum nobile experimentis et observationibus saepe confirmatum, cujus vires eximiae probantur facili medicatione, et prompta morbi hujus curatione. Optandum superest, ut eosdem salutares apud nos sortiatur effectus, medicina aegris tantopere utilis" 1 ).

Scherzhaft schreibt Linné über die fragliche Pflanze an seinen Freund Abr. Bäck:

„Ich bin recht besorgt um Ceanothus, seitdem ich von $\mathrm{Kalm}$ seine Kraft erfahren, und habe dem Gärtner befohlen, täglich nach ihm zu sehen, damit ich imstande sei, Dir, lieber Freund, zu dienen, wenn ein Unglück eintreffen sollte. Aber ich habe nicht mehr als drei Pflanzen; sobald Du verheiratet bist, bin ich die Sorge los" 2 ).

Mehrere Bemerkungen zeigen, daß Linnés Interesse an der Behandlung venerischer Krankheiten nicht nachließ $\left.{ }^{3}\right)$. Vielleicht waren es die Erinnerungen an die erste Zeit seiner ärztlichen Praxis, die dabei wirksam waren. Aus seinen Vorlesungen ersieht man, daß er seinen Schülern eine spezielle, ins einzelne gehende Schilderung von den venerischen Krankheiten und ihrer Behandlung gab. Unter anderem beschreibt Linné, wie das Initialstadium der Syphilis „mit Jucken an der angesteckten Stelle beginnt, welche sich zu röten und anzuschwellen anfängt, wonach ein kleiner Fleck mit Schuppen in der Umgebung entsteht, der sich immer naß hält und um sich frißt, und einen grüngelben, zähen Eiter bildet". Danach wird die Entwicklung der Krankheit in anderen Organen mit ihren verschiedenen Formen beschrieben. Unter den Wegen der Uebertragung des Ansteckungsstoffes werden Küssen, Säugen, gemeinsamer Gebrauch von Instrumenten zum Aderlaß und Schröpfen erwähnt, „soviel steht aber fest, daß Syphilis nur „per contactum humidum“ ansteckt. Die Behandlung der Syphilis besteht in dem Gebrauch von Lignum sanctum s. Guajaci während eines Monats und Schwitzen, „wonach die Kraft des Giftes verschwunden sein soll, das geht aber nicht gut in unserem kalten Klima, wenn das Gift lange eingewurzelt ist". Mercurialia in Form von Strikade mit Unguentum neapolitanum oder Pillen von Mercurius dulcis (Calomel) wurden daher als die zuverlässigsten Mittel angesehen. Die Anwendung der Schmierkur, welche der Kranke selbst vorzunehmen hatte, wird im einzelnen beschrieben. -- Die

1) Brief an Linné, dat. Paris, den 19. Febr. 175I, a. a. O., S. 218.

2) Brief 1751 .

3) Vergl. oben S. I 1, I 2. 
Gonorrhöe wurde teils mit Balsamica, teils örtlich mit Solut. sacch. saturn. und Decoct. herb. Equiseti oder auch Calomel zur Injektion behandelt.

In Linnés Briefwechsel mit Abr. Bäck stößt man auch auf einige diesbezügliche Mitteilungen:

„Mein Remedium gegen morbos syphiliticos ist im Auslande probiert worden und hat sowohl in siphilitide vera wie in gonorrhoea ungemeinen Erfolg gehabt" 1). "Ich habe num den dritten Bericht von Frankreich erhalten, daß mein Mittel gegen Franzosen, das ich einem Einzigen unter dem Eid kommuniziert habe, in dem größten Nosocomium versucht worden ist; daß es prompt Franzosen kurierte, ohne zu versagen, ohne Schmerz oder Evakuation zu verursachen, und daß Franzosen in 14 Tagen kuriert werden, Gonorrhoea aber geht langsamer als selbst die Franzosen, doch sicher. Ich hoffe, praemium zu erhalten, wenn ich es prïstieren kann“" 2).

Noch 1759 schreibt Linné an J. Rothman: „Gegen die venerische Krankheit wird nun beständig die Tinktur von mercurio sublimato mit großartigem Effelit gebraucht", und im selben Jahre an Sauvages: „Mit der Syphilis ist es eine eigentümliche Sache; ich möchte fast glauben, daß alle Gifte diese Krankheit heilen“"3). Es sei hier erwähnt, daß Li n né in seiner „Wästgötaresa“ („Reise durch Wästergötland"), S. 157, von dem im Volke herrschenden Vorurteil berichtet, daß man sich von venerischer Krankheit dadurch befreien kann, daß man einen anderen ansteckt. Lin né schlägt vor, daß eine Strafe für den festgesetzt werden soll, der sich dessen schuldig macht.

Sowohl in Linnés Flora Lapponica und Svecica als in seiner Öländischen und Gotländischen, Schonischen und Wästgötischen Reise finden sich eine Menge interessanter und wertvoller Angaben über das Vorkommen von Krankheiten an verschiedenen Orten, über die Anwendung einheimischer Pflanzen in der Medizin und über bei der Landbevölkerung gebräuchliche Hauskuren. Infolge dieser Beobachtungen wurden mehrere einheimische Drogen zur Benutzung in die Heilkunde aufgenommen, und auf Grund dessen entwickelte sich zum Teil die schwedische Volks- oder Hausmedizin mit ihren Volksschriften und zahlreichen sog. „Hausund Reiseapotheken" ${ }^{4}$ ), die in einem dünnbevölkerten Lande mit seinen wenigen und weithin zerstreut wohnenden Aerzten von so großem Nutzen gewesen sind und soviel Segen gebracht haben.

I) Brief vom 29. Jan. I $75 \mathrm{I}$.

2) Brief vom 18. Mai 1753 .

3) Brief an Sauvages vom 8. Aug. 1759.

4) O. E. A. Hjelt, Svenska och Finske Medicinalverkets Historia 1663-1812 II, S. $223-235$. 
Daß Linnés Tätigkeit in dieser Hinsicht von außerordentlicher Bedeutung für sein Vaterland gewesen ist, kann man aus mehr als einem Blatt in dieser Arbeit herauslesen.

Für die Entwicklung dieser |volkstümlichen Heilkunde interessierte sich Linné aufs höchste, und man kann sagen, daß er einer ihrer wirksamsten Förderer war. Er hielt sogar besondere Vorlesungen über diesen Gegenstand.

„Gegenwärtig“, schreibt er, „,bin ich damit beschäftigt, in öffentlichen und privaten Vorlesungen Materia medica zu behandeln, und ich lehre meine Studenten das Volk mit Medizin zu behandeln, die nichts kostet" 1). „Da das Volk die Apotheke flieht, wo oft das Leben teuer erkauft wird, sollten besonders die Geistlichen es lernen, die gewöhnlichsten Krankheiten mit der Medizin zu kurieren, die ohne Kosten vor der Tür eines jeden wächst.“

Linné hielt besondere Vorlesungen hierüber für angehende Geistliche. Aufzeichnungen aus diesen Vorlesungen finden sich noch erhalten ${ }^{2}$. Als Linné von der Akademie der Wissenschaften aufgefordert wurde, zur Anleitung der Geistlichen bei der Aufstellung der statistischen Sterblichkeitstabelle Vorschläge zur Benennung der Todesursachen mit schwedischen Namen zu machen, schreibt er im Dezember 1746 an den Sekretär der Akademie, Pehr E1vius:

„Ich wäre wohl willens und imstande, ein solches Verzeichnis zu geben, wenn ich sähe, daß etwas durch meine Arbeit ausgerichtet würde. Aber glauben Sie mir sicher, man wird nie hierdurch zum Ziel gelangen, denn wenn und solange die Studenten, die später Geistliche werden, nicht in der Akademie während all der Zeit, die sie dort auf die Weide gehen, 30 Stunden daran setzen können, um alle Krankheiten um ihres eigenen Lebens willen kennen zu lernen, hat man weit weniger $z u$ hoffen, daß sie es später lernen, wenn sie Pfarrer werden. Würde daher den Studenten angeraten, hieran einen einzigen Termin $z u$ wagen, eine Stunde täglich viermal die Woche, so würde man in einigen Jahren Geistliche bekommen, die dies mit Vergnügen und Sicherheit werden tun können, ohne Beschwerden zu haben."

Ein besonderes Verdienst um die Entwicklung der Pharmakodynamik hat sich Linné dadurch erworben, daß er klar aussprach,

I) Brief an Abr. Bäck vom I9. Nov. I754.

2) „In usum Theologorum studiosorum föreläsningar om sjukdomars kjennande hållne privatim uti 12 lectioner" (,Vorlesungen über die Erkennung von Krankheiten in usum Theologiae studiosorum, privatim in I 2 Lektionen gelalten"), Herbstsemester 1759. Siehe Carl von Linnés Svenska arbeten $i$ urval och med noter utgifna af Evald Aehrling, I, I 879, S. 177 , I80. - O. E. A. Hjelt, Svenska och Finska Medicinalverkets Historia $1663-1812$, II, S. 268. 
was man unter Gift im Verhältnis zu anderen Medikamenten zu verstehen habe, und daß er den stark wirkenden Mittcln ihren gebührenden Platz in der Therapie anwies. Viele Aerzte enthielten sich zu jener Zeit der Verwendung sog. venena, da es nicht klar war, was darunter eigentlich $\mathrm{zu}$ verstehen war. Unsere Heilmittel gegen Krankheiten, sagt Linné, sind teils Nährstoffe, teils Gifte (toxica); die ersteren erhalten die Gesundheit dadurch, daß sie die Körperkräfte unterhalten, die letzteren stellen sie dadurch wieder her, daß sie den Organismus verändern, Durch Zumischung der Flüssigkeiten des Körpers und durch die Tätigkeit der Eingeweide werden die Nahrungsmittel so verändert, daß sie die Natur dieser Flüssigkeiten annehmen, die Toxica dagegen führen deutliche Veränderungen im Zustand und in der Zusammensetzung des Körpers herbei. Das, was ohne schwereren Eingriff in die Funktionen den Körper verändert, nennt man Medikamente; das, was die Funktionen schädigt und aufhebt, oder die im Körper vor sich gehenden Lebensbewegungen zerstört, wird Gift genannt ${ }^{1}$ ). Die Grenze zwischen ihnen jedoch ist nicht bestimmt, und sie unterscheiden sich oft nur durch die Mengen, in welchen sie verwandt werden und durch den Grad ihrer Wirkung. Das schärfste Gift kann so als ein Heilmittel wirken, wenn es in kleiner Dosis angewandt wird, und ein Heilmittel kann in großer Dosis die Natur des Giftes annehmen. Sogar Nährstoffe, im Uebermaß genossen, werden uns schädlich \%). Man muß sich auch erinnern, was toxische (giftige) Gewächse betrifft, daß sie nicht immer ihrer ganzen Substanz nach giftig sind, sondern daß ihre Eigenschaft als Gift an gewisse Teile derselben gebunden ist. Die rastlose Arbeit der Aerzte ist auf die Erforschung dieser Teile gerichtet, denn wenn es gelingt, ihre Natur und ihr Verhältnis zueinander festzustellen, wird unsere Vorstellung von den Wirkungen der Medikamente allmählich zur Klarheit gelangen. Es ist daher notwendig, seine Zuflucht zur Chemie zu nehmen, als der Wissenschaft von dem inneren Grunde der Naturkörper (utpote scientia principiorum corporum naturalium ${ }^{3}$ ).

Man hat, sagt Lin né, eine scharfe Grenze zwischen Heilmitteln und Giften ziehen wollen und gemeint, daß die Gifte sogar in kleinen Dosen den Körper zerstören, dies ist aber ein Vorurteil. ja ein Irrtum, der aus der Wissenschaft entfernt werden muß (tamquam noxiam

I) Sapor medicamentorum $(175 \mathrm{I})$.

2) Lignum Colubrinum (1749). Derselbe Satz findet sich, außer an vielen anderen Stellen, auch in "Materia medica", Canon 17 ausgesprochen.

3) De methodo investigandi vires medicamentonum chemica (1754). 
haeresin e medicorum territorio eliminandam censemus). Denn kein verständiger und kundiger Arzt darf fürchten, je nach den Umständen Gifte in geeigneter Proportion und Dosis zu verschreiben. ,Medici sollten sie nicht verurteilen. sondern sie, wie die Chirurgi ihre Messer, vorsichtig gebrauchen." Dagegen können die vortrefflichsten Heilmittel in der Hand des Unkundigen wie ein Schwert in der Rechten eines Wahnsinnigen werden (medicamina heroica, in manu imperiti, sunt uti gladius in dextra furiosi). Wenn Linn é den Satz aussprach, daß die widerwärtigsten Gifte (venena teterrima), wenn sie recht gebraucht werden, uns die vortrefflichsten Heilmittel liefern, vertrat er die Sache der Wissenschaft und der Erfahrung. „Ich kann nicht sagen“, bemerkt er selbst, „welch großen Nutzen ich von diesem Lehrsatz bei der Erörterung der wichtigsten und schwierigsten Lehren der medizinischen Wissenschaft gehabt habe" ${ }^{1}$ ).

In einer der letzten der medizinischen Abhandlungen, die Linnés Namen tragen, „Canones medici“ (1775), werden die allgemeinen therapeutischen Ansichten, die sich aus diesem System ergeben und der praktischen Handlungsweise zugrunde liegen müssen, unter folgenden Gesichtspunkten zusammengefaßt: Die Natur ist der beste Arzt. Gegen die Natur vermögen die Heilmittel nichts. Wohin die Natur strebt, muß sie geleitet werden, und wenn sich ein Ausweg für sie öffnet, wählt sie ihn. Zwei Arten von Entleerungen können kaum gleichzeitig bestehen. Ein Schmerz vertreibt einen anderen. Jede Absonderung wirkt schwächend. Gifte heilen, Nährstoffe unterhalten den Körper. Die Natur entfernt außer dem Gift auch andere unreine Stoffe. Die schärfsten Gifte werden, wenn sie auf zweckmäloige Weise in kleinen Dosen benutzt werden, die wirksamsten Heilmittel. Die Gewohnheit schwächt die Wirkungen der Heilmittel ab. Ihr ständiger Wechsel verrät Unwissenheit. Die Wirkung der Heilmittel steht zur Krankheitsart, selten zur Krankheitsgattung in Beziehung, wird durch Geschmack und Geruch bestimmt und durch die Erfahrung bestätigt. Wer entgegengesetzte Stoffe miteinander mischt, ist ein Idiot. Die Gegensätze heilen ihre Gegensätze, die eine Krankheit die andere. Wo nur ein einziger Ausweg zur Rettung vorhanden ist, muß man, auch wenn er gefährlich ist, ihn versuchen. $\mathrm{Zu}$ rechter Zeit verwendet, hat das Heilmittel seine Wirkung, und bei richtiger Gelegenheit nützt es.

Außer den bereits erwähnten Schriften von Linné, soweit sie Gegenstände aus dem Gebiete der Pharmakologie und Pharmako-

1) Medicamenta sraveolentia ( 1758$)$. 
dynamik behandeln, finden sich noch eine Menge unter seinem Präsidium erschienener akademischer Abhandlungen, die alle mehr oder weniger diese Gebiete berühren und von dem Interesse Zeugnis ablegen, das er bei den jüngeren Ausübern der ärztlichen Kunst für derartige Untersuchungen zu erwecken verstanden hat. Wie die übrigen bereits angeführten Disputationen, sind sie auf Aufzeichnungen bei seinen Vorlesungen gegründet und von ihn durchgesehen worden. $\mathrm{Da}$ sie jedoch keine wichtigeren Beiträge zu der bereits gegebenen Schilderung von $\mathrm{L}$ innés medizinischer Tätigkeit enthalten, seien sie hier nur aufgezählt. $\mathrm{Zu}$ ihnen gehören: Ficus ejusque historia naturalis et medica (1744), Euphorbia ejusque historia naturalis et medica (1752), Rhabarbarum (1 752 ), Consectaria electrico-medica (1753), Fungus Melitensis (1755), De Cortice peruviano (1758), De Meloe vesicatorio ( 1762 ), De Hirudine ( 1764$)$, Opobalsamum declaratum (i 764 ), De Fraga vesca (1772), Planta Cimicifuga (1774), De Maro (1774), Opium (1775).

\section{IV.}

Im vorhergehenden ist, wie Verfasser hofft, Linnés vielseitige Arbeit auf dem Gebiet der Heilkunde in das rechte Licht gestellt und seinen Schriften der ihnen gebührende Platz in der Geschichte der Wissenschaft zurückgegeben worden. Wir haben gesehen, wie Linné in größeren und kleineren Abhandlungen die Erzeugnisse seiner fleißigen unermüdlichen Feder niedergelegt hat. Eine systematische Zusammenfassung seiner medizinischen Studien, Erfahrungen und geistvollen Hypothesen hat er uns jedoch nicht hinterlassen. Clavis Medicinae ist die einzige von Linnés Schriften, in der er eine kurze Uebersicht über seine medizinischen Theorien sowohl in ihrem gegenseitigen Zusammenhang, wie im Verhältnis zur Therapie und zu der von ihm sog. „Diät" (Diätetik) gegeben hat.

Die Uebertretung der Vorschriften der Diätetik ruft Krankheitszustände hervor, die mittelst der Kenntnis der in der Natur enthaltenen heilenden Kräfte nach Anweisung der praktischen Erfahrung bekämpft werden müssen. Die für Linné eigentünliche Theorie von dem Gegensatze zwischen der Natur und den Ursachen der Krankheiten und den gegen sie angewendeten Heilmitteln bildet den leitenden Gerlanken in dieser Arbeit. Gegrenüber jeder der oben erwähnten diätetischen Lebensbedingungen, deren Wichtigkeit in je einem einzigen charakteristischen Wort angedeutet wird, werden die bereits angeführten Hauptgruppen von Heilmitteln zusammengestellt. 
Ihre Eigenschaften aber werden weiter in "Clavis interior" angegeben, wo die einzelnen Heilmittel in 30 Gruppen in Form einer Materia medica angeordnet sind. Da diese Darstellung auf eine sinnreiche Weise, man kann sagen, Linnés ganze pathologischtherapeutische Anschauungsweise in ihrem inneren Zusammenhang veranschaulicht, und da es im Anschluf an die bisher gegebene Darstellung seines Systems nicht schwer sein dürfte, die Bedeutung der verwendeten technischen Ausdrücke $z u$ verstehen, so sei hier dieses Schema wiedergegeben ${ }^{1}$.

Diaetetica Vitia emendantur Naturae Qualitatibus.

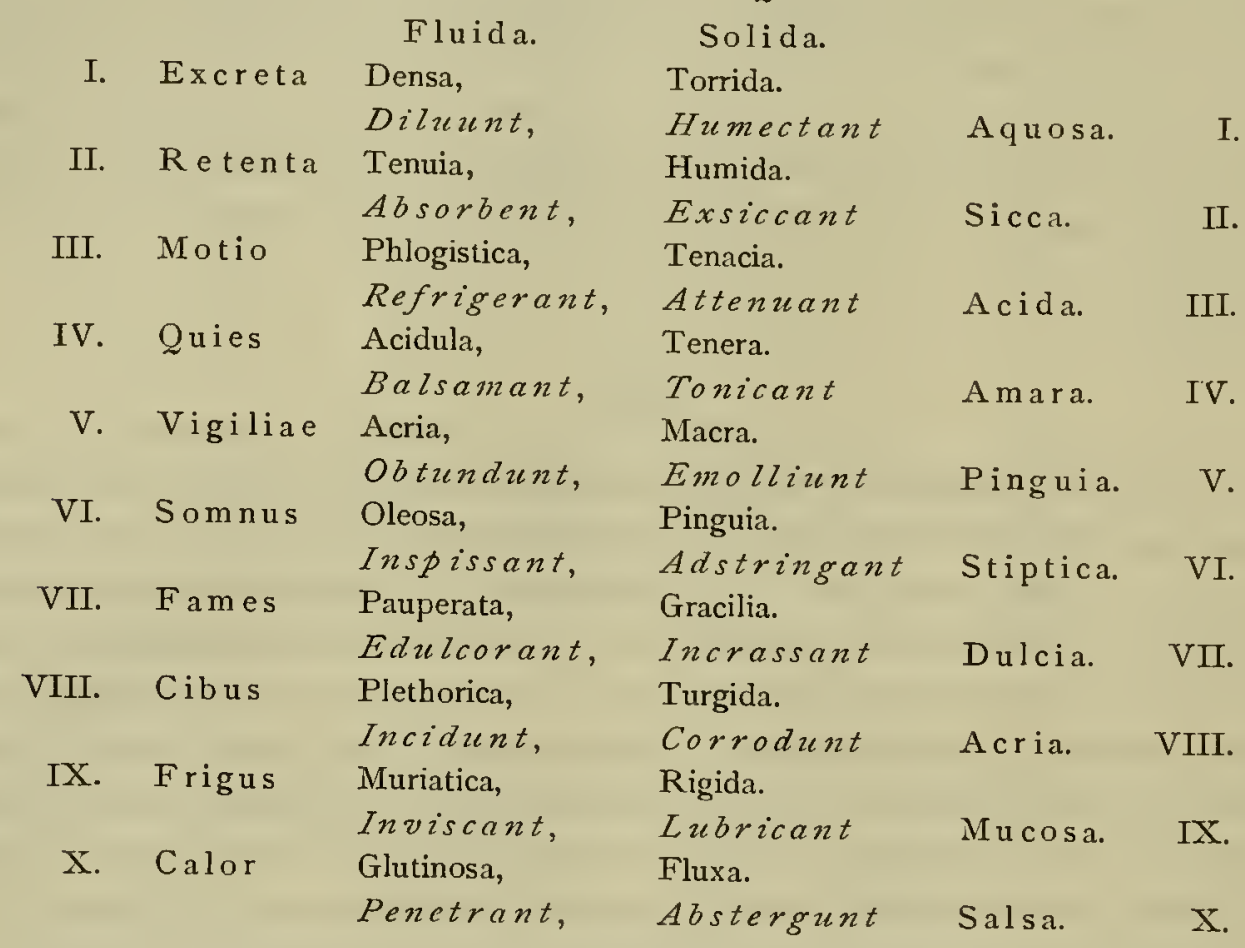

Clavis medicinae ist eine in hohem Grade bemerkenswerte Schrift in der schwedischen Literatur ${ }^{2}$ ). In der gedrängtesten Form enthält diese Arbeit die Hauptgedanken des praktisch-medizinischen Systems Linnés. Die Verschiedenheiten der pathologischen Zustände der organischen Elementarteile und ihr durch die Anwendung der vorgeschlagenen Heilmittel vorausgesetzter Uebergang in

I) Clavis Medicinae, S. Io. Vgl. oben S. $82-83$, I20-I22.

2) Caroli a Linné Clavis Medicinae duplex exterior et interior, Holmiae 1766 , 29 S., $8^{\circ}$. Zwei Schlüssel sind auf dem Titelblatt abgebildet, jeder mit fünf Fingern, und mit dem Motto: „Universum lucta discordium aeqvilibratur“. Die Arbeit ist "Medicis secularibus, Sigf. Albinus, Anatomico summo, Alb. von Haller, Physiologo summo, Gerardo van Swieten, Observatori summo, Franc. de Sa uvages, Pathologo summo, Nicol. v. Rosenstein, Therapeutico summo" dediziert. 
ihren (heilbringenden) Gegensatz sind es, welche die Schlüssel (claves) zum System enthalten und hinsichtlich der Diät und Therapie seine leitenden Grundgedanken darstellen. Daß diese Schlüsscl („exterior“ und „interior") zwei sind, beruht nach L, in nés eigener Erklärung darauf, daß, wie bereits oben erwähnt, zwei miteinander verflochtene Gewebc, die Kortikal- und die Medullarsubstanz, an dem Aufbau des Körpers teilnehmen ${ }^{1}$ ). Jedes derselben kann auf verschiedene Weise pathologisch verändert werden. Ueber diese pathologischen $\mathrm{Zu}$ stände der festen und flüssigen Teile des Körpers (vitia humorum et vitia fibrarum) ist oben berichtet worden ${ }^{2}$ ). In Clavis finden sie sich nebst ihren "Opposita“ in Tabelle III wieder. Dem Nervensystem ividmet Linné dagegen besonders die Tabellen VII, VIII und X.

Da Linn é sein pharmakodynamisches System auf die Einwirkung gründete, welche die Pflanzen durch Geschmack und Geruch auf den Organismus ausüben ${ }^{3}$ ), so hat man bei der Bekämpfung der genannten pathologischen Zustände und darauf beruhender Krankheiten seine Heilmittel in den Pflanzengruppen (.sapida et olida") zu suchen, über die Clavis in den Tabellen V und IX berichtet. Bei der speziellen Anordnung der dahingehenden Pflanzen macht Linné auf die dabei hervortretende wichtige Fünfzahl aufmerksam und bemerkt, daß „die Natur sich in allem zuerst in zwei und dann in fünf teile".

Diese Schrift ist ein geistvoller Versuch, auf Grund gewisser theoretischer Vorstellungen das ganze medizinische Lehrgebäude zu konstruieren, und sie bildet einen sprechenden Beweis für Linnés Vermögen, unter gemeinsamen Gesichtspunkten verschiedene Zweige der Wissenschaft zu einem Ganzen zu vereinen. Die aphoristische Kürze, in welcher Linné in „Clavis medicinae“ seine Sätze zu fassen liebte, macht diese Arbeit schwer verständlich, ja, fast unverständlich für einen jeden, der sich nicht die Mühe gegeben hat, in die Tiefe seiner Gedanken einzudringen. Es ist auch klar, dalb die mündliche Darstellung dazu bestimmt war, dieser Zeichnung ihr rechtes Relief zu geben ${ }^{4}$ ). Es kann sein Interesse haben, zu sehen, wie Linné

I) Vgl. oben S. 64 .

2) Vgl. oben S. $76-80$.

3) Vgl. oben S. $82-83$.

4) Nach Indices praelectionum zu urteilen, scheint Linné wenigstens einmal über Clavis vorgelesen zu haben, nämlich 1771 . Wahrscheinlich sind es diese Vorlesungen, wovon P. D. Giseke in "Termini botanici" etc., Hamburg I78 I, S. 103 schreibt: „Ich habe diesen Abschnitt unerklärt gelassen, da er im Clavis medicinae umständlicher enthalten ist, über welchen ich dereinst die Vorlesungen des Verfassers herauszugeben gedenke." Diese Arbeit ist indessen nicht herausgekommen. - Ein Heft Aufzeichnungen 
selbst diese seine Arbeit beurteilt. Offenherzig schreibt er in seiner naiven Sprache: „Mit Clavis Medicinae auf seinen 8 Paginae hat die Pathologie, die Grundlage der ganzen Medizin und aller Theoria medica, mehr gewonnen als mit 100 Autoren und Folianten. Er ist ein Meisterstück und eines der größten Juwele der Medizin“" ${ }^{1}$. Auch in seinem Briefwechsel finden wir darüber folgende Aeußerungen :

„Es hat mir ein Vergnügen gemacht, in aller Eile Clavis medicinae auszuarbeiten. Hier sind zwei Schlüssel $\mathrm{zu}$ dem medizinischen Heiligtum. Den einen glaube ich sicher wiedergefunden zu haben, und auch den rechten anderen meine ich erhalten zu haben. Du wirst hierüber lächeln, lieber Freund, wenn Du ihn aber sähest, glaube ich, würdest $\mathrm{Du}$ milder denken" 2 ).

„Es ist mir eine hinreichende Genugtuung, daß ich Deine und Arch. Rosensteins Approbation für meinen kleinen Clavis medicinae bekommen habe. Könnte ich ihn mit dir durchgehen und meine Demonstrationen geben, so hoffe ich, würde er verständlicher werden“" $\left.{ }^{3}\right\rangle$.

An seinen Freund Prof. A. Murray in Göttingen schreibt Lin n é über seinen eben herausgegebenen Clavis:

„Finden Sie, Herr Professor, etwas Anstößiges, so lassen Sie es mich wissen. Archiater Rosenstein hat auf meine Bitte alles examiniert und mir das ehrlichste Zeugnis ausgestellt und nichts gefunden, was ich nicht zu vollem Genüge habe demonstrieren können. Hält es stich, so muß es etwas zur materiae medicae certitudo beitragen" ${ }^{4}$ ).

Unter den medizinischen Wissenschaften, welche Linné nit besonderem Interesse bearbeitete, und über die ihm vorzulesen oblag, befand sich auch die Diätetik oder die Lehre von der Gesundheit des Individuums ${ }^{5}$ ). Linnés Ansichten in den diesbezüglichen Fragen kennzeichnen sich durch die praktische Anwendung, die er, auf zahlreiche scharfsinnige Beobachtungen sich stützend, ihnen zu geben verstand. Seine Vorträge über diese Gegenstände lenkten infolge ihrer Vielseitigkeit und ihres Reichtums an treffenden Bildern aus dem täglichen Leben die allgemeine Aufmerksamkeit

aus Linnès Vorlesungen über Clavis medicinae, die in der Bibliothek des Karolinischen Instituts in Stockholm aufbewahrt werden, hat Verf. Gelegenheit gehabt zu benutzen. Aus ihnen haben einzelne Sätze oben mitgeteilt werden können. In Anbetracht der mangelhaften und unvollkommenen Art, in der diese Aufzeichnungen redigiert worden sind, lassen sie sich bedaterlicherweise nicht im Druck herausgeben. Vgl. oben S. 76.

I) Egenhändiga Anteckningar, S. 262.

2) Brief an A br. Bäck vom I. Jan. I 766 .

3) Brief vom 3. April 1766 .

4) Brief vom 27. März 1766 .

5) Vgl. oben S. $26,46,47$. 
auf viele, bis dahin übersehene, für die Gesundheitspflege äußerst wichtige Wahrheiten. Linnés Vorlesungen verbreiteten unter den schwedischen Aerzten ein Interesse für die Lehren der Hygiene und eine Kenntnis derselben, wie sie höchst bemerkenswert sind. Mehrere der hervorragendsten Vertreter der medizinischen Wissenschaft in Schweden, wie Abr. Bäck, David Schulz v. Schulzenheim, C. H. af Hiärne, J. G. Wahlbom, Nils Dahlberg, J. L.Odhelius u. a., von denen die meisten seine Schüler gewesen waren, veröffentlichten später Schriften von hohem Wert auf dem Gebiete der allgemeinen Gesundheitspflege, wodurch auch das große Publikum die Wichtigkeit ihrer Forderungen einsehen lernte. Während die hygienische Wissenschaft noch in den großen Kulturländern unbearbeitet und zurückgesetzt war, kann die medizinische Literatur in Schweden nicht wenige Schriften auf diesem Gebiete aufweisen. Mit dankbarer Anerkennung sehen wir, daß der Same, der von Linné ausgestreut worden, sich entwickelt und reiche Früchte getragen hat.

Die Diätetik oder die Lehre von der naturgemäßen Lebensweise des Menschen stützte sich, nach der Ansicht älterer Aerzte und Linnés, auf sechs Hauptbedingungen (res non naturales), nämlich frische Luft, Körperbewegung und Ruhe, Wachen und Schlaf, die Entleerningen des Körpers und die Affekte der Seele (Gemiitsbewegungen) ${ }^{1}$ ). "Wenn wir", sagt Lin né, „beständig so wären, wie neugeborene gesunde Kinder es sind, in deren Körper alles gegeneinander balanciert und dann nicht mit der Diät diese Balance aufhöben, so wäre damit alle Ursache zur Krankheit beseitigt. Denn Krankheit entsteht nur excessu rerum non naturalium. Fehler gegen die Regel der Diätetik bleiben selten ungestraft und werden nür durch ihre Contraria geheilt“\%).

In genauer Uebereinstimmung mit seinen oben geschilderten pathologischen und therapeutischen Theorieen ging Linné auch bei der Darstellung der Lehren der Diätetik von denselben allgemeinen Sätzen aus und suchte sie auf dem Gebiet der Gesundheitslehre durchzuführen. Derartige Sätze sind die folgenden. Die Luft wirkt auf unseren Körper durch Wärme oder Kälte. Die Kälte macht die Fasern starr (solida rigida) und die Flüssigkeiten mehr salzig (fluida muriatica); die Wärme dagegen ruft Schlaffheit in den festen Teilen hervor und fördert die Bildung von Leimstoff (gluten). Warmes

I) „De effectu et cura vitiorum diaeteticorum generali“ (1766). Fast dieselben Gedanken werden in der Abhandlung: „De medico sici ipsizs" (1768) ausgesprochen.

2) Vorlesungen über Clavis medicinae.

H jelt, Carl von Linné. 
Klima macht die Fasern weich (fluxas). Wärme „affaibliert" und ruft Unlust zum Denken, zum Arbeiten und zu Anstrengungen hervor. Je weicher die Fasern sind, um so schneller gchen sie in einen gewissen Grad von Klebrigkeit über (oritur viscidum), der Gegensatz dazu ist das Salzige (oppositum glutinosi est salsum). Die Kälte bewirkt daher Auskristallisierung von Salzen und Steinbildung im Körper. Bewegung macht die Flüssigkeiten feurig, lebhaft (humores phlogistici) und die Fasern zäh (tenaces); bei der Bewegung entsteht Wärme, die Flüssigkeiten werden verteilt (dissipantur), und alle Teile nähern sich einander. Die Ruhe fördert Säurebildung in den Flüssigkeiten (aciduli) und macht die Fasern mürbe (teneras). Das Stillsitzen ist die Ursache, weshalb die höheren Stände mehr an Hysterie leiden als das Bauernvolk; Stein und Podagra kommen öfter bei älteren und wohlhabenden Personen vor. Bei hohem Alter werden die Fasern hart. Fatum senile ist Rigidität. Durch zu viele und zu starke Bewegung wird das Alter beschleunigt, daher ,ist es nicht gut, sich zu sehr anzustrengen“. Schlaf fördert Fettzunahme der festen Teile (solida pinguia) und macht die Flüssigkeiten ölig (humores oleosos), während die Fasern durch Nachtwachen mager (macilentae) und die Flüssigkeiten scharf (acres) werden. Diejenigen, welche die Nächte durchwachen, sind Fieber, Blutflüssen, Schwindel und Kopfschmerzen ausgesetzt, daher das Sprüchwort: „aut studes aut amas“. Das Beste, ja, ein spezifisches Mittel gegen zu große Beleibtheit ist Nachtwachen, und das ist die Ursache, weshalb fette Personen, die ihr Ehegemahl verloren (tori socia orbati) und an Schlaflosigkeit leiden, in kurzer Zeit an Leib und Seele erschlaffen (corpore et animo languent). . Durch Hunger werden die Flüssigkeiten vermindert oder arm gemacht (pauperati), und die Fasern werden dünn (graciles), während genügende Ernährung sie anschwellen (fibrae turgidae) und die Flüssigkeiten zunehmen (plethorici werden) läßt ${ }^{1}$ ). Was die Entleerungen betrifft, so ist bekannt, daß der Körper nicht weniger verliert, wenn seine Flüssigkeiten versiegen (si succi laudabiles amittantur), als wenn unbrauchbare Stoffe, wie sie bei der

I) Wie Linné sich im allgemeinen die Natur und Wirkung der Nahrungsmittel dachte, geht aus folgenden, der Abhandlung "De pane diaetetico" (1756) entnommenen Sätzen hervor: „Die Physiologie lehrt, daß jedes für den Menschen brauchbare Nahrungsmittel entweder in Form von Emulsion benutzt werden oder gelatinöser Natur sein $1 \mathrm{n} ß$. Emulsion ist vegetabilischen, Gelatine dagegen animalischen Ursprungs. Da aber der Mensch nicht lange nur von gelatinösen Nahrungsmitteln leben kann, sondern solchenfalls von Fieber und Phthisis befallen wird, so mul unsere wichtigste Nahrung aus emulsionierter oder Milchnahrung bestehen. Emulsion ist nämlich nichts anderes als artifizielle Milch, aus zerstoßenen und lange mit Wasser behandelten Stoffen erhalten." 
Arbeit des Lebens stïndig in der Blutmasse sich bilden, übermäßig lange zurückgehalten werden. Bei reichlichen und starken Entleerungen werden die Flüssigkeiten dick (densi) und die Fasern mager (torridae), der Körper wird geschwächt und Abmagerung tritt ein, während die festen Teile feucht (humida) und die Flüssigkeiten dünn werden, wenn die Absonderungen nicht regelmäfoig vor sich gehen ${ }^{1}$ ).

Th. M. Fries hat nachgewiesen, daß Lin né schon als Student Privatkollegs über die Gesundheitslehre oder was er "diaeta naturalis“ nannte, las. Seinen Vorträgen legte er einen von ihm ausgearbeiteten Entwurf zu einer Diätetik in 75 Regeln zugrunde, die ,ex principiis zoologicis, staticis. oeconomicis, experimentalibus, naturalibus. mechanicis et theologicis veteris et novi testamenti“ entnommen waren. Die Lektüre der Schriften verschiedener Autoren, unter denen er Sanctorius' bekannte Arbeit "Ars de Statica medicina" (1614). am höchsten schätzte, hatte wohl das Material geliefert zu der für Linné bereits in der Jugend originellen Weise, sich über die verkehrte, in vieler Hinsicht naturwidrige Lebensweise jener Zeit auszusprechen ${ }^{2}$ ).

Als Linné den einen der beiden medizinischen Lehrstühle übernahm, fiel ihm auch die Behandlung der Diätetik zu. Seine von Zeit zu Zeit über diesen Gegenstand gehaltenen Vorlesungen waren hochgeschätzt und vielbesucht ${ }^{3}$ ). Diese Vorträge wurden fleißig nachgeschrieben und in Lande verbreitet, wo sie gelesen und abgeschrieben wurden. Diese Abschriften, die man in Bibliotheken aufgefunden hat, sind es, denen wir unsere Kenntnis der Diätetik Linnés zu verdanken haben. Von seiner Darstellungsweise bemerkt in einer Gedächtnisrede S. A. Hedin in besonderem Hinblick auf die diätetischen Vorlesungen, die er selbst angehört hatte: „Sprach

I) Siehe Anmerkung auf S. I46.

2) Th. M. Fries, Linné, I, S. I18, I34, 183. - Ueber den fraglichen Entwurf zu "Diaeta naturalis", der in der Linnean (Society in London aufbewahrt wird, siehe E. A ehrling, Carl von Linnés Ungdomsskrifter (Carl von Linnés Jugendschriften), I (1888), S. 25, Ebenda wird noch eine andere umfangreichere Handschrift aus einer späteren Zeit unter dem Titel "Carl Linnaci Med. et Botan. Profess. Upsal. Lachesis naturalis, quae tradit Diatam naturalem innixam observationibus et experimentis etc.", $330 \mathrm{~S}$. in Folio aufbewahrt.

3) Nach den Vorlesungsverzeichnissen der: Universität Upsala hielt Linné Vorlesungen über "Diaeta ad longaevitatem" in den Studienjahren I742, I748, I755, I759 bis $1760,1763,1767$ und 1771 . Sein Plan, diese V'orlesungen im Druck herauszugeben, wurde wegen anderer dringender Arbeiten immer wieder aufgeschoben und kam nicht zur Ausführung. Vgl. oben S. 26,46 . 
von Linné von den Großtaten und der Majestät des Schöpfers so malte sich Ehrfurcht und Bewunderung in aller Angesicht . . . . Sprach er dagegen von den Vorschriften der Diät, so ließ er oft seine Schüler laut lachen, wenn er die törichten Launen der Mode abmalte, und unter leichtem angenehmen Scherz brachte er ihnen die nützlichsten Lehren betreffs der Pflege und Erhaltung der Gesund. heit bei."

Es würde uns zu weit führen, hier auf die Einzelheiten dieser Vorträge einzugehen, vielleicht aber verdient es untersucht zu werden, welche hygienischen Fragen Linné in den Kreis seiner Darstellung zog. Linnés "Collegium diaeteticum" ( $\left.175^{8}\right)$ hat z. B. folgenden Inhalt ${ }^{1}$ ). Nach einer Einleitung über die Entivicklung des menschlichen Lebens, ein Gegenstand, der in mehreren der akademischen Abhandlungen Linnés behandelt wird ${ }^{2}$ ), gibt der erste Teil der Diätetik „regulas generales": 1) infantis figura naturalis est servanda, 2) infans enutriatur lacte materna, 3) omne parit sui simile, 4) juventus facit vires senectuti, 5) consuetudo est quasi altera natura, 6) omnis subita mutatio periculosa, 7) omne nimium nocet, 8) varietas delectat. Von der Luft; vom Wetter; respiratio; transpiratio; attractio; vestimenta; lectus et cubile; somnus; aedes et domicilia. Der zweite Teil bezieht sich auf "motus et quies, morbi artificum“. Der dritte Teil handelt von ,ingesta, potus et cibus oder dem, was proprie Diät genannt wird“. Vom Wasser, seiner Prüfung und seiner Reinigung; von den Spirituosis; vom Wein; Tee, Kaffee, Branntwein, Bier, Tabal, Schnupftabak; cibus, schädlichen Zusätzen; vom Salz, Essig, Zucker, Honig, Oel, Butter, Speck, lacticinia oder Milchspeisen, praeparata lactea; Brot; carnes, Fleischspeisen, Blut; Vegetabilien, aromata, fructus horaei, Gewürzen; dem Tierreich. Gift in genere, Gift im Tierreich, Gift im Steinreich, giftigen Gefäßen. Vierter Teil: Excreta et retenta, sensus externi et interni; die Affekte; Venus. Con-

1) Ein detailliertes Eingehen auf Linnés diätetische Lchrsätze ist hier um so weniger vonnöten, als gelegentlich der Limnéfeier 1907 im Auftrage der medizinischen Fakultät in Upsala eine vollständige Bearbeitung seiner diesbezüglichen Vorlesungen unter Zugrundelegung aller bisher bekannten Abschriften ron Prof. A. O. Lindfors erschienen ist.

2) Hierher gehören dic akademischen Abhandlungen "Senium Salomoneum" (1759), "Diaeta per scalam aetatis humanae observanda" $(1764)$ und "Metamorphosis humana* ( 167 ). Sie enthalten allgcmeine Betrachtungen über den beiderseitigen Entwicklungsgang des Körper- und des Seelenlebens aus praktisch-psychologischen Gesichtspunkten. Lin né teilte die Lebenszeit des Menschen in I 2 Pcrioden von je 7 Jahren ein und gibt in liurzen, kräftigen Zügen cin Bild der für jede Periode charakteristischen körperlichen und seelischen Eigenschaften. Was über 7o Jahre hinausgeht, rechnetc er bereits zu ,rita decrepita“. 
jugium, dabei sind in Betracht zu ziehen: a) dona naturae (sanitatis, aetatis et pulcritudinis), b) dona educationis, oder Gremüt, Kenntnisse und Fertigkeiten, c) dona animac, eine gute und aufrichtige Gesinnung, d) dona status, ehrbarer Stand und Name, e) dona fortunae, dahin gehören 1) divitiae, daß die Frau aus wohlhabender Familie ist, 2) prosapiae, daß die Verwandtschaft klein ist.

Obwohl Lin né die Absicht gehabt zu haben scheint, seine Vorlesungen über Diätetik, die er mehrmals umarbeitete, herauszugeben, erschienen sie gleichwohl niemals im Druck, so sehr man auch darauf hoffte. In einem Brief von J. Zoega (in Kopenhagen) an Linné d. J. heilt es:

„Audivi collegium diaeteticum parentis optimi in lucen prodiisse; an ita est? Respondeas quaeso ad has quaestiones" ${ }^{1}$ ).

Dagegen wurde das Publikum durch eine Arbeit über die Gesundheitslehre überrascht, die von Magnus Frans Westerdahl, später Quästor an der Universität zu Upsala, herausgegeben und die ebensosehr zu Linnés Zeit wie auch später als auf Grund seiner Vorlesungen verfaßt angesehen wurde $\left.{ }^{2}\right)$. Diese Arbeit trägt auch in ihrem gesamten Inhalt überzeugende Spuren davon, daß sie eine Bearbeitung von Linnés Vorträgen über die Diätetik ist, obwohl er selbst in bezug darauf schreibt:

„Das diätetische Buch ist keineswegs mein Kollegium. Mein Kollegium ist nichts anderes als experimentell, d. h. auf Observationes beruliend. Das Buch ist nicht bei uns zensuriert, und ich wußte von ihm nicht eher, als bis es gedruckt, und da jemand sagte, es möchte wohl mein Kollegium sein, so kaufte ich ein Exemplar, das ist aber nicht der Fall ${ }^{3}$ ).

Bevor wir dieses Gebiet verlassen, dürften jedoch einige kurze Andeutungen darüber, was Linné in einzelnen Spezialabhandlungen betreffs verschiedener diätetischer Fragen geäußert hat, an Platze sein.

Eine Frage, auf deren große Wichtigkeit und Bedeutung er, so z. B. in mehreren seiner Abhandlungen, hinweist, und auf die er oft

1) Brief vom 26. Okt. 1765, abgedruckt bei J. C. Sciodtc, Naturhistorisk Tidskrift, III, 7,3 , Kopenhagen 187 I, S. 474.

2) Frans IV e sterd a hl, Underrättelse on hälsans bevarande, förklarad med nyttiga anmärkningar och grundad p̊̊ de berömligaste äldre och nyare Auctorers erfarenhet. (Nachricht von der Erhaltung der Gesundheit, durch nützliche Anmerkungen erlïutert und auf die Erfahrung der berühmtesten älteren und neueren Autoren gestützt), Upsala I 764 , 480 S., $8^{\circ}$; 2. Aufl. Ups. I 768,494 S., $8^{\circ}$; 3. Aufl. Hernösand I803, 422 S., $8^{\circ}$. In der Vorrede steht, daß Linnés Vorlesungen über die „Diät“ dem Inhalt des Buchcs zugrunde liegen, sowie daß er das Vorwort geschrieben und bei der ersten Auflage das Manuskript durchgesehen habe.

3) Brief an A br. Bäck vom 20. Nov. 1764 . 
zurückkommt, ist die Erziehung des heranwachsenden Geschlechts. Er spricht hierbei Wahrheiten aus, deren Einschärfung sicherlich dazu beigetragen hat, nicht nur das Interesse der Aerzte, sondern auch des Publikums für diese außerordentlich wichtige Frage zu erwecken, wenn sie auch nur allmählich in dem Bewußtsein des Volkes haben Wurzel schlagen können. Linné lenkt die Aufmerksamkeit darauf, daß die Grundlage für die Gesundheit des einzelnen Menschen oder die Bedingungen für einen gesunden und kräftigen Körper teils in der Erżeugung, 'teils in der Kindheit und Jugend geschaffen werden. Er gibt auf Grund dessen Vorschriften, in welcher Weise die Verhältnisse der einzelnen Lebensalter in Uebereinstimmung mit den Forderungen der Diätetik wie der intellektuellen Entwicklung $\mathrm{zu}$ ordnen sind ${ }^{1}$ ).

Während der Schwangerschaft soll die Frau viel in der frischen Luft sein und Bewegung haben; ,inde etiam embryo suum habet motum“. Daß Linné den Müttern aufs kräftigste die unabweisliche Pflicht einschärfte, selbst ihre Kinder zu säugen, und seine Erfahrung bezüglich der Pflege des Neugeborenen mitteilte, ist bereits erwähnt worden. Linné warnt die Frau, Korsetts, und die Männer, enge Halsbinden $\mathrm{zu}$ tragen.

Die Jugend wird ermahnt, während ihrer Studienzeit körperliche Uebungen zu pflegen, und der Nutzen des Aufenthalts in frischer Luft wird kräftig betont. Turnen, Fechten und Reiten werden den Jünglingen empfohlen. Das Schwimmen soll in der Jugend geübt werden. Personen, die ein stillsitzendes Leben führen, leiden im allgemeinen an Säure in den ersten Wegen, und diese Säurebildung bewirkt Gärung der Nahrungsmittel, sie frißt (rodit et vellicat) die festen Teile an, kristallisiert leicht und bildet ,in viscido concretiones tartareas", die dann den Grund zu habitueller Verstopfung, Hypochondrie, Gicht und vielen anderen Leiden legen. Das beste Heilmittel dagegen ist Körperbewegung bis zu vollem Schwitzen. - In einer besonderen akademischen Abhandlung wird der Einfluß erörtert, den die Körperbewegung auf die Gesundheit ausübt, und die Krankheiten, die auf einen Mangel an solcher zurückgeführt werden können, werden genau angegeben. Man soll jedoch zusehen, daß alle Körperbewegung in verständiger Weise geschieht, und ihre ver-

1) „Universa natura eo in puncto conspirat, quod illi foetus, qui maturo et ferventis veneris usu generantur, cum vitae viribus, tum etiam generositate praecellentes fieri. Itaque prima stabilitamenta vitae humanae in ipsa generatione conduntur." Fundamenta valetudinus ( 1756$)$. - Diaeta per scalam aetatis humanac observanda ( 1764$)$. 
schiedene Einwirkung wird nach dem Grade, wie sie getrieben wird, charakterisiert ${ }^{1}$ ).

Auf den Nutzen geräumiger Wohnungen und frischer reiner Luft wird klar und überzeugend hingewiesen, die Gefahr, die mit dem zu frühen Beziehen neuerbauter Häuser infolge ihrer Feuchtigkeit und unreinen Luft verbunden ist, wird eingeschärft und ebenso werden die Unzuträglichkeiten der damals noch allgemcinen Beisetzungen in den Kirchen erwähnt ${ }^{2}$ ). Wer sich seine Gesundheit erhalten will, muß ebensolche Aufmerksamkeit der Luft zuwenden, die cr atmet, wie der Speise, die er genießt. Man soll daher nicht in allzu niedrigen Räumen schlafen, oder sich in Luft aufhalten, die mit unreinen Dingen, verwesenden Stoffen und stillstehendem Wasser in Berührung gekommen, oder die mit Nebel und Dünsten erfüllt ist (aër suffocatus et putridus) $\left.{ }^{3}\right)$. Den städtischen Behörden liegt es ob, darüber zu wachen, daß3 alle Arten von Verunreinigungen sorgfältig aus den Städten entfernt werden $\left.{ }^{4}\right)$.

Die Winde spielen eine wichtige Rolle bei der Reinigung der Luft, und es ist überhaupt gesund, solche Stellen zu bewohnen, welche Sonne und Wind ausgesetzt sind. Thre Bewohner sind im allgemeinen gesund und kräftig, wie die Fische in reißenden Strömen und Flüssen kräftiger und schmackhafter werden ${ }^{5}$ ). Li n né spricht den Gedanken aus, dafo, da die Hautausdünstungen von der verschiedenen Beschaffenheit der Luft abhängen, auch eine Menge krankhafter Störungen sowohl in den festen wie in den flüssigen Teilen ihren Ursprung in dieser Luftkonstitution hat ${ }^{6}$ ). Bei trockner und kalter Luft entstehen entzündliche Krankheiten, wie Pleuritis, Peripneumonia, Angina, Rheumatismus, bei trockner und warmer Luft entstehen Störungen in den Gallenwegen, Cholera nostras, Dysenterie usw.; bei feuchter und kalter Luft Husten, Flüsse, katarrhalische und intermittente Fieber und bei feuchter, warmer Luft fäulnisartige Fieber ${ }^{7}$.

I) Mäßige Bewegung regt den Körper an, erhöht die Wärme, macht die Bewegung des Blutes kräftiger, fördert alle Entleerungen, begünstigt die Hautausdünstung, und entfernt verdorbene Flüssigkeiten; eine zu starke Bewegung ruft dagegen Ermattung hervor und bricht die Körperkräfte durch zu starke Arbeit, macht die Fasern starr und bewirkt ein zu frühes Altern.

2) Respiratio diactetica (1772).

3) Aer habitabilis (1759). Omne putridum est septicum et corrosivum, ipsi veluti naturae horrendum.

4) Febris Upsaliensis ( 1757 ).

5) Respiratio diaetetica (1772).

6) „Dyscrasiae tam fluidorum, quam solidorum a diversa aeris constitutione oriuntur.“

i) De perspiratione insensibili (1775). 
Die Krankheiten, die mit der Ausübung bestimmter Berufe verbunden sind, werden auch in einer Abhandlung erörtert, die sich zunächst an die bekannte Arbeit $\mathrm{Ramazzinis}$ anschließt ${ }^{1}$ ). Darin heißt es unter anderem von den "Literati“, wie z. B. Theologen, Professoren usw., daß sie infolge ihres vielen Aufenthalts in verdorbener Luft schwindsüchtig werden; infolge der Zusammenpressung des Bauchs bei ihrem beständigen Sitzen werden sie hypochondrisch und leiden an Verstopfung; infolge ihrer Beschäftigung mit Papier, Schreiben (und Lesen) werden sie kurzsichtig; infolge des Mangels an Körperbewegung leiden sie an mangelhaftem Appetit, werden mager und melancholisch und schließlich infolge der Ueberanstrengung schlaflos. Oben wurde bereits erwähnt, daß Linné auf die Gefahr hingewiesen hat, denen die Steinhauer in Orsa durch den Steinstaub, der bei der Arbeit entsteht, ausgesetzt sind.

Unter Linnés Disputationen finden sich einige bisher nicht erwähnte Abhandlungen, die, auf der Grenze zwischen wissenschaftlicher Botanik und praktischer Oekonomie stehend, Gegenstände berühren, die als in das Gebiet der Diätetik fallend anzusehen sind. Es dürfte hier der geeignete Ort sein, die Aufmerksamkeit auf jene Schriften zu lenken, in welchen Linné sich mit der Möglichkeit und Notwendigkeit beschäftigt, aus dem Pflanzenreiche neue Nahrungsmittel aufzunehmen und ins tägliche Leben einzuführen, die Anwendung bereits bekannter Nahrungsstoffe zu erweitern und zu vervollkommnen, wie auch bei Mangel an gewissen Lebensmitteln in anderen einen geeigneten Ersatz zu finden \%).

Was die Nahrungsmittel betrifft, so warnt Linné vor dem Gebrauch heißer wie kalter Getränke und Speisen. Die Speise ist heiß zu nennen, wenn sie $35-37^{\circ}$, d. h. die Normaltemperatur eines gesunden Menschen, übersteigt. Ein längerer dauernder Gebrauch solcher Speisen oder Getränke ist in mehreren Hinsichten schädlich,

r) Morbi artificum (1765).

2) Hierher gehören die Abhandlungen: Plantae esculentae patriae (1752), De aietariis (1756), De pane diaetetico (1757), Culina mutata (1757), Macellum olitorium (1760), Fructus esculenti (1763). Hortus culinaris ( 1764$)$, De varietate ciborum (1767). - Ton Linné existiert auch eine an 9. März 1757 Sr. Maj. dem König eingereichte Schrift über Kräuter und Pflanzen, die zur Brotbereitung dienen können, im selben Jahre gedruckt unter dem Titel: „Berättelse om de inhemska växter, som i brist pâ säd, kunna användas till bröd och matredning (Bericht über die einheimischen Pflanzen, die in Ermangelung von Getreide zur Bereitung von Brot und von Speisen verwendet werden können). Auf allergnädigsten Befehl Sr. Maj. des Königs von seinem Collegio medico zum Druck befördert." Neu abgedruckt in Modees Utdrag utur publ. Handl. ti3t -4738 . 
ebenso sind kalte, gefrorene Speisen und Getränke zu vermeiden 1). Von dem Genuf warmer und kalter Speisen, dem Gebrauch von Eis und kaltem Wasser heißt es zum Schluß: „Warmes und Kaltes hat je scinen Schaden und seinen Vorteil; wer den ersteren vermeiden und den letzteren gewinnen will, folge der alten Regel: moderata durant" 1). - Schokolade wird von Li n né als ein kräftiges Nahrungsmittel gepriesen und als besonders wirksam gegen allgemeine Magerkeit, bei atrophischen und marastischen Zuständen, Tabes, Hypochondrie usw. empfohlen. Auch bei Hämorrhoiden will Linné sie mit großem Erfolg angewandt haben \%. - Tee ist seiner Ansicht nach nur fetten Personen, nicht aber mageren zu empfehlen, er wirkt „attenuans et exsiccans" "3). Zuckerhaltige Stoffe erschlaffen die Lungen und machen die Fasern spröde und brüchig, ,weshalb Blutspeien nun allgemeiner ist als früher infolge des täglichen Gebrauchs von Tee und Zucker" ${ }^{4}$ ). - Gegen den überhandnehmenden Mißbrauch des Branntweins eiferte Linné kräftig. In seinen „Anmärkningar om Bränvin" („Bemerkungen über den Branntwein“), die in $\mathrm{Hj}$ orters Kalender für 1748 erschienen, sagt Linné: „Man glaubt, es sei eine Ersparnis im Haushalt, den Leuten einen Schnaps Branntwein statt anderen Essens zum Frühstück zu geben, das ist aber dieselbe Ermunterung wie ein Peitschenhieb für das Kutschpferd, es läuft wohl etwas danach, wird aber darum nicht fetter. - Man glaubt, daß Branntwein in Winter auf Reisen wärmt. Für eine kleine Weile ist das auch wahr, da aber aller Reiz nachträglich um soviel schwächt, als er zuvor gestärkt hat, so friert man auch danach um so mehr. „Ich sah, als ich bei der Königl. Admiralität Medicus war, daß zu der Zeit, als der Branntwein verboten war, die Seesoldaten während

I) Circa fervidorum et gelidorum usum paraenesis ( 1765$)$. Darin findet sich folgender Satz: So können sich Finnen und andere, die von Kindheit an daran gewöhnt sind, ohne Schaden aus einem warmen Bade hinaus ins Meer oder in den Schnee werfen.

2) De potu chocolatce (1 765$)$.

3) De potu Theae $(1765)$.

4) De Haemoptysi ( 1767$)$. - Es sei hier daran erinnert, daß, als man um die Mitte der I 740 er Jahre zur Förderung des ökonomischen Wohlstandes die Einfuhr gewisser sogenannter Luxuswaren verbieten wollte, die medizinische Fakultät in Upsala von dem Collegium medicum ,über succedanea Theae, Coffeae et Chocoladae" befragt wurde, „damit nach dem Wunsche Sr. Maj. von inländischen Pflanzen solche mögen angegeben werden, daß ausländische entbehrt werden können“. Nach vorhergehender Beratung mit Linné und auf Grund seiner Vorschläge erließ das Collegium I746 seine Bekanntmachung ,über den Mißbrauch und Ueberfluß, der mit dem Thee- und Kaffeetrinlien betrieben wird, nebst Anweisung schwedischer Pflanzen, die statt des Thees zu gebrauchen sind". 
ihres Aufenthaltes auf ider Werft nicht halb so krank waren und zehnmal weniger Exzesse bestraft wurden, was ich auch bei den anderen Regimentern hörte und beobachtete. Wir sollen den Höchsten bitten, daß wir unseren geringen Verstand behalten dürfen, und nicht uns selbst zu unvernünftigen Tieren machen, wo wir eher Ebenbilder des Bösen als Gottes werden: Wovon aber sollten soviel Hunderte von Schankwirten sich ernähren? Ja, ?wenn alle Wölfe ausgerottet würden, woher sollte man die Wolfspelze bekommen? Und wenn keine Küchlein ausgebrütet würden, wäre es nicht schade, daß die Habichte sterben müßten? Doch möchte ich glauben, daß der Branntwein einigen Nutzen für die hat, die der Marine angehören, oder nach Indien segeln, für Soldaten, die im Felde liegen, und für Landleute, wenn die oben erwähnten Seuchen (ansteckender Durchfall, Blutseuche) das Land verheeren."

In mehreren seiner akademischen Schriften behandelt Linné den Einfluß berauschender Getränke auf den Menschen und betrachtet sie von verschiedenen Gesichtspunkten aus in Bildern, die er dem Entwicklungsgange des Lebens entnimmt, stets zu dem Zwecke, ihren ruinierenden, verderblichen Einfluß in körperlicher und moralischer Hinsicht nachzuweisen. So wird in "Odores medicamentorum" ( 1752$)$ geschildert, wie der Rausch den der Trunksucht Ergebenen Schritt für Schritt zu einem Zerrbild dessen erniedrigt, was der Mann eigentlich sein sollte. Von dem Mut des Jünglings und der Kraft des Mannesalters sinkt er hinab zu dem untätigenł beschäftigungslosen Leben des Kindes, seinem stolpernden Gang und wirren Geschwätz.

Eine andere Schrift behandelt „Inebriantia" ( 1762 ), worunter die Stoffe verstanden werden, die das Nervensystem nicht nur hinsichtlich des Bewegungs-, sondern auch des Gefühlsvermögens verändern. Von den nativen Mitteln wird eine Menge Pflanzen mit ihren Eigenschaften aufgezählt, wie z. B. Opium, Hyoscyamus, Atropa, Millefolium und Lolium (bisweilen mit Bier gemischt) usw. $\mathrm{Zu}$ den künstlichen Mitteln gehören Wein, gegorener Birken- und Palmensaft, Bier und destillierte spirituöse Getränke. Danach werden beredt die Wirkungen der Spirituosen in ihrem Einfluß auf die Körperund Geisteskräfte geschildert. Zum Beweis dafür, wie tief die berauschenden Getränke auch sogenannte gebildete Personen erniedrigen können, wird in dieser Schrift eine Schilderung von einem Trinkgelage gegeben. Schritt für Schritt sinken die daran Teilnehmenden durch ihre Aeußerungen und Gebärden zu Tieren herab, deren Natur ein jeder nach seinem besonderen Charakter wiedergibt. So erinnert das ständige Geschwätz an den Papagei, das laute Schreien an den 
Hahn, die Unmäßigkeit an das Schwein, die Gewalttaten und Schlägereien an den Stier, die leichtfertigen und unkeuschen Gebärden an den Bock usw. Diese lebhafte Schilderung würde als Probe dessen, was eine akademische Disputation in älteren Zeiten enthalten konnte, durch eine Uebersetzung allzuviel von der ausdrucksvollen Frische der originellen Sprache verlieren und wird daher hier nicht mitgeteilt. Außer dieser mehr aus moralischem und ästhetischem Gesichtspunkte abgefaßten Betrachtung finden wir in einer späteren Abhandlung "Spiritus frumenti" (1764) eine Darstellung 'von der Einwirkung der geistigen Gretränke auf den menschlichen Körper in physiologischer und medizinischer Hinsicht. Sie werden dem Feuer verglichen, welches erquickt, wärmt, brennt und verzehrt. Als Folgen dieser Einwirkungen werden Verhärtungen in Leber, Milz und Drüsen, Veränderungen in den Blutgefäßen, Wassersucht, Gelbsucht, Lungenschwindsucht, Delirium (Meningitis) usw. angegeben.

In seiner Schonischen Reise spricht Linné seine Verwunderung darüber aus, daß Personen, die dem Trunke ergeben sind, frühzeitig ein altes Aussehen erhalten und altern. Als diätetisches Mittel ist Branntwein unter keinen Umständen zu empfehlen. Jedes Volk, das sich unmäßig seinem Genuß ergibt, wird schwach und elend. Wer diesen Volksfeind vertreiben könnte, würde dem Vaterlande mehr nützen als der, welcher Aufrührer unschädlich macht ${ }^{1}$ ). Dagegen empfiehlt Linné einen allgemeineren Gebrauch von gut gebrautem Bier als einem heilsamen Getränk, dessen Zubereitung jedoch viel Aufmerksamkeit erfordert \%. In der ganzen Materia medica findet sich kein spezifisches Mittel gegen die Trunksucht. Brechmittel mit Alkohol als Vehikel nützen bisweilen, oft aber auch gar nicht, eine Heilmethode, die an die in neuerer Zeit empfohlene "Schrebersche Kur" erinnert. Das Uebel muß in derselben Weise überwunden werden. wie es erworben wurde, durch die allmähliche Verminderung seines Gebrauchs (consuetudine sensim inducenda), auch ein Rat, der in den meisten Fällen sich als unzuverlässig erwiesen hat, wenn er nicht zur Abstinenz führt.

Diätetische Ratschläge in Bezug auf Brunnentrinken, die noch heutzutage vom Publikum befolgt werden, liefert Linné auf Grund der damals herrschenden Vorstellungen von den Wirkungen der Mineralwässer. Sie wurden als Lösungsmittel für eine Menge über-

1) Spiritus frumenti (1764).

2) Anmärkningar om öl in den Abhandlungen der Schwed. Akad. d. Wissenschaften 1763 , S. 52. Der Aufsatz findet sich auch in der Zeitung Stockholms Posten vom 4. Nov. 1786. 
flüssiger Salze aufgefalit, die durch die Harnwege entfernt wurden. Dem Eisen, das in den meisten der sog. „Sauerbrunnen" Schwedens vorkommt, wird das Vermögen zugeschrieben, die Neigung zur Säurebildung, wie sie in erschlafften Geweben entsteht, zu vermindern und diesen ihren Tonus wiederzugeben. Beim Brunnentrinken sind Diät und Lebensweise in einer Weise zu ordnen, die mit seinen Wirkungen übereinstimmt. Die Sommerzeit ist die geeignetste Zeit zum Brunnentrinken; alte und sehr schwache Personen können im Bett trinken; Abendkühle und Aufenthalt an Sümpfen und stehendem Wasser ist zu vermeiden; der Schlaf clarf nicht allzulang sein, und man muß sorgfältig der Neigung dazu entgegenarbeiten, obwohl die große Menge von Wasser im Körper, wie sie das Brunnentrinken mit sich bringt, die Gefäße ausdehnt, einen Druck auf das Gehirn ausübt und infolgedessen Schlaf hervorruft. Sonst können „die kleinen und schwächeren Gefäße des Gehirns bersten, was geschieht, wenn ein starker Blutdruck da stattfindet, wo der Widerstand geringer ist", wenn aber das Schlafbedürfnis zu groß für diejenigen ist, die daran gewöhnt sind und während der Nacht keinen Schlaf haben, so ist er zu gestatten, obwohl sparsam in sitzender Stellung in einem bequemen Stuhl. Saure und fette Speisen sind zu vermeiden, denn sie arbeiten dem Einfluß des Mineralwassers entgegen. Frisches Gemüse und feineres Fleisch sind am gesündesten, Milchspeisen veniger geeignet, Wein mehr zum Kosten als zum Trinken, „spiritus vini“ oder Kornbranntwein wird aber merkwürdigerweise, wie auch andere destillierte Wasser, in geringen Mengen gestattet, da diese, ,während das Mineralwasser im Körper zurückbleibt, den Magen (primas vias) stärken und die Diurese befördern". Um alle Unannehmlichkeiten und Sorgen, wie sie das häusliche Leben und die tägliche Arbeit mit sich bringen, $z u$ vermeiden, soll das Brunnentrinken, wenn es nützen soll, nicht zu Hause geschehen und alles Briefschreiben unterlassen werden $\left.{ }^{1}\right)$.

I) Diaeta acidularis ( $176 \mathrm{I})$. 
Mit dem Namen Carl von Linné ist die Erinnerung an eine der wichtigsten Entwicklungsperioden der Naturforschung eng verknüpft. Aus der oben gegebenen Schilderung seiner Tätigkeit als Arzt dürfte, wie Verfasser hofft, mehr als deutlich hervorgegangen sein, daß besonders die ärztliche Bildung in Schweden die Früchte cler Saat, die er in den Boden der vaterländischen Kultur streute, in reichstem Maße genossen hat und noch heutzutage genießt. Diese Schilderung zeigt zugleich, daß die Geschichte der Medizin bisher mehr als zulässig seine Arbeit im Dienste der ärztlichen Entwicklung und seine Bedeutung als medizinischer Verfasser übersehen hat. Wenn auch L,inné während seiner reformatorischen, schöpferischen Tätigkeit auf den verschiedenen Feldern der Naturwissenschaft, weder als ein Meister auf dem Gebiete der praktischen Heilkunst auftreten konnte noch wollte, wurde er doch, wie wir gesehen, durch sein Genie, seine Forschungen und seine Lehrtätigkeit dazu geführt, gewisse allgemeine Grundsätze von großuer Tragweite für die Entwicklung der Medizin aufzustellen. Wir erinnern hier an Linnés Gedanken über die Uebereinstimmung des Pflanzen- und Tierorganismus bei ihrer ersten Bildung, an seine bedeutsame Voraussage bezüglich der organischen Natur der Ansteckungsstoffe, seine Aeußerungen über die Ansteckungsfähigkeit der Lungenschwindsucht, seine erfolgreiche Arbeit auf dem Gebiete der pharmazeutischen Botanik, seine wichtigen Beiträge zur L-ehre von den pharmakodynamischen Eigenschaften der Pflanzen, seine tätige Anteilnahme an der Erörterung vieler schwebenden pharmakologischen Fragen, seine Verdienste um die Einführung der allgemeinen Gesundheitspflege in das öffentliche und private Leben usw. Mehrere von diesen Ideen und Aeußerungen Linnés, deren Bedeutung zu erfassen und $\mathrm{zu}$ verstehen seine Mitwelt nicht reif genug war, sind unter anderem Namen oder anderer Form in einer weit späteren Zeit von der Forschung wieder aufgenommen worden und haben zu Re- 
sultaten geführt, die in größerem oder geringerem Grade den Stand der Wissenschaft fverändert und sie wieder vor die Lösung neuer Aufgaben gestellt haben.

Völliger als irgendeiner seiner Zeitgenossen die bewundernswerte Planmäßigkeit und den üppigen Formenreichtum der organischen Natur überschauend, schließt Linné, wie es dem ehrlichen, demütigen Forscher geziemt, seine Säkulararbeit "Systema naturae“ mit den Worten: „Ea, quae scimus, sunt pars minima eorum, quae ignoramus". In anbetender Begeisterung bricht er in die Worte des Psalmisten aus: „Herr, wie sind Deine Werke so grof und viel! Du hast sie alle weislich geordnet, und die Erde ist voll Deiner Güter. Herr, mein Gott, groß sind Deine Wunder und Deine Gedanken, die $\mathrm{Du}$ an uns beweisest. Dir ist nichts gleich. Ich will sie verkündigen, und davon sagen, wiewohl sie nicht zu zählen sind." (Ps. 104:24; 40:6). 


\section{Verzeichnis der medizinischen und der Heilkunde nahe- stehenden Schriften Car1 von Linnés.}

\section{Besondere Schriften.}

I. Caroli Lin na i Materia medica. Lib. I. De plantis. Secundum Genera, Differentias, Synonyma, Loca, Durationes, Culturas, Nomina, Simplicia, Praeparata, Qualitates, Modos, Potentias, Vires, Usus, Composita digestus. Holmiae 1749, 254 p., 8:0.

Caroli Linnaei Materia medica per regna tria naturae. Ed. altera, auctior. Curante J. Chr. D. Schrebero. Lips. et Erlang. 1772, 266 p., S:O.

Ein Abdruck dieser Auflage ist in Wien herausgegeben 1773, 8:0.

In Leipzig und Erlangen ist ferner eine Auflage gedruckt 1782, 304 p., 8:o, nebst Mantissa editioni quartae Materiae medicae, adjecta a Joh. Chr. Dan. Schrebero. Erlangen I782, I6 p., 8:0.

Ed. quinta, auctior. Ed. J. Chr. D. Schreberus. Lips. et Erlang. 1787,318 p., S:o.

New medical discoveries, which a defense of the Linnaean doctrine and a translation of his vegetable materia medica, which new first appears in an english dress. By Charles Whit1aw. 1. 2. London 1829,272 et 254 p., 8:0.

2. Genera morborum in auditorum usum edita. Upsaliae $1_{763}$, 32 p., 8:0 min. (dazu Register). Erschienen als akademische Abhandlung 1759 und abgedruckt in Amoenitates academicae VI., Holmiae $1763,452-483$.

Von dieser Arbeit gibt es meines Wissens folgende Auflagen: Caroli à Linné, Genera morborum in auditorum publicata. Ed. iterata, foras dedit et nomina teutonica adjecit Joh. Christ. Kerstens. Hamb. et Gustraw s. a. (1774). 6r p. Lateinisch und Französisch im Nosologie methodique etc., trad. par Gouvion, T. X. Lyon 1772 . 
Caroli Linnaei, Genera morborum in auditornm usum publicata (!). Editio italica ex unica Upsaliensi iterata. Accedunt Canones quidam medici, nec non suis quaeque locis remedia nonnulla mirabili usurpata successu et idcirco ab eodem expertissimo auctore admirationis signo indicata. Curante Caesare Constantino Genio. Ferrariae 1776.

In der Vorrede zu dieser Auflage schreibt der Herausgeber: ,illa praeterea remedia suis quoque locis indicavi, quae $\mathrm{L}$ in $n$ a e u s ipse longo usu et repetitis experimentis perutilia esse, comperit".

3. Caroli à Linné, Clavis medicinae duplex exterior et interior. Universum luctâ discordium aequilibratur. Holmiae 1766, 29 p., 8:o.

Eine zweite Auflage ist in Deutschland erschienen mit dem Zusatz auf dem Titel: Iterata editio foras dedit et praefatus est Ern. Godofr. Baldinger. Longosalissae 1767,59 p., 8:o.

In der Vorrede äußert der Herausgeber: „Optandum est, ut omnibus ac singulis liceat cum Clave Linna ei recludere portam ad occlusum medicinae atrium. Miratus sum audaciam auctoris in definiendis rerum caussis atque effectibus. Multa enim inveni, inaudita prorsus et vix exspectata, maxime vero, cum de nervorum usu, morborum caussis et medicamentorum viribus sermo est."

\section{Akademische Abhandlungen ${ }^{1}$ ).}

A. Anatomie und Physiologie.

I. Generatio ambigena. Christ. Ramström. Upsaliae I 2./12. I757, I7 p., 4:o. Abdruck in Amoenitates academicae VI, Holmiae I763, I-16. De Afhanglykheid der voortteeling van de beide sexen i Hitgezogte Verhandelingen IX, 4I-62.

2. Antropomorpha. Christ. Em. Hoppius. 6./9. I760, i6 p.

3. Morsura serpentum. Joh. Gust. Acrell. i6./5. I762, ig p. Abdruck in Amoen. acad. VI (1763), 197-216.

4. Metamorphosis humana. J oh. Ad. Wa dström. i6./ I 2. г 67 , i 8 p. Abdr. in Amoen. acad. VII (1769), 326-344.

5. De venis resorbentibus. C. P. Thunberg. 2./6. I767, Iо p.

Abdr. in Amoen. acad. IX (1785), Erlangen, I31-142.

B. Allgemeine Pathologie.

6. De generatione calculi. Gr. med. Joh. Otto Hagström. 5./4. I 749,27 p.

I) Alle hier erwähnten Abhandlungen sind in 4:0. Weggelassen sind die akademischen Dissertationen, die, der Angabe nach, von den Schïlern verfaßt sind. Siehe oben S. 22. 
Abdr. in Amoen. acad. II, ed. 2. Holmiae 1762, 137-162. - Deutsch übersetzt in Carl von Linné, Auserlesene $A b$ handlungen aus der Naturgeschichte, Physik und Arzneywissenschaft III, Leipzig I776, No Io.

7. De morbis ex hyeme. G. m. Sveno Brodd. II./I. 1752, 23 p.

Abdr. in Amoen. acad. III (1756), 158-I82.

8. Obstacula medicinae. G. m. Joh. Georg Beyerstén. 9./2. I $75^{2}$, I 2 p.

Abdr. in Amoen. acad. III (1756), 65-73.

9. Nutrix noverca. Fred. Lindberg. 7./I I. 1752, 20 p.

Abdr. in Amoen. acad. III (1756), 256-270.

I o. De pulsu intermittente. G. m. Andr. Wåhlin. 5./5. 1756, I8. p.

Abdr. in Amoen. acad. IX ( 1785$), 43^{-6} 3$."

I I. Exanthemata viva. Joh. C. Nyander. 23./6. I757, I6 p.

Abdr. in Amoen. acad. V (1760), 92-105.

I 2. Theses medicae. G. m. Joh. Chr. Dan. Schreber. I4./6. i76o.

Abdr. in Amoen. acad. VI ( 1763$), 40-43$.

13. Mundus invisibilis. Joh. Mart. Roos. 6./3. 1767, 23 p.

Abdr. in Amoen. acad. VII (1769), 385-408.

C. Praktische Medizin.

I4. Diss. medica inauguralis, in qua exhibetur Hypothesis nova de Febrium intermittentium causa. Quam ex auctoritate magnifici Rectoris Joannis de Gorter - pro gradu doctoratus summisque in Medicina honoribus et privilegiis rite et legitime consequendis, eruditorum examini submittit Carolus Lin na eus Smol. Svecus ad diem 23 junii hora locoque solitis. Harderovici 1735 , 24 p., 4:0. - Ist Linnés Doktorabhandlung unter dem Präsidium von Johannes de Gorter in Harderwyk.

Abdr. in Amoen. acad. I. Lugd. Batav. 1749. I-I9 (von P. Camper) und ferner abgedruckt in Amoen. acad. X. Erlangen I790, I-I 2.

I5. Consectaria electrico-chemica. G. m. Petr. Zetzell. I2./10 I 753, 8 p.

Abdr. in Amoen. acad. IX (1785), Erlangen, 35-42.

I6. Febris Upsaliensis. G. m. A nd. Boström. 21./5. I757, I2 p.

Abdr. in Amoen. acad. V (1760), I 8-29.

I 7. Genera Morborum. G. m. Joh. Schröder. 5./12. I759, 32 p.

Abdr. in Amoen. acad. VI ( 1763$), 452-485$.

18. Raphania. G. m. Georg Rothman. 17.15. I763, 21 p.

Abdr. in Amoen. acad. VI (1763), 430-451. 
I 9. Lepra. G. m. Is a c. Uddman. 17./5.1763, 2 I p.

Abdr. in Amoen. acad. VII ( 1769$)$, 94-108.

20. De Haemoptysi. G. m. Joh. Mart. Gråberg. 13./5. 1767, I4 p.

Abdr. in Amoen. acad. IX (1785), I I 8-I30.

2I. De varia Febrium intermittentium curatione. G. m. Pet. C. Tillaeus. II./I2. I77 I, $56 \mathrm{p}$.

Abdr. in Amoen. acad. IX (1785), 143--194. - Auserlesene Abhandl. III, No. I.

22. De Haemorrhagiis ex plethora. G. m. Ernest J. M. ab Heidenstam. 23./5. I $772,32 \mathrm{p}$.

D. Materia medica. Pharmakologie.

23. Ficus ejusque historia naturalis et medica. G. m. Cornel. $\mathrm{He}$ gardt. 15./9. $1744,28 \mathrm{p}$.

Abdr. in Amoen. acad. I. Holm et Lips. 1749, 23-54. Auserlesene Abhandl. II, No. Io.

24. Lignum Colubrinum. Joh. Gust. Darelius. II./3. I749, 22 p.

Abdr. in Amoen. acad. II, ed. 2 (1762), 89-i II. - Auserl. Abhandl. III, No. 9.

25. Radix Senega. G. m. Jon. Kiernander. 8./4. I749, 32 p.

Abdr. in Amoen. acad. II, ed. 2 (1762), I 2-I36. - Auserl. Abhandl. III, No. 6.

26. Materia medica in regno animali. G. M. Jon. Sidrén. 25./5. I 750,2 I p.

Abdr. in Amoen. acad. II, ed. 2 (1762), 28I-303. - Desgleichen in Schrebers Auflage der "Materia Medica" (1773), p. I-40 und 1782, p. I-32. - Dictionnaire des Animaux, par de la Chenaye des Bois, IV, 593-608.

27. Materia medica in regno lapideo. G. m. Joh. Lindhult. I8.15. I $752,28 \mathrm{p}$.

Abdr. in Amoen. acad. III (I756), I32-157. - Desgleichen in Schrebers Auflage der "Materia medica“ (1773) p. 237-266 und 1782, p. $273-364$.

28. Rhabarbarum. Sam. Zi ervogel. I7./7. 1752, 24 p.

Abdr. in Amoen. acad. III (1756), 21 2-230.

29. Euphorbia ejusque historia naturalis et medica. Joh. Wi man. 6./5. $1752,33 \mathrm{p}$.

Abdr. in Amoen. acad. III (I756), Ioo-I $3 \mathrm{I}$.

3o. Plantae officinales. N. Gahn. I5./12. I753, 3 I p.

Abdr. in Amoen. acad. IV (1759), I-25. - Gilibert, Fundamenta botanica (1786) II, I55-I80. 
31. Censura medicamentorum simplicium vegetabilium. Gust. Jac. Car1bohm. I9./I2. 1753, 23 p.

Abdr. in Amoen. acad. IV (1759), 26-42. - Gilibert, Fundam. botan. (1786) II, 137-I53.

32. Fungus melitensis. Joh. Pfeiffer. I0.15. 1755, I6 p.

Abdr. in Amoen. acad. IV (1759), 351-367.

33. Specifica Canadensium. Joh. von Coelln. I9./6. 1756, 28 p. Abdr. in Amoen. acad. IV (1759), 507-536.

34. De Spigelia anthelmia. G. m. Johan Georg Colliander, 22./3. 1758 , I6 $\mathrm{p}$.

Abdr. in Amoen. acad. V (1760), I33-I47.

35. De Cortice Peruviano. Joh. Chr. P. Petersen. 10./5. 1758,38 p.

Abdr. in Amoen. acad. IX (1785), 64-105.

36. De Meloë vesicatorio. Canut. Aug. Lennaeus. 20./I 2. i 762. I 5 p.

Abdr. in Amoen. acad. VI (1763), $\mathrm{I}_{32}-\mathrm{I} 47$.

37. Lignum Qvassiae. G. m. Carol. M. Blom. 28./5. i763, i 3 p. Abdr. in Amoen. acad. VI (I763), 416-429. - Hitgezogte Verhandelingen IX, 394-4I4.

38. Opobalsamum declaratum. Wilh. Le Moine. 22./12. I764, ig p.

Abdr. in Amoen. acad. VII ( 1769 ), 55-73.

39. De Hirudine. Dan. Weser. 19.15. 1764, I5 p.

Abdr. in Amoen. acad. VII (1769), 42-54.

40. Dulcamara. Georg Hallenberg. 29./5. 177 I, 14 p.

Abdr. in Amoen. acad. VIII (1785), 63-74.

41. Fraga vesca. Sveno And. Hedin. 26./5. 1772. 13 p.

Abdr. in Amoen. acad. VIII (1785), I69-I8I.

42. Observationes in Materiam medicam. G. M. Joh. Lindwall 5./6. $1772,8 \mathrm{p}$.

Abdr. in Amoen. acad. VIII (1785), I82- 192.

43. Planta Cimicifuga. G. m. Joh. Hornborg. ./9. I 774, io p.

Abdr. in Amoen. acad. VIII (1785), 193-204.

44. De Maro. G. m. Joh. Ad. Dahlgren. 3.|I2. I774, 18 p.

Abdr. in Amoen. acad. VIII (1785), $22 \mathrm{I}-237$.

45. De Ledo palustri. Joh. Pet. Westring. 25./10. I775, I 8 p.

Abdr. in Amoen. acad. VIII (1785), 268-288.

46. Opium. Georg. Eberh. Georgii. I5./II. 1775, I7 p.

Abdr. in Amoen. acad. VIII (1785), 289-302.

47. Hypericum. G. m. Carol. Nicol. Hellenius. 20./1 I. I776, 14 p. c. tab.

Abdr. in Amoen. acad. VIII (1785), 318-332. 
E. Pharmakodynamische Schriften.

48. Vires plantarum. Fr. Hasselqvist. I./6. 1747, 37 p.

Abdr. in Amoen. acad. I, Holm. et Lips. I749, 418-453. - Auserl. Abhandl. I, No. I4. Gilibert, Fundam. botan. (I 786$)$ II, I-34.

49. Sapor medicamentorum. G. m. J a c. Rud berg. 20./2. i 75 I, 20 p.

Abdr. in Amoen. acad. II, ed. 2 (I762), 335-355. Auserl. Abhandl. III, No. I 2.

50. Odores medicamentorum. A nd. Wåhlin. 30./2. I752, I6 p.

Abdr. in Amoen. acad. III (1756), I83-201. Auserl. Abhandl.

II, No. 9. Journ. de Physique. Introd. II, 48I-495.

5I. De Methodo investigandi vires medicamentorum chemica. G. m. Laur. Hjortzberg. 2./10. I754, I6 p.

Abdr. in Amoen. acad. IX (1785), 23-34.

52. Medicamenta graveolentia. G. m. Jonas Th. Fagraeus. i3./6. 1758, 24 p.

Abdr. in Amoen. acad. V (1760), 148-i73. - Gilibert, Fundam. botan. II, I8I-205.

53. Ambrosiaca. G. m. Hideen. Iо./6. I759, 14 p.

Abdr. in Amoen. acad. IX (1785), Erlangen, 106-i 17.

54. Inebriantia. Olav. Reinh. Alander. 7./4. I761, 26 p.

Abdr. in Amoen. acad. VI (1763), i80-ig6.

55. Purgantia indigena. Pet. Strandman. 26./2. I766, I 7 p.

Abdr. in Amoen. acad. VII (1760), 293-3 го.

56. De Menthae usu. Carol. Gust. Laurin. 13.6. I767, i i p.

Abdr. in Amoen. acad. VII (1769), 282-292.

57. Medicamenta purgantia. G. m. Joh. Rotheram. 22./I I. I775, $24 \mathrm{p}$.

Abdr. in Amoen. acad. IX (1785), 245-267.

\section{F. Hygiene.}

58. Fundamenta Valetudinis. Petr. Engström. 17./6. I756, I3 p Abdr. in Amoen. acad. IV (1759), 496-506.

59. Aer habitabilis. Joh. Vict. Siefvert. 22./12. I759, 25 p.

Abdr. in Amoen. acad. V (1760), 442-460.

6o. Motus polychrestus. Christ. Lado. 23./12. I763, 20 p.

Abdr. in Amoen. acad. VII (1769), I-I7.

61. Circa Fervidorum et Gelidorum usum paraenesis. Carol. Ribe. I 2./6. I 765, $23 \mathrm{p}$.

Abdr. in Amoen. acad. VII (1769), 214-235. 
62. Morbi artificum. G. m. Nic. Skragge. I5./6. I765, 12 p.

Abdr. in Amoen. acad. VII (1769), 84-93.

63. De effectu et cura vitiorum diaeteticorum generali. G. m. Joh. Gabr. Bergman. I0./12. $1766,24 \mathrm{p}$.

Abdruck unter dem Titel "Cura generalis" in Amoen. acad. VII ( I 769), 345-369.

64. De medico sui ipsius. G. m. Joh. Grysselius. I5./6. i768, $12 \mathrm{p}$.

Abdr. in Amoen. acad. VIII (1785), r $3-25$.

65. Respiratio diaetetica. Joh. U11ho $1 \mathrm{~m}$. 29./4. I772, I5 p.

Abdr. in Amoen. acad. VIII (I785), I 5I-I68.

\section{G. Diätetik.}

66. Plantae esculentae patriae. Joh. Hjorth. 22./2. I752. ig p.

Uebersetzt in Auserl. Abhandl. II, No. 6. Abdr. in Amoen. acad. III (I 756), 74-99.

67. De Acetariis. Hieron. v. d. Burg. 29./6. I 756, i6 p.

Abdr. in Amoen. acad. IV (I 759), 536-552.

68. De pane diaetetico. Is ac. Svensson. 8./6. I757, 20 p.

Abdr. in Amoen. acad. V (1760), 50-67. Auserl. Abhandl. I, No. 8 .

69. Culina mutata. Magn. G. Österman. I6./I x. I757, I 2 p.

Abdr. in Amoen. acad. V (1760), 120-132.

70. Macellum olitorium. Petr. Jerlin. 20./12. I760, 23 p.

Abdr. in Amoen. acad. VI (1763), I I6- 131.

7. Diaeta acidularis. Ericus Vigelius. I8./2. I76I, I 2 p.

Abdr. in Amoen. acad. VI (1763), r48-i 59. Auserl. Abhandl. I, No. 7 .

72. Potus Coffeae. Hinr. Sparschuch. I6./12. i76I, i 8 p.

Abdr. in Amoen. acad. VI (1763), i6o-i 79. Auserl. Abhandl. I, No. 3 .

73. Fructus esculenti. Johannes Salberg. I I./6. I763, 22 p.

Abdr. in Amoen. acad. VI (1763), 342-364.

74. Hortus culinaris. Jon. C. Tengborg. 22./6. 1764, 26 p.

Abdr. in Amoen. acad. VII (1769), 18-4I.

75. Diaeta per scalam aetatis humanae observanda. Da n. Joh. Ö hrquist..$/ 5$. I 764, I 2 p.

Abdr. in Amoen. acad. VII (1 769), 74-83.

76. Spiritus frumenti. Petr. Bergius. I0./12. I764, $20 \mathrm{p}$.

Abdr. in Amoen. acad. VII (1769), 264-28I. Auserl. Abhandl. II, No. I I. 
77. De potu Chocolatae. G. m. Ant. Hoffman. 18./5. 1765, $10 \mathrm{p}$. Abdr. in Amoen. acad. VII (1769), 254-263. Auserl. Abhandl. II, No. 5. - Geneeskund. Jaarboeken II, 412-420. 78. Potus Theae. Petrus C. Tillaeus. 17.12. 1765, 16 p.

Abdr. in Amoen. acad. VII (1769), 236-253. Auserl. Abhandl. I, No. 4. - Geneeskund. Jaarboeken II, 324-338.

79. De varietate ciborum. Ad. Fr. Wedenberg. 18./12. 1767, $20 \mathrm{p}$.

Abdr. in Amoen. acad. VII (1769), 197-213.

III. Kleinere Aufsätze. (Sämtlich schwedisch.)

Verzeichnis der Medizinalpflanzen, die in den Apotheken aufbewahrt werden und in unserem Lande wachsen. Abh. $d$. schwed. Akad. d. Wiss., 1741, 81-96.

Beschreibung einer Art ostindischer Kräuter, die bei Steinleiden nützlich sind. Abh. d. schwed. Akad. d. Wiss., 1742, 202-206.

Lateinisch übersetzt: De Phaseoli Sinensi seu Zeylanico, optimo contra calculos renum et vesicae. Analecta Transalpina I. Venetiis $1762,220-229$.

Erforschung der Ursache der Epilepsie in Schonen und Werns Gerichtsdistrikt in Småland. Abh. d. schwed. Akad. d. Wiss., 1742, $279-284$.

Das Vergessen aller Substantiva, und besonders Namen. Abh. d. schwed. Akad. d. Wiss., 1745, 116-117.

Bemerkungen über Bier. Abh. d. schwed. Akad. d. Wiss., 1763, $52-59$.

Bericht über die einheimischen Gewächse, die bei Getreidemangel zur Brot- und Speisebereitung angewendet werden können. Stockholm 1757. 4:0. Siehe oben S. 152.

In den von $\mathrm{Hjorter}$ herausgegebenen Kalendern finden sich folgende Aufsätze: 1742 „Hauskuren bei Wechselfieber"; 1745 „Fortsetzung der Hauskuren bei epidemischen Krankheiten“; 1746 „Bemerkungen über Tee und Teetrinken“; "Bemerkungen über Kaffee“, und 1748 "Bemerkungen ïber Branntwein". Dieser letztere Aufsatz ist abgedruckt in Skara 1750 und in Stockholm 1804. Ferner ist er erschienen in Örebro 1868. 


\section{Inhalt.}

I.

Seite

Linnés medizinische Ausbildung in Lund. Johan Rothman.

Kilian Stobaeus . . . . . . . . . . . . . . . . I I

Linnés medizinische Jugendstudien in Upsala. Olof Rudbeck der

Jüngere. Lars Roberg

$2-5$

Sein Aufenthalt in Holland. Dolstorpromotion in Harderwyk 1735.

Johan de Gorter. Herm. Boerhaave . . . . . . . . 6-Io

Linné als praktischer Arzt in Stockholm . . . . . . . . 9-I4

Medizinische Verhältnisse in Upsala . . . . . . . . . . 20

Streit um die Professur der Medizin in Upsala . . . . . . 20

Linné wird am 5/5. I74 I zum Professor der Medizin in Upsala

ernannt . . . . . . . . . . . . . . . . . 2 I

Seine medizinische Lehrtätigkeit . . . . . . . $2 \mathrm{I}-23 \cdot 26-27$

Das medizinische Examenwesen in Upsala . . . . . . . . 24-25

Linnés Aeußerungen über sein akademisches Leben . . . 27-28

II.

Linnés Bekanntschaft mit Boissier de la Croix de Sauvages und sein Verhältnis zu ihm . . . . . . . . . . . 29-36

Linn és Gegner . . . . . . . . . . . . . . 37-38

Seine Verdienste um die schwedische Pharmakopöe . . . . . 40-42

Seine Verdienste um die Veterinärkunde in Schweden . . . . 42-45

Seine Verdienste um die Popularisierung der medizinischen Wissenschaft . . . . . . . . . . . . . . . . 46-47

Linnés Verhältnis zur Medizinalverwaltung . . . . . . 47-5 I

Linnés Verhältnis zu der Chirurgischen Societät . . . . 52-55

Li nnés Verhältnis zum Collegium medicum . . . . . . 55-58 
III.

Lin é seite

Linnés allgemeine medizinische Ansichten . . . . .59-66. 73-80

Sein pathologisches System und Genera Morborum . . . 67-73

Seine medizinisch-therapeutische Anschauung und sein pathologisch-pharmakodynamisches System. Theorie der Gegensătze . . . . . . . . . . . . . . . . . . 74-83

Seine Aeußerungen über gewisse Krankheitsursachen. Entstehung der ansteckenden Krankheiten . . . . . . . 84-87

Seine Aeußerungen über die Krankheiten des Herzens und der Blutgefäße

Ueber die Kleinkinderpflege . . . . . . . . . . . . 90-9 I

Linn és Aeußerungen über das intermittierende Fieber, Schwind-

sucht, Keuchhusten, die Kriebelkrankheit usw. . . . . 9I-IOT

Lin nés pharmakodynamische Ansichten. Seine Verdienste um

Materia medica (Drogenkunde) und die Pharmakodynamik I08-i 28

Pharmakologische Abhandlungen . . . . . . . . . . I 29-I 34

Behandlung der venerischen Krankheit . . . . . . . . I35-I37

Unter dem Volke gebräuchliche Hauskuren und Hausmittel . I37-I38

Die Lehre von den Giften . . . . . . . . . . . I39-I40

IV.

Linnés Schrift „Clavis Medicinae“ im Verhältnis zur Therapie und Diätetik . . . . . . . . . . . . . . . I4I-I 44

Seine Schriften über Diätetik und allgemeine Gesundheitspflege. Collegium diaeteticum. Einzelne Abhandlungen. Ueber den Branntwein. Brunnenkur . . . . . . . . . I $44-$ I 56

Einige Worte über die Bedeutung Linnés für die Entwicklung

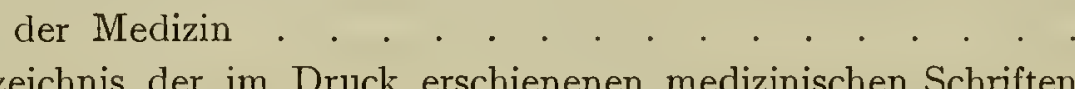

Verzeichnis der im Druck erschienenen medizinischen Schriften Linnés 



